Portland State University

PDXScholar

$1-1-1982$

\title{
Housing the low-income, urban elderly: a role for the single room occupancy hotel
}

Mary Ann Burki

Portland State University

Follow this and additional works at: https://pdxscholar.library.pdx.edu/open_access_etds Let us know how access to this document benefits you.

\section{Recommended Citation}

Burki, Mary Ann, "Housing the low-income, urban elderly: a role for the single room occupancy hotel" (1982). Dissertations and Theses. Paper 847.

https://doi.org/10.15760/etd.847

This Dissertation is brought to you for free and open access. It has been accepted for inclusion in Dissertations and Theses by an authorized administrator of PDXScholar. Please contact us if we can make this document more accessible: pdxscholar@pdx.edu. 


\title{
HOUSING THE LOW-INCOME, URBAN ELDERLY: \\ A ROLE FOR THE SINGLE ROOM \\ OCCUPANCY HOTEL
}

\author{
by \\ Mary Ann Burki
}
A dissertation submitted in partial fulfillment of the requirements for the degree of

\section{DOCTOR OF PHILOSOPHY \\ in \\ URBAN STUDIES}

Portland State University

1982 
TO THE OFFICE OF GRADUATE STUDIES AND RESEARCH:

The members of the Committee approve the dissertation of Mary Ann Burki presented January 20, 1982.

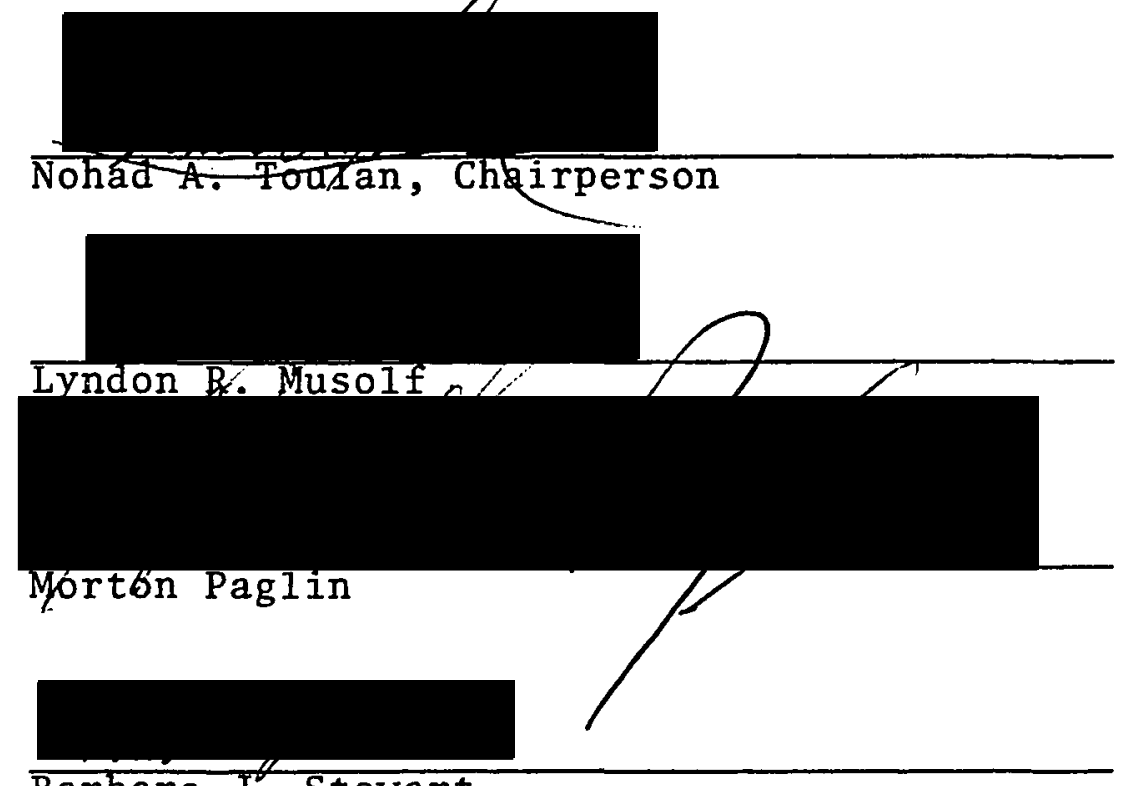

Barbara J. Stewart

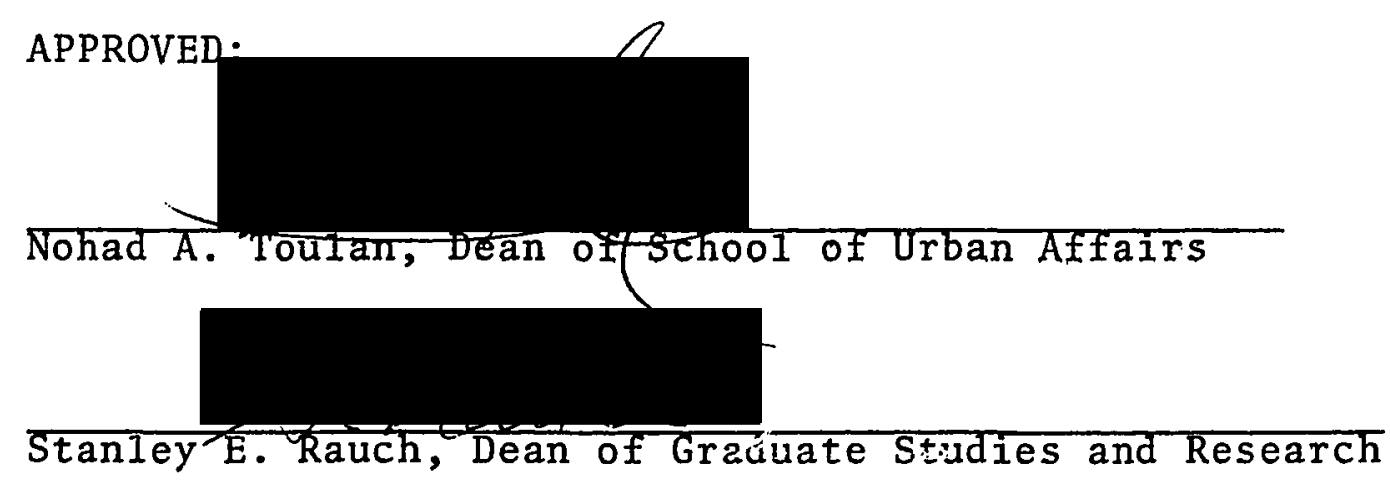


AN ABSTRACT OF THE DISSERTATION OF Mary Ann Burki for the Doctor of Philosophy in Urban Studies presented January 20, 1982.

Title: Housing the Low-income, Urban Elderly: A Role for the Single Room Occupancy Hotel.
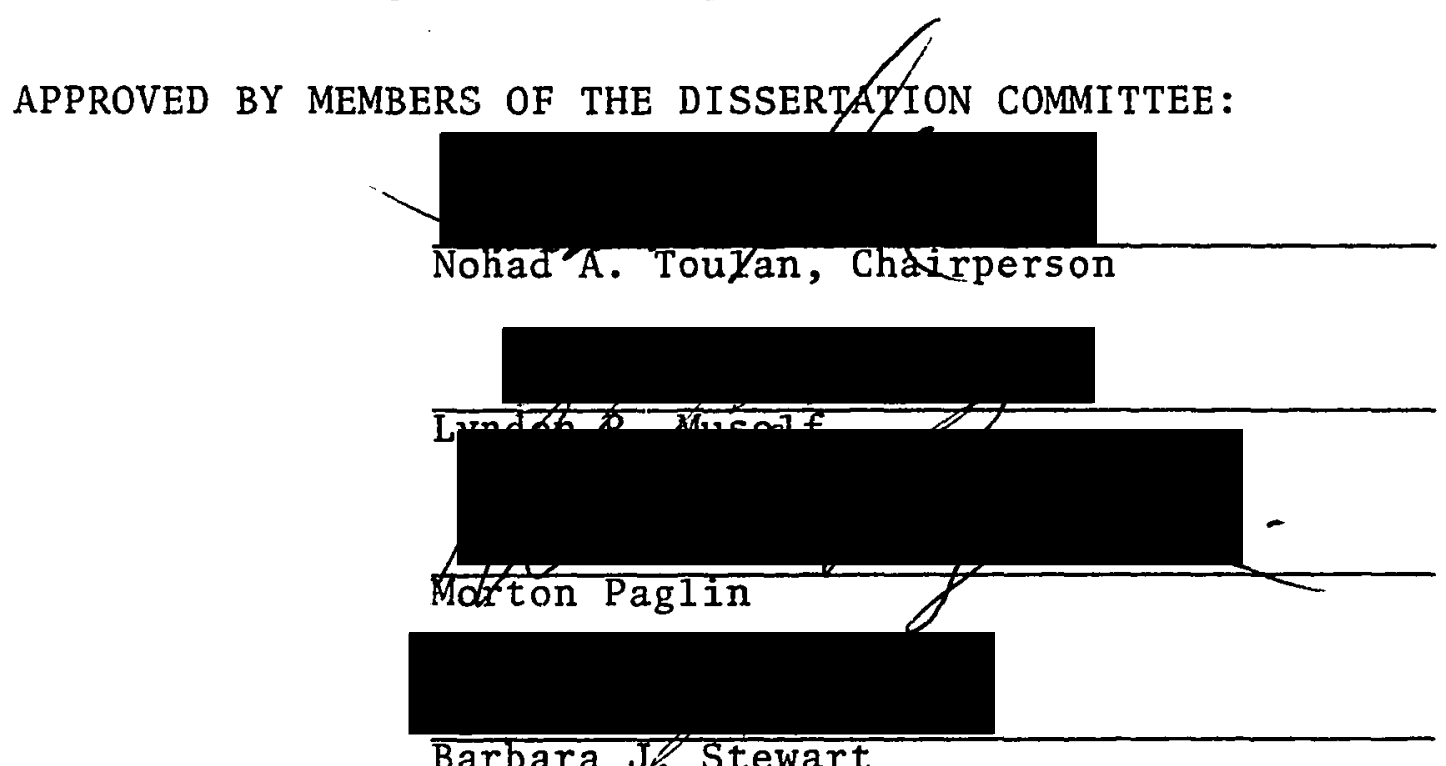

This study examines the question of whether there is a role for the single room occupancy (SRO) hotel as a form of housing for a select group of low-income, urban elderly persons. Such a focus was selected because it is the single room type of housing, with neither individual kitchen nor bath, which HUD defines as substandard. This definition is viewed as problematic for several reasons. First, it has been a major barrier to the use of Federal funds to support 
such housing either through rehabilitation or rent subsidy, and second, it has been a major incentive to the use of Federal funds to remove such housing through programs like urban renewal.

The study question is examined from several perspectives. One perspective looks at the hotel resident, his preferences and lifestyle, and compares these findings with a similar analysis of Section 8 apartment residents who previously resided in SRO hotels. Another perspective examines the cost of living for an SRO hotel resident in downtown and several other neighborhoods located throughout the City (Portland). A final perspective compares the cost to operate and maintain, rehabilitate, construct new, and subsidize SRO hotels and Section 8 apartments. This final perspective also compares the rate of return an owner receives from investing in the two forms of housing.

Analysis of the study data confirms that: a) there are preferential and lifestyle differences between the present and past hotel residents which reflect their differing housing choices, b) the cost of living for an SRO lifestyle is least expensive in the downtown neighborhood, and c) SRO hotels are less costly than Section 8 apartment to produce and operate from the standpoint of overall cost and amount of subsidy required, and SRO hotels can provide a reasonable return' on investment.

In conclusion, the study proposes that SRO hotels 
provide an appropriate setting for a select group of elderly persons, can be decent, safe, and sanitary, and as such, should be made the object of an intense Federal effort to facilitate their rehabilitation as single room housing units. 
To Bob Nash -.

for it was he who taught me that life in an SRO hotel could be dignified 


\section{ACKNOWLEDGEMENTS}

There are many people who made contributions to this dissertation. Without their challenges and assistance, it would neither have been conceived nor completed.

Social service agency personnel were infuential in the conceptualization of the problem in that it was they who persistently maintained that low-cost housing units were being lost from Portland's downtown, that people were being displaced, including many elderly, and that the loss of units was continuing.

My committee, whose members include Nohad Toular, Lyn Musolf, Mort Paglin, and Barbara Stewart, guided the development and completion of the research. Their questions kept me focused on the scholarly nature of a dissertation and their properly timed words of encouragement kept me writing. To Dr. Toulan, my chairperson, I owe a special gratitude, for without his wealth of knowledge which he so graciously shares, his standards of excellence, and his patience, this dissertation would not have been completed. Others also provided vital assistance. The owners and managers of the SRO hotels and Section 8 apartments in which interviews were conducted allowed access to their buildings, and in many cases, provided additional assistance 
in contacting individual residents. Staff members of the Housing Authority of Portland, the Portland Development Commission, the Area office of HUD, and the Housing Division of the State of Oregon each responded graciously and in a timely manner to my urgent requests for information from their records and files. Also, several graduate students assisted in some of the early interviews of Section 8 apartment residents.

The financial assistance for this study came from several sources. The Maurie Clark Foundation Fellowship from the School of Urban Affairs provided early support and a Dissertation Award from the Administration on Aging, Department of Health and Human Services provided later support. The always appreciated "money from the folks" filled in the gaps. To overstate the importance of these financial aids would be virtually impossible.

My family and friends, each in their own way, provided the personal support I needed to complete the lonely task of writing a dissertation. Carole, Gail, and Pat all made very special contributions for which I am very grateful.

The production of this dissertation was no small feat. Dawn Kuenle carefully typed portions of an early draft. The final drafts were ably prepared by Kathryn Mitche11 and Marie Beaudet-Walters, who, through dedication and persistence, despite all odds, got this document to the Graduate Studies Office on time. 
TABLE OF CONTENTS

PAGE

ACKNOWLEDGEMENTS ................. . . iv LIST OF TABLES . . . . . . . . . . . . . . $x$ LIST OF FIGURES . . . . . . . . . . . . . . . . xiii CHAPTER

I INTRODUCTION . . . . . . . . . . . 1

Study Definitions... . . . . . . 6

Single Room Occupancy (SRO) Hotel

Section 8 Apartment

Upper Skid Row

Study Limitations . . . . . . . . . 11

SRO Hotel Structure

Type of SRO Resident

Nature and Components of the Study . . . 13

A Policy Study

Components of Empirical Analysis

II REVIEW OF THE LITERATURE . . . . . . . . 20

PART A: The Functions of Housing . . . . 22

Shelter

Privacy

Access to Other Locations

Neighborhood Amenities

Affordability

PART B: Housing and the Elderly .... 34

The Elderly's Economic Condition

The Elderly's Housing 
PART C: Neighborhood and the Elderly . .

Neighborhood as a Resource

The Elderly's Use of Neighborhood Resources

Person-Environment Fit: A Theoretical Perspective

The Elderly's Satisfaction with their Environment

PART D: SRO Hotels and their Elderly

Residents............. . 75

SRO Hotels

Elderly SRO Hotel Residents

PART E: Policy Considerations . . . . . 97

Federal Decisions Related to SRO Hotels and their Residents

Local Decisions Related to SRO Hote1s and their nessidents

METHODOLOGY • . . . . . . . . . . . . 122

Hypotheses . . . . . . . . . . . . . . . 122

Hypothesis One

Hypothes is Two

Hypothesis Three

Study Parameters . . . . . . . . . . 125

Definition of Study Area

Definition of Resident Population

Definition of Hotel Population

Data Gathering . . . . . . . . . . .

Phase I - Resident Interviews

Phase II - Cost of Living

Phase III - Cost of Housing

Data Analysis Techniques . . . . . . . 158

Frequency Distribution and Descriptive Statistics

Comparison of Means Using $t$-tests

Correlational Procedures 
viii

CHAPTER

PAGE

Index Construction

Discriminant Function Analysis

A Comparison of the SRO Hotel Study Sample with Other SRO Hotel Samples . . . . 164

A Comparison of the SRO Hotel and Section 8 Apartment Study Samples on Housing Preferences and Lifestyles . . . . .

Housing Preferences

Neighborhood Preferences

Lifestyle Indicators

Conclusion

A Comparative Examination of the Cost of Living for an SRO Hotel Resident . . .

Use of Neighborhood Facilities

Cost of Living for SRO Hotel Residents Conclusion

A Comparative Examination of the Cost of Section 8 Apartments and SRO Hotels. .

A Comparison of the Actual Costs to Operate and Maintain, Rehabilitate, and Construct Section 8 Apartments and SRO Hotels

The Subsidies

Return on Investment

Conclusion

Summary of the Study

Other Issues . . . . . . . . . . . 285

A SELECTED BIBLIOGRAPHY . . . . . . . . . . . . . . 292

APPENDICIES . . . . . . . . . . . . . . . 304

A MEANS, STANDARD DEVIATIONS, AND $t$-TEST

COMPARISONS OF RANDOMLY SELECTED SRO HOTEL

RESIDENTS . . . . . . . . . . . . . 304

B SRO HOTEL RESIDENT SURVEY SCHEDULE . . . . . . 305 
C SECTION 8 APARTMENT RESIDENT SURVEY SCHEDULE -

D DETAILED LIST OF ITEMS CONTAINED IN THE SRO HOTEL RESIDENT COST OF LIVING SURVEY • • • 336

E MEANS, STANDARD DEVIATIONS, AND $t$-TEST COMPARISONS OF SRO HOTEL AND SECTION 8 APARTMENT RESIDENTS' ASSESSMENT OF SELECTED FUNCTIONS OF HOUSING . . . . . . . . . . 337

F RETURN ON INVESTMENT FOR OWNERS OF SECTION 8 APARTMENTS AND SRO HOTELS IN DOWNTOWN PORTLAND, OREGON . . . . . . . . . . 338 


\section{LIST OF TABLES}

TABLE

PAGE

I A Comparison of Facility Importance and Critical Distance. . . . . . . . . . . . . 54

I Sexual Composition of Selected Study Samples of Elderly Populations . . . . . . . . .

III Marital Status of Selected Study Samples of Elderly Populations . . . . . . . . 84

IV Income and Housing Costs of Selected Study

Samples of Elderly Populations . . . . . . 88

V SRO Hotel and Resident Sample . . . . . . . . 133

VI Section 8 Apartment and Resident Sample . . . . 142

VII Comparison of SRO Hotel Study Sample with Other

SRO Hotel Study Samples on Selected

Demographic Characteristics . . . . . . 166

VIII Means, Standard Deviations, and $t$-test

Comparisons of SRO Hotel and Section 8

Apartment Residents' Comments on an Open-

ended Assessment of their Most Recent SRO

Hote1 . . . . . . . . . . . . 176

IX Favorable and Unfavorable Assessments of SRO

Hotel Housing by Current Hotel and Section 8 Apartment Residents on their Most Recent SRO Hotel . . . . . . . . . . . . . 
TABLE

PAGE

$\mathrm{X}$ Comparison of the Ratings of Selected Functions of Housing by Two Samples: Current SRO Hotel and Section 8 Apartment Residents • . 186

XI The Most Important Difference Between SRO Hote1s and Section 8 Apartments as Reported by Present Apartment Occupants . . . . . 189

XII Responses of Current SRO Hotel Residents to a Question Regarding their interest in Moving to a Section 8 Apartment . . . . . . . . . 193

XIII Favorable and Unfavorable Assessments of

Neighborhood by Current SRO Hotel and Section 8 Apartment Residents . . . . . . 198

XIV Preferred Housing Location if Resident was

Forced to Move from Present Dwelling . . . 202 XV Means, Standard Deviations, and $t-t e s t$

Comparisons of SRO Hotel and Section 8

Apartment Residents on Selected

Sociodemographic Characteristics . . . . 207

XVI Description of Discriminant Analysis Functions

Used to Differentiate SRO Hotel and Section

8 Apartment Residents . . . . . . . . 210

XVII Comparison of Facility Usage of SRO and Non-SRO Elderly . . . . . . . . . . . . 220 
XVIII The Costs to Operate and Maintain, Rehabilitate, and Construct Section 8 Apartments . . . . 246

XIX The Costs to Operate and Maintain, Rehabilitate, and Construct New SRO Hotels . . . . . . 247

XX The Cost to HUD for Subsidizing Rents of Section 8 Apartments and the Anticipated Cost to Subsidize Rents for SRO Hote1s. . . . . . 258 XXI An Example of the Impact of Reduced Interest Rates on Operating Expenses . . . . . . 265 


\section{LIST OF FIGURES}

FIGURE

PAGE

1. Downtown Portland and Study Area . . . . . 127

2. Neighborhoods Surveyed for SRO Cost of Living . . 149

3. Example of Seven-by-seven-block Area Surveyed for Cost of Living . . . . . . . . . . . 151

4. Monthly Costs for the SRO Market Basket and

Component Categories by Neighborhood . . . 230

5. Comparison of Month1y Cost Differential for the

SRO Market Basket and Component Categories

Using Values for the Downtown Neighborhood

as Base Zero ............. 232

6. Cost of Selected Types of Housing Units in Four Neighborhoods . . . . . . . . . 237 


\section{CHAPTER I}

\section{INTRODUCTION}

The downtown of almost every major city in the United States contains a number of old, frequently rundown hotels. In some, the hotels are interspersed with new retail and office development. In others, they are clustered in small enclaves around the downtown. In either case, these hotels are home to their residents, many of whom have lived in the same hotel for years. It is on these hotels and their older residents that this study will focus.

The old hotels vary widely in size and type of accommodations, but the most common is referred to as the single room occupancy hotel. In such a hotel, one room is occupied by a single tenant. There are occasions where several persons occupy a single room but this is not the norm. Thus the name single room occupancy refers to the amount of space occupied by a resident.

A typical single room occupant hotel room, or SRO hotel room, is sparsely furnished with a bed, dresser, closet, chair, and wash basin. Bathrooms are shared, usually by several persons per floor, depending on the number of rooms on each floor. Cooking facilities are almost never available and are shared when they are, thus local 
restaurants and/or illegal hot plates in the resident's private room provide the alternatives for food preparation and eating. Some maid service and a weekly change of linen is generally included as part of the rent. Though the rents tend to vary, they are frequently the lowest unsubsidized rents available anywhere in a city.

Congress drafted and approved legislation in 1949 which set as a national goal the "decent, safe, and sanitary" housing of the American people. The SRo hotels were not the type of housing they foresaw as meeting that goal. More likely, many viewed the legislation as a step toward replacing such indecent, unsafe, and unsanitary housing. In order to direct the development of decent housing, criteria specifying minimum standaras for an acceptable dwelling unit were approved. Those criteria, known as the minimum property standards, defined an acceptable unit as being self-contained, i.e., one which included a complete bathroom and kitchen. Also addressed in those standards were the size of the unit, the amount of window space, and other design features; but it was the designation of units without complete bathroom and kitchen as substandard which most affected the SRO hotel.

By using the self-contained unit as the criterion for a standard unit, all SRO hotels were classified as substandard housing. What this meant was that the agency responsible for achieving the national goal of decent, safe, 
and sanitary housing, the Housing and Home Finance Agency (HHFA), would not be interested in spending their resources on maintaining such substandard units as SRO hotels. In fact, many urban renewal projects removed SRO hotels.

But HHFA and its successor, the Department of Housing and Urban Development (HUD), has not been the only force which precipitated the removal of SRO hotels. The increased value of land in the downtowns of nearly all major cities has caused a change in uses of select parcels of land. These changes are most pronounced in inflationary times. Most affected are those parcels which, in their existing use, are seen to be an underutilization of the site's full development potential. This could mean that the present structures do not contain the maximum number of square feet allowed by current zoning codes and thus are not producing their maximum potential rent or that the rent derived from the existing use is lower than the rent which could be garnered if the use were changed. Both definitions of underutilization assume that the ideal condition for any given parcel of land is for it to earn its maximum potential dollar return, i.e., be utilized for its highest and best use. Because SRO hotels typically have a lower square footage than that allowed on a site and may have a lower rent capacity than some other uses, they are often selected for razing or conversion to another use.

Yet another situation that tends to influence an SRO 
hotel's likelihood of continued operation is its physical condition. Periodic maintenance of the hotels is sometimes neglected and as a result both exterior and interior portions of a building may be in need of repair. An obvious state of disrepair tends to encourage neighboring property owners and businesses or local elected officials to view the SRO hotel as an undesirable element. Given such a perspective, removal of the old, run-down hotels is seen as a step toward improving or upgrading the downtown by making it more attractive to shoppers, business persons: convention goers, and the like.

Because of his appearance and behavior, the SRO hotel resident is not seen as a necessarily desirable or pleasant element of downtown but rather as a potential detriment to its development. Two general characteristics which describe nearly all the sRo hotel residents are that they live alone and they are poor. Additionally, the vast majority are male and a large number are elderly pensioners. Beyond those similarities the residents tend to differ. Some are long-term residents of their hotel while others are transient. Some drink excessively, almost constantly. Others do not drink. Because most residents are not employed, especially the elderly pensioners, they have little to keep them busy and thus tend to do such things as gathering in the hotel's lobby which is visible to the street, hanging around outside local businesses talking and watching 
passersby, appearing on the street when drunk, dressing in old clothes, and patronizing the less expensive restaurants and "seedy" establishments such as card rooms. Local elected officials, business persons, and property owners sometimes feel that attracting new investors and businesses to a downtown is easier without a noticeable contingent of SRO residents. Thus, plans, policies, and actions are frequently adopted which discourage the retention of SRO hotels in downtown locations.

To summarize, there are at least four forces currently working to reduce the number of SRO hotels in the downtown of most major cities across the nation. Those forces are:

1) a determination by HHFA and HUD that SRO hotels are substandard dwelling units, 2) an increase in the value of downtown land, 3 ) the extent of physical deterioration of the SRO hotels; and 4) the level of social unacceptability of the SRO hotel residents.

It is assumed in this study that a reduction in the lowest-cost housing stock is, in and of itself, problematic. With the current high cost of new construction and substantial rehabilitation, the present inability of public housing programs to satisfy the existing demand for low-cost housing, and the increasing number of persons in this country who are aging, low-income elderly face an increasingly difficult task of locating affordable housing. Based on this understanding, the following study examines 
SRO hotels as a form of housing for at least a portion of the low-income urban elderly.

\section{STUDY DEFINITIONS}

There are three terms used throughout this study for which early clarification of meaning is important. The reader may or may not have some familiarity with the terms. Presentation of the definitions at this point is an attempt to prevent misinterpretations, especially by those who use the terms differently than does this study.

\section{Single Room Occupancy (SRO) Hotel}

Various studies have addressed different aspects of single room occupancy hotels. Albeit description was provided in the preceding section, the following list of characteristics summarizes the typical sRo hotel and was constructed from the available literature on the subject (Eckert, 1978; Ehrlich, 1976; Fielding, 1972; Lawton 1976; Niebanck,1970; Plutchik, McCarthy, Hall, \& Silverberg, $1974 ;$ Plutchik, McCarthy, \& Hall, 1975; Silverberg, 1976; Stephens, 1976):

The typical SRo hotel is an older building, located in the downtown commercial area of a city. Most were originally constructed as hotels but some may have been converted from other uses, such as a multifamily apartments. 
The room size is small, generally about 9 feet by 12 feet, and is furnished with bed, bureau drawers, chair, sink, and small closet or wardrobe.

The toilet and shower facilities are shared, sometimes between two rooms, but more typically shared by the residents on each floor. If cooking facilities exist, they are also shared, i.e., one per floor or an illegal hot plate in the room.

The services of a maid and clean linen (once per week) are nearly always provided and a hotel clerk is usually present at the front desk. However, no formal support services such as meals or recreational programs are provided.

The SRO hotel is neither federally subsidized nor licensed for institutional care.

A hotel in which each unit contains its own bath facilities is not an SRO hotel according to this definition. Neither is an apartment house in which each unit contains a kitchen but the bath facilities are shared. Additionally, a room and board arrangement, even though it occurred in a hotel structure would not be classed as an SRO hotel due to the provision of meals. Such dwelling units are similar to an SRO hotel in selected ways but are not classified as a "true" SRO hotel. 
Section 8 Apartment

Section 8 refers to that portion of the Housing and Community Development Act of 1974 in which the rent subsidy program for low-income and elderly persons was created. The program is one in which a rent supplement is paid by HUD to the owner of an apartment building. The supplement is the difference betwesn the rent paid by the tenant and the actual rent for the unit. The apartment building must meet certain specifications in order to qualify and the regulation most pertinent to this study is the need for all units to be self-contained. This means sRo hotels do not qualify for the rent subsidy program.

The way the program generally works is as follows: An existing structure is rehabilitated or a new structure is constructed to meet building specifications for the program. The new tenants of the building, who must satisfy certain criterion, pay no more than 25 percent of their monthly income for rent. The remainder of the tenant's rent, which is established by HUD based on fair market rents, is paid by HUD. The program enables those with low incomes to afford decent, safe, and sanitary housing without paying an exhorbitant portion of their income for rent.

The specific section 8 program relevant to this study is that which serves elderly persons, i.e., those who are, a) low income and 62 years of age and over, or b) low income and disabled or handicapped. The phrase "section 8 
apartment" will be used to denote a dwelling unit in which a "subsidized" elderly tenant resides.

(Note: There is another section 8 program known as "existing section 8", which is operated through the local housing authority. In this program, a qualified recipient is responsible for locating his/her own housing unit from the existing stock of privately operated rental housing. Once that unit is approved by the housing authority, the resident pays no more than 25 percent of his/her income for rent and HUD, through the auspices of the housing authority, pays the remainder of the rent which is based on a fair market rental agreement.

With this program there is generally no substantial rehabilitation to a unit. If a unit does not meet the required standards for decency, safety, and sanitation, the recipient is encouraged to locate another unit or the landlord is encouraged to make the necessary repairs. Typically, recipients are not eager to wait the time required for a landlord to make substantial repairs to a unit and as a result select units which need little or no repair. Because there is little rehabilitation involved the fair market rents established for this program are lower than for the other section 8 program described above.

Though this program provides housing to the low-income at less cost to HUD, it is not used in this study's comparisons. The primary reason is the program depends upon 
the existing stock without the generation of major rehabilitation. Given that almost all SRO hotels would need some level of rehabilitation in order to make them into decent, safe, and sanitary housing, comparisons are limited to the program which could facilitate such rehabilitation.)

\section{Upper Skid Row}

Rather vague references have been made in the literature on skid row to "better" areas, areas where the population appears to be less alcoholic and more stable in terms of tenure at one location. It is one of these areas, here defined as "upper skid row", upon which this study focuses. This was the term used by residents of the area to distinguish "their" portion of downtown from what they described as the "less desirable" portion of downtown, i.e., the skid row area.

A similar distinction may not exist in all downtowns which contain SRO hotels. The downtown examined in this study (Portland, Oregon) contains a prominent physical separation between upper skid row and skid row, i.e., a six lane boulevard. The differences between the two areas are apparent even to the outsider. SRO hotels are more expensive in the upper skid row area usually by $\$ 20$ to $\$ 30$ per month or by about 30 percent more. The tenants of the upper skid row hotels tend to appear more socially acceptable in that they generally do not gather on the streets, drinking or just hanging about. The upper skid row residents view 
themselves as a cut above the skid row residents. They indicate skid row is a place where they do not wish to go.

The distinction between the two skid rows is important for two major reasons. First, it puts the reader on notice that comparison of this study's findings with those of other skid row populations may vary to some degree. Secondly, it will hopefully encourage researchers to examine similar differences in other locations.

To summarize, the intent of this section is to eliminate any confusion about this study's use of the terms single room occupancy hotel, Section 8 apartment, and upper skid row.

STUDY LIMITATIONS

Several parameters of this study should be noted before proceeding further. The first relates to the type of SRO hotel structure and the second, to the type of SRO resident that is examined in the study.

\section{SRO Hotel Structure}

Only those structures originaliy constructed as hotels are examined in the present study. In the definition of SRO hotels, it was noted that some SRO structures were created through the conversion of buildings from other uses. Usually such conversions were from multifamily apartments houses. In such cases, the various rooms of the apartments were separated through the use of partitions. This process allows 
for the rental of each room as a single unit. In some locales, this type of single room housing comprises a substantial portion of the city's single room stock. This is more likely to be the case in eastern cities where a stock of older walk-up apartments was available for conversion. However, in Portland, no converted units existed in the downtown area; thus SRO units created though the subdivision of larger units are not included as part of the sample of SRO hotels examined in this study.

\section{Type of SRO Resident}

For the purpose of this study, only single residents occupying a single room will be considered. This parameter is noted in an attempt to avoid any confusion with the situation of an antire family residing in a single room. This is a circumstance which has occurred in the past and will no doubt continue to occur, especially as the cost of housing increases. It is not a situation this study addresses.

In addition to one person per room, this study examines only the elderly male SRO population. Previous studies of skid row or SRO residents have reported a high proportion of the population to be male and elderly (Bogue, 1963; Vander Kooi, 1967; and Eckert, 1978). It has also been noted that men tend to have higher incomes than their female counterparts (Ehrlich, 1976). Given the likelihood of finding relatively few female sRo residents and the 
differing circumstances under which they must subsist, women were not included in this study's sample. It was thought that elderly, female SRO residents or simply female SRO residents should be the subject of a future study. Similarly, it was thought that the younger, male SRO population, i.e., those under 55 years of age, would best be examined in a separate study.

By establishing the above parameters for the study, it was felt the findings would be less encumbered by factors which could only introduce extraneous variance.

\section{NATURE AND COMPONENTS OF THE STUDY}

This is a policy study. In it a problem is examined, the impact of the problem is assessed based on empirical findings, and recommendations are proposed as a means of resolving the problem. To properly examine the various facets of the problem, several perspectives are considered. These facets can be seen as the different perspectives of interested parties. In addition to considering various perspectives, the components of the problem are identified and each is examined empirically. Findings from the empirical analysis are interpreted and synthesized with respect to the various perspectives.

\section{A Rolicy Study}

In a policy study, there is the assumption that a condition exists which is either currently problematic or 
has the potential of becoming so. In the case of this study, it is assumed that the loss of SRo hotels, some of the lowest-cost, unsubsidized rental housing in existence today, is currently a problem and has the potential to become increasingly severe. The foundation for this assumption is based on the writings of housing experts, economists, gerontologists, and government officials. They suggest that the low production of rental housing, the on-going inflation, the increasing number of elderly persons, their deperdence upon fixed incomes, and the government's inability to satisfy current demands for low-cost housing all point toward a continuing problem of housing the low-income elderly.

Given the basic understanding of the issue, it is then necessary in a policy study to examine the problem from the perspective of different interests. As noted earlier, there are a number of forces which have the impact of reducing the number of SRO hotels. From the perspective of the resident, he is a renter and as such no doubt wishes to see his hotel remain open and the rents to remain low. The owner of a hotel may have a different view though; he may be holding a property for speculative purposes. If an offer is made, the owner may be more than willing to break the manager's lease in order to sell the property. Local officials might be delighted to see an SRO hotel replaced or rehabilitated into a structure which will pay a higher property tax. On the 
other hand, local officials might not welcome the need to provide social services to displaced residents in addition to assisting their move to another location. From the perspective of federal housing officials, they may be pleased that a portion of the "substandard" housing stock is being removed, but on the other hand, increased perssure may be placed on them to provide additional low-cost units despite little or no adjustment to their program budget.

The consideration of these differing interests is necessary if the proposed resolution is to incorporate major elements of the problem. This process can be seen as establishing the "gestalt" of the problem. Once the context of the situation is known, the empirical analysis can draw from that background.

\section{Components of the Empirical Analysis}

Based on the different perspectives regarding the loss of SRO hotels, three components are identified as essential to this study. They are the housing unit, its location or neighborhood, and the resident of the housing unit. Cost is a fourth component and is integrally related to the other three.

The Housing Unit. The major focus of this study is a particular type of housing unit, the SRO hotel. Because this investigation addresses the impact of loss of such housing units, it is necessary to examine not only the SRO hotel but alternative housing as well. The hotel units are low-cost 
rental units and thus any alternative housing would need to be similar in cost. Section 8 rent subsidized apartments are low-cost and that program is currently the major impetus for the creation of low-cost rental housing. Based on section 8's major role in providing new low-cost housing, it is the alternative type of housing with which SRO hotels are compared in this study.

The two types of housing are examined using a modified pre- and post-test format. For the SRO hotel, current residents as well as previous residents are interviewed. The previous residents are those who moved to section 8 apartments from an SRO hotel. Both groups are asked to evaluate the SRO hotel on a number of criterion. For the Section 8 apartments, current residents and potential residents are interviewed. The current apartment residents are the previous SRO hotel residents. The potential residents are the current hotel residents who could qualify for section 8 apartments. Again, both groups are asked to evaluate the Section 8 apartments, the former from their experience as a resident and the latter from their expectations. This allows the study to address questions of preference for and satisfaction with the two types of low-cost housing, as well as to compare objective factors such as the percent of income paid toward rent.

The Location or Neighborhood. The consideration of policy matters regarding housing, especially housing for the 
elderly, cannot be divorced from an examination of the environmental setting. For this reason, neighborhood is also a major component of this study. In any examination of the SRO hotel, downtown is an obvious neighborhood which must be considered. Based on the premise that a continued loss of SRO hotels would lead to a reduction of low-cost housing in downtown, there is an equally obvious need to consider neighborhoods outside the central area.

In this study, investigation of several neighborhoods, outside downtown, in addition to downtown, allows an analysis of the "fit" between person and his environmental setting. The environments are neighborhoods recognized by local housing experts as "good" locations for eideriy persons due to availability of stores and services nearby. Comparison of the neighborhoods is based on such essential elements as the level of rents in the area, the price of selected commodities and services, and access to or availability of facilities. In addition to comparing neighborhoods in terms of ability to meet various needs of low-income elderly, the study also addresses the hotel resident's preference for a residential location and satisfaction with his current neighborhood.

The Resident. Though the major focus of this study is the housing unit, any consideration of policy would be decidedly inadequate without an examination of the resident. In this case, the sample is a select portion of all current 
SRO hotel residents, i.e., only the elderly male residents. Additionally, as noted above, a second sample of residents is considered in a portion of the study. These are previous SRO hotel residents who moved to section 8 apartments located in the downtown area.

As the reduction in the number of sRo hotel units is a nation-wide occurrence, the sample of Portland's elderly SRO residents is compared with samples from other cities. Such a comparison helps to determine the similarities and differences among SRO populations in various cities. These results have implications for generalizing findings based on the Portland sample. Comparison of the current and past SRO hotel populations is helpful in attempting to distinguish any differences between those who chose to move to section 8 apartments and those who remain SRO hotel residents. Given that section 8 apartments are currently the primary mode of replacing lost low-cost units, the identification of variation between SRO and section 8 residents could be particularly noteworthy if there were some indication that it reflected fundamentally different lifestyles.

cest. To this point, the description of study components has addressed the matter of cost from the perspective of the resident of the housing unit. How much is the rent? How much does it cost to live in the neighborhood? The other perspective considered in the study is the cost of providing housing as opposed to the cost of affording 
providing housing as opposed to the cost of afforaing housing. From the perspective of the provider, the cost of housing includes such elements as the price of land, construction, operation, maintenance, taxes, and debt service. If the housing provided is an SRO hotel, costs of provision are based on either maintaining an existing hote 1 or constructing a new one. If the housing provided is a Section 8 apartment, costs of provision are basea on new construction or converting a building from another use to an apartment house.

Comparison of these costs provides a partial assessment of the economic viability of the various modes of generating low-cost housing. In conjunction with situational factors, such as government subsidies, tax incentives, and economic constraints, the reasonableness of one mode of provision over another can be assessed.

Thus, these four components, the housing unit, the location or neighborhood, the resident, and costs are the basic elements to be examined in this study. Stated another way, they are the matters on which data is to be collected. The policy recommendations, which are the ultimate product of this study, are a synthesis of the findings from these data. 
CHAPTER II

\section{REVIEW OF THE LITERATURE}

This study examines the elderly sRo resident, his housing, his neighborhood, and the concomitant question of policy.

The review of the literature notes that overall, the cost of housing is a significant factor for a majority of the elderly population. This is so because the elderly are, on the whole, a lower income group; most live on a relatively fixed income. Ability to pay the price for iousing is therefore of paramount concern, and as such, a parameter which guides the elderly's selection of their housing.

Cost, though, is by no means the only consideration. Given that the elderly's ability to cope with their environment generally tends to decrease with increasing years, the concept of congruence between person and his environment is particularly relevant to the study of an older population. Theoretical models of person-environment interaction suggest that a "match" or "fit" between a person and his environment can result in an ability to obtain needed resources and an ability to deal with "press" or forces from the environment. Thus, the individuals' need or 
preference for particular amenities relative to a housing unit or neighborhood and his capacity to respond to environmental press also influence the selection of housing. The selection of a particular housing unit and neighborhood is a means to satisfy some personal needs and preferences. Any assessment of a person's success at satisfying those needs and preferences, or achieving congruence between individual capacities and environment, must first determine the categories to be examined. Relative to housing and neighborhood there are a number of "basic functions" which such environmental considerations can be expected to satisfy. Those "basic functions" include provision of shelter from the elements, privacy from other individuals, access to neighborhood amenities and access to transportation--all at an affordable cost. They represent the primary functions the housing unit and its surrounding environment are expected to satisfy.

Needs, preferences, and competencies are not fixed conditions; they vary with the individual and his personal situation. The elderly, as a group, are noted for their diversity rather than for their homogeneity. As such, different subgroups of the elderly population tend to select certain housing and neighborhood amenities over others. When compared with other elderly persons, on the basis of demographics, social characteristics, use of neighborhood facilities, preference for housing and the like, SRO hotel 
residents are quite different. Such a diversity implies the need for equally diverse environments. With the ideal of a match between the person and his environment and the given diversity among the elderly population, consideration of the person's needs, preferences, and competencies is of utmost importance in any attempt to plan an environment for the elderly.

The implication for the SRO resident and his hotel is that prior to the adoption of any policy, both the housing unit and its surrounding environment must be examined relative to its congruence with the inhabitants. The need for such a review is made timely by the ongoing loss of SRO hotels in most major cities. If the downtown neighborhoods with their SRO hotels provide a congruence between person and environment then their loss may alter the hotel residents ability to satisfy personal needs and preferences given individual competencies.

The review of the literature which follows is divided into five parts: the functions of housing; housing and the elderly; neighborhood and the elderly; SRO hotels and their elderly residents, and policy considerations.

\section{PART A: THE FUNCTIONS OF HOUSING}

When households consume "housing," they purchase or rent more than the dwelling unit and its characteristics. They are also concerned with such diverse factors as health, security, privacy, neighborhood, and social relations, community facilities and service, access to jobs, and control 
over the environment (Pynoos, Schafer \& Hartman , 1973, p.1).

The term "housing" is commonly described by way of reference to a particular function or set of functions which a dwelling unit is expected to fulfill. This section explores the basic functions of a dwelling unit. These functions are examined from the perspective that in addition to an objective measure of the unit's functioning, there is an equally important consideration, i.e., the perspective of the individual occupant of the housing unit and the expectations he holds for fulfillment of a unit's functioning. In this context, fulfillment of a function is similar to the provision of a service and it is from this standpoint that the basic functions of housing are examined in relation to their importance for a low income, urban elderly population.

In his book Housing: The social and Economic Elements, Wallace Smith (1970) identifies five basic functions of a dwelling unit: the provision of shelter, the provision of privacy, the provision of access to other locations, the provision of environmental amenities, and the provision of an investment. He describes shelter, or the protection of dwellers from the elements and enemies, as only a portion of what constitutes housing. In fact, he sees shelter as a "relatively minor aspect," of housing. Privacy is characterized as a social concept though its attainment is primarily through physical or architectural solutions. An 
assessment of what is private and what is not is dependent upon such things as an individual's cultural background and personal preferences. Access to other locations refers to some means of travel and the distances which must be traveled. Housing is typically selected with some awareness of available modes of transit and the proximity of desired resources and activities such as employment and shopping locations. Smith notes that there are practical limits to the dispersion of housing based on a "...desire to economize on the time and cost of transportation." The environmental amenities are described as "...the characteristics of the surrounding area which affect the desirability of the residence." Such amenities as quality of schools, fire and police bureaus, availiability of parks, hospitals, and physical appearance of the neighborhood (trees, cleanliness) are mentioned as contributing to the desirability of a neighborhood. Smith's last function, investment, is directed toward those who own their place of residence as opposed to those who rent.

Because the present research focuses on SRO hotel residents who do not own their places of residence and are unlikely to be able to do so in the future, Smith's descriptions of the functions of housing are re-examined. The description of shelter, privacy, and access to other locations are general enough that they would apply to nearly any population. However, for the purpose of this study, the 
description of environmental amenities needs some modification. As is noted in a later part of this chapter (Neighborhood and the Elderly), the characteristics of a neighborhood which affect its desirability are to some degree dependent upon the perspective of the indiviaual, i.e., personal tastes and needs (Campbell, Converse, \& Rodgers, 1976; Hamovitch \& Peterson, 1969). Some of the characteristics Smith lists, such as the quality of schools and police protection and the availability of parks and playgrounds, might best describe the tastes and needs of a family with children. For the low-income elderly, such amenities are rated as less important when compared with basic services such as a local shopping center and easy access to transit (Golant, 1972; Regnier, 1975). Golant (1972) noted in his study of the elderly's behavior in selecting a residential location, that ratings of importance of neighborhood chracteristics tended to vary between those of different income groups. Drawing from Kahana's (1975) and Lawton's (1977) theoretical perspective of congruence between person and environment, personal needs and capabilities are suggested as a more accurate basis for determining the characteristics which would constitute their particular environmental amenities.

Smith's notion of housing as an investment also needs some modification. Renters do not receive an investment from their dollars spent on housing as do homeowners. Instead, 
they receive a fixed amount of services such as an apartment for one month with all the utilities paid. Consequently, for the renter, especially the low-income renter, a measure of affordability is a more appropriate description of the economic function of housing for its occupant. Given the modest, relatively fixed-income of most low-income elderly, successful fulfillment of this economic function of housing is imperative. With these modifications then, the five functional categories of housing examined in this study are: (a) shelter, (b) privacy, (c) access to ether locations, (d) neighborhood amenities, and (e) affordability.

The underlying purpose for investigating the functions of housing is based on the assumption that through examination of the various functions which a dwelling unit is expected to fulfill, an assessment of the unit's usefulness to a selected population can be determined. It is thus postulated that the level of usefulness is an appropriate criterion for assessing the acceptability or unacceptability of a particular style of housing for a particular population. The discussion which follows examines each function of housing from the perspective of its importance to a low-income elderly population. It also addresses the matter of identifying components of each function which can be measured either objectively or subjectively. 
Sheltex

A very basic function of a dwelling unit is to provide shelter to its occupants both from the weather and from those with criminal interests. For an elderly person adequate shelter can mean the difference between health and illness. With increasing age, extremes of temperature tend to be more difficult to tolerate (Kart, Metress, \& Metress, 1978). It has been reported that low temperatures tolerable to a younger person may, in fact, bring on hypothermia in an older person.

Adequate shelter can also help reduce an elderly person's chances of being victimized. Secure doors and windows, and monitored entrances to multifamily buildings help to assure a safe dwelling unit. As an elderly person ages and experiences a reduction in muscle tone, strength, and response rate, the need for a secure dwelling unit increases (Harris, 1978). The current rate of crime perpetrated against elderly persons adds to the importance of this type of protection. For an elderly occupant, shelter provided by a dwelling unit can aid in the preservation of health and safety.

To measure a dwelling unit's level of functioning relative to provision of shelter, several approaches are possible. Objectively, a unit's temperature can be measured, inspection for water and wind leaks can be made; doors and windows can be checked for security of locks. Another 
approach is to survey the occupant for his views relative to security. Is there adequate heat? Does he worry about someone breaking into his dwelling? Both approaches would provide information with which to judge a unit's level of functioning: the first, an objective measure which could be compared to some standard limits of acceptability or unacceptability; the second, a subjective assessment, based on the tenant's own perspective. The latter would reflect how well matched were the resident's personal needs and competencies, and his present living environment.

\section{Privacy}

Smith (1970) describes privacy as having both physical and psychological components. As a function which housing is expected to fulfill, the physical aspect of privacy is associated with the notion of actual separation. Traditionally in the United States this means one family per dwelling unit and a buffer from sounds emanating from inside neighboring units. The psychological component is not directly dependent upon physical separation and tends to be influenced by an individual's cultural background, expectations, and past experiences (Altman, 1975). For the elderly, privacy in housing takes on a special meaning. Frequently, reliance on teetering legs and failing eyesight in one's own home is seen as preferable to a less independent, less private environment of living with relatives or in a home for the aged (Lawton, 1970). This 
protection of independence reflects both the physical and psychological aspects of privacy, the desire for a separate unit as well as the desire for a sense of separateness. The physical aspect of privacy lends itself to a degree of objective analysis. A survey of dwelling units and their inhabitants can ascertain such information as the number of persons per housing unit and persons per acre. This would not, however, address the auditory component of physical privacy, i.e., whether sound, and how much sound, was audible from neighboring units. One means of measuring such sound would be the use of specialized equipment. Another would be to interview the unit's occupants. Given that many elderly persons have reduced auditory capacity, equipment may report "excessive" levels of noise even though the elderly resident may report hearing no noise at all. This distinction is noted in order to highlight the role of the occupant in assessing a housing unit's ability to fulfill various functions.

Regarding the psychological aspect of housing privacy, the occupant's personal history and expectations are a major factor in any assessment of a unit's functioning. A dwelling unit which is seen as providing ample privacy for one individual may be far too intimate for another. Eliciting the residents satisfaction or dissatisfaction with his current dwelling unit relative to the level of privacy and separation it provides is the most direct method of 
assessing the unit's functioning.

\section{Access to ether Locations}

Much of a later section in this literature review will address the importance of access to other locations for low-income elderly persons (see Neighborhood and the Elderly). It is noted that physical capabilities tend to decrease as age increases and that one consequence of this reduction is increased difficultly with mobility (Kart, et al., 1978). Driving an automobile after dark may become impossible due to poor night vision, or driving altogether may become dangerous due to restricted movement of an arthritic arm or hip. Boarding or leaving a bus may become too difficult due to the height of the initial step. For these and similar reasons, access to other locations may be restricted to either walking or being driven by a friend or relative. Proximity to necessay "other locations" via footpath or sidewalk is a minimal requirement for the assurance of some degree of access. This is especially important for the low-income as they tend to have only limited resources which can be set aside for the purchase of transportation services. Person-environment theories suggest individuals select living arrangements which complement their needs and preferences, be those physical or economic. Having the best bus service in town means nothing to those who cannot board a bus; neither does it have meaning for those who cannot afford it. 
In terms of measuring access to other locations, the availability of public transit, highways, sidewalks, bicycle paths, and the like can be tabulated with their presence or absence representing an objective measure of access. It is imperative, though, that a person's own capabilities for using such a means of access also be considered. The question of access to other locations then becomes, is there a means of transportation available when it is needed?

\section{Neighborhood Amenities}

This function is closely related to the function of access to other locations. The primary need is for access to the various neighborhood amenities such as grocery store, church, pharmacy, and restaurant. For the elderly, the existence of these amenities in the neighborhood can mean the difference between self-sufficiency and dependence especially for the impaired or deprived (Lawton, 1980). For the low-income elderly, the existence of facilities which carry modestly priced goods is extremely important. That the elderly use neighborhood amenities and report satisfaction with a neighborhood which contains amenities and dissatisfaction with one which does not is well documented (Golant, 1972; Lawton, Kleban \& Carlson, 1973; Regnier, 1973).

In order to measure how well a dwelling unit fulfills the provision of proximity to amenities for its residents, some assessment of the preferred or necessary amenities is 
paramount. Based upon the residents' preferences and needs, a survey of the surrounding area can be used as a means for rating a dwelling unit's fulfillment of the function.

\section{Affordability}

To the low-income elderly who live on fixed incomes, the matter of affordable housing is uppermost in their minds. Not only does affordable mean paying less than some set amount of rent per month, it also means that other costs associated with housing either directly or indirectly are kept as low as possible. If the rent for one unit is slightly higher, but there is little need for public transit due to the unit's convenient location, then such a unit would be comparable, at least in some respects, to a unit which was slightly cheaper but required more use of public transit. One cost can be traded for another in an attempt to minimize total expenditures.

Traditionally, affordability of housing has been measured as the portion of rent and other housing costs paid out relative to the amount of income (Milgram, 1979). For many years, 25 percent of the household income has been used as the standard for calculating the maximum amount a family should pay for housing (Milgram, 1980). In addition to the percent of income paid for housing, any measure of affordability for low-income elderly would be incomplete without consideration of other economic costs such as transportation, groceries or meals, personal items, and 
recreation.

An assessment of these housing functions forms the basis for measuring the adequacy of a dwelling unit. Consideration of the occupant's perspective rather than a simply objective assessment allows for varying interpretations of the same conditions. Such variation is related to the congruence between person and environment in a later review section. 
PART B: HOUSING AND THE ELDERLY

\begin{abstract}
Housing is an indispensible essential for human life. Programs of nutrition, physical and mental health care, income maintenance, transportation, retraining for employment, involvement as a volunteer, continuing education, and leisure and recreational activities are ineffective if the "right home", in terms of location, adequacy and safety, is not available at reasonable cost for the older adult. (Mathieu, 1976, p.154)

Housing is the number one financial expenditure for the elderly, and, on the average, it accounts for over one-third of their budget. The task of providing adequate housing throughout old age on a relatively fixed income and in the face of rising costs is becoming increasingly impossible for a large segment of the older population. (Harris, 1976, p. 176)
\end{abstract}

It has been estimated that 16 percent or about 3.9 million elderly persons in the United States had incomes below the poverty line in 1980 (U.S. Bureau of the Census, 1981a). For this group and for those with incomes only slightly above the poverty level, the price paid for housing becomes a major consideration as they attempt to balance expenditures with available resources. The current condition of spiraling inflation only tends to exacerbate the difficulty many of these low-income elderly persons have as they search for affordable housing. The cost of utilities, maintenance, labor, and money all contribute to the increasing cost of housing. As these costs increase, the range of housing choices which are attendable to those with the lowest income tends to decrease. 
The Elderly's Economic condition

Two factors which affect the elderly person's income following retirement are the source(s) of that income and any periodic adjustment of that income. Sources of income might range from public programs, such as Social security and Supplemental security Income (SSI) to private sources such as pension plans or return on investments. Periodic adjustments might include such things as cost-of-living increases added to social security payments or returns from equity from increasing value of property investments. An important consideration in this discussion of the elderly's economic situation is whether individuals have sufficient resources to meet their needs, especially given the continuing inflationary trend. The typical SRO hotel resident is in the precarious position of being among the poorest of the elderly and as such is ill-prepared to handie increased economic burdens.

In his Eact Book on Aging, Harris (1978) describes the economic situation of the elderly population of the United States. The median income for families with heads 65 years of age or over was $\$ 8,057$ in 1975 . For households composed of unrelated individuals or those living alone or with non-relatives the median income for the older population was $\$ 3,311$. Of those with below median incomes, Harris notes that there are two subpopulations, the "poor" and the "near poor". The poer are those who fall below the poverty line, 
which in 1975 was $\$ 3,232$ for two-person elderly families, and $\$ 2,791$ for unrelated elderly persons. ' The near peor are those with incomes of 125 percent of the poverty level. For those with heads 65 years of age or over, the near poor were defined as two-person families with incomes of at least $\$ 4,040$ in 1975 or unrelated persons with incomes of $\$ 3,215$ or less. Using these guidelines, one quarter $(5.5$ million) elderly households in the United States were classified as near poor and one-half $(3.3$ million $)$ of the unrelated elderly households were classified as near poor. Additionally, of the unrelated elderly households, almost one-third $(2.1$ million) had incomes below the poverty line and were thus classed as poor.

As for elderly SRO hotel residents, Ehrlich (1976) reported that the median monthly income for her st. Lou is sample was $\$ 231$ or an annual income of $\$ 2,772$. Ehrlich collected her data in early 1975 which means it is directly

\footnotetext{
In 1980, the poverty level for a two-person elderly household was $\$ 4,983$ and $\$ 3,949$ for a one-person elderly household. Since 1975, the percentage of elderly persons with incomes below the poverty level has remained virtually unchanged; it was 15.3 percent in 1975 and 15.7 percent in 1980. However, the rate has decreased since the early 70 s when Social Security, Supplemental Security Income, and some Veterans Pensions were linked to the Consumer Price Index. In 1970, 24.5 percent of the elderly had incomes below the poverty level. It should be noted that the income figures used to calculate the number of persons who have poverty level or lower incomes does not inc? ide the value of transfer payments from such sources as food stamps, rent subsidies, and medicare payments. If the value of these payments were included in the calculation of income the number of persons below the poverty level would be decreased.
} 
comparable to Harris' figures. It can be seen that the annual median income for the St. Louis SRO resident is just below the poverty line for unrelated individuals or those living alone or with non-relatives. Eckert's (1978) sample of elderly San Diego SRo residents had a median income of \$289 per month. Though this represents a slightly higher income, it must be noted that Eckert's data was collected in early 1976. Thus, it can be concluded that SRO residents are definitely among the low-income elderly.

The sources from which the elderly draw their retirement incomes are varied but the most important is Social security. In 1975,90 percent of the unrelated individuals or those living alone or with non-relatives who were 65 years of age or over received Social Security (Harris, 1978). Fifty-four percent received the next most frequent source of income, i.e., property incomes such as interest and dividents. Only 23 percent had any income from private pension plans. Fourteen percent received SSI. By comparison, 84 percent of the St. Louis SRO residents received Social Security payments (Ehrlich, 1976). Twenty-two percent received income from SSI and fourteen percent received some wages. No mention was made of whether any received income from private pensions. It is difficult to compare these two sets of data because some individuals tend to have more than one source of income. It is probably safe, though, to presume that SRO residents are at least 
equally if not more dependent upon public sources for retirement income than is the general elderly population of those living alone or with non-relatives. (See Table IV for additional information on the sources of SRO hotels residents' income).

There are several reasons why the SRO residents tend to be dependent upon public sources of income after retirement. During their working years, they generally held semi-skilled or unskilled positions (Rubenstein, 1977; Eckert, 1978). Historically, those positions have been associated with low wages and a high job turnover rate. Research has confirmed that the SRO resident received low wages during his working years (Ehrlich, 1976; Eckert, 1978; Rubenstein, Howell, \& Rosenberg, 1977) and had a tendency to hold a series of different jobs (Stephens, 1976). With such a work history, it is not surprising that few receive private pensions. Kolodrubetz (1973) notes that those in full-time, low paying positions (below $\$ 5,000$ ) are only half as likely to be covered by a private pension plan as those in higher paying $(\$ 5,000-\$ 9,999)$, full-time positions. In addition to low-paying positions not offering pension plans, those pensions which are offered often require a minimum period of employment. Those who change jobs frequently are less likely to be vested in a pension plan (Clark, 1977). Thus, even with the growing number of businesses offering private pension plans, the semi-skilled or unskilled laborer 
who changes jobs may not benefit. This suggests that those with work histories similar to current SRO residents may not increase their potential retirement income through a private pension plan (Thompson, 1978; Seidman, 1975). This is important in light of the emphasis being placed on the role of private pension plans in improving the economic condition of future elderly generations.

For those primarily dependent upon public sources of retirement income the past decade has brought significant increases, though prospects for the future may not be as promising (Kreps, 1976). In 1972, Congress tied increases in Social Security, SSI, and some veteran pensions to the Bureau of Labor's Cost-of-Living Index (CPI) (Schulz, 1976). This meant the public portion of the elderly's income would advance along with increasing prices. With the continuing high rate of inflation, and a general downturn in the economic growth of the nation, Kreps (1976) suggests the elderly could be hard hit. Depending on such national policies as mandatory retirement age, acceptable levels of unemployment, and acceptable rates of economic growth the impact on the elderly's income would vary, but the general trend could be toward less improvement in retirement incomes or less opportunity to build a retirement income due to a constricted worklife. In either case, current dependence on public retirement income sources probably means modest increases in pension payments as the cost of living 
advances. For future generations who are dependent on public retirement incomes, the prospect for improvement relative to other income groups is low, especially given the current status of the Social Security Fund (Newsweek, 1981).

That current increases for Social Security, SSI, and Veterans are tied to the CPI is one example of why those dependent on public retirement income may see little improvement in their economic situation. This is because the commodities on which the elderly tend to spend the greatest share of their income have been increasing at faster rates than other commodities (Gionet, 1978; Lamale, 1978). Those commodities which have increased most are food, housing, and medical care (Harris, 1978; Gionet, 1978). It has been recommended that, based on this differential impact of inflation on the elderly, a special cost-of-living index be calculated, a CPI-Elderly (Alexander, Dobra, \& Qayum, 1977; Lamale, 1978, Gionet, 1978). Another concern with the current method of adjusting public pensions is that the recipient achieves parity only once each year during the month in which the increase is first added (Gionet, 1978). This means that during the other eleven months, as inflation continues, the adequacy of the pension decreases.

This discussion of the elderly's current economic condition and the prospects for those dependent upon public retirement income suggests that the lower-income elderly, as a group, will not soon become a thing of the past. Even if 
some reduction in the percentage of the elderly who are low income were to occur due to public and private pension increases, the total number of low-income elderly would not necessarily decrease because of projected increases in the total elderly population. ${ }^{2}$ The implication for the current study is that the total amount of income available to cover housing cost will no doubt continue to be limited for many elderly persons, especially those who are currently dependent upon public retirement incomes and those who have little opportunity of altering the prospect of such dependence.

The Elderly's Housing

There is a distinct relationship between the elderly's economic situation and their housing. Lower-income elderly are far more likely to be renters than homeowners. As renters, the lower-income elderly have a choice between private market housing and public market housing. Whichever type of housing they select, the renter is faced with two conditions. The first is the obvious necessity of being able to pay the rent. The second condition is equally obvious and that is locating a vacant unit within the elderly renter's "price-range." In the private market, few new rental units

\footnotetext{
2 In 1970, the percent of the U.S. population 65 and over was 9.8 percent or about 20 million persons. By 2020 , it is expected that about 14.6 percent of the population will be 65 an over; that would be 42.8 million people (Harris, 1978).
} 
are being constructed and some existing units are being converted to other uses. In the public market, the demand for housing units far exceeds the current level of production. The combination of continuing inflation which pushes up the price of rents and the low level of production which reducss vacancies in existing units given the increased rate of household formation means those on fixed incomes, like the low-income elderly, will find it increasingly difficult to compete for private-market rental housing units.

The current Housing Situation. The majority of elderly households own the homes in which they live. Figures from the 1978 Annual Housing Survey reported that 61.4 percent of those households 65 years of age and over and residing within a Standard Metropolitan Statistical Area (SMSA) owned their homes (U.S. Bureau of the Census, 1980). That meant approximately one-third of the elderly urban households were renters (Struyk \& Marshall, 1973; Walther \& Gillespie, 1978). Lawton (1980) reports that the median income for elderly homeowners in 1975 was $\$ 6,800$ while that for elderly renters was only $\$ 5,000$. Given these facts, it should be clear that elderly SRO residents are neither typical elderly homeowners nor typical elderly renters. The elderly SRO resident has a lower income than the typical elderly renter and also pays a lower rent than the typical elderly renter. Harris (1978) reports the median monthly rent paid by those 
65 years of age and over was $\$ 100.50$ in 1973. Ehrlich (1976) reports the monthly median rent for elderly, St. Louis SRO residents in 1975 was $\$ 69.09$.

It was previously noted that the cost of housing has been increasing faster than many other commodities (Harris, 1978; Gionet, 1978). Because the lower-income elderly tend to have no other source of income but their public pensions, they lose purchasing power as the cost of housing surpasses their pension increases. As a group, the elderly pay a higher proportion of their income to housing services than does the general population (Walther \& Gillespie, 1978). This is partially the result of the elderly's decreased income following retirement with no accompanying decrease in housing costs. For the population as a whole, 38 percent of all renters paid more than one-quarter of their income for housing while 23 percent paid 35 percent or more for housing (Harris, 1978). For the elderly renter though, 60 percent paid more than one-quarter of their income for housing and 40 percent paid 35 percent or more. Generally, 25 percent is the accepted maximum level of income that should be spent for housing (Milgram, 1980). Some suggest 30 percent is a more appropriate figure for the elderly population (Milgram, 1980, Struyk, 1977). Even using the latter figure, nearly half the elderly renters paid excessive amounts of their income for housing.

Single elderly renters also spend a large portion of 
their income on housing. Walter and Gillespie (1978) analyzed the data from the 1968 Demographic and Economic Survey of the Aged and reported that 46.4 percent of the one-person, elderly, rented households paid 35 percent or more for housing. of the two-person, elderly, rented households, only 21.3 percent paid a similar proportion for housing.

The Private Housing Market. For the purpose of this study, the private housing market is defined as all those housing units, either owner or renter-occupied, which are owned and operated by private parties, i.e., non-governmental. This type of housing constitutes the vast majority of the existing residential units in the United states. During the past decade though, several conditions have altered the private housing market. First, the rate of household formation increased. Young adults have been leaving home at an earlier age, the elderly have not been sharing a home with children or relatives, and fewer people of all ages are "doubling up" (Frieden \& Solomon, 1977).3 All this has been occurring during a time when the production of rental housing has been low (U.S. General Accounting office, 1979 ).

3 More recent data suggests that there has been some reversal of the trends of the earlier 70s. Persons of all ages are beginning to seek ways to decrease their housing costs given the continuing inflation. One observable means of reducing these costs has been a trend toward doubling up. 
Because increases in rent have not matched the general increase in prices, developers have found rental units uneconomical to produce (Frieden \& Solomon, 1977). The current low rate of production means the price of existing rental units will rise. As more people search for those increasingly costly rental units, those on low, fixed incomes will be least able to compete in the private housing market.

A circumstance which compounds the impact of low production of new units is the conversion or removal of some existing rental units. When rental units are converted, it represents a loss from the stock of existing rental units. The units generally are converted to either condominiums or to such non-housing uses as office or retail space. It has been suggested that preserving the existing rental stock is one way in which the impact of low production can be, at least partially, mitigated,

In an age increasingly aware of resource limitation and the need for conservation, some housing analysts have argued that the United States can, and should, meet a large part of its housing needs by prolonging the life of existing buildings rather than building new ones. The rising cost of new construction may well effectively slow down the rate at which we replace oid housing, a trend that has already begun. As a result of high construction costs, market pressures are now working in favor of housing rehabilitation and the improvement of existing neighborhoods to a greater extent than at any time since the 1940s. (Frieden \& Solomon, 1977, p.131)

Preservation of the low-cost stock could be especially important because any replacement units would of necessity, 
due to rising costs, either have higher rents or need a subsidization to make rents comparably low.

The Public Housing Market. The public housing market includes housing operated or leased by local housing authorities and, for the purposes of this study, those units which may be privately owned but where tenants receive governmental assistance in the form of a rent subsidy, such as section 8 apartments. The basic intent behind public housing was to provide adequate housing for those were unable to secure such housing in the private market due primarily to an inadequate income (U.S. Congress, 1937). The extent of the need for such housing was assessed and goals for production were set. Those goals have not been met,

While Federally subsidized units have increased as a share of the total in recent years, the absolute numbers have fallen far short of the ten-year goal set by Congress in 1968 of providing 6 million Federally subsidized units for the poor. During the same period, Congress has [sic] intended that 20 million private units be constructed. While the private housing industry responded by providing over 17 million units, or 85 percent of the goal, the Federal Government provided only 2.7 million of the new or rehabilitated units for the low-income group- -45 percent of the ten-year goal. (U.S. Congress, Joint Economic Committee, 1979, p.172)

It is assumed by some that there will never be sufficient production of public housing to satisfy the need (General Accounting office, 1979). Testimony presented to a subcommittee of the Senate Banking, Housing, and Urban Affairs Committee (1979) noted the extensive waiting lists for public market elderly housing, 
I should like to conclude by emphasizing again the urgency in solving the elderly housing problem. We feel that because of the excessive length of the housing waiting lists, many of the 35,561 older people in New Jersey on such lists will never live long enough to enjoy this good housing (Vivian F. Carlin, Supervisor, Housing and support Services, New Jersey Division on Aging, p.16).

As the cost of housing in the private market increases more lower-income elderly will be expected to seek some reliet in the public housing market. In its current state, the public market cannot meet its present demand, much less any increase in demand.

The cheice. The choice for many lower-income elderly is to pay an increasing proportion of their income for housing in the private market or seek assistance in the public market. Past research has noted tha's some elderly, who were determined to be eligible and were offered a unit, chose not to move into housing provided by the public market. Carp (1976b) reports that from Victoria Plaza's qualified applicant pool of just over 350,51 decided, after having toured the building and its units, that they did not wish to move in,"[M]any commented to this effect: 'It is a wonderful place - but not for me.'" In fact, those 51 people refused the opportunity to move into a new unit at a lower cost than their current housing. This matter of preference suggests that even if there were an adequate supply of low-rent public market housing, some elderly might still opt for another form of housing.

The economic consideration of housing is a major 
factor for the elderly. This is particularly so for single, low-income, elderly renters who characteristically pay a higher portion of their income to housing than do other elderly subgroups. They are faced with the choice of paying a greater proportion of their income for private market housing or seeking assistance from the public housing market. In either market, production of units has been low and thus preservation of existing low-cost rental units is one method by which some pressure on cost and availability can be mitigated. SRO hotels tend to provide some of the lowest-cost, rental units in an urban area and as such are potential candidates for a preservation effort. 
PART C: NEIGHBORHOOD AND THE ELDERLY

To overstate the role of neighborhood in the elderly person's life in nearly impossible. For most elderly, the neighborhood is clearly more than simply a physical space in which to reside. It can be a resource which facilitates acquisition of needed or desired commodities and services. On the other hand, the neighborhood which contains few stores and services can be a barrier to an elderly person's attempts to secure commodities or services. Neighborhoods vary in the type and variety of services available and the elderly vary in their use of those services whicn are available. The definition of neighborhood used in this study focuses on the person-environment interaction, that is, the accessibility of stores and services in an area and the resident's use of those facilities. Such a focus is especially critical when an elderly population is considered.

\section{Neighborhood as a Resource}

One approach to determining a neighborhood's value is to assess the resources which the neighborhood contains. In her discussion of neighborhood, Reller (1967) suggests that residents value a neighborhood based on its "convenient 1 or inconveniently accessible" facilities and the importance of those facilities to the individual,

...the importance of the neighborhood seems to vary according to the resources of the residents. These resources may be economic, psychological, cultural 
or ecological. Those immobilized by old age, family responsibilities, ill health, ignorance or isolation need the neighborhood most....[they] are really no more than "block dwellers"... (p.105-6)

In his discussion of the resident's valuing of the neighborhood, Lawton (1977) suggests the basis for assigning value is dependent upon personally preferred and used resources rather than some fixed set of elements assumed to be appropriate. The three "resource environments" he identifies are a product of the individual's interaction with the neighborhood. The functional resource environment is composed of all the facilities used by an individual, those that have some function for the individual. The perceived resource environment is that geographic space an individual defines or sees as being his/her neighborhood, and the salient resource environment is those elements of the neighborhood on which the individual construes a significant value either because of need or personal desire. Thus, the individual assesses the value of a neighborhooa based on the facilities they use, their perception of what constitutes the neighborhood, and how crucial the facilities are to them. Lawton notes that the resource environments "may be either idiosyncratic to a particular individual or consensual..."

Whether or not there is general agreement about a neighborhood's resources, access to the facilities is crucial if they are to serve as resources to the resident. When considering an elderly population, a definition of 
access or convenience might be expected to differ, especially between those dependent upon public transit and those with private automobiles or even more, between those who are unable to use public transit due to physical limitations and those who have use of a private automobile. Their perception of convenient or inconvenient might be expected to influence the residents' use of a neighborhood. For those with no access to a private auto and limited ability to use public transit, the usefulness of neighborhood resources would increase dramatically. In such cases, it would be expected that the perceived resource environment would be limited in scope and that the facilities included in their functional resource environment would be proximate to the residence.

In recent years, there has been much interest shown in examining the elderly's use of their functional resource environment and in determining the salience of the facilities used (Noll, 1973; Newcomer, 1975; Niebanck \& Pope, 1965; Regnier, 1973, 1975; Cantor, 1975). These studies are based on the proposition that accessibility to neighborhood facilities is one condition which fosters independence, particulatly for the older adult, and that proximity of the facilities is related to usage by an older person. Thus, any examination of an elderly population's personal well-being or general satisfaction with life circumstances, much less their housing conditions, must 
consider environmental or neighborhood factors.

\section{The Elderly's Use of Neighborhood Resources}

Previous studies indicate the elderly are frequent users of neighborhood resources and that proximity of those stores and services influence their level of use. Some note is made that various subgroups of the elderly population tend to make use of different neighborhood facilities, that is, functional and salient resource environments differ amoung subpopulations of the elderly. Generally, it is concluded that accessible facilities should be a component of any planned housing for the elderly.

The past twenty years has seen a number of studies of the elderly's use of neighborhood facilities (Niebanck \& Pope, 1965; Noll, 1973; Newcomer, 1975; Newcomer \& Friss, 1979; Regnier, 1975; Chapman \& Beaudet-Walters, 1978). Most have surveyed elderly persons about their use of, distances traveled to, and importance of a facility. However, one early study surveyed the managers of elderly housing projects (Niebanck \& Pope, 1965). In that study, 117 managers of publicly supported or subsidized housing were asked to indicate for what type of facilities, was location an important factor to consider in planning an elderly housing project. Managers were also asked to indicate at what distance residents began to express dissatisfaction with a particular facility, i.e., the distance beyond which residents preferred not to travel--or the "critical 
distance" within which they preferred to travel. Table I shows the ranking of twelve facilities by importance and recommended distance for a housing project site. Recommended distances are based on critical distances. There is little or no correlation between the importance of a facility and the recommended distance of that facility from a project site.

In another study, Newcomer (1975) interviewed nearly 600 elderly residents of public housing about their use of 24 services. He included all but one facility studied by Niebanck and Pope (1955) plus a number of additional services and activities. For the purpose of easy comparison, Table I also reports Newcomer's findings. It shows the ranking of services and activities in order of importance to the resident and the critical and recommended distances. A comparison of the results of the two studies show some differences. Several services determined important by Niebanck and Pope were near the bottom in Newcomer's list, i.e., church and physician. Critical distances varied some but the major difference was that Newcomer was unable to establish a specific critical difference for some facilities such as church, physician, library, luncheonette, and movies. The recommended distance of services and activities from a housing project site also differed. Though there are variations in the findings, there are also many consistencies and these consistencies suggest that there are 
T A B L E

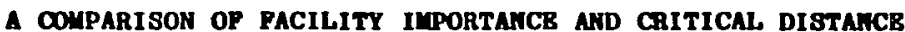

\begin{tabular}{|c|c|c|c|c|c|c|}
\hline \multirow[b]{2}{*}{ Fac1lity } & \multicolumn{3}{|c|}{ Nlebanck and Pope's Findings a } & \multicolumn{3}{|c|}{ Newcomer's Findings b } \\
\hline & $\begin{array}{l}\text { Rank of } \\
\text { Importance }\end{array}$ & $\begin{array}{l}\text { Critical } \\
\text { Distance }\end{array}$ & $\begin{array}{l}\text { Recommended } \\
\text { Distance from } \\
\text { Elderly Housing }\end{array}$ & $\begin{array}{l}\text { Rank of } \\
\text { Importance }\end{array}$ & $\begin{array}{l}\text { Critical } \\
\text { Distance }\end{array}$ & $\begin{array}{l}\text { Recommended } \\
\text { Distance From } \\
\text { Elderly Housing }\end{array}$ \\
\hline $\begin{array}{l}\text { Grocery store } \\
\text { Bus stop } \\
\text { Church } \\
\text { Drug store } \\
\text { Medical } \\
\text { Bank } \\
\text { Soclal center } \\
\text { Library } \\
\text { News, tobacco } \\
\text { Restaurant } \\
\text { Movie theater } \\
\text { Bar }\end{array}$ & $\begin{array}{r}1 \\
2 \\
3 \\
4 \\
5 \\
6 \\
7 \\
8 \\
9 \\
10 \\
11 \\
12\end{array}$ & $\begin{array}{l}2-3 \text { blocks } \\
1-2 \text { blocks } \\
1 / 4-1 / 2 \text { mile } \\
3 \text { blocks } \\
1 / 4-1 / 2 \text { mile } \\
1 / 4 \text { mile } \\
\text { indeterminate } \\
1 \text { mile } \\
1 / 4 \mathrm{mile} \\
1 / 4-1 / 2 \text { mile } \\
1 \text { mile } \\
\text { 1ndeterminate }\end{array}$ & $\begin{array}{l}1 \text { block } \\
\text { adjacent to site } \\
1 / 2 \text { mile } \\
1 \text { block } \\
1 \text { mile } \\
1 / 4 \text { mile } \\
\text { on site if possible } \\
1 / 2 \text { mile } \\
1 / 4 \text { mile } \\
\text { no consensus } \\
1 \text { mile } \\
\text { no importance }\end{array}$ & $\begin{array}{r}3 \\
1 \\
10 \\
20 \\
7 \\
11 \\
21 \\
2 \overline{3} \\
15 \\
23\end{array}$ & $\begin{array}{l}1-3 \text { blocks } \\
1 \text { block } \\
\text { indeterminate } \\
- \\
\text { indeterminate } \\
1-3 \text { blocks } \\
1-3 \text { blocks } \\
\text { indeterminate } \\
-- \\
\text { indeterminate } \\
\text { indeterminate } \\
\text { no importance }\end{array}$ & $\begin{array}{l}1 \text { block } \\
\text { adjacent to site } \\
\text { indeterminate } \\
-- \\
\text { Indeterminate } \\
3 \text { blocks } \\
3 \text { blocks } \\
\text { indeterminate } \\
-- \\
\text { Indeterminate } \\
3 \text { blocks } \\
\text { no importance }\end{array}$ \\
\hline $\begin{array}{l}\text { Park/outdoor } \\
\text { Laundromat } \\
\text { Post of flce } \\
\text { Service center } \\
\text { Cleaners } \\
\text { Department store } \\
\text { Senior citizen club } \\
\text { Bingo, cards } \\
\text { Arts, crafts } \\
\text { Parties, socials } \\
\text { lectures, discussions } \\
\text { Organized trips } \\
\text { Dentist }\end{array}$ & & & & $\begin{array}{r}2 \\
4 \\
6 \\
8 \\
9 \\
10 \\
12 \\
13 \\
14 \\
16 \\
17 \\
18 \\
22\end{array}$ & $\begin{array}{l}1-3 \text { blocks } \\
\text { on-si te } \\
4-10 \text { blocks } \\
1-3 \text { blocks } \\
4-10 \text { blocks } \\
4-10 \text { blocks } \\
\text { on-site } \\
1-3 \text { blocks } \\
1-3 \text { blocks } \\
1-3 \text { blocks } \\
\text { indeterminate } \\
\text { indeterminate } \\
\text { indeterminate }\end{array}$ & $\begin{array}{l}\text { adjacent to site } \\
\text { on-site } \\
3 \text { blocks } \\
\text { on-site } \\
3 \text { blocks } \\
3 \text { blocks } \\
\text { on-site } \\
\text { on-site } \\
\text { on-site } \\
\text { on-site } \\
\text { on-site } \\
\text { indeterminate } \\
\text { indeterminate }\end{array}$ \\
\hline
\end{tabular}

a Nlebank \& Pope, 1965, p. 64.

b Newcomer, 1973 (in Regnter, 1975, p. 309.) 
services which are seen as salient to an elderly population and that proximity of these services to one's place of residence is important.

In a review article, Regnier (1975) concluded, after examination of findings from his and other studies, that a "critical mass" of services is needed in order to make a neighborhood viable as a location for elderly housing. He defines this "critical mass" of services as a specific set of facilities which, when clustered in a particular location, contributes to a site's viability for elderly housing. The six facilities he identifies as critical are: a bus stop, grocery/supermarket, drug/variety store, bank, post office, and church. Ideally, they should be within walking distance of the elderly's residence, which he defines as three to six blocks. It is interesting to note that with the exception of a post office, which Niebanck and Pope (1965) did not include, the facilities defined as critical by Regnier are the same facilities ranked as most important by the housing project managers. A comparison with the services identified by Newcomer (1975) as important shows some difference.

Newcomer and Friss (1979) took a slightly different approach to the matter of facility usage and critical distance. Using the critical distance identified for each of 14 services, Newcomer and Friss calculated the "trip generating" effect of each service. The trip generation 
effect was defined as the difference between usage of each facility based on its location, i.e., either inside or outside the critical distance zone. What they found was that there appeared to be a difference in the ability of services to generate trips by elderly residents:

Iife-supporting services like shopping or health have rather expansive critical distances. Or in other words, people continue to use a service regardless of its convenience--because they need it. (Newcomer \& Friss, 1979, p.339)

Examination of the trip generating effect of services is one way of identifying Lawton's salient resource environment.

In that same study, Newcomer \& Friss (1979) also noted that much of the research on elderly use of facilities had focused on residents of public or subsidized housing. They cautioned that the "typical" resident of such housing was an elderly, white female, who lived alone and may have had different use patterns than other elderly subgroups. In fact, Ehrlich's (1976) study of elderly SRO hotel residents in St. Louis confirms this belief. She compares the rate of non-use of selected facilities for two samples; her St. Louis SRO hotel residents, and Newcomer's (1975) elderly public housing residents. She found such a comparison dramatized the differences between the two populations. Of eighteen facilities compared, only two non-usage rates fell within a ten-point spread of the other sample, i.e., cleaners and dentists are used or not used at about the same rate by the two groups. The facilities on which the samples' 
usage differed were luncheonette, bar, food market, bank, senior center, physician, and church. Ehrlich concluded that it is not surprising the groups differed on use of luncheonette as the SROs had no cooking facilities whereas the public housing sample most likely did have. She also noted that SRO residents tended to be frequent users of "basic" services like luncheonettes, food markets, and drugstores but much less frequent users of "supportive services" like post office, physician, and department stores. They were relative underusers of "recreational" services such as senior centers and libraries. Using Lawton's terminology, saliency of the various facilities differed substantially for the two groups or, in other words, their rates of usage differed.

It was noted earlier that access to a facility is of utmost importance to usage; without access, use is prevented. Despite this obvious condition, mode of travel has generally not been part of the studies of neighborhood facility use. However, in his review article, Lawton (1977) does note that "barriers to mobility" may necessitate additional expenditures of energy if usage is to occur. He also noted that,

Adequate transportation may act as a functional equivalent to proximity to the resource, as seen in the virtually unlimited accessibility of far-flung resources to the affluent automobile driver. (p.280)

Thus poor access to transportation or some barrier to personal movements may be viewed as an intervening variable 
in the usage of neighborhood facilities. Additionally, the economic status of an elderly person may influence his selection of a transit mode. Together, such factors can work to restrict the range of travel and thus the use of more distant facilities by lower-income and physically frail elderly.

Relative to an elderly SRO population, Ehrlich (1976) noted that SRO residents tended to be frequent users of neighborhood facilities. Their central city location was a resource rich environment, containing many more facilities than Regnier's (1975) critical mass suggests is minimal. Additionally, they tended to be low-income and thus have little to spend on the purchase of transportation.

\section{Person-Environment "Eit": A Theoretical Perspective}

To this point, the neighborhood has been defined as a resource to its residents, in particular, the elderly resident who tends to be less mobile than his younger counterpart. It has also been shown that elderly residents tend to be frequent users of the facilities in their neighborhood. Note was made that various subgroups of the elderly population tend to use a different set of facilities--that salience differs among subgroups. It was also noted that downtowns are a resource rich environment. They provide many opportunities to secure resources, and thus can satisfy many personal needs with a minimal amount of effort. A consideration of congruence between the person 
and his environment becomes especially important in a study of an elderly SRO population in that loss of hotel units from the central city location necessarily implies relocation of residents to neighborhoods outside the central area.

In this section two models of person-environment "fit" are examined. These theoretical perspectives emphasize the importance of congruence between the person and the environment. Rahana's (1975) model of congruence suggests there is an optimum environment which matches the personal needs of the individual. The more congruent the fit between person and environment, the greater the personal well-being of the individual. Lawton and Nahemow's (1973) model of person-environment fit emphasizes adaptation. They suggest that as a person ages there is a tendency toward a reduction in their individual level of competence. In turn, this implies a reduced ability to deal with the environment. A person's reduced ability to adapt to pressure from the environment varies with the person's individual competencies and the strength of the environment press.

In more detail, Kahana's (1975) model of person-environment fit focuses on the congruence between the environment and the needs of the individual. She suggests that the individual functions optimally when the environment provides the opportunity to satisfy needs. It is self-reported needs and preferences which shape the 
individual's demands on the environment. This means an "optimal environment" is specific to the individual's needs. Lawton (1977) states that in Kahana's model:

Congruence is most important under threshold
conditions where options are limited either by
personal vulnerability, environment restrictions or
the individual's perception of a high degree of
external control. (p.295)

Rahana sees congruence or optimum fit between the person and environment as leading to satisfaction of needs whicn she operationalizes as personal well-being. Any definition of optimal, though, must consider differences among indiviauals and variations in environmental setting. Based on variations in personal needs and preferences, the same environment could be found to be either congruent or incongruent.

Lawton and Nahemow (1973) propose a model whicn is similar to Rahana's though it emphasizes the indiviaual's capabilities rather than personal needs. Lawton (1977) describes the model as one of adaptation. He proposes that as an individual ages, his/her ability to perform various tasks is reduced, i.e., competency is reduces (environmental docility hypothesis, Lawton \& Simons, 1968). He also suggests that environments create demands on the indiviaual which, in turn, necessitate a response, thus, the press of the environment on the individual precipitates some outcome. Given that competencies vary among individuals, the mode 1 suggests that there exists $a$,

...theoretical upper limit of capacity of the individual to function in the areas of biological 
health, sensation perception, and motoric behavior and cognition. (p.296)

The outcome then of some environment press on the individual is a particular behavior or set of behaviors. Depending on the individual's level of competence and the strength of environmental press, the behavior may be adaptive, marginal or maladaptive. The more competent the individual, the more likely will the environmental demand be met with an adaptive behavior. Conversely, the lower the level of competence, the weaker must be the environmental press in order that adaptive behavior results.

Though the two models have different points of emphasis, they should not be seen as conflicting. Kahana's focus is personal needs or preferences and the selection of an environment which can optimize those needs or preferences. Lawton and Nahemow's focus is the press of the environment and the individual's ability to adapt. Kahana's model would predict selection of an optimal environment while Lawton and Nahemow's would predict adaptation to some environmental press. Relative to the current study, SRO residents can be seen as selecting an optimal environment as well as responding to the press of that environment.

The concepts of congruence, environmental press, personal needs or preferences and individual competencies are all relevant in that it is maintained in this study that the elderly SRo resident, in general, has a low level of individual competence, has a special set of needs and 
preferences, experiences considerable environmental press, and therefore, must seek out an environment which does not over-tax his competencies. Lawton (1980) states that:

The SRO is perhaps the best of all available examples of person/environment congruence built around marginal individuals. Though the deprivation and sometimes unasked-for isolation are less than ideal, were it not for these environments, many of these elderly would be dealing with stronger press than their competence could tolerate. (p.68-9)

The Elderly's Satisfaction with Their Environment

As noted above, an elderly person's ability to maintain himself is inextricably related to the environment in which he/she lives. The environment is a resource from which needs can be satisfied, but it is also a source of pressure to which some adaptation is demanded. Neither use of nor adaptation to the environment implies satisfaction with or preference for that environment. In fact, frequent use of neighborhood facilities may represent an adaptation to the current situation due to lack of attainable alternatives, such as moving to a new neighborhood or securing a different mode of transit. In such cases, reported satisfaction with the current situation would be expected to be low and preference for some alternative expected to be high.

This section examines the elderly's satisfaction with and preference for elements of their environment. Both the neighborhood and the individual housing unit will be covered in this discussion. Though previous discussions in this 
chapter have separated neighborhood and housing unit, the separation tends to be artificial. As noted below, there is a strong correlation between satisfaction with the neighborhood and satisfaction with the housing unit, particularly for the elderly.

Satisfaction with Neighborhood. Many studies have been conducted which examine the elderly person's satisfaction and/or dissatisfaction with and preference for particular qualities or elements of a neighborhood. In most cases, subjective measures have been used to determine satisfaction but objective ratings conducted by independent observers have also been used. In some studies, respondents have been asked to evaluate their neighborhood by indicating their level of satisfaction to a fixed set of elements. In other studies, residents have been asked open-ended questions about likes and dislikes of their neighborhood. Some studies of neighborhood satisfaction are comparative across neighborhoods while others are not. Additionally, the different studies have surveyed a variety of residents (young-old to old-old, movers and non-movers, public housing and private market tenants, low-income to high-income) and a variety of neighborhoods (slums, multifamily and single-family areas, high density and lower density elderly areas, high crime areas). This means that comparison of the findings across studies is confounded by the use of dissimilar samples and methodologies. 
Several general conclusions have emerged from these studies though. First, it has been noted that elderly persons tend to make fewer negative comments about their neighborhood than do younger persons (Lawton, 1978; Campbe11, Converse \& Rodgers, 1976; National Council on Aging, 1975). In fact, it has been found that elderly persons tend to express less dissatisfaction generally, regardless of the matter considered (Campbell, et al., 1976; Carp, 1976a). This finding has been noted particularly where causal observation of the neighborhood under investigation would lead one to expect a less satisfactory rating than that given by its elderly residents (Hamovitcn \& Peterson, 1969; Carp, 1976a). One explanation of this tendency suggests that the favorable evaluations are a result of an attempt to reduce "cognitive dissonance", that is, where the individual resolves himself/herself to a "less desirea" circumstance by adjusting attitudes to fit the current situation, i.e., reducing the disparity between objective and subjective reality (Lawton, 1980). Another explanation suggests a relationship between age and satisfaction based on cohort analysis, that is, elder cohorts have been more accepting of the status quo throughout their lifetime and that acceptance of a given condition is more natural for the elderly than criticism (Campbell, et al., 1976). Both explanations are grounded in attitudinal studies of elderly persons (Carp, 1975; Lawton, 1978). 
A second general conclusion is that different subgroups of the elderly population have distinctly different preferences and thus one subgroup may report satisfaction with a particular condition whereas another. subgroup may not;

In effect, different individuals have different skills, tastes and needs, such that an objective situation which might be very gratifying for one person might be thoroughly oppressive for another. (Campbe1l, et al., 1976, p.158-9)

For instance, Hamovitch and Peterson (1969) reported different preferences between those who lived in neighborhoods with a high density of elderly persons (more than 358 over 50 years of age) and those who lived in lower density neighborhoods (less than 10 percent over 50). They found that 59 percent of the elderly persons living in densely elderly neighborhoods did not want children in the neighborhood while only 27 percent wanted children. Those in less dense elderly neighborhoods felt more positive about children in the neighborhood, 45 percent did not want them and 42 percent did. In another study elderly persons were asked to indicate which variables, from a list, were important in the selection of their current residence (Golant, 1972). Differences were found between low-income and high-income groups and between single and multifamily groups. The lower-income group placed more emphasis on easy access to transit and on a good price for the housing (or rent) than did the higher-income group. The multifamily 
dwellers emphasized access to transit and shopping facilities. The single family and higher-income groups were more likely to have the use of an automobile.

Frieden (1960) also found preferential differences between two groups of displaced elderly, one group was composed primarily of single, female tenants of a residential hotel in downtown Boston, the other group was composed of displaced couples from Boston's ethnic Westend. The former group had no interest in moving into a so-called "residential" area and cared little about the ethnicity of their new neighborhood while it was of great importance to the Westenders that they relocate in an area which had a sufficient number of ethnic institutions like stores, churches, and gathering places.

Despite the many differences in preference, some common findings have emerged regarding satisfaction/dissatisfaction with a neighborhood. One such finding is the proximity of stores and services. In particular, those elderly without automobiles tend to report the nearness of facilities as an important component of neighborhood satisfaction (Mcfuley \& Miller, 1977; Carp, 1976a; Golant, 1972; Hamovitch \& Peterson, 1969). Another component of satisfaction, again primarily for those without personal cars, is access to points outside the neighborhood. This is generally interpreted to mean convenient access to public transit (Golant, 1972). This positive relationship 
between neighborhood satisfaction and access to facllities and transit compliments earlier statements regaraing the importance of neighborhood in providing resources to the elderly person.

Another common finding of neighborhood studies is the relation between fear of crime or actual level of crime and satisfaction (National Council on Aging, 1975; Carp, 1976a). Lawton (1980) notes that "virtually every investigator who has included personal security in a list of neighborhood attributes has found it to be extremely highly related to overall satisfaction with the neighborhood" (p.48). No doubt the elderly's concern regarding personal safety in the neighborhood is related to an awareness of their vulnerability. A preference for having neighburs who are similar has been reported. Age, race, and class have all been identified as dimensions which, if similar, tend to be related to the elderly's satisfaction with neighborhood (Hamovitch \& Peterson, 1969). Nearness, or at least access to family has also been found to be a preferred situation for many elderly (Hamovitch \& Peterson, 1969; Frieden, 1960), though at least one researcher found such concerns as access to stores and transit to be of more importance in the selection of the elderly person's current residential location (Golant, 1972).

Because virtually all of the studies of elderly satisfaction/preference with neighborhood have been 
self-report it is important to note that social psychologists have suggested observation of behavior as a more accurate measure of "true" attitudes or preferences (Deutscher, 1973). Such an approach is based on the premise that deeds are more representative of attitudes than are words. Relative to satisfaction with neighborhood, it might be expected that those dissatisfied with their neighborhood would move to another location. Data available on elderly households indicate they change residence only about half as frequently as do younger households, i.e., approximately ten percent of the elderly population move each year (Goldscheider, Van Arsdol\& Sabagh, 1966). This low frequency of moving can be seen as supporting the finding of elderly satisfaction with neighborhood, but because a change of residence tends to necessitate an outlay of energy and money plus a disruption of current behavior patterns, it is probably not an adequate measure to judge the elderly's dissatisfaction with neighborhood (Lawton, 1980). It is unclear to what extent barriers to moving such as health, mental health, and finances influence the perception of the neighborhood, as being "not so bad after al1."

To summarize, the elderly generally report satisfaction with their neighborhood, though this satisfaction does not always correspond to an objective rating of the neighborhood. The various methodologies and samples of the neighborhood studies make direct comparison 
of results difficuit but a number of factors have been identified which were found to be related to satisfaction.

Satisfaction With Housing. The studies which have examined the elderly's satisfaction with their dwelling unit are very similar in nature to the studies of neighborhood satisfaction. The primary focus of the studies has been to determine what qualities of the housing unit are related to the elderly's satisfaction or dissatisfaction with their housing. Like the neighborhood studies, the housing studies have used various methodological approaches and have sampled various subgroups of the elderly who reside in different types of housing units. In some instances, the survey instrument has been open-ended in order to elicit more spontaneous responses, while in others it has been carefully structured in order to allow different types of statistical analysis. Other methods of data collection have emphasized observer ratings of the housing unit. As for respondents, much of the information regarding satisfaction with housing has been collected from tenants of planned elderly housing projects, though elderly tenants and owners of private-market housing have also been surveyed. Comparisons between movers and non-movers have been used to demonstrate preferences for qualities of the new unit and dislikes for qualities of the previous unit.

The most general finding of the housing satisfaction studies, like those of the neighborhood, is that elderly 
persons tend to be very positive in their overall rating of housing. When compared with responses by other age groups, the elderly consistently report higher levels of satisfaction with their housing (Lawton, 1980; Campbell, et al., 1976; McAuley \& Miller, 1977). Explanations offered for the favorable evaluations are generally the same as those posited for favorable ratings of neighborhoods, i.e., reduction of cognitive dissonance and tendency toward acceptance of a situation rather than criticism. Lawton (1980) suggests another possible explanation of the positive ratings. Using data from the Annuzl Housing Survey, Lawton found a correlation of .36 between the elderly residents subjective rating of their housing and an observer's objective rating of the same housing. This suggests there may in fact be some objective basis for the elderly's favorable ratings. The importance of the correlation should not be overemphasized, but Campbell et al., (1976) also suggest at least one explanation which supports the idea that the ratings partially reflect reality. Using a person-environment model, they propose that as persons age they have the opportunity to seek out those "niches" which most reflect their preferences.

One general finding which may influence the results of all studies of housing satisfaction is that personal circumstances of the elderly tend to be related to their level of satisfaction with housing. McAuley and Miller 
(1977) noted several personal circumstances which were found to have a significant correlation with housing satisfaction. For elderly persons they found better health, being white, and degree of integration into the present community were all positively related to satisfaction with housing. Campbell, et al. (1976) noted another personal circumstance related to satisfaction. They found that housing satisfaction increased with length of residence. Because age of the respondent was not controlled for in that particular analysis, generalizations about the elderly should be seen as speculative, though it might be expected that elderly persons would be longer term residents of their units than younger persons.

In terms of specific qualities of housing units, there have been several identified which are generally agreed to be related to satisfaction with housing. One quality is the matter of privacy. Hamovitch and Peterson (1969) reported that both groups, those in densely elderly neighborhoods and those in less dense areas, rated privacy as an important component of satisfaction. In her study evaluating a planned elderly housing project, Carp (1976b) reports that the greatest dislike of other tenants is the nosiness and gossip, a form of invasion of privacy sometimes facilitated by building designs. Another quality found to be relaked to satisfaction with housing was the cost of housing to its elderly resident (McAuley \& Miller, 1977). Golant (1972) 
found cost to be an important quality, especially when selecting a new place of residence.

Several other housing qualities have been found to be both related and not-related to housing satisfaction by elderly persons. Lawton (1980) reports a list of qualities which were related to dissatisfaction with housing. From the Annual Housing Survey data he notes that in addition to "...presence of rats, holes in plaster, cracks in ceilings or walls, [and] peeling paint...", an incomplete kitchen was related to dissatisfaction. Carp (1976b) however found from her study of planned elderly housing that not all tenants felt kitchens were an important or necessary component of a planned elderly housing unit. To her surprise, she reports, 11 percent of the tenants indicated they preferred not to cook. Another quality of housing for which research findings differ is the size of the dwelling unit. Findlay and Morris (1976) noted that a "too small" unit generated more dissatisfaction than did a unit which was felt to be "too large." On the other hand, Lawton, Kleban, and Carlson (1973) reported that a dwelling unit with too much space is an incentive for an elder person to change their place of residence. It may be that these differences reflect variations between subgroups and their perceptions of congruence with the environment.

Elderly persons generally report satisfaction with their housing. Some of this satisfaction may be the result 
of a reconciliation between what they see as alternatives to their current situation but an equally strong explanation is that the respondent is living in housing which is congruent with his/her personal needs and preferences, in other words, it is perceived to be an appropriate niche.

Though this section has discussed correlates of satisfaction with neighborhood and housing independently, they are highly correlated with each other. Using the Annual Housing Survey, Lawton (1978) found a correlation of .53 between the elderly respondents' subjective ratings of their neighborhoods and their housing. Campbell, et al. (1976) also found high correlations between satisfaction with housing and neighborhood $(.44)$ and satisfaction with housing and community (.45). In other words, given the elderly population, satisfaction with neighborhood is a strong predictor of satisfaction with housing and vice versa.

In summary, the neighborhood can be a vital resource for its elderly residents. Studies reported in the literature indicate that elderly persons do use their neighborhood facilities and prefer housing in areas which have the kinds of facilities they consider important. This use and preference for an environment which contains the needed stores and services is an example of an attempt to match a living environment with personal needs and preferences. For elderly persons, a match between person and environment is seen to facilitate independence. For SRO 
hotel residents, the central city location provides easy access for a special group of elderly who have needs which can be satisfied through use of inexpensive stores and services available in a downtown area. 
PART D: SRO HOTELS AND THEIR ELDERLY RESIDENTS

Single room occupancy or SRO hotels ${ }^{4}$ are not recent phenomena. Nearly every major city in the United States and many smaller cities once had such structures in their downtown. They served a vital and historical function in housing many early urban settlers. Today, in most urban areas, these hotels continue to provide housing for a select group of people.

SRO Hotels

Most existing sRo hotels were constructed just prior to or just after the turn of the century (1880s to 1920s), with those in the western part of the United States generally slightly younger than those in the eastern regions. Regardless of its locale, a hotel's early history tends to follow one of two scenarios (Eckert, 1978; MacColl, 1979). Some of the hotels began as the "grande dames" of their day, catering to a fashionable clientele. With the construction of newer hotels in "better" parts of the city, their grandeur began to fade and eventually the hotels slipped from first to third class. Other hotels began as lodging for the working class, catering to loggers, sailers, warehousemen, and other laborers of the time. For those hotels, their clientele changed little over the years. At

${ }^{4}$ Reference is made here solely to those structures originally constructed as a hotel and not to those which were converted from other uses. 
the time the hotels were constructed, there was a need to house workers close to their employment because transportation systems were less well developed then. A single room with no cooking facilities and a shared bathroom was seen to meet the housing needs of that working class population. Thus, the SRO hotel has been in existence for many years and has housed a wide variety of people over that time.

Many of these original SRo hotels or these finer hotels which declined over a period of years are no longer in existence today. Chapter I of this study noted that there were at least four reasons for the loss of these hotels; increase in the value of downtown land, HUD's assertion that SRO hotels are substandard, extent of physical deterioration of SRO hotels, and social acceptability of sRo hote $\perp$ residents. These losses have been nationwide and not restricted to any particular region of the country. For example, some 30 sRo hotels were closed in st. Louis over a period of about 15 years (Ehrlich, 1976). As part of Chicago's Madison-Canal urban renewal it was estimatea that some 2000 "homeless" men would be displaced from their hotels (Levy, 1968). In New York City, 52 low-priced hotels were closed between January, 1975 and March, 1978 (Kopp \& Murphy, 1979). Portland, Oregon lost approximately 1,300 SRO hotel rooms over a period of eight years ending in 1978 (Portland Development Commission, 1978) and the loss 
continued with 450 units being closed in the thirteen months between August, 1979 and September, 1980 (Galbreath, 1981).

The hotels which remain are rather varied in their basic characteristics. Some are very large and others are quite small. Eckert (1978) reports that in San Diego SRO hotels range in size from 25 rooms up to 325 . Levy (1968) notes that the average size of a large SRO hotel in New York City is about 100 rooms. The typical size of an SRO hotel in Portland is approximately 50-60 rooms but they range from 24 up to 147 rooms (Portland Development Commission, 1978). The larger hotels tend to have elevators but this is not always the case; most smaller hotels are strictly walk-ups. Presence of an elevator does not guarantee that it is in operable condition. Lobbies are almost never associated with walk-up hotels (Eckert, 1978) and any "lobby-like" area in a walk-up is usually only a widened corridor near the manager's unit or office. The larger hotels nearly always have a lobby on the ground floor. Though the lobbies tend to differ in size, furnishing, and house rules from hotel to hotel, they are nearly always used by the residents as the common gathering place for such activities as observing other's comings and goings, watching television, reading, or chatting with other residents. The physical condition of the hotel is also a characteristic which tends to distinguish one from another. Some are well maintained with repairs made when needed while others seldom, if ever, receive even 
cosmetic attention.

There are also a number of similarities among the hotels and several were noted in the definition of an SRO hotel given in Chapter $I$. One basic similarity is the composition of the hotel room which contains no tub, shower, toilet, or cooking facilities. The room usually contains a bed, dresser, chair, wash basin, and closet. A linen service, if not maid service, is another common feature. Rental arrangements vary some, but typically the resiaent may rent a room by the month, week, or day, with the longer rental being at the least expensive rate.

Beyond its physical characteristics of room arrangement and accompanying furnishings, the SRO hotel takes on a particular identity. Each hotel, as a result of different management practices, tends to develop a "personality" of its own. These different personalities can be quite distinct and are usually known to hotel residents and others. A hotel management's operating policy might range from "wide-open" (Shapiro, 1967) to "closed" (Siegal, 1978) but most SROs are maintained somewhere between the extremes. In his study of SRO hotels in New York City, Seigal describes the two opposing poles of management practices;

The "openness" of the building determines the quality of life for the residents ensconced there. Openness, however, is defined in two ways. In the first, an "open building" is simply one in whicn there is more than one entrance and there is no control placed upon who enters or leaves the 
building. Anyone, therefore, has unimpeded access to the building, its residents, and their possessions.... The second and even more significant factors [sic] determining an "open" building is the manager's willingness to give a room to almost anyone who can pay for it. The "closed" S.R.O. or hotel, conversely, demands that its prospective tenants meet certain standards of dress (such as clean, not overly shabby clothing), deportment, employment or finances, before a room will be rented to them. (p.68-9)

As a result of the differing policies of management, some hotels become known for their tolerance of heavy drinkers, others as havens for prostitution, drugs, and crime, while other hotels are known to tolerate little deviant behavior. Those who are heavy drinkers know their tenure would be short at a closed hotel and thus seek housing in the more open hotels. Those who prefer a quiet and secure environment know an open hotel would proviae little of either and thus seek housing in those hotels with a reputation of being closed. ${ }^{5}$ It is entirely possible that a closed hotel and an open hotel could be located next door to one another, each providing housing to a slight different type of SRO resident; such a distinction is not based on the hotel's location.

The cost of an SRO hotel room tends to be one of the lowest unsubsidized monthly rents available anywhere in a city. In 1974, the City of Portland's Human Resources Bureau

\footnotetext{
5 Reflecting on Lawton and Nahemow's 1973 conception of personal competence and Rahana's 1975 conception of personal needs, an SRO resident's ability to select the "appropriate" type of hotel may be seen, in part, as a match between the person and his environment.
} 
made an attempt to identify comparably priced housing outside the downtown area. They surveyed two areas which had potential to serve as a relocation site for SRO hotel residents if hotel closures continued. The report cited that:

The rent levels in the areas are not comparable to those found in the Burnside-Lowndale areas. As was previously stated, the average rent in the Burnside-Lowndale areas is now $\$ 38$. In the areas surveyed, less than one-quarter of the total inventory rents at less than $\$ 50$. It is also significant that approximately $89 \%$ of the Burnside-Lowndale residents pay less than $\$ 50 /$ month for rent. Along with the fact that over one-half the residents of the Burnside-Lowndale presently pay over $25 \%$ of their income for rent, it is probabiy [sic] that most of the persons involved would have difficulty relocating in the areas surveyed. (Human Resource Bureau, 1974, p.66)

More recently, City agencies conducted two additional studies of rental costs. The Portland Development Commission found, in 1978, that the average rent for an "upper" skid row SRO hotel in Portland, Oregon ranged from just below $\$ 75$ to slightly over $\$ 100$ per month (Portland Development Commission, 1978). Rent for a skid row SRO hotel was slightly cheaper, ranging from about $\$ 50$ to $\$ 75$ per month. By contrast, an efficiency unit in downtown Portland, which typically contains a kitchenette, bathroom but not bedroom, was renting for an average cost of just under $\$ 150$ to nearly $\$ 250$ per month.

That hotel rents are among the lowest available anywhere in a city is not unique to Portland. Both Niebanck (1970) and Rapkin (1966) note that SRO hotels are very 
inexpensive, especially when compared with the cost of alternative types of housing such as an apartment. Additionally, though they do not compare the cost of sRo hotels to other housing, Erickson and Eckert (1977) and Goode, Lawton, and Hoover (1979) do note the match between hotel residents' low income and their concomitantly low rents.

\section{Elderly SRO Hotel Residents}

This section reviews the literature on the demographic and personal characteristics of elderly SRO hotel residents. Examination of the results of a number of studies on hotel residents suggests there is considerable similarity among the sampled populations. By contrast, comparison of the hotel samples with a national sample of elderly in congregate housing and the general elderly population suggests the sRo resident has a number of atypical characteristics.

One way in which elderly hotel populations are similar is in their sexual composition; they tend to be predominantly male. This finding is particularly noteworthy in that the percentage of females in the total population begins to outnumber the percentage of males at about age 19 (U.S. Bureau of the Census, 1953, 1961, 1972). Table II provides a comparison of selected study samples. The random hotel samples from St. Louis, San Diego, and Syracuse are typical of others reported in the literature in that the 
T A B L E I I

SEXUAL COMPOSITION OF SELECTED STUDY SAMPLES OF ELDERLY a POPULATIONS

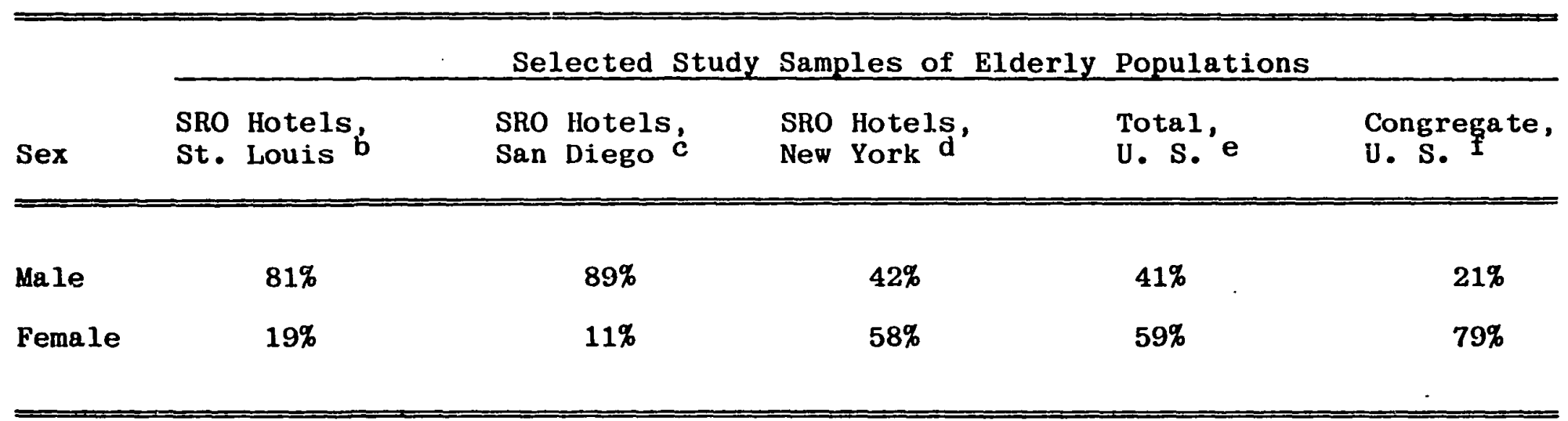

a Definitions of elderly vary in these study samples.

b Ehrlich, 1976, p. 8 .

c Eckert, 1978, p. 230 .

d Felton, et al., 1977, p. 1 .

e National Council on Aging, 1975, p. viii.

f HUD, 1976, p. 71 . 
percentage of males far outnumbers that of females (Ehrlich, 1976; Eckert, 1978; Rubenstein, et al., 1977). Only the New York City hotel sample, which was also random, has a sexual composition similar to that of the general elderly population, i.e., about 48 percent male (Felton, Lehmann, Adler, \& Burgio, 1977; National Council on Aging, 1975). This may reflect a regional difference in hotel population or it may be related to the particular hotels from which the study sample was drawn. The congregate housing sample ${ }^{6}$ has quite a different sexual composition with only 21 percent male residents (HUD, 1976).

Another characteristic on which the hotel populations have similar patterns is marital status. In general, hotel residents are more likely to be single or never married, and less likely to be married, living with their spouse, than the typical elderly person. Examining the three SRO samples in Table III, there is some variation in the percentage of "single, never married," but all are at least four to five times greater than the total U.S. sample of four percent (NCOA, 1975). There is virtually no variation among the samples for "married, spouse present" in that the largest number reported was only five percent (Ehrlich, 1976; Eckert, 1978; Felton, et al., 1977). By contrast, about 78

\footnotetext{
6The sample was a randomized survey of elderly residents from HUD assisted congregate housing projects. These projects all provided such services as meals and recreation programs in addition to housing.
} 
T A B L I: I I I

MARITAL. STATUS OP SERECTED STUDY SAMPLES

OP EIDEFLY POPULATIONS

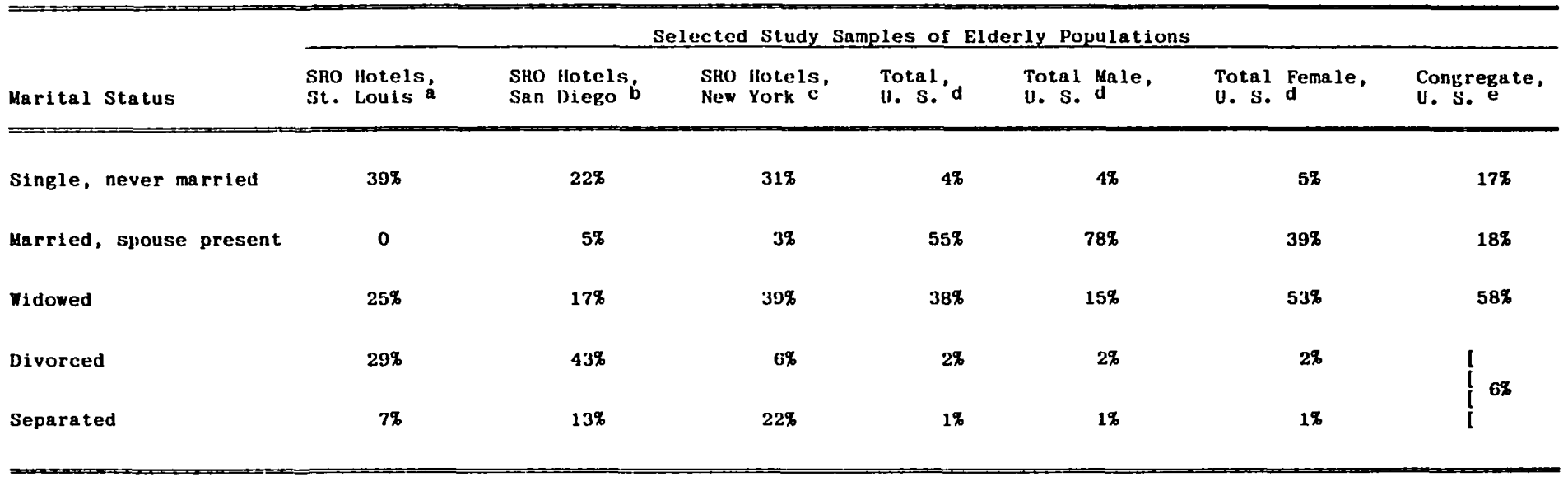

a Ehrlich, 1976, p. 8.

b Eckert, 1978, p. 230.

c Felton, et al., 1977, p. 1

d National Council on Aging, 1975, p. 237.

e IIUI), 1976, p. 75 . 
percent of the elderly males in the United States are married, living with their spouse (NCOA, 1975). Such a difference is not unexpected in that nearly all SRO hotel residents live alone.

For the status of "widowed," there is a large spread among the hotel samples with New York City having the highest percentage of widowed residents ( 398 ) and San Diego the lowest $(17 \%)$. Because females have a greater probability of being widowed, the higher percentage in the New York City sample may well be reflecting its higher percentage of females. Though the hotel samples show considerable variation on the proportion of divorced and separated, they have consistently higher percentages than those of the elderly United States total. Because congregate housing represents a population which, for the most part also lives alone, some similarities might be expected between it and the hotel samples. This is not the case however, in that over half the congregate sample was widowed, 17 percent were never married, and only six percent were either divorced or separated (HUD, 1976). In general then, the hotel population's marital status reflects a pattern which differs considerably from other elderly populations.

Many of the studies of hotel residents have not reported the racial characteristics of their samples. For the total U.S. elderly population, the racial composition is 90 percent caucasian, eight percent black, and two percent 
other (NCOA, 1975). Two hotel samples from New York City reported distributions quite similar to the national average, i.e., 90 percent caucasian, nine percent black, one percent hispanic (Cohen \& Sokolovsky, 1977), and 86 percent caucasian, 14 percent black (Felton, et al., 1977). Ehrlich and Eckert do not report the racial composition of their samples. In his study of the syracuse hotel population, Rubenstein, et al., (1977) found 20 percent of his sample to be minority (14 percent black, and six percent other). Bogue's (1950) study of Chicago's skid row reported that only 3.6 percent of the sample was minority. Given the most current information reported in the literature, the elderly SRO hotel population seems to generally reflect the racial composition of the total elderly population. Even though all the reported samples are from New York state, it seems clear that minorities are not overrepresented in the sRo hotel samples.

As for education, the typical elderly hotel resident has had approximately nine years of schooling. Studies vary in their manner of reporting, Eckert's (1978) sample had a mean of 9.5 years of schooling, Felton, et al., (1977) reported a mean of 10.3 years, Cohen and sokolovsky (1977) found one-third had had some college, Rubenstein, et al., (1977) reported a mean of about eighth grade. Nationally the NCOA (1975) study reported 63 percent of the elderly had some high school or less and 30 percent were high school 
graduates with some college. Though these findings are somewhat difficult to compare directly, they do suggest that hotel residents have a slightly lower level of education than the general elderly population.

An earlier discussion of the economic status of the elderly population noted that elderly hotel residents have average incomes lower than those of the general elderly population. Table IV provides a comparison of the median income of selected study samples. Due to rapid inflation in recent years, the studies selected for comparison were ones conducted within a similar time period, i.e., 1974-1976. The median income of the hotel resident was under $\$ 300$ per month during that time period while the incomes of the general elderly population, and the congregate housing sample were well over $\$ 300$ per month (Ehrlich, 1976; Eckert, 1978; Rubenstein, et al., 1977; NCOA, 1975; HUD, 1976). A 1976 study of Chicago's elderly by Bild and Havighurst found that aged public housing residents in that city had a median income of $\$ 205$ per month. Hotel residents may not be the very lowest income elderly but given that they pay an unsubsidized rent, a larger portion of their slightly higher income is spent on housing.

Examination of the various income sources suggests several reasons for the different income levels see Table IV. Though the percentage of each sample receiving Social Security is very similar, about 85 percent. Hotel residents 
I A B L E I V

INCONB NND BOUSING COSTS OP BELBCTED SAMPLBS OP BDDERY POPULATLONY

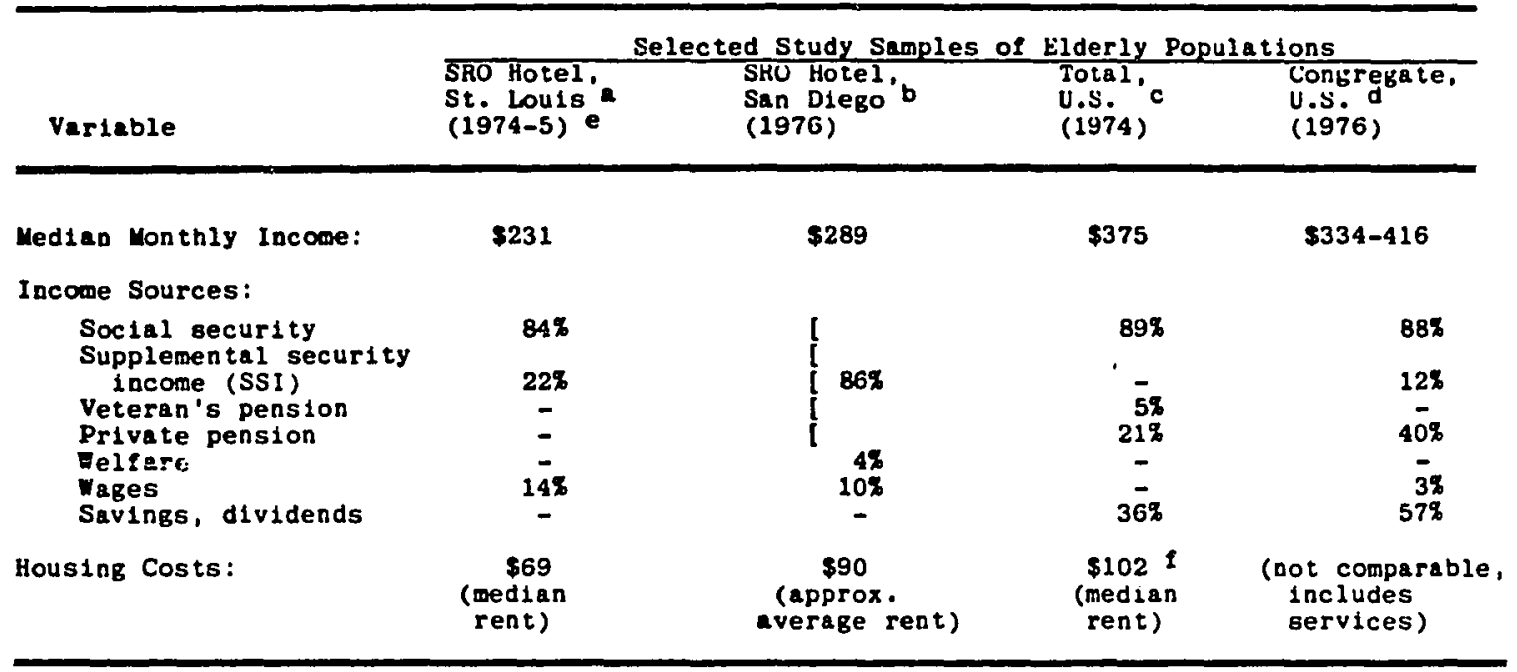

a Ehrlich, 1976, P.8-9.

b Eckert, 1978, p. 228-231 and Eckert, 1979, p. 499.

c National Council on Aging, 1975, p. 235-236.

d HUD, 1976, p. 62-63.

e Date indicates approximate year data was collected.

1 Harris, 1978, p. 183. No housing costs vere included in the National Council on Aging's Study. 
do not report savings and/or dividends as a source of income. By comparison, 36 percent and 57 percent of the total U.S. and congregate samples, respectively, report savings and dividends as an income source. Those samples also report income from private pensions whereas hotel residents generally do not. In addition to Social Security, hotel residents receive Supplemental Security Income (SSI)., i.e., 22 percent in St. Louis (Ehrlich, 1976). Only a few report receiving welfare, i.e. four percent in San Diego (Eckert, 1978). One major difference then, between income sources is the receipt by many of the general elderly population of at least some income from savings and dividends and/or private pensions. There also may be some difference in the amount of income received from the common sources such as Social Security, but that information was not available.

Based on the monthly rent, an SRO hotel may be one of the least expensive forms of urban housing available. Ehrlich (1976) reported a monthly median rent of $\$ 69.09$ for the St. Louis hotel sample and Eckert (1978) noted rents varied from one hotel to another but that an average was approximately $\$ 90$ per month (see Table IV). A direct comparison of the total elderly population's housing cost is confounded by the fact that most elderly persons own the home in which they live. Additionally, national samples frequently include the cost of housing in rural areas which 
has a tendency to lower the average rent. Though the study data was collected in 1973, Harris (1978) reports a national average monthly rent for the urban elderly renter, of about $\$ 102$. Despite the spread of time between this study and those previously noted, the median SRo hotel rents in st. Louis, San Diego, and Syracuse, even after one-and-one-half to three years of inflation had not reached that of the national average for the elderly in 1973. This suggests that rents paid for an SRO hotel room may be some of the lowest rents available anywhere in a city. The survey conducted by the City of Portland, Bureau of Human Resources (1974) supports this conclusion and, in fact, it found few units in other parts of the City which had equally low rents.

A characteristic more difficult to quantify is the health status of the SRO. Eckert's (1978) dissertation is the most recent effort. He notes that some previous studies, such as shapiro (1966) and siegal (1978) suggest SRO's are in "exceedingly poor physical and emotional health," while others, such as Tissue (1971) and Ehrlich (1976) assert that this population's perception of their health is one which recognizes few difficulties. Using the Cornell Medical Index and the Index of Incapacity, Eckert concluaes that his san Diego sample could not be defined as being in the best of health. In comparison to Shanas' (1968) national sample of elderly persons, a higher percentage of hotel residents reported difficulty in carrying out such tasks as getting 
about the hotel (house), dressing, and putting on shoes. Felton, Lehmann, and Alder (in press) do not proviae comparative data, but do state that the incidence of mental disturbances seems to be higher in the SRO population than in the general population. ${ }^{7}$ From her study of hotel residents, Ehrlich (1976) notes that there is a strong association between their physical and mental health. Eckert's findings offer support for such a relationship. He states that for each SRO resident who reported a condition of emotional disturbance (63 percent of the sample), he found a corresponding report of "serious physical disorders."

Despite suggestions of relatively poor quality physical and emotional health, Eckert notes that many SRO residents :

...perceive themselves to be getting along quite well,... [and that] for the older cohort, this perspective is essential for continued independent living. For this group, denial of bodily and emotional symptoms is a positive adjustment in maintaining self-reliance and an independent life style. (pp.255-6)

And Ehrlich:

...wonders if we are dealing from a health point of view with a "survival of the fittest" population. A group of individuals who do not let health problems, identified by a like-aged group of persons, become problems for them. A group who disregard typical symptoms and resulting diseases and survive the disease or condition by sheer will power. (p.32)

7A practice which is not uncommon in many areas is to use SRO hotels as the "dumping place" for patients released from mental hospitals. 
Thus, for an SRO population, comparison of specific ailments or disabilities appears to be less important than comparison of the older person's ability to continue an independent lifestyle.

In terms of social interaction patterns, it is generally held that SRO hotel residents are not similar to the typical elderly person. Aspects of interaction most commonly addressed which show variability are: frequency of contact; persons with whom contact is made; and the level of intimacy of the interaction. In his study of elderly male recipients of Old Age Assistance, Tissue (1971) compares a downtown and suburban sample. The suburban group was significantly more likely to report having three or more close friends and having seen at least one of their children in the past month, than was the downtown group. On the other hand, the downtown group reported significantly more contact with 10 or more trades people. In another study, Eckert (1978) describes the hotel resident's primary support system of relatives and children as definitely "underdeveloped," and suggests excessive alcohol consumption as at least one factor which influences those relationships. He also notes, as does Stephens (1976), that most friendships reported by hotel residents are based on utilitarian principles. According to Cohen and Sovolovsky (1977), the method used to measure types and levels of social interaction tends to shape a study's findings. They suggest the view that hotel 
residents are isolated is generally a myth, supported primarily because the indices used to assess social interaction do not take into consideration the life pattern of the hotel resident. Observation is suggested as an alternative to more traditional pencil and paper tests.

Health and social interaction are two variables commonly associated with life satisfaction, especially for the elderly (Alexander, 1978). This is another area in which hotel residents and the general elderly population show some differences. Tissue (1971) reports that for the suburban sample of older men, poor functional health and infrequent contacts with friends were both predictors of low morale; for the downtown sample of older men, only poor functional health was related to low morale. Felton, et al. (1977) also report little association between life satisfaction and interaction for their hotel sample. They examine both contact within the hotel and contact with friends outside the hotel and found neither to be significantly correlated with life satisfaction ( $p<.05)$. Tissue's findings on functional health complement Eckert's statement regarding the importance of at least perceived good health to life in an SRO hotel. Cohen and Sovolovksy's findings call into question the validity of associations between social interaction and life satisfaction for hotel residents. In their support, Tissue reported differences in the frequency of contact and with whom the contact was made, but no 
difference between life satisfaction or morale of his two samples.

Based on these comparisons, the most obvious conclusion is that though there are some similarities between the elderly hotel resident population and the general elderly population (racial composition and level of education), on many demographic and personal characteristics there is considerable variation (sexual composition, marital status, amount of income, sources of income, and housing costs). For other characteristics such as health, social interaction, and life satisfaction, measurement is less quantified. This makes comparison less precise and leaves open to some question whether hotel residents are similar, or how similar they are, to other elderly populations. Examination of only the means and medians can camouflage real differences within the groups. The general elderly population has been described as an extremely heterogeneous group (Harris, 1978). Likewise, the elderly hotel population is a variable lot. Some attended college, graduated and held professional or management level positions, whereas others had only a few years of schooling and spent their working time as semi-skilled laborers. Some receive pensions while others need the assistance of SSI to make ends meet. But there are other differences too, ones which suggest differences in lifestyle.

One of the ways in which SRO residents differ from one 
another is in their length of tenure at a hotel. Some residents are viewed as "permanent" while others are seen as "transient." Stephens (1976) used at least one year's occupancy and paying rent by the week or month as the criteria for identifying a permanent resident; Eckert (1978) used the time period of at least six months at a hotel as his criterion. Those of shorter residency were classed as transient, a category generally recognized by both hotel management and other residents. One important distinction between permanents and transients is their interaction pattern around the hotel. Stephens notes that the two groups "constitute separate societies." The permanent residents may interact with one another but tend to exclude the transients from their gatherings. Permanents may even help one another when the need arises. Typically, but not always, the permanent residents are older and the transient residents younger. The age difference compounds the separation between permanents and transients and Eckert notes that even long tenured, younger residents may be seen as transient. It is presumed they will move on at some time, whereas the older residents tend to view life at the hotel as home, possibly their last before death or institutionalization.

Eckert (1978) reports another type of distinction between older SRo hotel residents, one which is based on three general "life trajectory patterns." They are: a) the lifelong lone $x, b)$ the retreatist or marginally socially 
adjusted, and c) the late isolate. The lifelong loner is just that. Typically, he chose a non-conformist lifestyle early on and pursued employment which necessitated considerable geographic mobility. Independence has been an important part of his life. The retreatist lifestyle is quite different, however. An attempted conventional lifestyle ending in failure is the pattern here. Past losses, alcohol, a sense of defeat, and self-recrimination contribute to the retreatist's marginal adjustment. The late isolate is one who has outlived his intimate friends and family and finds himself living and feeling alone. Eckert notes that these different life patterns influence residents' satisfaction or dissatisfaction with hotel life:

An important aspect of older hotel residents' satisfaction and acceptance of hotel life is whether or not the "alone" pattern of living has been voluntarily chosen. For example, many late isolates feel forced into hotels for health and financial reasons. If the change and circumstances are too drastic, poor adjustment and severe isolation may result.

In the case of "lifelong loners" the "alone" pattern of living is a voluntarily chosen alternative within the limits of perceived alternatives. For this group, the hotels are a "natural" habitat. The social climate of the hotels is well suiced to their values, needs, interests, and finances.... As long as their autonomy is not threatened through severe physical and mental decrement, the hotels provide an optimal living environment.

Those whose life followed a pattern of marginal social adjustment frequently blame the "system" or "others" for their present situation. Although the hotels and the commercial environment meet most of their needs, they feel unhappy, angry, or defeated about their situation." (p.220-1) 


\section{PART E: POLICY CONSIDERATIONS}

It should be quite clear to the reader by this point that SRO hotels and their residents have generally not been seen as desirable neighbors. Predominant values have described sRo hotel buidings as ugly, unfit for habitation, blocking future development, and therefore undesirable. The goal has been to eradicate or otherwise transform the hotels into more acceptable forms. A continuing emphasis on the redevelopment of central cities has provided a mechanism by which this goal could be achieved. As for the hotel residents, the predominant belief has been that they form an abberrant population. They have been typified as social outcasts, isolates, alcoholics, transients, and more generally, bums. As a group, with the possible exception of the elderly or handicappied, they have been generally classed as unworthy, undeserving, poor. Because of the view that the hotel residents are neither worthy nor deserving and because they represent a politically powerless group, there has been little perceived obligation to proviae assistance to this population. Rather, the general goal has been to remove the population, "to clean up the streets," and to make the population disappear. Again, the continuing effort to redevelop central cities has provided a convenient mechanism to achieve this goal.

That SRO occupants are abandoned to a Victorian squalor is due to the prevalence of the concept, equally Victorian, of the "worthy poor." Perhaps the 
problem is that SRO occupants cannot be fitted into the middle-class patterns and these determine where the help is given. (Levy, 1968, p.579)

Rejection of the sRo hotel as a legitimate or acceptable form of housing and the lifestyle of the hotel resident as a choice of one among many is reflected in the decisions made by both Federal and local officials.

\section{Eederal Decisions Related to SRO Hotels and their Residents}

A history of Federal decisions which impacted SRO hotels and their residents is recorded in Congressional committee hearings and reports, and in the legislation ultimately approved by congress and signed into law. Additionally, the administrative rules and regulations developed by Federal agencies to implement legislation comprise statements of intent.

Demolition of SRO Hotels. In 1937, Congress passed the first United States Housing Act when it authorized the public housing program. This program was designed to do more than provide badly needed housing; it was the nations's initial effort to eliminate slum housing. The underlying assumption in the legislation was that one sure method of reducing slum housing was to demolish it (U.S. Congress, 1937).

It was not until after World War II and passage of the Housing Act of 1949 that the elimination of slum housing began in earnest, however. Public law 81-171 was one of the new Congressional programs designed to provide a boost to 
the post-war economy. In addition to establishing a national housing policy, the law furthered the goal of eradicating blight and slums:

The Congress hereby declares that the general welfare and security of the Nation and the health and living standard of its people require housing production and related community development sufficient to remedy the serious housing shortage, the elimination of substandard and other inadequate housing through the clearance of slums and blighted areas, and the realization as soon as feasible of the goal of a decent home and a suitable living environment for every American family, thus contributing to the development and redevelopment of communities and to the advancement of the growth, wealth; and security of the Nation. The Congress further declares that such production is necessary to enable the housing industry to make its full contribution toward an economy of maximum employment, production, and purchasing power. (U.S. Congress, 1949)

Even though the Housing Act specified as a goal the realization of a decent home and suitable living environment, that was not the primary intent of the legislation. As Meechan (1977) notes, "In both the 1937 and 1949 Housing Acts, the major concerns were underemployment and slum that clearances; low-income housing was only a peripheral goal." The result was that clearance of slum housing outstripped production of low-cost housing units (National Commission on Urban Problems, 1969). Estimates are that between 1937 and 1967, public housing and urban renewal projects were responsible for the removal of at least 581,000 low-cost units. That figure does not include demolitions for highway construction and other activities such as local code enforcement. When estimates of the units 
demolished by those activities are added, the total number of units lost comes to just over one million.

There are no figures which indicate just how many of the units demolished for urban renewal or other public projects were SRO hotels. It seems evident, however, that the number may have been substantial. The Journal of Heusing contained an article in 1961 entitled, "Skid Row gives renewalists rough, tough relocation problems." In it, the relocation problems of 11 cities were discussed. By 1961 , Minneapolis had relocated approximately 2,000 men. Sacramento reported having 5,000 to 6,000 single men and 731 householders within the boundaries of one of three renewal areas. Duluth noted that 618 single individuals would be relocated; Toledo had 725 to relocate. That cities were eager to pursue the use of urban renewal funds in order to redevelop their skid row areas is demonstrated in the report from Chicago:

Good press coverage of sections of the report as they were released along the way has stirred up reactions that seem to promise strong support for getting renewal of the city's three skid row areas in the works. Raymond Hillard, director of cook County department of public aid, called for an action program to set the recommendations of the study in motion, and, if necessary, new laws and state funds to "eradicate the skid rows in five years." (p.332)

Through the urban renewal program, the federal government paid a substantial portion of the cost of slum clearance. It was not a program local jurisdictions could dismiss lightly; on the average, the federal government 
covered approximately 70 percent of the cost to acquire the land, demolish the structure, and prepare the site for redevelopment (Anderson, 1964). By 1962, 79 percent of the cities with populations of 100,000 or greater had at least one urban renewal project. It can be presumed, based on the assumption that the 11 cities reported in the Journal of Housing article were representative of the other 93 with renewal projects, that many of those projects had earmarked SRO hotels for demolition.

Displacement of SRO Hotel Residents. Accompanying the demolition of occupied housing units is the inevitable displacement of the residents of those dwellings. It is impossible to achieve the first condition without also obtaining the latter. The urban renewal program which called for the eradication of slum housing via clearance also contained requirements on the relocation of displaced persons. That legislation specified the conditions local jurisdictions were to meet prior to approval of renewal projects by the Housing and Home Finance Agency (HHFA). By its silence on certain matters, though, the legislation provided a guideline both for what was necessary and what was not necessary to satisfy the intent of the law. In general, much of the criticism of the urban renewal program has focused on what was left out of the requirements for relocation (Hartman, 1964, 1972); and much of the program's defense has focused on the increased level of benefits 
provided to displacees over the history of the program (Monson, 1966). Throughout this debate, however, most discussions have failed to note the implication of the relocation for the individual residing in a single, furnished room. The discussion which follows traces the history of relocation assistance to hotel residents, and notes that decisions have been made to allow displacement with little or no assistance.

The provisions of the 1949 Housing Act state that assistance was to be provided to "displaced families" in the form of help to locate replacement housing (U.S. Congress, 1949). No financial assistance was to be provided. That the phrase "displaced families" appeared in the legislation without mention of "individuals" meant that assistance was not likely to be directed toward single persons.

It was not until the Housing Act of 1956 that Congress saw fit to provide even a minimal relocation payment (U.S. Congress, 1956). At that time, they authorized payments which would cover only "...reasonable and necessary moving expenses... and shall not exceed $\$ 100$ in the case of an individual or family..." The regulations prepared by the Housing and Home Finances Agency, which was the agency responsible for implementing the Housing Act, were such that an SRO hotel resident would have no moving costs. In order to be found eligible to receive payment for moving costs, it was necessary that the displacee had furniture or other 
belongings which needed moving. Because hotel residents rented furnished rooms, they had no furniture to move and therefore were ineligible for any payment under the 1956 Act. To many, this seemed to be fair treatment for the hotel population; as one hotel manager explained, "'Ain't any of them that couldn't move in a hour and a half," (Levy, 1968). It was noteworthy, though, that individuals were specifically mentioned in the Act as potential eligibles for assistance.

The 1957 Act did little to improve the eligibility status of single persons living in furnished rented rooms. It added an "in lieu of " clause to the section on relocation payments which allowed a fixed payment in lieu of the displacees' moving cost up to an amount of $\$ 100$ (U.S. Congress, 1957). This fixed payment was based on a formula which took into account consideration the number of rooms contained in the dwelling unit to be demolished. For the SRO hotel resident, his unit consisted of only one room and therefore was presumably eligible for the fixed amount of five dollars. From the literature, it is not entirely clear whether the local authorities even bothered to provide this token payment to many hotel residents (Journal of Housing, 1961).

In 1959, Congress amended the payment amount for both actual moving costs and the fixed moving cost allotment to a maximum of $\$ 200$ (U.S. Congress, 1959). No change was made in 
the eligibility criteria, thus leaving SRO hotel residents with a possible five dollar payment.

Five years later, in 1964 , Congress approved several substantial amendments to the displacement/relocation process (U.S. Congress, 1964). One change was to replace all references to "families," in the section dealing with relocation, to "individuals and families." This meant single persons would now be eligible to receive the same benefits that families received. The legislation also called for the formulation of a relocation assistance program for each renewal area, "at the earliest possible date." For the first time, Congress dilineated the types of services that were to be provided to displaced persons, which included assessing needs of the displaced, providing information and help, and assuring coordination of relocation activities. Another section of the 1964 amendment authorized a relocation adjustment payment to two special groups: a) families, and b) individuals 62 years of age and over. In authorizing this payment, Congress acknowledged the financial hardship which often resulted from displacement. These adjustment payments were designed to help cover the increased rent experienced by those not relocating to public housing. A maximum payment to cover the rent differential for one year following relocation was $\$ 500$. This payment was in addition to the previously mentioned moving assistance. Though these amendments were a distinct improvement for some, the single 
person under the age of 62 who was displaced from a rented, furnished hotel room would still receive only five dollars. Handicapped persons became eligible for relocation adjustment payments in 1968 (U.S. Congress, 1968). Also in that year, Congress increased the maximum amount of the payment to $\$ 1,000$. That amount was to cover the rent differential over a period of two years. Again, those who were single and neither handicapped nor at least 62 years of age were excluded from the relocation adjustment payments.

It was not until the passage of the Uniform Relocation Assistance and Real Property Acquistion Policies Act of 1970 that nonhandicapped, nonelderly, single persons became eligible for relocation adjustment payments (U.S. Congress, 1970a). This was twenty years after the creation of the urban renewal program. Up until that time, the Federal government had facilitated the displacement of thousands of hotel residents, paid them no more than five dollars, and reported that progress was being made toward the goal of eliminating substandard housing. The 1970 Act did much to rectify the previous injustice to single individuals, and it remains virtually unchanged as of 1981 .

In spite of improvements in relocation benefits, inequities still remain. One criterion of eligibility for assistance which continues to prevent some hotel residents from receiving benefits is the requirement of at least a 90 day residency at the location from which displacement occurs 
(Yale Law Journal, 1970). It is also possible to avoid the entire burden of relocation, which is now paid for out of local rather than Federal funds. In the case of rehabilitation of hotels into other uses, the vacation of a building prior to sale to a new owner who wishes to seek financial assistance from the Federal government, will relieve the new owner of the obligation to make relocation payments (Galbreath, 1981).

The National Commission on Urban Problems' report of 1969 contained a statement on relocation and urban renewal which still seems apt 11 years later:

The Commission suggests further, however, that the time has come to reassess relocation policy and practices in broader terms. For it seems hard to escape the conclusion that the primary purpose of relocation practice, if not of announced policy, has changed but little. In the earlier stages of renewal it might be summarized: get the site occupants out of the way of project construction with as little delay and outright hardship as possible. More recently a clause might be added to the preceding sentence: "and with as much improvement in their housing as market conditions allow and with some respect for their dignity as human beings." ...Relocation should be seen essentially not as a groundclearing operation but as a direct and integral step in the march toward the national housing goal--"for every American family." (National Commission on Urban Problems, 1969, p.90)

Non-replacement of SRO Hotels. With the understanding that the primary intent of urban renewal legislation was not the provision of low-cost housing, non-replacement of SRO hotels is more comprehensible. Since 1949., Congress has established various production goals. Those goals were based on assessments of the need for low-cost housing, but were 
never assumed to satisfy all of the needs identified. The actual level of production failed to meet Congressional goals, much less the actual level of need. The National Commission on Urban Problems (1969) noted that:

...the 1949 authorization of 135,000 public housing units a year for 6 years, to a total of 810,000 has never been approached. Instead, in the 19 years since the Housing Act of 1949, only about 460,000 units of public housing have been completed, with another 60,000 to 70,000 underway. We have moved in this program at about one-fifth of the rate authorized in 1949. (p.83)

And the level of success between 1968 and 1978 was no better. HUD achieved only 45 percent of the ten-year goal of six million units established by congress (U.S.Congress, Joint Economic Committee, 1979).

But these production goals and achievement levels were for "standard" low-cost housing units, not SRO hotels. The hotels were seen as slum housing and not as decent, safe, and sanitary dwelling places. Through the consideration of amendments to the Housing Act, Congress confirmed its view that SRO hotels did not represent a form of standard housing and therefore should not be produced with the aid of federal funds.

One amendment approved as part of the Housing Act of 1959 addressed the specific issue of hotel construction in an urban renewal area (Yale Law Journal, 1970). The American Hotel. Association lobbied for the amendment which mandated an independent analysis of the need for a hotel or "transient" housing be conducted prior to specific 
development plans. The intent on the part of the Hotel Association was no doubt motivated by a desire to minimize new competition. The effect on SRO hotels, though, was to almost certainly assure that none would be constructed in an urban renewal area as replacement housing due to additional cost of the independent analysis.

The likelihood that this amendment had a substantial effect on the future development of SRO hotels is slight, but it is interesting to note that both Minneapolis and Sacramento considered the construction of SRO hotels as replacement housing for their displaced, single, male, skid row population in the late 1950 s (Journal of Housing, 1961). It was reported that the Minneapolis project failed, due to an inability to locate a site where the prospective neighbors would not protest, and that the high cost of land doomed the Sacramento project.

Another action, which had an impact on the potential production of SROs as replacement housing, was the development of the minimum property standards. Prior to 1956, each local area office of HUD was free to establish minimum requirements for their own area (Lesher, 1981). After 1956, specific guidelines were prepared for the development of Federally assisted housing projects. These guidelines, which detailed the minimum requirements of a standard housing unit as including a self-contained kitchen and bathroom and being at least 300 square feet, were to be 
applied nationwide. SRO hotel units contained neither their own kitchen nor bath, were considerably less than 300 square feet, and therefore were not classified as standard housing. This designation meant no direct Federal assistance would be provided to SRO hotel projects. As noted earlier, even with Federal assistance, the level of production in standard, low-cost housing did not achieve established goals. Without Federal assistance, the prospect of producing any SRo hotels was all but eliminated.

Even though HUD had clearly defined what constituted a standard housing unit, there seemed some prospect of a reconsideration based on the 1969 Weiker Amendment to the Housing Act. (Yale Law Journal, 1970). That amendment called for the one-to-one replacement of low-cost housing units which were demolished as a result of urban renewal projects. Though hotel units were certainly low-cost housing, the final amendment did not require their replacement.

A year later, the Moorehead Amendment was introduced (Yale Law Journal, 1970). This amendment proposed that as part of the congregate housing program for the elderly and handicapped, structures with "... common bathroom, community kitchens, common dining areas, and other shared facilities..." be financed by the Federal government (U.S. Congress, 1970b). If approved as originally drafted, the amendment would have allowed approval of Federal assistance for the development of SRO hotels as one type of low-cost 
housing. However, the original amendment was revised and approved without reference to common bathrooms, thus confirming the reluctance of Congresss to assist that type of housing.

Tentative Reconsideration. To date, the urban renewal program has been providing aid to cities for the purpose of redevelopment for over 30 years. As the previous discussion indicates, during that time, the SRO hotel was never considered to be adequate or acceptable as an alternative form of low-cost housing by either Congress, HHFA, or its successor, HUD. Recent actions by both Congress and HUD, however, suggest that there has been some reconsideration of this position.

The first action taken by Congress was to approve the use of 312 loans for the rehabilitation of SRO hotels U.S. Congress, 1980). This represented a major shift from the previous policy of providing no direct financial assistance from HUD to structures defined as substandard. Approval of the use of 312 loans for SRO hotels meant owners could make application directly to HUD for low-interest loans to upgrade their buildings. The maximum allowable expenditure per dwelling unit was set at $\$ 15,000$. This is noteworthy in that it is $\$ 20,000$ less than the $\$ 35,000$ maximum allowed for self-contained dwelling units. It is also worth noting that substantial cuts in the 312 loan program were proposed by 
the Carter Administration for fiscal year $80-81.8$ On the one hand, Congress had given HUD its approval to process 312 loans for SRo hotels; on the other hand, it seemed likely that any applications by hotel owners would be competing for a substantially reduced amount of authorized funds. The irony of Congress approving the use of HUD program funds for SRO hotels at the same time those funds were being reduced is difficult to miss.

The action taken by HUD in 1980 was more definitive than that taken by Congress. HUD agreed to approve a demonstration grant whereby a rent subsidy, similar to that of the Section 8 program, would be provided for residents of SRO hotels (Galbreath, 1981). Along with approval of the rent subsidies, HUD agreed to waive two major requirements of its minimum property standards, i.e., complete bath facilities and at least 300 square feet per unit. Instead, shared bath facilities and a minimum of 100 square feet per room would be allowed, and a small appliance unit which contained a combination hot plate/refrigerator/sink would be required in each hotel room. In order to qualify, it would be necessary for the owner of a hotel to comply with local code requirements and spend a minimum of $\$ 1,000$ per unit in rehabilitation costs. For the City of Portland's

\footnotetext{
8The legislation, which was approved for fiscal year 81-82 under the Reagan Administration, allowed the 312 program to operate only on repayment funds, (Milgram \& Bea, 1981).
} 
demonstration grant award, HUD had also agreed to waive the requirements of age or handicap associated with a Section 8 rent subsidy and base eligibility purely on the applicant's income. 9

Funding of this demonstration project was the first time Section 815, which authorized HUD to undertake special demonstration projects, was to have been utilized for SRO hotels (Lincoln, 1980). The section was approved, seven years ago, as part of the Housing and Community Development Act of 1974. It was not, however, the first time that HuD had provided funds for an SRO hotel project. In the past two years, HUD approved several proposals to rehabilitate SRO hotels using funds from the innovative grant program. HUD also approved, in 1980, a neighborhood self-help grant which aided in financing the rehabilitation of a hotel. The significant difference between these grants and the demonstration project is the ongoing rent subsidy. The innovative and self-help grants assist in financing rehabilitation of the structure, whereas the demonstration project causes the structure to be rehabilitated and guarantees rent subsidies for a period of 15 years.

In order for hotels to be subsidized on more than a demonstration basis, changes were needed in the existing

9At this writing, the Washington of $f$ ice of HUD has reneged on its original willingness to process the grant application. The program is believed to be dead with only a modest chance of resurrection (Galbreath, 1981). 
legislation. As part of the Omnibus Budget Reconciliation Act of 1981, Congress gave discretionary authority to the Secretary of HUD for the use of rent subsidies to SRO hotels under an existing program of moderate rehabilitation (U.S. Congress, 1981). It is believed that this action could provide the necessary incentive to fund Portland's SRO Demonstration Project but there has been no word as of this writing.

The willingness of Congress and HUD to give at least $a$ tentative reconsideration to a program other than demolition of SRO hotels did not occur without substantial lobbying efforts. Numerous informed citizens had been attempting to "capture the legislative ear" for some time. There were two national conferences held which focused on the plight of the SRO hotel residents and their vanishing low-cost housing (U.S. Senate, 1978). The U.S. Senate Special Committee on Aging (1978) published an information paper, "Single Room Occupancy: A Need for National Concern." In 1979, the annual Conference of Mayors adopted a resolution asking HUD to "... encourage, through demonstration or other programs, the feasibility of rehabilitation and new construction of single room occupancy housing" (U.S. Conference of Mayors, 1979). If a program of rehabilitation or new construction and subsidization of SRO hotels is be pursued, it will be necessary for Congress and the Secretary of HUD to make a commitment of adequate resources, and until that occurs, SRO 
hotels and their residents will receive only token assistance.

Lecal Decisions Related to SRO Hotels and their Residents

The distinction between local and Federal decisions, especially on the issue of SRO hotels and their residents, is not always clear. In general, Federal decisions tend to have a tremendous influence on the decisions made by officials of local jurisdiction. Programs such as urban renewal, or, more recently, the community development block grant (CDBG) offer local jurisdictions the option of participation. Agreement to participate means the local jurisdiction will be able to use the resources earmarked for that program to carry out specific projects developed at the local level. In other words, the Federal government sets the broad parameters for participation and the iocal jurisdiction designs its plans and projects to conform with those standards. In the case of urban renewal, Congress established the goals of slum clearance, creation of jobs, and development of decent low-cost housing. Local jurisdictions, if they chose to participate in the program, selected the site to be cleared and designed a plan for its redevelopment. It is these decisions which reflected local goals.

By contrast, there are Federal programs which allow little or no discretion at the local level. An example is the Uniform Relocation Assistance Act which requires that 
all jurisdictions provide specified assistance to residents and businesses who are displaced by actions which are the result of Federal programs. Failure to comply with the law could result in the loss of Federal support to the local jurisdiction. In this case, the program established by Congress is the program implemented at the local level.

Even though Federal programs influence and sometimes dictate local actions, most were not adopted without considerable input from local officials. Using urban renewal as an example, cities were eager to have the Federal government provide financial assistance for the redevelopment of their blighted central city neighborhoods (Scott, 1969). When regulations were perceived as too restrictive, local officials lobbied for changes and frequently Congress adopted less restrictive amendments. In a practical sense, unless participation in a Federal program was mandatory, Congress was forced, at least to some degree, to address the concerns of those who would be implementing the program. In the case of urban renewal, participation was considerable.

Demolition of SRO Hotels. As noted above, slum clearance was an activity in which local jurisdictions had a keen interest. Participation in the program meant an opportunity to redevelop blighted areas with the city paying only a fraction of the total cost. In turn, successful redevelopment meant an improved tax base which then 
contributed to the city's economic growth. Few jurisdictions refused the offer; as the earlier discussion indicated, only 21 percent of the cities with populations of 100,000 or more were not participating by 1962 (Anderson, 1964).

The selection of the urban renewal site was the decision of the local authorities and, therefore, the decision to demolish SRo hotels was a local one. The 1961 Journal of Housing article on skid row demolition began this way, "The relocation problems posed by skid row as a renewal area have caused some sities to pause for a long probing look at the make-up of skid row before striding ahead with renewal plans" ( p. 327, emphasis added). The indication throughout the article was that skid row and SRO hotels were the targets of clearance projects in many cities.

Dispersion of Hotel Residents. For local officials, demolition created a problem of what to do with the displacees. There were several possible approaches; one was to plan for relocation by providing new housing with the assistance of public housing or other federal housing programs. Another was to assume an adequate supply of housing existed and simply assist displacees in locating vacant units. The most common approach was to assume sufficient vacancies to absorb those displaced.

Relocation of SRO hotel residents created a special problem. In general, there was a distinct desire by local officials to eliminate skid row (its housing units and the 
institutions which supported it) and to prevent another from developing elsewhere in the city. It was noted that many hotel residents would not "fit" into public housing or more conventional housing, either because of their choosing or because managers would find them undesirable tenants (Yale Law Journal, 1970). Development of special housing for hotel residents could lead to the creation of a new skid row (Journal of Housing, 1961).

Facing those considerations, the basic approach was to disperse the population and to provide assistance when requested (Journal of Housing, 1961). The goal was to have the hotel residents be "... absorbed into the community, rather than act upon the community to recreate the skid row environment elsewhere," and many cities reported confidence that there was little danger of another skid row forming due to the wide dispersal of the population. The obvious benefit of dispersion for the city's politicians was that they could then claim to have "cleaned up the city." Dispersion was also an inexpensive approach to relocation; there was no need to allocate financial resources or time toward the production of new low-cost housing.

conversion of SRe Hotels. During the $50 \mathrm{~s}$ and $60 \mathrm{~s}$, urban renewal focused on clearance, but in more recent times, there has been some consideration given to renovation as well. In lieu of demolition, conversion of an SRO hotel to another use could achieve approximately the same goals, 
i.e., displacement of the population upon renewal of the area, in this case, renewal of the building. The current economic situation, which has increased the cost of any type development, has also encouraged developers and local officials to consider the potential of new uses for existing structures. Federal programs such as Urban Development Action Grants, Section 312 commercial or housing rehabilitation loans, Section 8 rental assistance, and historical landmark designation could provide assistance in reducing the overall cost of building renovation. Because these programs offer substantial economic benefits, developers have been eager to secure buildings with potential for renovation

Any use of these programs must be approved by local officials; thus, either directly or indirectly, a policy is established for the acceptable or unacceptable uses of those development aids. In Portland, city officials have approved the use of such programs for the conversion of SRO hotels to subsidized section 8 rental apartments and to commercial space (Galbreath, 1981). New York City has gone a step further by offering an additional tax incentive, known as $\mathrm{J}-51$, to developers who renovate old hotels, or other existing structures, into apartments or cooperatives (New Yerk Times, 1979). It is presumed that the willingness of local officials in Portland and New York City to approve the use of Federal or other assistance programs for the 
conversion of SRO hotels is representative of decisions in other cities.

Limited Preservation of SRO Hotels. The tentative reconsideration by Congress and HUD of the issue of SRO hotels, is due, in part, to an initiative from the local level. It cannot be said, however, that all communities have recognized the special housing needs of hotel residents.

New York City has the largest total stock of SRO hotels of any city in the United States, and as might be expected, was, at one time a leader in publicly recognizing that the hotel population had special needs which were not being met. In 1972, New York established the Mayor's Office on SRO Housing, with the purpose of coordinating

...the work of social service agencies, local health care facilities, housing departments, the police and courts, [and] to aid the residents in SRO facilities by providing on site services and upgrading living conditions. (U.S. Senate, Special Committee on Aging, p. 3)

Two years later, the City of Seattle officially recognized the need for SRo hotel units when it supported the seattle Housing Authority's purchase of the Morrison Hotel (Lincoln, 1980). No funding from HUD was used in the purchase or upgrading. Since that time, the City has approved the upgrading of several hotels in the downtown area.

In addition to actually approving the upgrading and preservation of SRO hotels in Seattle's downtown, Mayor Royer testified before the House Task Force on Rental Housing: 
Now is also the time for the Federal Government to seriously consider funding single room occupancy hotels. With the recent rehabilitation of the Lewiston Hotel, Seattle has shown that Government can, for a modest price, transform a worn-out old hotel into a decent place to live. Rehabilitated hotels are not spacious and they don't offer each tenant individual kitchens. But there are those who need only a small space and those who find waiting in a corner cafe far preferable to cooking alone in an apartment. We need the Federal Government to recognize that it is better to have a warm room without a kitchen than to bed down under a viaduct. The minimum property standards for subsidized housing should be adjusted and single room occupancy programs should be adequately funded. (U.S. House of Representatives, 1980 , p. 667-8)

Portland's former Mayor McCready also spoke publicly in support of SRO housing. In an attempt to inform owners and lessees of the programs available for rehabilitation of hotel units, she sponsored a special workshop (eregenian, April, 1980). She also approved and lobbied for the City's SRO Demonstration Project.

Despite these obvious signs of support for SRO housing, it is important to compare official words with actions. What emerges is that statements of policies or goals and particular actions are not necessarily consistent and one action may not be consistent with another. Take New York City, for example. The Mayor's Office of sRo Housing was establishea in 1972, yet in 1976, the City added old hotels to the list of structures which, if renovated into apartments or cooperatives, would command a tax freeze on improvements for a period of 12 years (New York Times, 1979). On one hand, the City proposed to provide special 
services to hotels and their residents, while on the other, encouraged the conversion of the structures to apartments. Likewise, the former Mayor of Portland encouraged owners and lessees to upgrade their building using low-cost loans from the City while, at the same time, approving the conversion of a hotel to subsidized Section 8 rental apartments. A real commitment to preserving SRO hotels appears to be limited.

Emphasis on the redevelopment of central cities over the past 30 years has had a tremendous impact on the SRO hotel and its residents. Numerous hotels have been removed or renovated through urban renewal programs and thousands of hotel residents have been displaced with little or no compensation. Decision makers at both the federal and local level have, through the adoption of policies and programs, facilitated these events. Only in the past several years have some decision makers begun to promote the idea of preserving SRO hotels as an alternative for housing for a select group of individuals. Their efforts, to date, have done little to change the thinking of other decision makers and as a result have had very limited success in generating either new policies or programs. The net result has been an ongoing reduction in the stock of low-cost, unsubsidized housing units. 
CHAPTER III

METHODOLOGY

The question to which this research responds is whether there is a role for SRO hotels in housing the low-income urban elderly poor. As noted in the first chapter, this is a policy study and, as such, examines the question from several perspectives. One perspective looks at the hotel resident, his preferences and lifestyle, and compares those findings with a similar analysis of Section 8 apartment residents who were previous residents of SRO hotels. Another perspective looks at the neighborhood in which the hotels are located and compares it with neighborhoods elsewhere in the City which were noted as good locations for elderly housing. A final perspective looks at several modes of housing and compares the costs of a range of options from maintaining existing units to constructing additional units.

HYPOTHESES

Three hypotheses will be examined in this study.

Hypothesis one

Those who chose to move out of single room occupancy hotels and inte subsidized section 8 apartments, on the 
whele, have a different life style than those who, to date, have chosen to remain in their hotels.

The literature suggests that elderly SRO hotel residents tend to differ from the general elderly population. Though they tend to differ on the basis of income, sexual composition, and other similar variables, they also tend to differ in their general approach toward life. This "deviation from the norm" manifests itself in such things as the hotel resident's lower frequency of marriage, his social interaction patterns, and his selection of housing.

If it is presumed that those who moved from an SRO hotel to a section 8 apartment did so by choice and that those who remained were aware that other low-cost housing was available in the downtown area, then it may be that those who remained did so also by choice. Hypothesis one proposes that there are lifestyle differences between those who currently live in SRO hotels and those who have chosen to move out of a hotel and into a subsidized section 8 apartment. Data from interviews with residents of SRO hotels and Section 8 apartments are used to examine the relationship between housing style differences and life style differences. The implication for policy is that a housing option not generally available under existing HUD regulations may be a preferred housing style for some portion of the elderly population. 
Hypothes is Two

It is less expensive for a single room eccupancy hotel resident to live downtown than to live outside downtown.

The cost of goods and services is a fundamental consideration for those who have a low income; the lower the income, the more cost becomes a consideration. Because elderly hotel residents tend to have extremely low incomes, the availability and cost of basic necessities such as food, shelter, transportation, and the like, are primary considerations in the selection of a housing location. Maximizing the proximate availability of goods and services while reducing the overall cost would enable the hotel resident to get the most value out of his expenditures.

This hypothesis proposes that it costs less, in terms of actual monthly expenditures, for an SRO hotel resident to live in downtown than to live outside downtown. If the loss of SRO hotels from central city areas continues, residents will be forced to seek housing in neighborhoods outside downtown. The data sources used to test this hypothesis include detailed information about the hotel residents' use of stores and services and a survey of the cost of living in four neighborhoods.

Hypothes is Three

The maintenance and rehabilitation of single reom eccupancy hotels is less expensive than providing ether 
modes of housing for low-income urban elderly persons.

In these times of escalating costs, the price of housing has not escaped the ravages of inflation. The combined cost of money, material, labor, and land have all but stopped the production of new rental units and those which have been produced are not affordable to the low-income unless substantial subsidies are provided either for production or rents or both. Due to these increasing costs, experience indicates that maintenance and rehabilitation have emerged as a less costly method of providing decent, safe, and sanitary housing, particularly for the low-income.

This hypothesis proposes that the maintenance and rehabilitation of SRO hotels is a less costly method of providing housing for a portion of the low-income urban elderly. The section 8 subsidized apartment program, which currently produces the bulk of the low-cost elderly housing units, is used as a comparison. Based on estimates of the cost to maintain, rehabilitate, renovate, or construct either SRO hotels or Section 8 apartments, comparisons are made of the cost to produce and operate the particular mode of housing, to rent the housing, and to subsidize the housing.

\section{STUDY PARAMETERS}

In order to properly interpret the findings of this 
study, it will be important for the reader to keep in mind several significant parameters. They are especially important when results of other studies are compared. One important parameter, alluded to earlier, is the geographic limits of the study area. Other parameters delimit the resident population surveyed and the type of hotel from which respondents were selected.

\section{Definition of Study Area}

For planning purposes, the City of Portland had defined its downtown as that area enclosed by the Willamette River to the east and the I-405 Freeway loop to the north, south and west (see Figure 1). That area is bisected by West Burnside Street which runs east and west. The area north of Burnside Street contains what is commonly known as "skid row". Here one finds the classic components of a skid row-the missions, the service agencies, the old hotels, and the men who sit in doorways drinking wine. That area is not part of this study. With the exception of a small section which abuts Burnside Street, the hotel area south of Burnside is known as "upper" skid row. It is the upper skid row area which is encompased by this study.

The northern portion of downtown, that is, skid row, was excluded from this study in an attempt to achieve a relatively homogeneous population of SRO hotel residents. It was felt the concomitant problems of alcoholism and more transient life styles encountered among residents of that 


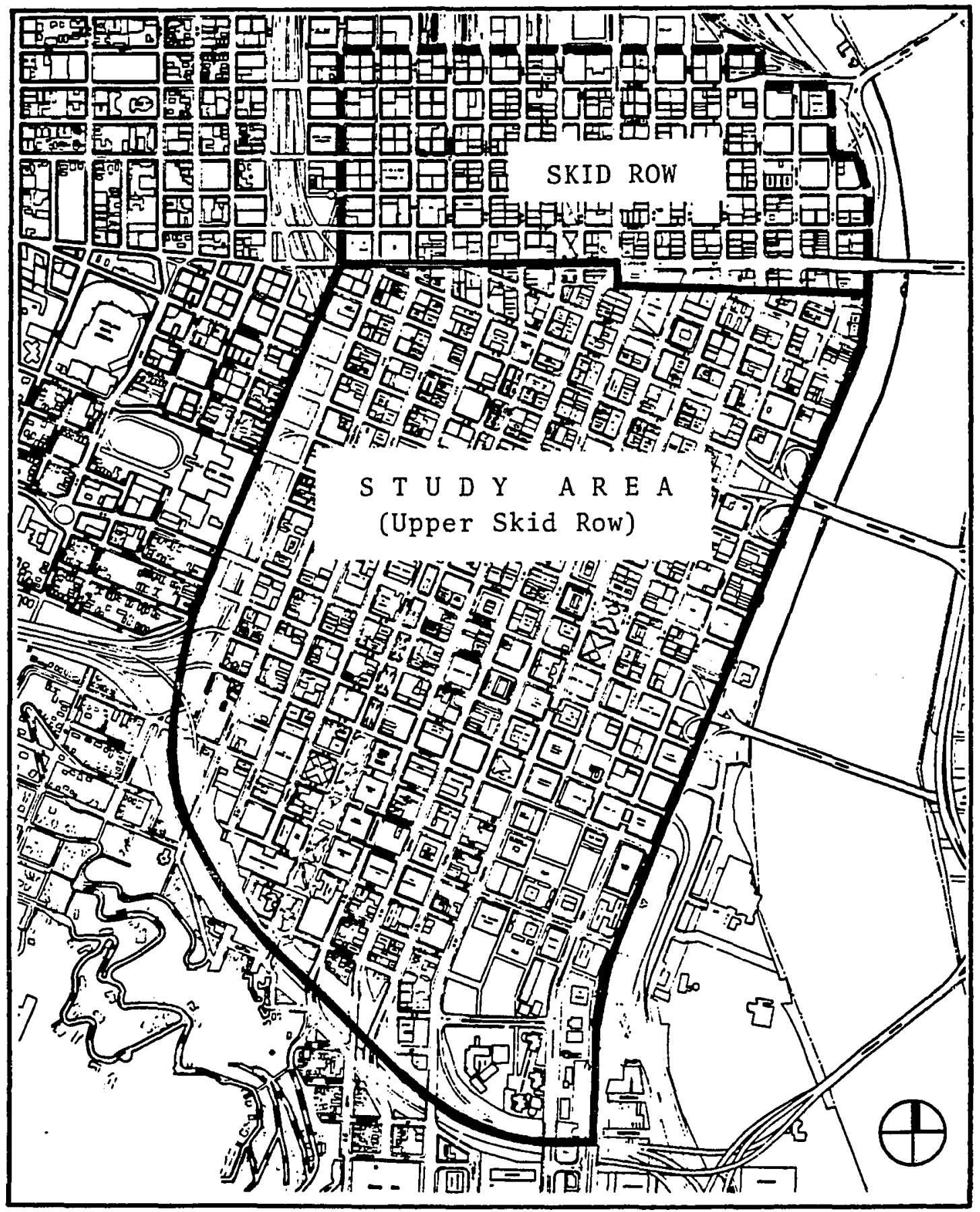

Figure 1. Downtown Portland and study area. 
area would contribute variance inconsistent with the goals of the research.

\section{Definition of Resident Ropulation}

Previous research has generally found that men outnumber women in SRO hotels, sometimes by a ratio as high as 9 to 1 (Ehrlich, 1976; Eckert, 1978). In addition to being a minority population, female residents tend to have lower monthly incomes than do their male counterparts (Goode, Lawton \& Hoover, 1979). It is likely this difference, as well as differences in male and female life styles and preferences, would introduce considerable variance on obtained measures. For these reasons, this study is a study of male SRO residents. Obvious future research would be a comparative study of female and male SRO residents.

In addition to sex, age was also used as a delimiter of the respondent population. Though much of the past research has examined only the elderly population, it has been estimated that between one-quarter and one-half of the SRO population is elderly (Hull, 1980). It is this population that has little likelihood of dramatically increasing its income. In essence, the elderly SRO residents are prisoners of fixed incomes and in many cases too old or too disabled to pursue gainful employment. This condition makes them vulnerable to changes in their environment, especially increases in rent or in the price of restaurant 
meals. By restricting the study to those 55 or over, the sample becomes one of vulnerable male SRO hotel residents. Further studies could examine differences between the younger SRO residents and those who are older.

\section{Definition of Hotel Ropulation}

In Chapter I, the Introduction, it was noted that only structures that were originally constructed as hotels would be included in the study definition of SRO hotels. Another criterion used to identify the study's hotel population was that the structures would have predominately single rooms with no cooking or bathing facilities in the units. Several hotels were excluded from the population because they contained cooking facilities and/or bathrooms in nearly all the units.

These definitions of study area, residential population, and hotel population constitute the major parameters of the study; any additional delimiters will be discussed whe re relevant.

\section{DATA GATHERING}

There were two types of data gathered in this study, interviews with residents and two cost surveys, one of the cost of living, the other of the cost of housing.

\section{Phase I - Resident Interviews}

Sampling procedures for the SRO hotels and Section 8 
apartments which were included in the study varied as did the selection of residents from those structures. For this reason, each is discussed separately.

Hotel Resident Interviews. The Downtown Housing Inventory compiled by the City of Portland formed the basis for identification of the SRO hotel sample (Portland Development Commission, 1978). The entire area covered by this study was included as part of that inventory and therefore, it was possible to identify all those structures which were composed primarily of single room occupant units. Table $V$ contains a listing of the 17 structures so identified in the upper skid row area.

With assistance from an agency which provides housing services in the study area, the managers and/or owners of each hotel were contacted by letter. The letter, prepared on agency stationery, introduced the researcher, briefly described the nature of the study, and encouraged cooperation. The letter was followed by a phone call or personal visit by the researcher. The purpose of this initial contact was twofold; first, to gain the manager's or owner's acceptance and second, to ascertain if, in fact, the structure met the study definition of SRO hotel. Table $V$ notes the results of this initial contact. Three hotels were found to have either cooking or bathing facilities in nearly all rooms, thus violating the study definition. In the case of four other hotels, either the manager or owner would not 
allow the researcher access to the building.

The resultant sample of SRO hotels was composed of ten structures which contained 757 rooms. It is possible that some unknown and systematic bias was introduced by the need to eliminate the four hotels from the study sample. However, with the exception of one hotel which contained 44 rooms (Drake), those dropped from the sample tended to "specialize" in either female or minority (Mexican-American) tenants and thus tended to be less representative of the SRO hotel population in Portland's upper skid row. For this reason, generalizations from the study findings will include the consideration that certain minority populations were not part of the study sample.

The Downtown Housing Inventory was also used in the identification of the SRO hotel resident sample, as it provided a total count of the number of rooms in each hotel and an estimate, obtained from the manager, of the percentage of persons 60 years of age and over who were residents of the building at the time of the inventory. The room count and percentage of elderly residents were then used to calculate an estimate of the number of elderly persons living in each of the ten buildings included in the study. Table $V$ shows the results of these calculations. Though this study's definition of elderly included persons 55 years of age and over, the inventory's estimate using 60 years of age and over was used as a reasonable equivalent 
proxy.

Based on the goal of conducting 40 interviews with elderly male residents, a formula was developed to assure that a representative number of interviews were conducted in each of the hotels. The formula was a ratio of the total number of interviews to be completed to the estimated number of elderly residents residing in the ten hotels. Multiplying that ratio by the number of elderly persons in a particular hotel gave the number of interviews needed from that hotel. It was felt that a weighted sample was critical if generalizations from the study findings were to be made. It was previously noted that SRO hotels tend to develop "personalities" and that prospective residents may be attracted to one hotel over another based on such a personality (Eckert, 1978). By using this weighting technique, residents of one hotel would not dominate the sample simply because they were more gregarious and willing to be interviewed. Table $\mathrm{V}$ shows the number of interviews to be completed at each hotel.

A system of randomized room numbers was used to achieve a representative sample of elderly respondents from each hotel. This involved obtaining all the room numbers for each hotel and then, using a random number table, preparing an ordered list of room numbers. In most cases, nearly all the room numbers for a particular hotel were drawn and ordered appropriately. Large draws were necessary to assure 
T A B L E V

SRO HOTBL AND RESIDENT SAMPLE

\begin{tabular}{|c|c|c|c|c|c|c|c|c|c|c|c|c|}
\hline \multicolumn{2}{|c|}{ Hotel Sample } & \multicolumn{3}{|c|}{ Demographics of llotel } & \multicolumn{2}{|c|}{ Interview Sample } & \multicolumn{4}{|c|}{ Kefusals, Etc. } & \multicolumn{2}{|c|}{ Handomness } \\
\hline Hotel & Description & $\begin{array}{l}\text { Total } \\
\text { No. of } \\
\text { Hooms } \\
\end{array}$ & $\begin{array}{l}\text { 6 of } \\
\text { Occupants } \\
\text { Elderlyb }\end{array}$ & \begin{tabular}{|l|} 
Est. No. \\
Elderly \\
Hesidents \\
\end{tabular} & $\begin{array}{l}\text { No to be } \\
\text { Inter- } \\
\text { viewed } \\
\end{array}$ & $\begin{array}{l}\text { Number } \\
\text { Inter- } \\
\text { viewed }\end{array}$ & $\begin{array}{l}\text { Outright } \\
\text { Hefusals } \\
\end{array}$ & $\begin{array}{l}\text { Uther } \\
\text { Keusons d }\end{array}$ & $\begin{array}{l}\text { Total } \\
\text { Hefusa 1s }\end{array}$ & $\begin{array}{l}\text { Not } \\
\text { Able to } \\
\text { Contacte } \\
\end{array}$ & Randon $f$ & $\begin{array}{l}\text { Non- } \\
\text { Handom }\end{array}$ \\
\hline Admiral & $\begin{array}{l}\text { Cooking in most } \\
\text { rooms / not SRO }\end{array}$ & -- & -- & -- & -- & -- & - & - & - & -- & -- & -- \\
\hline Clayton & Talk-up & 47 & $70 \mathrm{~B}$ & 33 & $4(3.72)$ & 2 & $\mathbf{2}$ & $\mathbf{0}$ & 2 & $\mathbf{0}$ & 2 & $\mathbf{0}$ \\
\hline Clyde & $\begin{array}{l}\text { Elevator, } \\
\text { bathrooms in } \\
\text { some units, } \\
\text { reopened af ter } \\
\text { fire }\end{array}$ & 96 & $30 \mathrm{~h}$ & 29 & $3(3.26)$ & 4 & 1 & 0 & 1 & 0 & 2 & 2 \\
\hline Cornellus & Elevator & 84 & 50 & 42 & $5(4.73)$ & 3 & 1 & 1 & 1 & 2 & 1 & 1 \\
\hline Danmoore & $\begin{array}{l}\text { Bathroom with } \\
\text { each room/ } \\
\text { not sho }\end{array}$ & -- & - & -- & -- & -- & - & -- & -- & -- & -- & -- \\
\hline Drake & $\begin{array}{l}\text { Entry not } \\
\text { permitted }\end{array}$ & (44) 1 & (75) & (33) & -- & - & - & -- & $\rightarrow$ & -- & -- & - \\
\hline Fairfield & Eleva tor & 70 & 70 & 49 & $6(5.52)$ & $\mathbf{5}$ & $\mathbf{0}$ & $\mathbf{0}$ & $\mathbf{0}$ & 0 & 5 & 0 \\
\hline Governor & $\begin{array}{l}\text { Entry not } \\
\text { permitted, } \\
\text { mostly female } \\
\text { residents }\end{array}$ & (123) & (70) & (77) & -- & -- & -- & - & -- & -- & -- & -- \\
\hline $\begin{array}{l}\text { Hachie } \\
\text { Annex }\end{array}$ & $\begin{array}{l}\text { Entry not } \\
\text { permitted } \\
\text { mostiy Mexican- } \\
\text { Americans }\end{array}$ & (10) & (20) & (2) & -- & -- & -- & -- & -- & -- & -- & -- \\
\hline $\begin{array}{l}\text { Hachle } \\
\text { Hooms }\end{array}$ & $\begin{array}{l}\text { Entry not } \\
\text { permitted } \\
\text { mostiy Mexican- } \\
\text { Americans }\end{array}$ & (24) & (30) & (7) & -- & -- & -- & -- & -- & -- & -- & -- \\
\hline Hami 1 ton & $\begin{array}{l}\text { Elevator, largest } \\
\text { hotel in area }\end{array}$ & 147 & 25 & 37 & $4(4.16)$ & 4 & 3 & 0 & 3 & 0 & 3 & 1 \\
\hline Joyce & $\begin{array}{l}\text { Elevator, manage-- } \\
\text { ment perfers } \\
\text { older male } \\
\text { residents }\end{array}$ & 75 & 88 & 66 & $7(7.43)$ & 5 & 3 & 1 & 4 & 2 & 5 & 0 \\
\hline
\end{tabular}




\begin{tabular}{|c|c|c|c|c|c|c|c|c|c|c|c|c|}
\hline \multicolumn{2}{|c|}{ Hotel Sample } & \multicolumn{3}{|c|}{ Demographics of Hotel } & \multirow[b]{2}{*}{$\begin{array}{l}\text { Interview } \\
\text { No. to be } \\
\text { Inter- } \\
\text { viewedc }\end{array}$} & \multirow[b]{2}{*}{$\begin{array}{l}\text { Sample } \\
\text { Number } \\
\text { Inter- } \\
\text { viewed }\end{array}$} & \multicolumn{4}{|c|}{ Refusals, Etc. } & \multicolumn{2}{|c|}{ Randomness } \\
\hline Hotel & Description & $\begin{array}{l}\text { Total } \\
\text { No. of } \\
\text { Rooms a } \\
\end{array}$ & $\begin{array}{l}\text { of } \\
\text { Occupants } \\
\text { Elderlyb }\end{array}$ & $\begin{array}{l}\text { Est. No. } \\
\text { Elderly } \\
\text { Residents } \\
\end{array}$ & & & $\begin{array}{l}\text { Outright } \\
\text { Hefusals } \\
\end{array}$ & $\begin{array}{l}\text { Other } \\
\text { Reasons d }\end{array}$ & $\begin{array}{l}\text { Total } \\
\text { Refusals } \\
\end{array}$ & $\begin{array}{l}\text { Not } \\
\text { Able to } \\
\text { Contacte }\end{array}$ & Random 1 & $\begin{array}{l}\text { Non- } \\
\text { Random }\end{array}$ \\
\hline Laurel & $\begin{array}{l}\text { Cooking in } \\
\text { most rooms/ } \\
\text { not sho }\end{array}$ & -- & - & -- & - & -- & -- & -- & -- & -- & -- & -- \\
\hline Lownsdale & Elevator & 45 & 75 & 34 & $4(3.83)$ & 4 & 1 & 1 & 2 & $\mathbf{0}$ & $\mathbf{3}$ & 1 \\
\hline Miller & $\begin{array}{l}\text { Elevator, } \\
\text { higher } \\
\text { transiency }\end{array}$ & 110 & 408 & 44 & $5(4.95)$ & 1 & 1 & 1 & 2 & 2 & 1 & $\mathbf{0}$ \\
\hline New Ritz. & Falk-up & 46 & 19 & $\mathbf{9}$ & $1(1.04)$ & 1 & 1 & $\mathbf{0}$ & 1 & $\mathbf{0}$ & $\mathbf{0}$ & 1 \\
\hline Taylor & $\begin{array}{l}\text { Walk-up, } \\
\text { large rooms }\end{array}$ & 37 & 33 & 12 & $\begin{array}{l}1(1.35) \\
-\end{array}$ & 1 & 1 & $\begin{array}{c}0 \\
-\end{array}$ & 1 & $\begin{array}{c}0 \\
-\end{array}$ & $\begin{array}{c}1 \\
-\end{array}$ & $\mathbf{0}$ \\
\hline Totals & & 757 & $\underset{(\operatorname{mean})}{50}$ & 355 & 40 & 30 & 13 & 4 & $17^{j}$ & 5 & 24 & 6 \\
\hline
\end{tabular}

a Houglng Inventory, Portland Development Commission, April 1978.

b Estimates made by Portland Development Commission as part of the Housing Inventory; elderly were defined as 60 years of age or over.

c Based on formula: (No. desired Interviems/total No. elderly residents)(estimated No. elderly residents in hotel); 1.e., Clayton Hotel, $(40 / 355)(33)=3.72$.

d Includes two with severe handicaps (blindness and deaf mute), one who worked at his hotel and preferred not to talk, and one who spoke little English.

e Includes those where at least five attempts were made to contact resident.

I In most cases these were recommendations of the managers as persons of 55 years of age or over and who would likely be wiling to talk with the interviewer.

g Managers indicated the percentage of elderly was less than that reported in the inventory. This may huve been due to the time lag between the inventory and the time of the interviews.

h Estimate of manager in Summer 1979 because hotel was closed during time of the inventory.

1 paranthese indicates those hotels which met the study definition but where entry was not permitted by elther manager or owner.

I value used to calculate rate of refusal which was $36 \%$. 
sufficient rooms remained after the unacceptable ones were removed from the list. A room was determined to be unacceptable if it were occupied by a male under the age of 55 or a female of any age. Units which were efficiency apartments (contained cooking facilities) were also determined to be unacceptable and removed from the list.

The hotel manager's assistance was sought to aid in identifying the rooms which were unacceptable. Use of the manager for this preliminary screening proved beneficial. First, it reduced the amount of time needed to locate the elderly male hotel residents, but more importantly, it turned out that the manager generally provided at least some information about the residents who satisfied the study criteria. The most frequent information included when the resident was usually in his room or around the hotel, how receptive he was likely to be to a request for an interview, and his current health status. Names of the hotel residents were not sought and it may be that such anonymity encouraged hotel managers to be more cooperative in aiding the researcher.

When describing the nature and purpose of the study to managers, the researcher made careful note that all respondents who completed the interview would be paid the small sum of three dollars. It is possible that willingness to pay respondents was an early inducement for managers to cooperate with the researcher. 
It should be noted that managers played an important role in this study. As mentioned earlier, four refused the researcher entry to their hotel and of the ten who cooperated with the study, most were initially cautious, wanting detailed explanations of what the study was about, who was doing the study, and why their hotel had been selected. Some initially thought the researcher was a City building inspector in disguise. Several managers were dubious of the study's value, and viewed the researcher as an interruption to the business of managing a hotel. However, most managers were generally helpful, wanting to talk about the study and greeting the researcher with friendly hellos. Desk clerks and maids were generally friendly, occasionally offering to introduce the researcher to hotel residents whose room numbers had been drawn.

The interview procedures involved contacting residents in order to ascertain: a) that they were male, 55 years of age or over and living in a single room as defined for this study, and b) that they were willing to be interviewed. Armed with an ordered list of potential respondents, the researcher proceeded to make contact. The number of interviews to be completed in each hotel was the guide. Letters were left in the resident's hotel mailbox. The letter explained the nature of the research, asked to interview the resident, provided a phone number to call, and stated a payment of three dollars would be made for 
completed interviews. With the letter as an initial contact, the researcher then proceeded door-to-door attempting to locate the occupant and secure an interview.

If an interview were refused, a letter was left for the occupant of the next random room number and subsequent contact was attempted. This process continued until all interviews for a hotel were completed. In cases where at least five attempts were unsuccessful at contacting the resident, the next room number on the random list was substituted. In several cases, either because making contact was extremely difficult or there were few residents in a hotel who met all the study criteria, or because some who met the criteria were very likely to be inhospitable to the researcher, recommendations of the manager were used as substitutes for the random list. An example of an instance where the manager's recommendation was accepted was in the case where the resident left early in the morning, drank all day and spoke only broken English. In total, six interviews (20 percent) were completed with nonrandom residents. Comparison of means of the random and nonrandom samples on selected demographic and attitudinal measures suggests no significant differences between the groups (see Appendix A). The comparisons do not guarantee the absence of any systematic bias, but they suggest that the likelihood is low.

The interviews were conducted during the Spring and 
Summer of 1979. Though a goal of 40 interviews had been established early in the planning stage of the research, only 30 interviews were completed.1 The 30 interviews represent an 8.5 percent sampling of the estimated number of elderly SRO residents, for which access to the hotel was permitted. They represent a 6.3 percent sampling of the total estimated number of elderly SRO residents within the study area.

Despite information in the literature suggesting SRO residents tend not to receive visitors in their rooms (Stephens, 1976), 80 percent of this study's interviews were conducted in the respondent's room. The location of first contact seemed to be an important factor in determining the place where the interview occurred. The role of a young female interviewing an aging gentleman should not be discounted as a reason for this higher than expected openness. A young woman, willing to pay an older man for several hours of conversation is not the usual fare around an SRO hotel. In fact, the researcher became somewhat of a novelty at several hotels, known as the lady who rides a bicycle wearing a crash helmet and who pays older men to talk with her.

The interviews took an average of just over one and

\footnotetext{
$I_{A}$ sample of 30 was determined to be satisfactory for the type of analyses which would be carried out on the interview data, i.e., primarily t-tests and Pearson correlations.
} 
one-quarter hours. A number of interviews took much longer, the longest being two and one-half hours. Nearly one-third of all interviews took only one hour. Some respondents answered the questions in a very polite and businesslike manner, without lavish embellishments. Others told detailed stories of their past lives and it took some effort by the interviewer to return the respondent to the interview questions. All interviews were conducted personally by the researcher.

The SRO hotel resident interview schedule is composed of three sections: personal history, current housing and alternatives, and neighborhood environment (see Appendix B).

The personal history section includes demographic questions such as age, race, income, employment, education, marital status, number of children, etc. Also included are either standardized scales or sets of questions previously used with other elderly or SRO samples (self-reported health, mobility, life satisfaction, and primary supports). This information is used to compare the study sample of SRO residents with SRO samples from other locations (Bogue, Chicago: Tissue, Sacramento; Ehrlich, St. Louis; Eckert, San Diego) and with other non-SRO elderly populations

The current housing and alternatives section includes questions about the respondent's housing history, i.e., length of time residing in various locations, type of dwelling unit lived in, occupant status, and rents paid. An 
assessment of the respondent's current hotel and preferences for future housing, if forced to relocate, are also examined. Specific questions ask for the respondent's consideration of section 8 apartments in general and an evaluation of selected attributes of the apartments. The housing history is used both to compare the study's SRO sample with other groups (SRO and non-SRO) and to categorize this study's sample of current SRO residents. The respondent's assessment of his current hotel environment and preference for future housing forms the substantive base upon which this study's policy recommendations are founded. The respondent's comments on section 8 apartments are examined in relation to their assessment of the SRO hotel.

The neighborhood environment section examines the respondent's perceptions and use of his neighborhood. Questions of perception include the resident's concern for his personal safety as well as his assessment of the neighborhood's good and bad characteristics. Questions of use include an extensive inventory of the stores and services frequented by the resident. This information is used in conjunction with the cost-of-living survey (detailed in later section of this chapter) to assess the economics of residency in the downtown area. The extent of social service utilization is also examined in this section. The role neighborhood plays in the life of an SRO hotel resident is reflected in the policy recommendations. 
Appendix $B$ contains a copy of the current SRO resident questionnaire. The current housing and alternatives section includes pages 1 to 8 of the survey instrument, neighborhood environment covers pages 9 to 14 , and the personal history section includes pages 15 to 21 .

Section 8 Apartment Interviews. Local housing officials aided in the identification of all section 8 apartment projects in the downtown study area. Table VI identifies the five projects. Two are operated by the local housing authority, the Rosenbaum Plaza with 76 apartments and The Twelve with 42 apartments. The three remaining projects, which are privately owned, are managed by the same property management firm. Included are the Washington Plaza, the oldest project, with 74 apartments, the Roosevelt Plaza with 56 apartments, and the Oak Plaza with 90 apartments. All of the projects contain at least some one-bedroom units, but the vast majority are efficiency units. For the purpose of this study, no distinction was made between the two apartment sizes. The pertinent comparison is between an unsubsidized SRO hotel room and a subsidized, self-contained apartment unit. The researcher's previous associations with local housing authority personnel and with the owner of the private projects were helpful in securing access to the buildings and cooperation of managers. This was an especially critical element because previous sRo residents were identified from the project records. 
T A B LE V I

BECTION 8 APARTMENT AND HESIDENT SAMPLE

\begin{tabular}{|c|c|c|c|c|c|c|c|c|c|c|c|c|c|}
\hline \multicolumn{2}{|c|}{ Section 8 Apartment } & \multirow[b]{2}{*}{$\begin{array}{l}\text { Sample } \\
\text { Total } \\
\text { No of } \\
\text { Apart- } \\
\text { ments }\end{array}$} & \multicolumn{5}{|c|}{ Intial Sample Identification a } & \multicolumn{2}{|c|}{$\begin{array}{l}\text { Second Sample } \\
\text { ldentified }\end{array}$} & \multicolumn{4}{|c|}{ Total Sample Identified } \\
\hline Apartment & $\begin{array}{l}\text { Descrip- } \\
\text { tion }\end{array}$ & & $\begin{array}{l}\text { No. of } \\
\text { Previous } \\
\text { SHO Hotel } \\
\text { Residents }\end{array}$ & $\begin{array}{l}\text { No. } \\
\text { Inter- } \\
\text { viewed }\end{array}$ & $\begin{array}{l}\text { Outright } \\
\text { Mefusals }\end{array}$ & $\begin{array}{l}\text { Other } \\
\text { Heasons } \\
\text { For } \\
\text { Hefusal } \\
\end{array}$ & $\begin{array}{l}\text { Not } \\
\text { Able } \\
\text { To } \\
\text { b Con tact c c } \\
\end{array}$ & $\begin{array}{l}\text { No. of } \\
\text { Previous } \\
\text { Sho llotel } \\
\text { Hesidents }\end{array}$ & $\begin{array}{l}\text { No. } \\
\text { Inter- } \\
\text { viewed }\end{array}$ & $\begin{array}{l}\text { No. of } \\
\text { Previous } \\
\text { sho Hotel } \\
\text { Mesidents }\end{array}$ & $\begin{array}{l}\text { No. } \\
\text { Inter- } \\
\text { viewed }\end{array}$ & Refusals & $\begin{array}{l}\text { Not } \\
\text { Able } \\
\text { To } \\
\text { Contact }\end{array}$ \\
\hline Oak Plaza & $\begin{array}{l}\text { Private, } \\
\text { opened } \\
1978\end{array}$ & 90 & 2 & 0 & 0 & 1 & 1 & 3 & 3 & 5 & 3 & 1 & 1 \\
\hline $\begin{array}{l}\text { Roosevel t } \\
\text { Plaza }\end{array}$ & $\begin{array}{l}\text { Private, } \\
\text { opened } \\
1977\end{array}$ & 56 & 4 & $\mathbf{3}$ & 1 & 0 & $\mathbf{0}$ & -- & -- & 4 & 3 & 1 & 0 \\
\hline $\begin{array}{l}\text { Rosenbaum } \\
\text { Plaza }\end{array}$ & $\begin{array}{l}\text { Public, } \\
\text { opened } \\
1978\end{array}$ & 76 & 3 & 1 & 0 & 1 & $1 \mathrm{~d}$ & 2 & 2 & 5 & 3 & 1 & 1 \\
\hline The Twelve & $\begin{array}{l}\text { Public, } \\
\text { leased } \\
\text { only }\end{array}$ & 42 & 2 & $\mathbf{0}$ & 1 & 0 & 1 & -- & -- & 2 & $\mathbf{0}$ & $\mathbf{1}$ & 1 \\
\hline $\begin{array}{l}\text { Washington } \\
\text { Plaza }\end{array}$ & $\begin{array}{l}\text { Private, } \\
\text { opened } \\
1972\end{array}$ & 74 & 11 & 8 & o & 3 & 1 & -- & -- & 11 & 8 & 3 & 1 \\
\hline Totals & & 338 & 22 & 12 & 2 & 5 & 4 & 5 & 5 & $27 \mathrm{e}$ & 17 & 71 & 4 \\
\hline
\end{tabular}

2 Previous SRo hotel residents were sought in two phases. "Initial sample" comprises phase one while "Second Sample" comprises phase two.

b Included one who made interview appointments but did not keep them, one who was too 111 , one who refused to complete the last half of the interview, one who hid from the interviewer giving faise names, and one who burned his dinner while listening to interviever expla in the purpose of the interview。

c Includes those where at least five attempts were made to contact resident.

d Moved to nursing home prior to interviewer making contact.

e Total sample identifled as previous sho hotel residents represents two separate at tempts to identify the entire population of previous residents.

$f$ value used to calculate rate of refusal which was $29 \%$. 
The process of identifying the sample of Section 8 apartment residents who were previous SRO hotel residents differed slightly, depending on whether the project was publicly or privately owned and operated. The criterion for inclusion in the study sample was the same for both project types, i.e., the project tenant had to have lived in an SRO hotel within the study area prior to moving into the downtown Section 8 project. The hotels which were acceptable as previous places of residence included the 14 hotels identified in Table $\mathrm{V}$ as SRO hotels and several others which were closed prior to this study.

Using the tenants' application for admittance to the project, the address of the applicant's previous residence was compared with those of the acceptable SRO hotels. When there was a correspondence between addresses, a check was made on the tenant's sex and age. Verification by the project manager was used to determine if the tenant met the study criteria of male and 55 years of age and over.

For the three privately owned projects, the researcher sought and gained permission of the owner and property management firm to examine current tenants' applications for their previous addresses, age, and sex. The researcher provided information to the local housing authority and their staff examined tenant records for the two public projects. The guarantee of confidentiality made this procedure necessary. 
A goal of 20 interviews with elderly, male, previous SRO residents was established during the early planning stages of the research. Theoretically, the process used to identify previous SRO residents was such that it would identify the entire population at a given period of time. The initial round of record examination found 22 previous SRO residents (see Table VI). It should be noted that the number of elderly, male SRo residents living in any project has no relation to the project size. The number is most likely based on the differing characteristics or personality of the project and its residents. The Washington Plaza was composed of 15 percent previous SRO residents, while the Oak Plaza had only two out of 90. The length of time the project had been in existence may also have had some impact on the number of previous SRO residents. At any rate, an effort was made to interview a similar proportion of the previous SRO residents in each Section 8 project.

Following identification of the sample to be interviewed, each manager was asked for his assistance in getting to know the previous SRO residents. In some cases, managers arranged introductions; in others, interviewers made contact on their own. Cooperation of the manager was particularly important because all projects had locked front doors.

The interview procedures were similar to those for the SRO hotel residents; letters were left for the resident 
explaining the nature of the study, asking for an interview and indicating that a payment of three dollars would be made for a completed interview. Follow-up contacts were made and Table VI shows the results in terms of number of successful interviews, number of refusals, and number not able to be contacted.

Because only 12 of a possible 22 contacts ended in successful interviews, a second attempt was made to identify additional previous SRO hotel residents. The initial examination of records occurred in January 1979. The second examination of records occurred in June 1979. The rate of successful interviews at the Washington Plaza (73 percent) and the Roosevelt Plaza (75 percent) was high enough to warrant not seeking additional respondents from those projects. The records at the Oak Plaza indicated three new tenants met the study criteria of the elderly, male, previous SRO resident. Each was interviewed. No interview attempts were successful at the Twelve and due to difficulty contacting residents and hesitancy on the part of the managers, no supplemental sample was sought from that project. Personal knowledge of a social service agency representative was used to supplement the sample at the Rosenbaum where two additional previous hotel residents were identified and interviewed. This approach was used in lieu of requesting the housing authority to reexamine its records. 
The total population $(\mathrm{N}=22+3+2=27)$ of male, previous SRO residents who were at least 55 years of age was approximately 8 percent of the total resident population of the five Section 8 apartments. The sample interviewed in this study represents 63 percent of those identified as previous SRO residents who used to and still lived within the downtown study area.

The interview with the previous SRO residents was about 15 minutes longer than with current SRO hotel residents. This was due to several sets of paired questions evaluating the previous residence (SRO hotel) and the present residence (Section 8 apartment). The percentage of residents who were interviewed in their apartments was nearly identical to the number of SRO residents who were interviewed in their rooms, 82 percent for Section 8 and 80 percent for SROs.

The Section 8 apartment resident interview schedule was basically the same as that for the SRO sample. The personal history section was identical. There were several modifications and additions to the current housing and alternatives section. The respondent was asked to assess the SRO hotel from which he most recently moved and his current housing. The neighborhood environment sections differed only in that the questions regarding perceptions of personal safety and good or bad neighborhood characteristics were sought for both the previous and present neighborhood. 
Appendix C contains a copy of the section 8 apartment resident interview schedule.

\section{Phase II - Cost of Living Survey}

This phase of data collection addresses both the cost and availability of goods and services used by SRO hotel residents. For the purpose of this study, cost is defined as the actual cash expenditure necessary to purchase a particular good or service. Availability is defined as being within reasonable proximity of the dwelling unit and is operationalized for the cost of living survey as a walking distance of seven city blocks or approximately one-third of a mile. The data gathered in this phase is used to address the second hypothesis.

Sample of Neighborhoods. In order to assess the cost of living downtown, it was necessary to select several other neighborhoods for the purpose of comparison. A study commissioned by the Housing Authority of Portland was used as the basis for selecting the other neighborhoods. That study developed criteria for the identification of suitable locations for elderly housing (Sharpe \& Ritzdorph, 1977). The criteria include the proximity of a full service grocery store, bank, restaurant, and the frequency of bus service.

The goal in this study was to identify sites which satisfied the Housing Authority's criteria and which were located at varying distances from downtown. Distance from downtown were used to assure geographic distribution of the 
neighborhoods and to provide some control on the cost of land in the neighborhoods selected. The latter was based on the premise that the cost of land can generally be related to its distance from the central city (Chapin, 1972).

The data collected for the Housing Authority's study were used to select the sites for this study. In order to assure that the sites selected for the cost of living survey would contain sufficient services to which an SRO hotel resident was accustomed, the criteria for selection included a full service grocery store, two restaurants, two banks, and bus service of at least one per hour in the off-peak hours. Three sites were identified which met the criteria and were located at varying distances from the central city. The Housing Authority was consulted as to the appropriateness of the sites as housing for the elderly. It was confirmed that the three locations were considered to be at least potential development sites for new elderly housing projects. This validation was used as a check on the method of site selection.

The location of the three sites selected is shown in Figure 2. Each is located within an established neighborhood of the City of Portland. Irvington is approximately three-quarters of a mile east of downtown, and is noted for a large retail shopping complex, the Lloyd Center. It is an older neighborhood with a mix of housing types, from medium-sized apartment houses ( 40 units) to many two to 


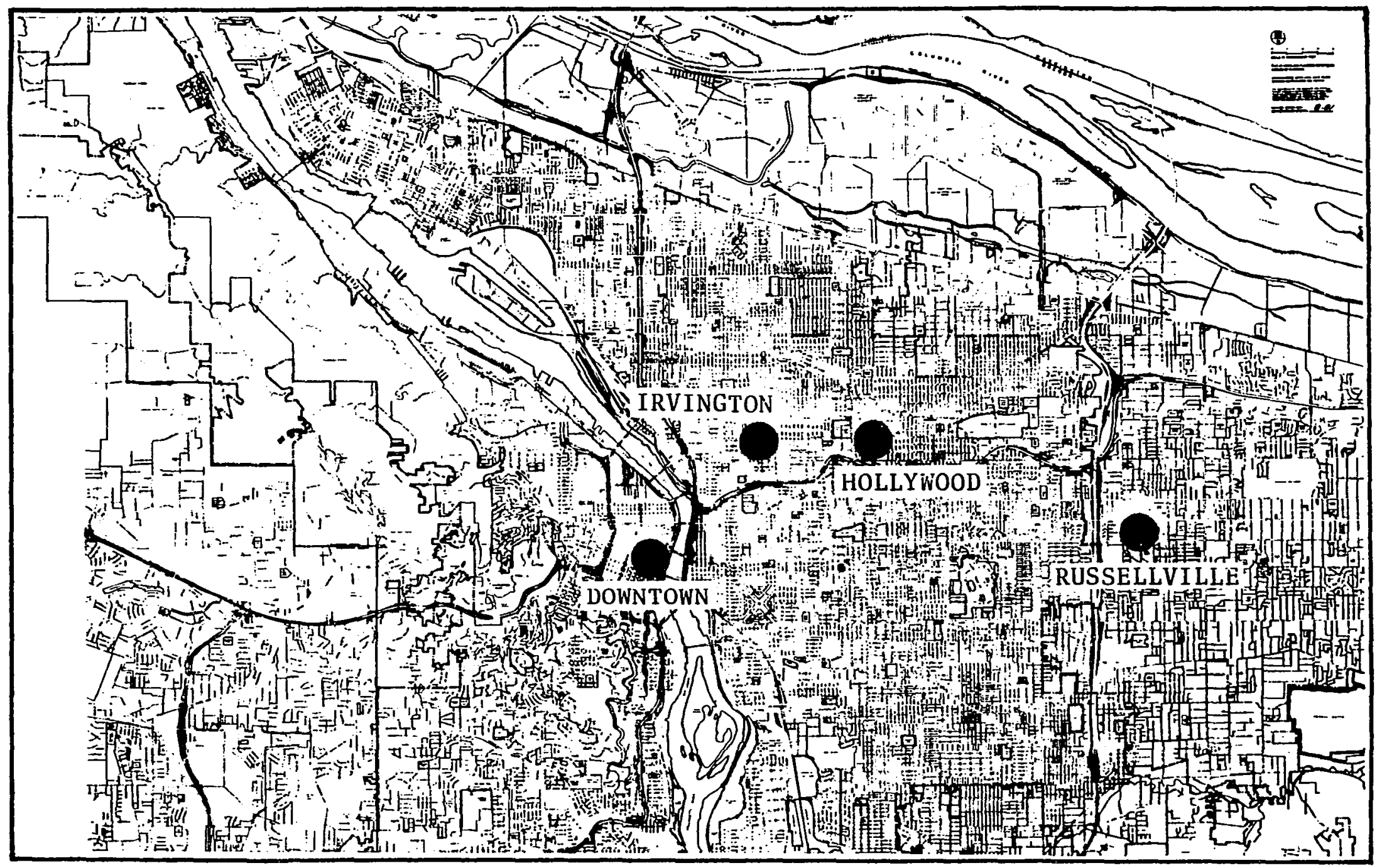

Figure 2. Neighborhoods surveyed for SRO cost of living. 
eight-plexes interspersed with single family homes. The Housing Authority has one elderly project in the neighborhood and has recently completed construction on another. Hellyweed is further from downtown, approximately two miles. It is also an older, well established neighborhood with a substantial commercial center. Hollywood is known as a "good" location for elderly persons, and, in fact, has a large elderly population. Many elderly own their own homes, but there are also several elderly housing complexes, both public and private, in the neighborhood. Russeliville is nearly six miles east of downtown. In anticipation of a new freeway, a medium sized shopping center was constructed in the area. Nearly all of the older housing is small, single family homes. There are some new multifamily units, but the majority of the housing construction in the area has been single family. There are currently no elderly housing projects in this suburban type neighborhood.

Based on data from the SRO hotel resident survey (Phase I), the mean number of blocks travelled by those persons to various stores and services was calculated. From those means, it was determined that the area within seven blocks of the hotel provided most of the goods and services consumed by SROs. This finding was then used as the factor which determined the extent of the area to be surveyed in each neighborhood (see Figure 3 ). 


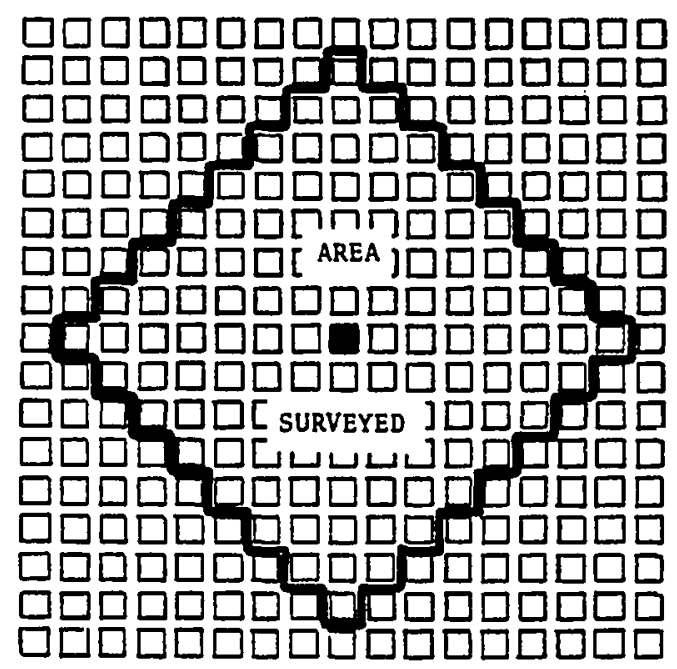

Eigure 3. Example of seven-by-seven block area surveyed for cost of living.

In order to identify the specific area to be surveyed, a particular parcel within each neighborhood was selected to represent the potential housing site for sRo hotel residents. For downtown, the block with the most occupied SRO hotel units was selected. In Irvington, the block containing the new Housing Authority project was selected. The parcel in Hollywood was an underdeveloped site within three blocks of a major supermarket. For Russellville, a vacant parcel of land located several blocks from the shopping center and other stores and services was selected. Again, consultation with the Housing Authority confirmed that the parcels were acceptable as potential housing sites for the elderly.

Cest of Iiving Survey Instrument. The U.S. Bureau of 
Labor Statistics' (BLS) cost of living survey was deemed inappropriate for the SRO hotel population in that it contained numerous goods and services which were not consumed by the typical hotel resident. For this reason, a special survey instrument was designed to collect information on the cost of living for an elderly, male SRO hotel resident. However, the BLS survey was used as a guide, as was the Institute on Aging's cost of living survey (Gionet, 1978), the information obtained in Phase I of this research, a paper on eating habits of hotel residents (Bohannan, 1977), and an informant who had been a hotel resident for six years. Based on these sources of data, an instrument was designed which contained a representative sample of goods and services consumed by current SRO hotel residents.

The major categories included in the survey were: food away from home, food at home, alcohol, tobacco, variety and personal care, transportation, and housing. Entertainment was not included because information from the resident survey showed that hotel residents seldom spend money for activities such as movies. Because the purchase of clothing was extremely limited and much of what was purchased came from local thrift shops, no the information was collected on the cost of clothing in the neighborhoods. Within each major category, specific products were enumerated, such as six ounces of processed American cheese or a haircut with no 
wash or styling. Appendix IV contains a detailed list of the items included in the survey.

The Survey Brocedure. With the block containing the parcel of land identified as the potential housing site for the focal point, an area with a radius of seven blocks was identified in each neighborhood. This was the area to be surveyed. In each neighborhood, all stores which sold any of the goods or services appearing on the survey instrument were surveyed. This included all supermarkets, grocery stores, bars, taverns, variety stores, pharmacies, barber shops, cleaners, and public and private transit. Restaurants which served at least some lunches for less than $\$ 3.00$ and some dinners for less than $\$ 4.50$ were included. Those with more expensive meals were excluded.

The cost of living survey was conducted over a period of three weeks. If items were on sale, the regular price was reported.

Hotel Resident Expenditure Record. A number of hotel residents were asked to keep diaries of their expenditures for a period of one month. Information from the diary would then be used as an aid in determining the proportion of income a "typical" hotel resident spent on the various categories of goods and services.

The criterion used to identify the hotel residents who would be asked to keep diaries was their income remaining after payment of rent. The median amount remaining for the 
SRO hotel resident sample was $\$ 240$. Because there was a considerable variation in the amount remaining after rent $(\$ 84$ to $\$ 830)$, it was determined that diaries kept by those whose income after rent most closely approximated the median value would provide the most typical view of SRO expenditures.

A sample of ten residents was identified lone-third of the entire hotel sample) with an income after rent of between $\$ 160$ to $\$ 320$. This represented a range of + to $-\$ 80$ from the median. of the ten residents, three completed usable expenditure reports, two made erratic attempts, two refused, two died, and one was hospitalized prior to this phase of the research.

Weighted Market Basket. In order to allow direct comparison of the costs in one neighborhood with those in another, a weighted market basket was constructed from the items included in the survey. The weighting system was based on the quantity of each item consumed by the typical sRo resident over the period of one month. That quantity was determined using information from the resident survey (Phase I) on the frequency of use of various types of facilities such as restaurants, grocery stores, and the barber. Other data sources used to develop appropriate quantities were Bohannan's (1977) article on eating behavior, the expenditure diaries of three hotel residents, sRo hotel informant, and a county public health nurse familiar with 
the eating habits of hotel residents. Given the quantities consumed and the price paid for each item, calculation of the cost of living was a simple mathematical procedure:

quantity/month $\mathrm{x}$ price/item $=$ cost/month/item

A summation of all items in a particular category would enable comparison of the cost to purchase the various goods and services in the four neighborhoods.

Phase III - Cost of Housing

The last phase of data collection focuses on the cost of housing. Specifically, data is collected which addresses three areas: a) a comparison of the cost to operate and maintain, rehabilitate, and construct new either section 8 apartments or SRO hotels, b) an examination of subsidies included in maintaining and/or producing the two housing types, and c) the rate of return an owner might anticipate from an investment in either housing form. Unlike the two previous phases of data collection, this phase depended almost exclusively on secondary rather than primary data. ${ }^{2}$

Sorts and sources of Data. The data necessary for an analysis of the above mentioned housing costs includes rather detailed financial information. In order to

\footnotetext{
2Without the generous cooperation of staff members from the various "data sources" noted analysis of the cost of housing would have been virtually impossible. The author is grateful for their courteous and prompt assistance.
} 
accurately calculate the total cost of operation and maintenance, information was needed on the cost of utilities, management, payroll, repairs, insurance, taxes, debt service, replacement reserves, and any other miscellaneous costs. In order to determine total income, information was needed on both the residential and commercial portions of the building. Additionally, information on the amount, terms, and payments on the mortage, the total development costs, the owners equity in the project, the site cost, and amount of rent subsidization was needed. It was presumed that individual building owners would be hesitant to provide such detailed information but that public agencies from whom loans or rent subsidies were sought would be able to provide the information through access to public documents.

In fact, this was the case. Information on Section 8 apartments was provided by the Area Office of the Department of Housing and Urban Development, the Housing Division (State of Oregon), and the Housing Authority of Portland. It consisted of either audit statements from the calendar year 1980, budget statements for 1981, or projected costs from proposed and approved loan packages. Information on SRO hotels was more difficult to assemble given that no rent subsidies had been available in the past and few loans were made to such structures. However, the Portland Development Commission had several sources of data on SRO hotels. In 
1980, their staff completed a survey of lessees of SRO hotels on the cost of operation and maintenance. Also, the Commission had made loans or was working on loan applications for several SRO hotels in the downtown area. That information, along with operation and maintenance costs plus income statements from a non-profit agency which managed a hotel facility, was used for the assessment of SRO hotels costs.

More detailed data on the site costs was obtained from the County Tax Assessor's Office, i.e., the true cash value of both land and improvements.

An estimate of the cost to construct a new SRO hotel was obtained from a local architect who recently completed a Section 8 apartment project.

Types of Information computed. A number of cost related values were calculated from the secondary data. Prior to any calculations, all the data were examined to assure comparability from one source to another; where variations appeared adjustments were made. An example of needed adjustments was for the "total development costs" which the agency provided. In some cases, the site cost was included (when it was financed along with the rehabilitation or construction) and in other cases it was not (when the site was owned free and clear). All costs figures were adjusted to 1981 dollars. This was accomplished using various measures of rate increase such as Boeckh Indexes for 
Apartments, Hotels, and Office Buildings. The actual rent increases, and estimates were made by experts in the housing business.

Using the amended data, equivalent values were calculated for Section 8 apartments and SRO hotels. These values inciuded the cost per unit to operate and maintain, rehabilitate, and construct new units. Also calculated were the net cash flow, amount of the mortage payment which went to interest and principle, value of the building for the purpose of depreciation, income produced by the building for the purpose of taxes, whether the building provided a tax shelter to the owner, and rate of return on the owner's investment. Comparison of these values is the basis for policy recommendations.

\section{DATA ANALYSIS TECHNIQUES}

A number of procedures are used to analyze the study data. In this section, these procedures are identified and their general application is discussed.

Information from the survey of hotel and subsidized apartments residents was stored on tape for analysis on a Honeywell Series 6000 and Series 60 level 66-GCos systems computer. Analysis of the resident data was carried out with the assistance of the Statistical Package for the secial Sciences (SPSS), Second Edition (Nie, Hull, Jenkins, Steinbrenner, \& Bent, 1975). Data from the cost-of-living 
survey and the cost of maintenance/production survey were not stored on the computer. Neither the volume of data nor the procedures used in their analysis justified computer usage.

\section{Erequency Distributions and Descriptive Statistics}

The first procedure used in the analysis of the resident survey data was the construction of frequency distributions. This procedure provided a general view of the study data. For a variable with nominal data, it gave a simple count of the number and percent of responses to each category. For a variable with ordinal, interval, or ratio data, it provided considerably more information, such as measures of central tendency and variability. In all cases, examination of a variable's frequency distribution preceded further analysis with that variable.

When information about a variable's distribution is reported in the chapter on findings, the general format includes means and standarà deviations. In some cases, medians are reported. The range, skewness, and kurtosis of a variable were examined but are not reported.

Comparison of Means Using t-tests

The t-test was used to assess the degree of similarity of difference between the means of two sample groups on a particular variable or characteristic. In this study, when comparing SRO hotel residents with subsidized 
apartment residents, the 5 - test for independent groups was utilized. When comparing the previous and present housing locations of the subsidized apartment residents, the $t$ - test for paired groups was utilized. The nature of the hypothesis being tested determined whether a one or two-tailed test of significance was used to interpret the $t$ statistics. Where one group was predicted to have a larger mean, the one-tailed test was used; if not, the two-tailed test was used. Generally, in this study, a value of $t$ with a probability level of .05 or less is defined as representing a significant difference between the sample means. When variations from this guideline occurred, they are reported. When a test of difference between two "means" on a dichotomous variable was desired, a test for difference between proportions was utilized. SPSS calculates both the test of proportion and the $t$ - test with the same procedure, therefore no special adaptation was necessary.

\section{Correlational Procedures}

The Pearson product moment correlation was used to measure the linear association between two continuous, or at least, clearly ordered variables. A positive correlation meant that that an increase in one variable was accompanied by an increase in the other variable. Conversely, a negative correlation meant that an increase in one variable was accompanied by a decrease in the other. A correlation which approached zero meant there was no linear relationship 
between the two variables, while a correlation that approached + or -1.00 indicated a strong linear relationship. Generally, a correlation which met the following two criteria was considered meaningful for discussion in this study: its absolute value was .30 or greater and it was significantly different from zero at $p$ < .05. The correlations are reported in one of two formats; as the Pearson correlation $(x)$ and its probability level, or as the Pearson correlation squared $\left(x^{2}\right)$, which is the percentage (when multiplied by 100) of variance that the variables have in common.

\section{Index Construction}

A number of variables from the resident survey were combined in order to develop indices of particular traits or attitudes. This process is commonly referred to as scale development, and it is generally held that a properly constructed scale or index is a better measure of a trait or attitude when compared to a single item. Some of the indices constructed in this study were based on similar kinds of items and indices used in past research of elderly persons or SRO hotel residents. Examples of indices used in past research are life satisfaction, health, and mobility. Other indices were based on theoretical propositions or a priori assumptions such as rating of the hotel, use of services, and the level of social interaction. Note is made in the findings chapter on the rationale for each index 
constructed.

Two methods were used to construct the indices. In the case where each variable to be included in the index had the same number of values, i.e., all on a four-point scale, the values were summed directly. Where variables had different-point scales, the values were first standardized via conversion to z-scores. This was done to eliminate bias due to the weighting of one variable over another.

Before using a constructed index in further analysis, each was subjected to several tests. The internal-consistency reliability or alpha coefficient gives a measure of the expected correlation of the constructed scale with a similar scale, if it were to be constructed. For indices measuring a homogeneous attribute, an alpha coefficient of .70 is generally considered an acceptable level of reliability for research purposes (Nunnally, 1978). The item-total correlation is used to determine if each variable in the index is sufficiently related to the total index. For indices composed of six or more variables, each item was correlated with the total index. For indices with five or fewer variables, each item was individually removed from the total index prior to correlation in order to eliminate inflated correlations due to an item's correlation with itself. Variables which did not meet the requirement of having an absolute correlation of .30 or greater and being statistically significant with a probability of .05 or less 
are removed from the index. Exceptions to this guideline are noted in the findings chapter.

\section{Discriminant Eunction Analysis}

Discriminant analysis is a multivariate statistical procedure which assesses the ability of a set of variables to differentiate between subjects assigned to preselected groups. In this study, it is used to differentiate between SRO hotel and Section 8 apartment residents on a set of a priori or theoretically selected variables, such as measures of interaction.

Given $M$ preselected groups, the SPSS procedure derives up to $M-1$ functions, which in this study is $2-1$, or a single function. Depending on the option selected, i.e., direct or step-wise, all or some of the variables are used in the construction of the function. SPSS reports the weights for each variable included in the function, the variance explained by the function ( 1.00 minus Wilks' Lambda), and the probability level associated with the function. Using the derived function, the SPSS procedure further calculates the percentage of cases assigned to the correct group by comparing actual with predicted group membership. Generally, a function which explains at least 20 percent of the variance (lambda $<.80$ ) with a probability of .05 or smaller is defined as significant. 
CHAPTER IV

\section{STUDY FINDINGS}

Findings from this study are divided into four sections. The first section is a comparison of this study's SRO hotel sample with sRo hotel samples from other studies, particularly, those discussed in the literature review. The second section examines the study data with respect to the first hypothesis which states that there is a lifestyle difference between present sRO hotel residents and those who were hotel residents but chose to move into section 8 apartments in the downtown area. The third section examines the cost of living for an sRo hotel resident and addresses the second hypothesis which states that downtown is a less costly neighborhood for an sRo hotel resident to live in than others outside downtown. The fourth section looks at the issue of housing costs and compares the cost to maintain, rehabilitate, or construct both SRO hotels and subsidized section 8 apartments, as a test of the third hypothesis.

A COMPARISON OF THE SRO HOTEL STUDY SAMPLE WITH OTHER SRO HOTEL SAMPLES

The SRO hotel sample identified and examined in 
Portland is generally similar demographically to SRO hotel samples reported in other studies. That there are commonalities among the samples compared does not suggest the individuals who compose those samples are alike, but that when taken as a group, the samples do tend to have similar profiles. An earlier discussion in the literature review noted that SRO hotel residents are a diverse lot. For example, some have little education and others have college degrees. Despite such variation in the population, the general profile of the SRo hotel samples does tend to be quite consistent.

The similarity of reported SRO hotel samples is apparent after examination of Table VII which presents demographic information on Portland's upper skid row sample $(\mathrm{N}=30)$, and three other SRO hotel samples, Ehrlich's (1975) St. Louis sample $(N=110)$, Eckert's (1978) San Diego sample $(N=75)$, and Felton, et al.'s (1977) New York City sample $(N=36)$. Figures from the National Council on Aging's broad-based sample of elderly persons ( $N=2797$ ) is repeated for the purpose of comparison. As noted earlier, the Portland sample was designed to be 100 percent male in order to reduce undesired variation due to differences between male and female SRO hotel residents.

An examination of the data on marital status of the SRO hotel samples shows a common trend of relatively large percentages of "single, never married," in each case, i.e., 
T A B L E V I I

COMPARISON OP SHO HOTBL STUDY SAMPLE WITH OTHER SRO HOTEL STUDY SAMPLES ON SELECTED DEMOGHAPHIC CHARACTERISTICS

\begin{tabular}{|c|c|c|c|c|c|}
\hline Variable & $\begin{array}{l}\text { Portland } \\
\text { SHO } \\
\text { Sample } \\
(\mathrm{N}=30)\end{array}$ & $\begin{array}{l}\text { St. Louis } \\
\text { SHO } \\
\text { Sample a } \\
(N=110)\end{array}$ & $\begin{array}{l}\text { San Diego } \\
\text { ShO } \\
\text { Sample b } \\
(N=75)\end{array}$ & $\begin{array}{l}\text { New York } \\
\text { SRo } \\
\text { Sample c } \\
(\mathrm{N}=36)\end{array}$ & $\begin{array}{l}\text { National } \\
\text { Sample of } \\
\text { Elderly } \\
(\mathrm{N}=2797)\end{array}$ \\
\hline
\end{tabular}

Sex:

Ma:

Female

Marital Status:

Single, never married Married, spouse present Widowed

Divorced

Separated

$100 \%$

$81 \%$

$19 \%$

$89 \%$

$11 \%$

$42 \%$
$58 \%$

$41 \%$

\section{$33 \%$}

$10 \%$

$40 \%$

$39 \%$

$25 \%$

$29 \%$

$5 \%$
$17 \%$

$43 \%$

$13 \%$

NA $f$ NA

NA

NA

Black

Native American

97\%

3\%

NA

NA

NA

NA

Education :

Some elementary school

Some high school

Some college

$33 \%$

$33 \%$

$20 \%$
$4 \%$

\begin{tabular}{cccc} 
NA & $47 \%$ & mean & $63 \%$ \\
NA & $32 \%$ & 10.3 yrs. & $37 \%$ \\
NA & $21 \%$ & - & - \\
- & - & - & \\
\hline
\end{tabular}


T A B L E V I I - Continued

\begin{tabular}{|c|c|c|c|c|c|}
\hline Variable & $\begin{array}{l}\text { Portland } \\
\text { SHO } \\
\text { Sample } \\
(\mathrm{N}=30)\end{array}$ & $\begin{array}{l}\text { St. Louis } \\
\text { SRO } \\
\text { Sample a } \\
(\mathrm{N}=110)\end{array}$ & $\begin{array}{l}\text { San Diego } \\
\text { SkO } \\
\text { Sample b } \\
(N=75)\end{array}$ & $\begin{array}{l}\text { New York } \\
\text { SRo } \\
\text { Sample c } \\
(N=36)\end{array}$ & $\begin{array}{l}\text { National } \\
\text { Sample of } \\
\text { Elderly } \\
(\mathrm{N}=2797)\end{array}$ \\
\hline
\end{tabular}

Past Employment:

Major professional

Semi-professional

Clerical/sales, tech. $\quad 26.0 \%$

Clerical/sales, tech.

$\begin{array}{ll}\text { Semi-skilled worker } & \mathbf{4 3 . 3 \%} \\ \text { S3.3\% }\end{array}$

Unskilled worker

$$
\text { - }
$$

$\begin{array}{lr}\text { NA } & = \\ \text { NA } & - \\ \text { NA } & 6 \% \\ \text { NA } & 12 \% \\ \text { NA } & 28 \% \\ \text { NA } & 28 \% \\ \text { NA } & -\end{array}$

-
$6 \%$
$12 \%$
$28 \%$
$25 \%$
$28 \%$
-

$5.7 \%$ B
$40.0 \%$
$42.9 \%$
$8.6 \%$
$2.9 \%$

NA
NA
NA
NA
NA
NA
NA
NA

Hollingshead Social Class:

$\begin{array}{cr}\text { I } & 6.7 \% \\ \text { II } & 16.7 \% \\ \text { III } & 40.0 \% \\ \text { IV } & 26.7 \% \\ \text { V } & 6.7 \% \\ \text { No response } & 3.4 \%\end{array}$

$\begin{array}{cc}- & \text { NA } \\ 4 \% & \text { NA } \\ 8 \% & \text { NA } \\ 42 \% & \text { NA } \\ 46 \% & \text { NA } \\ - & \text { NA }\end{array}$

Income: $\mathbf{h}$

Median

Mean

$\$ 328$

$\$ 376$

$\$ 231$

$\$ 289$

NA

NA

NA

Rent :

Median

$\$ 81$
$\$ 92$

$\$ 245$

$\$ 301$

$\begin{array}{ll}\text { NA } & \text { NA } \\ \text { NA } & \text { NA } \\ \text { NA } & \text { NA } \\ \text { NA } & \text { NA } \\ \text { NA } & \text { NA } \\ \text { NA } & \text { NA }\end{array}$

Mean

$\$ 69$

$\$ 69$
$\$ 86$

NA
$\$ 90$

NA

NA

$\$ 375$

$\begin{array}{lr}\text { NA } & \text { NA } \\ \text { NA } & \$ 100\end{array}$ 
T A B E V I I - Continued

\begin{tabular}{|c|c|c|c|c|c|c|}
\hline Variable & & $\begin{array}{l}\text { Portland } \\
\text { SRo } \\
\text { Sample } \\
(\mathrm{N}=30) \\
\end{array}$ & $\begin{array}{l}\text { St. Louis } \\
\text { SkO } \\
\text { Sample a } \\
(N=110)\end{array}$ & $\begin{array}{l}\text { San Diego } \\
\text { Sllo } \\
\text { Sample b } \\
(N=75)\end{array}$ & $\begin{array}{l}\text { New York } \\
\text { Sko } \\
\text { Sample c } \\
(\mathrm{N}=36)\end{array}$ & $\begin{array}{l}\text { National } \\
\text { Sample of } \\
\text { blderly a } \\
(\mathrm{N}=2797)\end{array}$ \\
\hline \multicolumn{7}{|c|}{ Residency Downtown: } \\
\hline $\begin{array}{l}\text { Median } \\
\text { Mean }\end{array}$ & & $\begin{array}{r}9.0 \text { yrs. } \\
13.0 \text { yrs. }\end{array}$ & $\begin{array}{l}14.6 \text { yrs. } \\
15.9 \text { yrs. }\end{array}$ & $\begin{array}{l}5.0 \text { yrs. } \\
7.8 \text { yrs. }\end{array}$ & $\begin{array}{l}\text { NA } \\
\text { NA }\end{array}$ & $\begin{array}{l}\text { NA } \\
\text { NA }\end{array}$ \\
\hline \multicolumn{7}{|c|}{ Residency in Present Hotel: } \\
\hline $\begin{array}{l}\text { Median } \\
\text { Mean }\end{array}$ & & $\begin{array}{l}5.0 \text { yrs. } \\
7.2 \text { yrs. }\end{array}$ & $\begin{array}{l}3.4 \text { yrs. } \\
6.6 \text { yrs. }\end{array}$ & $\left\{\begin{array}{l}45 \% \\
1 \text { to } 5 \text { yrs. }\end{array}\right.$ & $\begin{array}{l}\text { NA } \\
8.5 \text { yrs }\end{array}$ & $\begin{array}{l}\text { NA } \\
\text { NA }\end{array}$ \\
\hline
\end{tabular}

a Ehrlich, 1976.

b Eckert, 1978.

c Felton, et al., 1977.

d National Council on Aging, 1975.

e Males on $1 y$

$f$ Not available

B These are approximations only as the categories in the New York study were soriewhat different.

h Direct comparisons are misleading due to time elapsed between studies.

1 Harris, 1978. 
33 percent in Portland, 39 percent in St. Louis, 22 percent in San Diego, and 31 percent in New York City. By contrast, the national elderly sample of males only has a relatively small percentage of "never marrieds" ( 4 percent) and a relatively large percentage of "married, spouse present," i.e., 78 percent for the national sample. The SRO hotel samples had virtually no married couples, i.e., 0 percent for Portland's, 0 percent for St. Louis, 5 percent for San Diego's, and 3 percent for New York's. Portland's sample has the lowest percentage of "widowed," but given that elderly females are more likely to have survived the death of a spouse, the low figure probably reflects the "maleness" of the sample. The other SRO hotel samples are comparable when the percentage of females in the sample is accounted for. Though the percentage of widowers in the national elderly male sample is similar to those for the hotel samples, the proportion of marriages terminated by death rather than divorce or separation is quite different. The ratio for the national sample is 15 by death to 3 by divorce or separation or $5: 1$, but for Portland it is $1: 5.7$, for St. Louis it is 1:1.4, for San Diego it is $1: 1.3$, and for New York it is 1:4.1. In all cases, except for the New York sample, which has a comparatively high percentage of females, more marriages are terminated by personal decisions (divorce or separation) than by death. This is especially pronounced in the Portland sample. 
Race is a variable which has not been reported for all the SRO samples. The Portland sample contains fewer minorities than the New York sample or the national elderly population as a whole. The minority population in Portland is lower than many eastern cities, but even so, the SRO sample has a lower percentage than the City as a whole, which is 86.5 percent caucasian, 7.6 percent black, 2.9 percent asian, 1 percent native american (U.S. Bureau of Census, 1981b). Due to the lack of comparable information, it is imposisible to state whether Portland's SRO hotel sample falls within a "normal range" relative to racial composition. As noted in the literature review, SRO populations are not generally known for their high percentage of minority members, but are known more for their predominance of caucasian members.

On education, the distribution of the Portland sample by highest level of education achieved is nearly identical to that of the San Diego sample, i.e., just under one-half with at least some elementary school, about one-third with some high school, and about one-fifth with some college. No figures were available from the St. Louis study. Though difficult to compare directly, the 10.3 years of education as the mean for the New York sample is only slightly higher than the levels for the Portland and San Diego, but the national elderly sample may have a higher level of education with over one-third having graduated from high school and 
had some college. Generally, then, Portland's SRo sample has an education level similar to that of other sRo samples, i.e.p one which may be slightly lower than the national average for their age cohorts.

Typically, past employment bears a close relationship to level of education. Examination of the distribution of past employment for the Portland and San Diego samples shows more Portland SRO residents with higher skilled positions. This difference may reflect, at least in part, the maleness of the Portland sample if the assumption is made that elder females are most likely to have been employed in low or unskilled positions. By contrast, the New York sample has a greater percentage of SRO residents in the higher skilled categories. This trend tends to correspond with their higher education level. Similar information was not reported for the national elderly sample, but it is expected that elder SROs generally had positions requiring fewer skills than the average elderly person.

The Hollingshead social class scale, which is constructed from information on education level and past employment, was available for the st. Louis sample. By comparison, the Portland sample had a higher rating on the scale. That higher rating is interpreted as a higher social class. Because nearly 20 percent of the St. Louis sample is female, it might be anticipated that the sample would have a lower rating due to the fact that women have not been able 
to achieve similar occupational positions as men. The "femaleness" of the St. Louis sample no doubt accounts for at least a portion of the difference, but may not account for the total difference. Given similar educational levels between Portland and San Diego samples, but higher skilled employment by Portland SROs, San Diego would have more persons in the lower social classes based on the Hollingshead scale. Generally speaking, though, the SRO hotel samples are primarily lower class.

Comparing specific dollar amounts for either the SROs' income or rent is somewhat problematic. First, the samples came from various locales and the cost of living may differ from one to another. Additionally, the data for the various SRO samples were collected at different times; St. Louis was collected in 1975, San Diego in 1977, Portland in 1979, and the national sample in 1974. Despite these problems, both income and rent figures are presented in Table VII. As was noted in the literature review, SRO hotel residents tend to have low incomes and pay low rents, especially when the time of data collection is considered.

The information on residency suggests the SROs sampled were not transient either with respect to living in the downtown or their current hotel. The St. Louis sample reported the longest tenure in downtown, with a median of 14.6 years and San Diego the shortest with 5 years; the Portland sample had lived downtown for an average of 9 
years. The St. Lou is sample also reported a shorter residency in the current hotel. Portland and New York samples showed longer residency in hotels. Though there is variation among the SRO samples, it is generally within a similar range, i.e., neither transient nor long, long term residents.

In summary then, there seems to be no substantial reason to assume that the SRO hotel sample selected in Portland is not generally comparable to the SRO populations in other cities.

A COMPARISON OF THE SRO HOTEL AND SECTION

8 APARTMENT STUDY SAMPLES ON HOUSING PREFERENCES AND LIFESTYLES

This section on study findings addresses the first hypothesis, which states that those who chose to move out of single room occupant hotels and into subsidized Section 8 apartments, on the whole, have a different lifestyle than those who, to date, have chosen to remain in their hotel.

Examination of an assessment of SRO hotels by current and past hotel residents indicates that the two samples have substantially different views about SRO hotels. Further examination of the data suggests that Section 8 apartment residents are quite satisfied with their housing, especially when contrasted with the previous hotel. By comparison, 
current hotel residents report having made little or no effort toward securing Section 8 apartments and only modest interest in considering such a move. Based on these findings, it is proposed that the resident's dwelling, either SRO hotel or Section 8 apartment, represents his current housing preference.

Based on the strong reported association between satisfaction with housing and satisfaction with neighborhood, the resident's assessment of his neighborhood was also examined. Current hotel residents and previous hotel residents reported different aspects of their hotel neighborhoods as favorable but basically agreed on the unfavorable aspects. Section 8 residents were more satisfied with their new apartment neighborhood than with their old hotel neighborhood. Additionally, both samples indicated a preference for urban living, in particular for a residence in downtown.

Finally, a comparison of individual demographic characteristics of the hotel and apartment residents suggested several areas of difference which reflect personal choices or lifestyle decisions. These areas are marital status, socio-economic status, and residence in downtown. Further examination of these demographic characteristics and other indicators of personal choice or lifestyle decisions using discriminant analysis suggested additional differences between the hotel and apartment residents. Analyses of both 
interaction patterns with friends and personal life satisfaction successfully distinguish the groups. Based on these findings, it is concluded that the housing preferences of the two samples examined in this study are reflections of the personal choices or lifestyles of the residents. In the words of the person-environment perspective, the housing preferences reflect a match between the individual's needs, desires, or competencies and his environment.

\section{Housing Preferences}

The current hotel residents' assessment of their hotel and the section 8 residents' assessment of their previous hotel were substantially different in almost all categories considered. They differed in the number of favorable and unfavorable comments given in response to open-ended questioning of their likes and dislikes about SRO hotels. The specific comments they gave also differed in substantive areas. Also their evaluation of a list of functions which a housing unit can be expected to provide showed substantial differences.

Eavorable and Unfavorable Aspects of SRO Hotels. To examine these findings in some detail, Table VIII shows the results of a comparison of the mean number of favorable and unfavorable comments about SRO hotels made by the two samples. Each respondent had two opportunites to report favorable and unfavorable comments. Based only on the number of comments, either none, one, or two, current hotel 
T A B L E $\quad$ V I I I

MEANS, STANDARD DEVIATIONS, AND t-TEST COMPARISONS OF SHO HOTEL.

AND SECTION 8 APARTMENT RESIDENTS COMMENTS

ON AN OPEN-ENDED ASSESSUENT OP THEIR

MOST RECENT SHO HOTEL.

\begin{tabular}{|c|c|c|c|c|c|}
\hline $\begin{array}{l}\text { Type of } \\
\text { Comment }\end{array}$ & $\begin{array}{l}\text { SRO } \\
\text { Sample } \\
(\mathrm{N}=30) \\
\text { Mean Number }\end{array}$ & $\begin{array}{l}\text { Section } 8 \\
\text { Sample } \\
(\mathrm{N}=17) \\
\text { of Comments } \mathrm{a}\end{array}$ & $\underline{t}-$ Value & $\begin{array}{l}\text { Degrees of } \\
\text { Freedom }\end{array}$ & $\begin{array}{l}\text { One-tail } \\
\text { Probability }\end{array}$ \\
\hline Favorable & $\begin{array}{c}1.30 \\
(0.70) b\end{array}$ & $\begin{array}{c}0.69 \\
(0.70)\end{array}$ & 2.81 & 44 & .007 \\
\hline Unfavorable & $\begin{array}{c}0.83 \\
(0.75)\end{array}$ & $\begin{array}{c}1.59 \\
(0.62)\end{array}$ & -3.53 & 45 & .001 \\
\hline
\end{tabular}

a Possible scores are 0,1 , or 2 .

b standard deviations. 
respondents reported significantly more favorable comments ( $t=2.81, p=.007)$ and significantly fewer unfavorable comments $(t=3.53, p=.001)$ than did the section 8 apartment residents. The results support the prediction that current SRO hotel residents would view the hotels more favorably than would previous residents who chose to move to Section 8 apartments. It should be recalled that all section 8 units included in this study are located in the same general downtown area as are the SRO hotels.

Examination of the specific comments provides some indication of why SROs liked their hotels and why section 8 residents did not. The information in Table IX, which is based on the open-ended questions of likes and dislikes, reports the frequencies and percentages on all responses which were mentioned by at least 10 percent of either sample, i.e., at least three hotel residents or two apartment residents. What emerges are five aspects of SRO hotels or hotel living which are seen as favorable by at least some of the hotel residents, i.e., the hotels are inexpensive, they are in convenient locations, they allow sufficient independence, other tenants are viewed in a favorable light, and the maid service is seen as desirable. Only 17 percent of the SRO sample reported that the SRO hotels had no favorable aspects. By contrast, significantly more ( 41 percent) Section 8 residents reported no favorable aspects of their SRO hotels. Of the substantive comments 
T A B L E I X

TAVORABLB ATD UNPAVORABLB ABSESSUBNTS OF SBO BOTEL BOUSING BY CURRENT GOTHL AND SBCTION 8 APABTURNT RBSIDENTS ON THEIR WOST RECENT SRO HOTEL

\begin{tabular}{|c|c|c|c|c|}
\hline \multirow[b]{2}{*}{ Assessment } & \multicolumn{2}{|c|}{$\begin{array}{l}\text { SRO } \\
\text { Sample } \\
(\mathrm{N}=30) \\
\end{array}$} & \multicolumn{2}{|c|}{$\begin{array}{l}\text { Section } 8 \\
\text { Sample } \\
(\mathrm{N}=17) \\
\end{array}$} \\
\hline & $\begin{array}{l}\text { Number of } \\
\text { Responses }\end{array}$ & $\begin{array}{l}\text { Percent } \\
\text { of Total } \\
\text { Sample }\end{array}$ & $\begin{array}{l}\text { Number of } \\
\text { Responses }\end{array}$ & $\begin{array}{l}\text { Percent a } \\
\text { of Total } \\
\text { Sample }\end{array}$ \\
\hline \multicolumn{5}{|l|}{ Favorable Aspects: } \\
\hline $\begin{array}{l}\text { Inexpensive } \\
\text { Convenient location (downtown) } \\
\text { Independence a } \\
\text { Other tenants a } \\
\text { None a } \\
\text { Maid service a }\end{array}$ & $\begin{array}{l}\mathbf{8} \\
\mathbf{7} \\
\mathbf{7} \\
5 \\
5 \\
\mathbf{3}\end{array}$ & $\begin{array}{l}27 \% \\
23 \% \\
23 \% \\
17 \% \\
17 \% \\
10 \%\end{array}$ & $\begin{array}{l}3 \\
5 \\
2 \\
0 \\
7 \\
0\end{array}$ & $\begin{array}{l}18 \% \\
29 \% \\
12 \% \\
\overline{41 \%} \\
-\end{array}$ \\
\hline \multicolumn{5}{|l|}{ Unfavorable Aspects: } \\
\hline $\begin{array}{l}\text { None a } \\
\text { Other tenants } \\
\text { Rent increases } \\
\text { Too noisy } \\
\text { No kitchen } \\
\text { Level of disrepair } \\
\text { Dirty, bugs a } \\
\text { Sharing bathroom }\end{array}$ & $\begin{array}{l}9 \\
6 \\
3 \\
2 \\
2 \\
2 \\
1 \\
1\end{array}$ & $\begin{array}{r}30 \% \\
20 \% \\
10 \% \\
7 \% \\
7 \% \\
7 \% \\
3 \% \\
3 \%\end{array}$ & $\begin{array}{l}0 \\
4 \\
2 \\
3 \\
2 \\
2 \\
5 \\
2\end{array}$ & $\begin{array}{l}24 \% \\
12 \% \\
18 \% \\
12 \% \\
12 \% \\
29 \% \\
12 \%\end{array}$ \\
\hline
\end{tabular}

Note: The "Percent of Total Sample" reflects the percent of the sample naming that aspect as one of two most liked or disliked characteristics. In other words, each respondent had the opportunity to name two favorable and two unfavorable aspects of their most recent SRO hotel, therefore the sum of the percentages may exceed 100 percent. The question format was open-ended. Only those aspects which were identifled by at least 10 percent of either sample are listed here.

asing a test of proportions, the difference between the number of sRo and Section 8 residents wo mention this aspect is significant at $\mathbf{p} \leq .05$. 
reported, fewer of the Section 8 residents indicated that inexpensive rent and independence were favorable aspects of SRO hotels, though the differences were not significant. None of the Section 8 residents reported either the other tenants or the maid service as favorable qualities, whereas signficantly more current SRO hotel residents mentioned those as favorable aspects.

Of unfavorable aspects of SRO hotels, at least one was reported by all the previous residents, while 30 percent of the current residents reported none. This difference was significant. Further examination of unfavorable categories mentioned by at least 10 percent of the residents shows the previous hotel respondents reported seven categories of negative aspects, while the present residents reported only two. Other tenants and rent increases were aspects more frequently mentioned by the present hotel residents, while dirtiness and bugs, other tenants, and amount of noise were most frequently mentioned by previous hotel residents. There were significantly more previous hotel residents who mentioned dirtiness and bugs as a negative aspect of SRO hotels. Not having a kitchen or bathroom and the level of disrepair were among the least frequently mentioned aspects for both samples.

It is interesting to note that some current residents viewed the other SRO tenants as favorable and some viewed them as unfavorable but no apartment residents viewed the 
other SRO tenants as favorable. This rejection by some apartment residents of the other hotel tenants along with the dislike by some for the level of dirtiness and bugs plus the level of noise at their previous hotel suggests a preference for a different type of living environment. That 29 percent of the apartment residents mentioned the dirtiness and bugs in their previous hotel as opposed to only 3 percent of the current hotel residents only dramatizes the different perspectives of the two samples. This is especially true given that the hotels from which the apartment residents moved are the same hotels where the current residents now reside.

Evaluation of the Eunctional Aspects of SRO Hotels. In addition to having the hotel and Section 8 residents provide spontaneous remarks about what they saw as the favorable and unfavorable aspects of SRO hotels, they were also asked to evaluate, on a three-point scale lexcellent=1, okay=2, poor $=3$ ), the level at which a selected list of housing functions were satisfied by their hotel. The funtions evaluated were those noted in the Review of the Literature. Each of the five functions was operationalized by specific questions. Shelter was defined as both the amount of heat provided to the hotel room in the winter and the amount of protection the room provided from persons who might wish to break into the room or otherwise harm its occupant. For the function of privacy, two questions were asked, whether the 
amount of privacy and the amount of quiet or separation from neighboring residents was sufficient. The function of access to transit was defined as access to some transportation mode, either bus or taxi, whichever they tended to use. Access to neighborhood amenities was operationalized as access to stores and to services. Affordability was defined as the resident's perception of the amount of rent paid, i.e., an excellent, okay, or poor deal. Additionally, two "functional areas" deemed relevant to SRO housing were added, one being the operability of essential utility services and the other being the maintenance of sanitary conditions at the hotel. The first was defined as operable plumbing and sufficient light in the room and the second as the level of cleanliness of bathroom facilities as well as efforts and effects of rodent and pest control.

The purpose of examining these functions was to ascertain how the residents, both present and past, would assess the level of functioning of an SRO hotel. It was presumed that such an assessment would identify which functions were most satisfactorily met and which were not. It was also presumed that there would be a substantial difference in the assessments of present and past residents. In other words, the assessment would be an evaluation by the resident of how well he thought the various functional elements of housing were satisfied by his current or most recent SRO hotel. Areas of major difference would provide 
clues as to what was deemed important by one sample and not by the other.

of the 13 variables examined, $t$ - test comparisons on 11 were highly significant $(p=.007)$. The current hotel residents rated their hotels as satisfying the selected functions of housing significantly better than did the previous hotel residents on all variables except access to transportation and closeness to stores. 1 The reason for the highly significant $t$ - tests becomes apparent when it is noted that the lowest mean value on a variable rated by the current hotel sample was 1.96 or nearly equivalent to the central value of the three-point scale, i.e., 2.00 (see Table $x$ ). Except for the three variables which measure locational qualities (the function of access to transit and the function of access to neighborhood amenities), the highest mean value on a variable rated by the previous hotel sample was 2.38 , somewhat less than the lowest mean rating for the current hotel sample. In general then, the present hotel residents rated their hotel's satisfaction based on the set of variables as "excellent" or on the high side of "okay." But the previous hotel residents rated their hotel quite differently. Except for the locational qualities, all the ratings were on the low side of "okay" or "poor."

\footnotetext{
1Appendix $E$ contains detailed information on all $t$-test comparisons. That the two mentioned variables were not significantly different is no doubt related to the easy access to transit in downtown and the large number of stores throughout the area.
} 
A closer examination of the ratings of the selected functions reveals some interesting differences between the two samples. Current hotel residents rated the amount of privacy in their SRO hotel as excellent, while previous hotel residents rated it as borderline, between okay and poor $(t=-5.18, p<.001)$. The second variable used as a measure of the function of privacy, amount of quiet and separation, had a smaller spread, but was also dramatically different $(t=-4.49, p<.001)$. Based on the fact that both samples either lived or were living in the same sRo hotels and were thus rating the same group of hotels, this finding suggests a distinct difference in the interpretation of what constitutes privacy for the hotel and apartment resident.

The assessment of the maintenance of sanitary conditions was also quite different for the two samples. The ratings of the effects of rodent and pest control showed the largest difference $(t=-4.07, p<.001)$. Whereas the current hotel residents rated all the variables for this function about the same, the previous hotel residents were somewhat less critical of the efforts at bug control $(t=-3.33$, $p=.001)$ and cleanliness of the bathroom facilities $(t=$ $-2.73, p=.005$ ) than they were of the results of the bug control efforts.

The variables for the function of shelter were also rated substantially different. Though both amount of heat in the winter and protection from others were rated among the 
least satisfactory for the current residents, the differences were still highly significant. The amount of protection had the greatest difference $(t=-4.30, p<.001)$ and the amount of heat in the winter had only a somewhat smaller difference $(t=-2.58, p=.007)$.

The function of affordability or the amount of rent paid also generated divergent responses. The current hotel residents gave this variable an "okay" rating but it was one of their lower okay ratings. The previous hotel residents reported amount of rent paid as poor and the resulting comparison showed the assessments to be substantially different $(t=-3.90, p<.001)$.

There was also a considerable difference between the two sample's ratings of the essential utility services. The plumbing in the rooms was rated okay by the current residents and poor by the previous residents $(t=-4.04$, $p<.001)$ and the amount of light was rated okay by both samples but the difference between the mean values was still substantial $(t=-3.01, p=.002)$.

Again, it is important to recall that the hotels in which the current residents lived were the same hotels in which the apartment residents used to live. Therefore, these findings suggest that current hotel residents are content with the ability of their dwelling to fulfill the basic functions a housing unit is expected to satisfy. They also suggest that apartment residents were not content with the 
ability of their previous hotel housing to fulfill the basic functions, with the exception of the locational qualities noted earlier. The implication is that the apartment residents' low estimation of an SRO hotel's ability to satisfy the functions of housing may have been at least one component of their decision to move.

When the same variables were used to compare the apartment residents' assessments of their previous hotels and current section 8 apartments, the differences were even greater. The mean rating for the Section 8 apartments, on all variables, were clustered in the excellent category, i.e., no mean value exceeded 1.50 on the three-point scale (see Table $x$ ). of the 12 comparisons, nine were highly significant $(p<.001)$; in each case, the apartment was rated substantially better than the previous SRO hotel. Even one locational variable, access to services, had a statistically significant difference $(t=2.43, p=.015)$. The other locational variables, access to transit and access to stores, were not statistically different.

The variables which emerge with the highest mean rating for the section 8 apartments were the components of the functions of privacy and maintenance of sanitary conditions. Amount of quiet or separation from others and amount of privacy were rated respectively, poor and borderline between poor and okay, for the previous hotels but were rated nearly perfect for the apartments. The large 
T B L E X

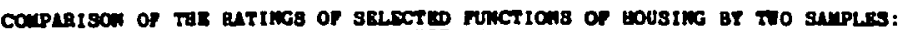

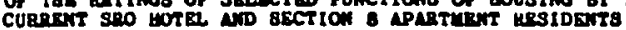

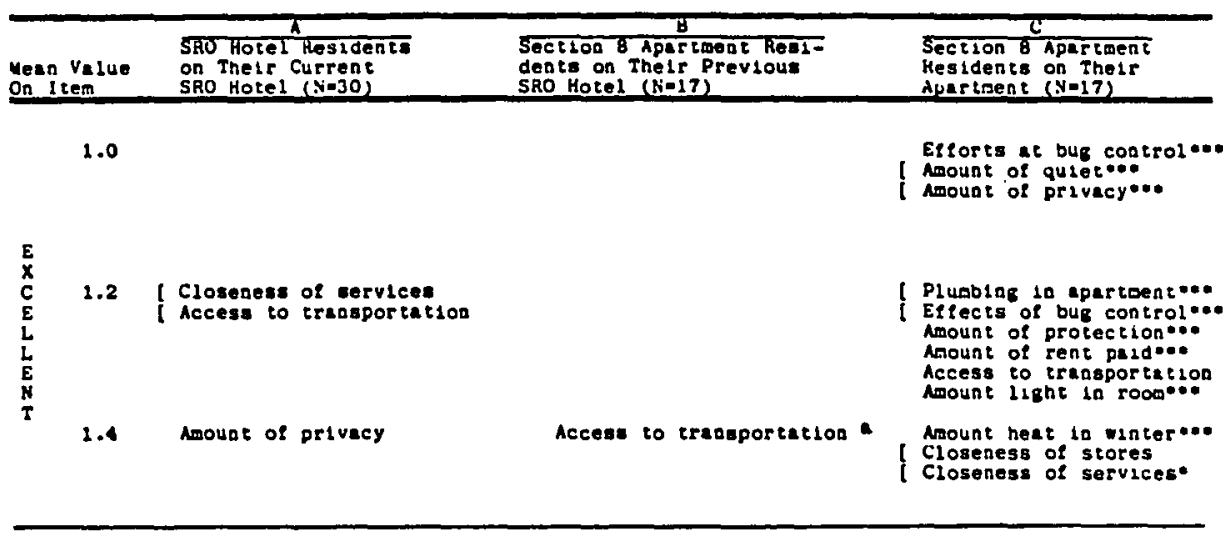

1.6 Closeness of store.

Closeness of stored

Amouts of quitet
clesaliness of beth fac.

Closeness of stores

1.8 Effects of bur control

Awount light in roos

Plumbing in room

Anount of protection
Amount of reot pald

Closeness of services"ut

$\begin{array}{ll}0 & \\ k & \\ \mathbf{A} & 2.0\end{array}$

Amount heat 10 wloter

2.2

Cleaniness of beth lac.:

2.4

( Amount of l1ght ing rooo"

2.6

( Amount heat 10 winter"o

Plumbing in roomo

$\mathbf{P}$
$\stackrel{0}{0}$
$\mathrm{H}$

2.8

Amouat of teat pald

Anount of quletan

controlen

Amouat of protection.e.

3.0

Note: All anterlake 20 Columb B denote the level of sigatftcace for t-tests botveen varlable weens from Columa A and B. All asterlaks la Column C denote the level of sigalficance

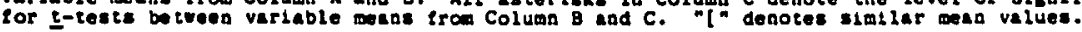

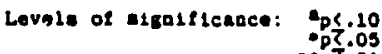

$\cdots$ ? 
t- values indicate the magnitude of the difference; for quiet or separation it was 9.68 ( $p<.001)$ and for privacy it was.8.17 ( $\mathrm{p}<.001)$. The differences were less for the component variables of maintenance of sanitary conditions but were by no means inconsequential. The $t$ - value for efforts at bug control was 7.07 ( $p<.001)$ and 7.58 ( $p<.001)$ for effects of bug control efforts. One component of the function of shelter had the most dramatically different comparison. Amount of protection received the poorest rating of all variables for the previous hotel and a near top rating for the apartment with the resultant difference of $t=$ $13.79(\mathrm{p}<.001)$.

As mentioned above, all the variables showed substantial differences, but it is noteworthy to consider the consistency of the section 8 apartment resident's responses. The aspects of SRO hotels which the apartment residents reported most frequently as unfavorable were too dirty, other tenants, and too noisy, in that order. The two functions, privacy and maintenance of sanitary conditions, address those aspects of housing about which the previous hotel residents reported most concern. As will be noted later in the analysis of neighborhood preferences, interest in the amount of protection in SRO hotels is no doubt related to their concern of crime and a dislike for at least some of the other hotel tenants. Such high ratings for these and the other variables suggest that section 8 residents 
view their individual apartment and the building in general as fulfilling the functions of housing extremely well. For them, the contrast between the two types of housing was substantial.

Assessment of Differences Between SRO Hotels and Section 8 Apartments. Additional information on the housing preferences of the previous hotel residents is provided by their responses to the question of the most important differences between SRO hotels and section 8 apartments. Examination of Table XI shows that there was not just a single aspect of the apartments which distinguished them from the hotels, but rather a number of aspects. In fact, no category of major difference was mentioned by more than three residents. As with the questions on likes and dislikes of SRO hotels, the question of major differences was openended, thus eliciting a spontaneous response rather than a scaled response to a set of specific items.

The resulting responses were easily classified into five general categories with none emerging as more prevalent than the others. Good tenants living in the apartments and having one's own kitchen were each mentioned by three residents (18 percent) as the most important difference. That the building and its units were "fixed-up," "clean and nice," and a "safe place" were each mentioned by two residents ( 12 percent). The other five responses covered a variety of areas such as having one's own bathroom, that the 
THE MOST IMPORTANT DIPFERENCE BETWEEN SRO HOTELS

AND SECTION 8 APARTMENTS AS REPORTED

BY PRESENT APARTUENT OCCUPANTS

\begin{tabular}{lcc}
\hline $\begin{array}{l}\text { Most Important } \\
\text { Difference }\end{array}$ & $\begin{array}{c}\text { Number of } \\
\text { Responses }\end{array}$ & $\begin{array}{c}\text { Percent of } \\
\text { Total Sample }\end{array}$ \\
\hline Good tenants in apartments & 3 & $18 \%$ \\
Own kitchen in apartment & 3 & $18 \%$ \\
Building/units are "fixed up" & 2 & $12 \%$ \\
Building/units are "clean and nice" & 2 & $12 \%$ \\
Building/units are a "safe place" & 2 & $12 \%$ \\
Other & 4 & $24 \%$ \\
No Difference & 1 & $6 \%$ \\
Totals & 17 & $100 \%$ \\
\hline
\end{tabular}


apartment was better in every way, that there was a good manager, that the people in the neighborhood were nicer (24 percent), and one comment that there was no difference ( 6 percent).

That good tenants were reported as a major difference is consistent with the Section 8 residents reporting that one unfavorable aspect of hotel life was the other tenants. The comments about the building and its units being fixed up, clean and nice, or a safe place seem to be a response to the quality of the apartment building and its amenities such as remodeled units, with fresh paint and carpeting, lack of rodents and roaches, and a locked front door. Appreciation of these qualities is consistent with their expressed concern about SRO hotels being too dirty, not providing sufficient protection, and their level of disrepair. It is interesting to note that though privacy and quiet received such disparate ratings between previous hotel and apartment, they do not appear as a most important difference. This may be because the major differences of good tenants, a clean and nice place, and a safe place cover aspects of the privacy functions. It is also interesting to note that despite the expectations by some such as HUD that no cooking facilities would be a major disadvantage, only 18 percent of the Section 8 residents mentioned having a kitchen as a major advantage. Some 35 percent of the residents reported that they prepared no more than half their meals in the 
apartment.

These findings suggest that having one's own kitchen or bathroom does not surpass other aspects of housing for the status of most important difference. What emerges is that there are aspects of housing which appear to be more important to the previous hotel resident and they include other tenants and the quality and operation of the building. As demonstrated by the comparisons of favorable and unfavorable comments about SRO hotels and assessments of housing functions, the Section 8 apartment residents tend to value or express satisfaction with different aspects of housing than do the current hotel residents.

SRQ's Interest in Moving. Still further data suggesting a definite preference on the part of hotel residents for SRO hotels comes from analysis of their reported interest in moving to section 8 apartments. The finding was that residents were less than eager to move. When asked about their awareness of housing for which the tenant paid only one-quarter of his income for rent, all indicated they were aware that such apartments were available in the downtown area and that the maximum rent paid for the units would be approximately one-quarter of their income. Despite awareness of this alternative, only one hotel resident out of the 30 interviewed had made an effort to secure such housing. When that resident was offered a Section 8 unit by the housing authority, he 
refused to move because the unit was outside downtown. Thus none of the 30 residents were actively seeking section 8 apartments.

Table XII contains a paraphasing of the hotel residents' responses to the question of their level of interest in moving to a section 8 apartment. They are arranged in approximate order of interest fron "possibly would consider", "might consider, but...," to "not interested". The residents classified as "possibly interested" were those who reported some thoughts of moving to a Section 8 apartment but with the exception of the case mentioned above, had made no effort to secure a unit. Those classified as "might consider, but..." reported less interest and concluded their statement with a reason for their lack of interest. Reasons included insufficient information to make a decision, concern about location and other tenants' behavior, waiting lists, cost of furniture, and preception that they were ineligible. Those who indicated "no interest" in moving were quite emphatic. Some reported no interest in Section 8 units specifically; others reported no interest in moving, period. The distribution of the hotel sample by category was 29 percent "possibly interested," 37 percent "might consider, but...," 30 percent "not interested," and 7 percent "other."

Rent subsidized apartments in the form of section 221 $d(3)$ units had been available in downtown Portland since 
T A B E X I I

RESPONSES OP CURRENT SRO HOTBL RESIDENTS

TO A QOBSTION BBGABDING THEIR INTRREST

IN DOVING TO $\triangle$ SBCTION 8 APABTUENT

\begin{tabular}{|c|c|c|c|}
\hline $\begin{array}{l}\text { Level of } \\
\text { Interest }\end{array}$ & Paraphrase of Response & $\begin{array}{l}\text { Number } \\
\text { Giving } \\
\text { Response }\end{array}$ & $\begin{array}{l}\text { Percent } \\
\text { of Total } \\
\text { Sample }\end{array}$ \\
\hline \multirow[t]{3}{*}{$\begin{array}{l}\text { POSSIBLY } \\
\text { INTERESTED }\end{array}$} & $\begin{array}{l}\text { Interested, got on Housing Authority's watting } \\
\text { list but refused offer because it was located } \\
\text { outside of downtown. }\end{array}$ & 1 & $3 \%$ \\
\hline & $\begin{array}{l}\text { Knew about the availability of such units, thought } \\
\text { about them but never did anything about it, like } \\
\text { get an application. }\end{array}$ & 5 & $17 \%$ \\
\hline & $\begin{array}{l}\text { Would consider the units if had a steady source } \\
\text { of tacome. }\end{array}$ & 2 & $7 \%$ \\
\hline \multirow{5}{*}{$\begin{array}{l}\text { MIGHT } \\
\text { CONSIDER } \\
\text { BUT }\end{array}$} & $\begin{array}{l}\text { Might consider but did not have enough information } \\
\text { to make a decision. }\end{array}$ & 2 & $7 \%$ \\
\hline & $\begin{array}{l}\text { Might consider depending upon such things as } \\
\text { locetion of the unt ts and regulation of behavior } \\
\text { of tenants. }\end{array}$ & 2 & $7 \%$ \\
\hline & Might consider but most have vaiting lists. & 1 & $3 \%$ \\
\hline & $\begin{array}{l}\text { Might consider but could not afford to buy } \\
\text { furniture }\end{array}$ & 2 & $7 \%$ \\
\hline & $\begin{array}{l}\text { Might consider but probably ineligible due to } \\
\text { income or age }\end{array}$ & 4 & $13 \%$ \\
\hline \multirow[t]{4}{*}{$\begin{array}{l}\text { NOT } \\
\text { INTERESTED }\end{array}$} & $\begin{array}{l}\text { Not interested, prefers present situation or some } \\
\text { alternative other than section } 8 \text { apartments. }\end{array}$ & 5 & $17 \%$ \\
\hline & Not interested in moving at all, period. & 4 & $13 \%$ \\
\hline & Other responses. & $\underline{2}$ & $7 \%$ \\
\hline & Totals & 30 & $100 \%$ \\
\hline
\end{tabular}


1972. At the time the resident interviews were being conducted, there were 338 rent subsidized units in downtown (see Table VI ). Additionally, 235 new Section 8 units were nearing completion and 30 more were in the process of being renovated. There were sufficient rent subsidized units in downtown that acquisition and completion of an application could mean an opportunity to move within less than a year. Thus, the hotel resident's reluctance or resistance to pursuing alternative housing at a cheaper rent appears to be unreasonable consumer behavior, especially given the low income of most SRO residents.

Adding to the seeming contradiction are the residents' responses to a set of questions asking their assessment of selected attributes available with a section 8 apartment. They were asked to indicate whether they thought the attributes would be an advantage, made no difference, or be a disadvantage. Overall, the hotel residents reported that having low rent, a private bathroom, and a kitchen would be advantageous, that having a new or remodeled unit, a bedroom, more space, and mostly elderly neighbors would make no difference, and that having to furnish an apartment would be a disadvantage. Again, in spite of the knowledge that those attributes they indicated would be an advantage were available with a rent subsidized or section 8 apartment, none were actively seeking such housing. That high rents and individual bathrooms or kitchens were mentioned by only a 
few hotel residents as unfavorable aspects of SROs suggests they are not priority concerns. Considering the aspects of hotels the residents reported as favorable such as being inexpensive, situated in convenient location, and allowing sufficient independence, their lack of effort to secure Section 8 apartments appears more reasonable.

In summary, then, there seems to be sufficient evidence to suggest that SRO hotel residents do have different housing preferences than those who chose to move into Section 8 apartments. That any person would actually consider such "substandard" housing as preferable to the alternative of Section 8 apartments should not be viewed as unrealistic. As noted in the literature review, Carp (1976b) reported that one-third of the legally qualified applicants for a new, low-rent elderly housing project decided not to move in. In her study of the 352 applicants to victoria Plaza, she found 51. who, despite being first on the list for the 184 units, did not accept the offer. She concluded:

older people probably have considerable self-insight and understanding of their own desired lifestyles; the tour of the new facility may have reinforced the desirability of the new setting for some but indicated to others that, despite the disadvantages of their present milieux, victoria plaza was not the place for them. Person-situation congruence is a major factor in defining the "goodness" of any environment for an individual. (p.104)

In another study, Lawton et al. (1973) noted that a perception of realistic alternatives was an important factor in the willingness of elderly slum dwellers to report 
dissatisfaction with their substandard housing in a crime ridden neighborhood. In the case of the present study, all current SRO hotel residents were aware that a realistic alternative existed, i.e., Section 8 apartments. Overall, they reported satisfaction with their hotels and only one out of the 30 interviewed pursued the alternative to the extent of completing and submitting an application for Section 8 housing. This suggest a self-selection process has occurred, that those who wanted other housing sought it and secured it, while those who were more satisfied remained in their hotel. It does not suggest that time and circumstances might not alter perceptions, but for the present, hotei residents, on the whole, do not report attempting to move from their hotels, nor do they rate the hotel as functioning poorly relative to the functions housing should provide. The residents are not oblivious to unfavorable apsects of hotel living but they also identify sufficient favorable qualities that provide a congruence between lifestyle and environment.

\section{Neighborhood Preferences}

It was noted in the Review of the Literature that there tends to be a strong relationship between satisfaction with housing and satisfaction with neighborhood. Those who express satisfaction with the housing are similarly likely to express satisfaction with their neighborhood (Lawton, 1978; Campbell, Converse \& Rogers, 1976). This being the case, a comparison of SRO hotel and Section 8 apartment 
residents' ratings of their neighborhood would expect to find the current hotel residents more satisfied with their neighborhood than past hotel residents and apartment residents more satisfied with their new (apartment) neighborhood than with their previous hotel neighborhood. In fact, that is precisely what the findings reflect. Additionally, despite expressions of some dissatisfaction with their current neighborhood, the majority of both samples would prefer to continue living downtown.

Favorable and Unfavorable Aspects of Neighborhoods. In order to assess satisfaction with neighborhood, a format similar to that used to identify favorable and unfavorable aspects of housing was utilized. Each respondent had the opportunity to report two favorable and two unfavorable aspects of his neighborhood. Again, the responses were coded as to the number of each type of comment, i.e., zero, one, or two.

Comparing the mean number of favorable responses given by the hotel residents about their current neighborhood and previous hotel residents about their past neighborhood, the hotel residents reported significantly more favorable aspects $(t=2.59, p=.007)$. Interestingly, however, there was no difference between the two samples on the mean number of unfavorable aspects reported $(t=.40, p=.350)$.

The specific favorable and unfavorable aspects reported are shown in Table XIII. Sixty percent of the 
T A B L E X I I I

PAVORABLE AND URPAVORABLB ASSESSYENTS OP NEIGHBORHOOD BT CURRBNT SRO HOTEL, AND SECTION 8 APARTHENT RESIDBNTS

\begin{tabular}{|c|c|c|c|c|c|c|}
\hline \multirow[b]{2}{*}{ Assessment } & \multicolumn{2}{|c|}{$\begin{array}{l}\text { SRO Sample } \\
(N=\mathbf{3 0})\end{array}$} & \multicolumn{2}{|c|}{$\begin{array}{c}\text { sect } 10 n \\
\text { Hotel } \\
\text { Neighborhood }(\mathrm{N}=16)\end{array}$} & \multicolumn{2}{|c|}{$\begin{array}{c}8 \text { S a in p l e } \\
\text { Apartment } \\
\text { Ne1ghborhood }(\mathrm{N}=17)\end{array}$} \\
\hline & $\begin{array}{l}\text { Number of } \\
\text { Responses }\end{array}$ & $\begin{array}{l}\text { Percent } \\
\text { of Total } \\
\text { Sample }\end{array}$ & $\begin{array}{l}\text { Number of } \\
\text { Responses }\end{array}$ & $\begin{array}{l}\text { Percent } \\
\text { of Total } \\
\text { Sample }\end{array}$ & $\begin{array}{l}\text { Number of } \\
\text { Responses }\end{array}$ & $\begin{array}{l}\text { Percent } \\
\text { of Total } \\
\text { Sample }\end{array}$ \\
\hline
\end{tabular}

Favorable aspects:

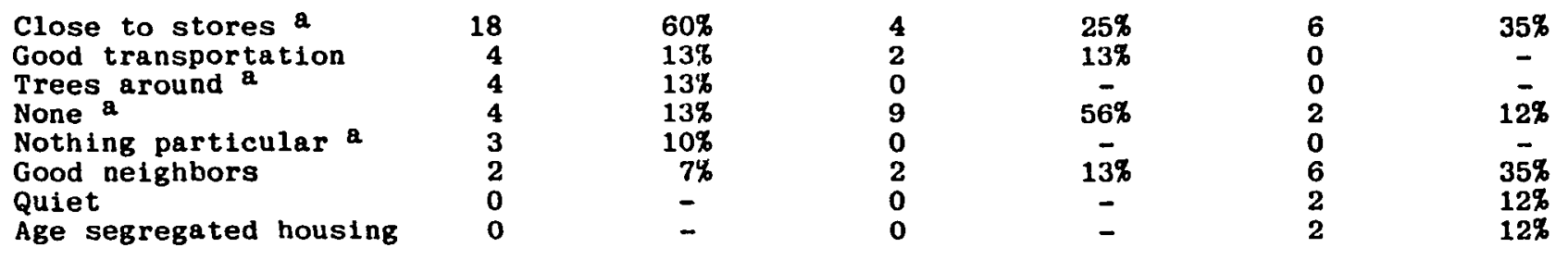

Unfavorable aspects:

\begin{tabular}{|c|c|c|c|c|c|c|}
\hline $\begin{array}{l}\text { Bad neighbors } \\
\text { High crime } \\
\text { None } \\
\text { Street people a } \\
\text { Noisy a }\end{array}$ & $\begin{array}{r}10 \\
9 \\
9 \\
3 \\
1\end{array}$ & $\begin{array}{r}33 \% \\
30 \% \\
30 \% \\
10 \% \\
3 \%\end{array}$ & $\begin{array}{l}5 \\
6 \\
4 \\
0 \\
2\end{array}$ & $\begin{array}{l}31 \% \\
38 \% \\
25 \% \\
- \\
13 \%\end{array}$ & $\begin{array}{r}1 \\
3 \\
10 \\
0 \\
0\end{array}$ & $\begin{array}{l}6 \% \\
19 \% \\
63 \% \\
- \\
-\end{array}$ \\
\hline
\end{tabular}

Note. The "Percent of Total Sample" reflects the percent of the sample naming that aspect as one of the two best or worst characteristics. In other words, each respondent had the opportunity to name two favorable and two unfavorable aspects of their neighborhood, therefore the sum of percentages may exceed 100 percent. The question format was open-ended. only those aspects which were identified by at least 10 percent of either sumple are listed here.

a Using a test of proportions, the difference between the number of sho and Section 8 residents who mention this aspect about the hotel neighborhood (present or past) is signifiicant at $p \leq .05$. 
current hotel sample reported the closeness of stores as a favorable aspect of their neighborhood and 13 percent reported good transportation as another. These are both generally seen as prominent features of a downtown neighborhood. Other favorable aspects noted by hotel residents were the proximity of trees to their hotel ( 13 percent) and good neighbors ( 7 percent). Only 13 percent of the sample reported no favorable aspects. By contrast, significantly more (56 percent) of the previous hotel residents reported that there were no favorable aspects to their old neighborhood. Others, however, did report some positive aspects such as the closeness of stores (25 percent), good transportation (13 percent), and good neighbors (13 percent). These substantive aspects were generally similar in content, if not percent who mentioned them, to those mentioned by the current hotel residents. Of the unfavorable neighborhood aspects, the present and past hotel samples were in nearly complete agreement. About one-third of each sample mentioned both bad neighbors and high crime. These, too, can be considered a prevalent feature of urban living. Additionally, the percentage of residents reporting no unfavorable aspects to the neighborhood was quite similar, 30 percent for current hotel residents and 25 percent for previous hotel residents. Paralleling the previous hotel residents' mention of their dislike for noise and a low rating of privacy and quiet and 
separation relative to SRO hotels, significantly more mentioned noise as a negative aspect of neighborhood.

Clearly, all present hotel residents do not agree as to the favorable or unfavorable aspects of their neighborhood. More report no unfavorable aspects than report no favorable. More mention bad neighbors and street people than mention good neighbors. Iikewise, all previous residents do not agree; over half report no favorable aspects and one-quarter report no unfavorable. More report bad neighbors than good. Both samples do note the closeness of stores and good transportation as favorable aspects though. In sum, then, the current hotel residents reported a greater number and a slightly wider variety of favorable neighborhood aspects than did the previous hotel residents. This finding is congruent with the current hotel resident's more favorable assessment of their SRO hotel.

Another comparison is the assessment of the previous hotel neighborhood and the current apartment neighborhood by Section 8 apartment residents. Based on their assessment of housing, more favorable and fewer unfavorable comments on the apartments' neighborhood would be expected. Indeed, both comparisons were significantly different, i.e., there were more favorable aspects noted $(t=2.07, p=.028)$ and fewer unfavorable aspects $(t=-3.09, p=.004)$.

Again, referring to Table XIII, it can be seen that the closeness of stores was mentioned as a favorable aspect 
of the apartment neighborhood as frequently as were good neighbors (35 percent). The quiet and age segregated nature of the (elderly) housing were both noted by 12 percent of the sample as favorable aspects. Twelve percent also noted that there were no positive aspects to their current neighborhood. By comparison, 63 percent reported no unfavorable aspects. However, both high crime (19 percent) and bad neighbors ( 6 percent) were reported by some residents, though by fewer than for either the current hotel neighborhoods or the previous hotel neighborhoods.

Overall, then, the urban services such as proximity to stores and good transportation consistently emerged as a favorable part of the SRO hotel neighborhood. The current hotel residents tended to recognize and report unfavorable aspects of their neighborhood, in fact, at nearly the same level as the previous hotel residents. And, the section 8 apartment sample reported increased satisfaction with their new neighborhood, especially in the areas of people relations (good/bad neighbors; crime) and sounds (quiet/noisy).

Preference of Neighborhood Lecation. Given that both samples noted the favorable aspects of urban services, it was not surprising that the majority of hotel and apartment residents indicated another location downtown would be their first choice if they were forced to relocate (see Table XIV). In addition to the samples' similar preferences for 
T A B L E X I V

PREPERRED hOUSING LOCATION IF RESIDENT MAS FORCED TO MOVE PROI PRESENT DNELLING

\begin{tabular}{lcccc}
\hline & \multicolumn{2}{c}{ SRO Sample } & Section 8 Sample \\
\cline { 2 - 5 } Preferred Location & $\begin{array}{c}\text { Number of } \\
\text { Responses }\end{array}$ & $\begin{array}{c}\text { Percent } \\
\text { of Total } \\
\text { Sample }\end{array}$ & $\begin{array}{c}\text { Number of } \\
\text { Responses }\end{array}$ & $\begin{array}{c}\text { Percent } \\
\text { of } \\
\text { Sample }\end{array}$ \\
\hline \hline $\begin{array}{l}\text { Downtown } \\
\text { Close in central city }\end{array}$ & 17 & $57 \%$ & 9 & $53 \%$ \\
$\begin{array}{l}\text { Farther out, either in } \\
\text { city or just outside }\end{array}$ & 4 & $13 \%$ & 2 & $12 \%$ \\
$\begin{array}{l}\text { Another city } \\
\text { No difference }\end{array}$ & 1 & $13 \%$ & 2 & $12 \%$ \\
Don't know & 3 & $3 \%$ & 2 & $12 \%$ \\
Totals & 1 & $10 \%$ & 1 & $6 \%$ \\
\hline \hline
\end{tabular}


living in downtown, the distribution of other responses was nearly identical. Only 13 percent of the SRO hotel sample and 12 percent of the section 8 sample noted a preference for a distinctly less urban setting, i.e., further out, either in the city or just outside. It thus appears that urban living and preferably downtown living is particularly attractive to both present and past hotel residents. On the other hand, a suburban or rural setting seems to hold little attraction for these elderly men. A typical response to the question of relocation was, "And what would I do in a residential neighborhood, I'd just have to come downtown anyway."

The preference for downtown living distinguished the hotel and apartment residents from other elderly who prefer a more residential environment. Because the apartment residents viewed their new neighborhood as a considerable improvement over their old neighborhood, it was not unexpected that they would express a preference for downtown; after all, they had made an effort to remain in downtown when they moved to their section 8 apartment. The current hotel residents did not express the same level of satisfaction with their neighborhood as did the apartment resident though. For this reason, less interest in a continued downtown residency might be expected. That the hotel residents reported equal interest in remaining in downtown suggests downtown has a special attraction for 
them. In fact, downtown has many services which the hotel residents recognize and use; additionally, there are very few SRO hotels outside the downtown area. This suggests that for the hotel resident downtown living is an attempt to reconcile personal needs and competencies with the environment.

\section{Life Style Indicators}

The hypothesis addressed in this section states that preferences for housing and neighborhood are related to the lifestyle and personal choices of the residents. Carp (1976b) made note of preferences for housing as related to the individual's perception of what is congruent between a personal situation and environment when she noted that one-third of the first list did not move into the new low-income elderly housing project, Victoria Plaza. It should also be recalled that Eckert (1978) addressed the relationship between housing preference and life style. He noted that the three types of hotel residents (lifelong loner, retreatist, and late isolate) come from differing backgrounds and life histories and that they varied in their adjustment to life in an SRO hotel. It is based on these perspectives that the present study predicts variations in life style to be useful in distinguishing between SRO hotel and Section 8 residents.

Sociodemegraphic Characteristics. The assumption is that factors which reflect variation in life style would be 
most likely to distinguish between the two samples and that other variables which reflect an existing condition, such as age, would be less likely to show any difference. Table XV shows the results of the $t$ - test comparisons on 12 sociodemographic characteristics. Of the comparisons, only two are significant ( $p<.05)$, level of education and Hollingshead socio-economic status. The Section 8 sample had completed about the same mean number of years of schooling (7th to 9 th grade) as had the average elderly person (see Table VIII), but the hotel residents had significantly more schooling, on the average (10th to 11th grade). The SROs also achieved higher status jobs during their working years and this was reflected in the difference between the Hollingshead scale scores.

Several other variables, though not statistically different using a two-tailed test, did approach a level of significance which indicated further examination would be prudent. That only two-tailed levels of significance were reported in the table is an indication that the direction of the relationships was not predicted. That is not entirely true for the variable of marital status however. Research on SRO hotel residents suggests that marital status is a characteristic of considerable descriptive power for that population. A disproportionate percentage of SRO hotel residents were never married as compared with other elderly populations and of those who were married, a greater 
percentage were either divorced or separated rather than widowed. Assuming that the current SRO hotel population was more likely to be never married or separated or divorced, then a one-tailed test of significance would be appropriate. In that case both marital status variables, married vs. never married and separated or divorced vs. widowed, would have significant probability levels, i.e., $p=.054$ and $\mathrm{p}=.049$, respectively. Another variable, number of years the two samples had lived in downtown, also approaches a level of significance $(p=.106)$ with section 8 residents having been in downtown for almost 20 years compared to the hotel residents' 13 years.

The literature suggests a number of predisposing factors which can be used to predict an elderly person's move to different housing. Frequently mentioned are major changes in a person's life cycle, such as death of a spouse or divorce, poor or degenerating health, and inability to navigate one's environment (Riley \& Foner, 1968; Yee \& Van Arsdol, 1977). Because both samples examined in this study are composed of persons who lived alone, it is unlikely that they would experience either death of a spouse or divorce. The comparisons shown in Table XV indicate that neither of the variables self-rated health nor mobility successfully differentiate between the hotel and apartment residents.

Economic considerations can prompt an elderly person to contemplate moving (Ferraro, 1981). Though the hotel 
T A B L E X V

MEANS, STAKDABD DETIATIOHS, AND E-TEST COMPABISONS OP SBO BOTEL AND SBCTION 8 APARTIIBNT RBSIDBNTS ON

8ELLCTED 8OCIODENOGRAPAIC CBARACTERISTICS

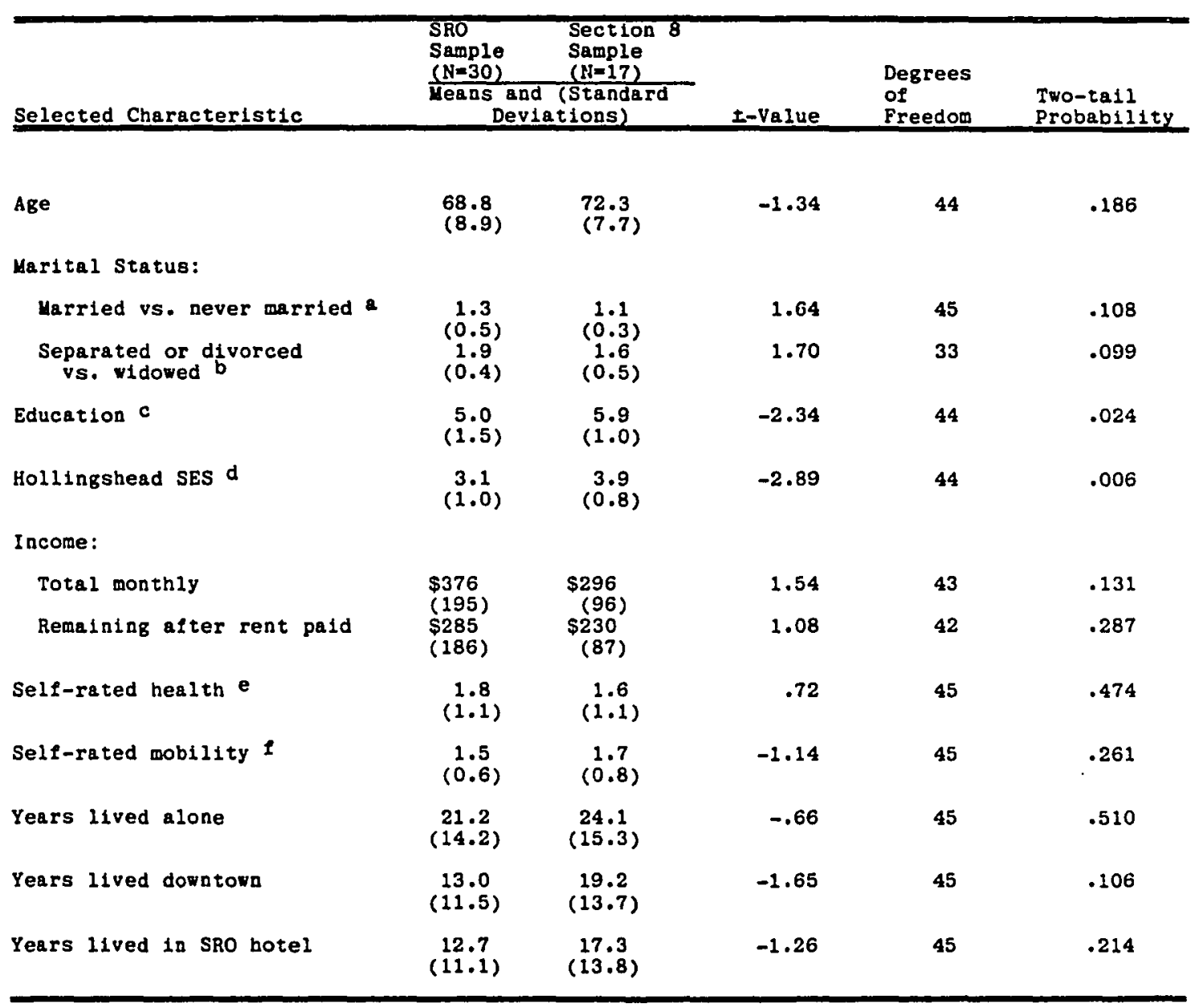

a Possible scores are 1 = ever married and 2 = never married.

b Possible scores are 1 - separated or divorced and 2 - vidowed; $N=20,15$.

c Possible scores rage from 1 - graduate or professional training to 7 = less than 7 th Grade.

d Possible scores range from 1 - higbest SES to 5 - lovest SES.

e Possible scores range from 0 - poorest health to 3 - best health.

I Posstble scores range from 1 = easy to do to 4 - unable to do. 
residents do have a higher mean income, the difference is not significant for either measure, total income or income remaining after payment of rent. Because the incomes are so low, the mean difference of $\$ 55$ per month seems a considerable amount. It should be recalled though that not one section 8 resident mentioned receiving the low rent paid for his apartment when asked about specific likes of the apartment or major difference relative to a sRo hotel. Additionally, only two (12 percent) apartment residents mentioned receiving a rent increase as an unfavorable aspect of their former hotel.

Yet another reason occasionally mentioned for considering a move is the search for companionship (Carp, 1966). A comparison of the mean number of years lived alone as a measure of isolation showed no statistical difference between the samples. Last, the difference between the samples on the mean number of years lived alone was not significant.

In summary then, the sociodemographic characteristics which best differentiate between the two samples are those which also reflect personal choices and life style decisions. Though education for many elderly persons was not a necessity and not always available, the opportunity usually existed for the continuation of interrupted schooling. Work experience is frequently related to education but not dependent upon it, particularly for those 
in the less specialized work force of the 1930s, 1940s, and 1950s. Personal decisions made relative to the type of jobs are reflected in the Hollingshead socio-economic status scale. The choice to marry or not to marry is also a life style descision. Only the death of a spouse and the resultant status of widower is not a choice, though the decision to either remarry or not is a personal choice. Characteristics which are beyond the parameter of personal choice and life style include age, health, and mobility.

Based on these initial findings, several of the significant sociodemographic characteristic variables were entered into a step-wise discriminant analysis in an effort to further differentiate between the hotel and apartment samples. The "sociodemographic" discriminant function shown in Table XVI is the result of that procedure. A function composed of the two variables, Hollingshead socio-economic status scale and marital status (married vs. never married), was constructed. The discriminant function was highly significant (lambda $\left.=.7114, \mathrm{x}^{2}=14.64, \mathrm{p}=.001\right)$ and explained 29 percent of the variance between the two samples; the SRO sample was characterized as having a higher socio-economic status and being never married, while the apartment sample tended to have a lower socio-economic status are were more likely to have been married at some time in the past. As shown in the table, the validity of the demographic function to correctly classify the two samples is not equal (see 
T A B L : $\quad X$ Y I

DESCRIPTION OP DISCRIMINANT ANALYSIS PUNCTIONS USED TO DIPPBRENTIATE

SRO HOTKL AND SECTION 8 APARTMENT RESIDENTS

\begin{tabular}{|c|c|c|c|c|c|c|c|c|c|c|}
\hline \multirow{2}{*}{$\begin{array}{l}\text { Discriminant } \\
\text { Punction Name }\end{array}$} & \multirow{2}{*}{$\begin{array}{l}\text { Component Variables } \\
\text { and Standardized } \\
\text { Discriminant Punction } \\
\text { Coefficients }\end{array}$} & & \multirow{2}{*}{$\begin{array}{l}\text { Number of } \\
\text { Cases: } \\
\text { SRO, } \\
\text { Section } 8 \\
\end{array}$} & \multirow{2}{*}{$\begin{array}{l}\text { Tilks' } \\
\text { Lambda }\end{array}$} & \multirow{2}{*}{$\begin{array}{l}\text { Ch1- } \\
\text { Syuare }\end{array}$} & \multirow{2}{*}{$\begin{array}{l}\text { Degrees } \\
\text { of } \\
\text { Freedom } \\
\end{array}$} & \multirow[b]{2}{*}{ S1gnificance } & \multicolumn{3}{|c|}{$\begin{array}{c}\text { Percent Correctly } \\
\text { Classified } \\
\end{array}$} \\
\hline & & & & & & & & $\begin{array}{l}\text { 2s } \\
\text { SRo }\end{array}$ & $\begin{array}{l}\text { as } \\
\text { Section } 8\end{array}$ & Total \\
\hline $\begin{array}{l}\text { Soc1o- } \\
\text { demographic }\end{array}$ & $\begin{array}{l}\text { Socto-economic status } \\
\text { Marital status a }\end{array}$ & $\begin{array}{r}-.9136 \\
.6902\end{array}$ & 29,17 & .7114 & 14.64 & 2 & .001 & 93.1 & 58.8 & 80.4 \\
\hline $\begin{array}{l}\text { Interaction } \\
\text { ith friends }\end{array}$ & $\begin{array}{l}\text { visit with friends } \\
\text { in person } \\
\text { visit with friends } \\
\text { on phone } \\
\text { See friends over } \\
\text { hol idays }\end{array}$ & $\begin{array}{r}-.0255 \\
.6740 \\
.6486\end{array}$ & 25,16 & .7861 & 9.02 & 3 & .029 & 76.0 & 68.8 & 73.2 \\
\hline $\begin{array}{l}\text { Life } \\
\text { Satisfaction }\end{array}$ & $\begin{array}{l}\text { Wore breaks in life } \\
\text { than others } \\
\text { Life could be happler } \\
\text { Change much of past } \\
\text { life } \\
\text { Got what expected } \\
\text { f rom life }\end{array}$ & $\begin{array}{r}-.7147 \\
-.6620 \\
-.3811 \\
-.2957\end{array}$ & 26,14 & .7073 & 12.47 & 4 & .014 & 84.6 & 71.4 & 80.0 \\
\hline $\begin{array}{l}\text { llealth } \\
\text { status }\end{array}$ & $\begin{array}{l}\text { Age } \\
\text { Mobility } \\
\text { Self-reported health }\end{array}$ & $\begin{array}{l}-.8211 \\
-.5553 \\
-.2680\end{array}$ & 30,16 & .9249 & 3.32 & $\mathbf{3}$ & .345 & 93.0 & 25.0 & 60.6 \\
\hline
\end{tabular}

Married vs, never married. 
Table XVI). Just over 90 percent of the hotel residents were correctly classified but only about 60 percent of the apartment residents were correctly classified. Overall, then, 80.4 percent of the total cases included in the analysis were correctly classified.

That a significant function was constructed from the sociodemographic characteristics which reflect personal choices and life style further confirms that such characteristics do differentiate between hotel and apartment residents. Additional evidence is the substantial portion of each sample which was correctly classified.

Interpersonal Interactions. A second set of variables which measure the level of interaction between the resident and his friends was also entered into a discriminant analysis. It was assumed that the pattern of interaction with friends was a result of personal decisions and life style and this should differentiate the hotel and apartment samples. Three variables were included in the analysis; 1) frequency of visiting with friends in person, 2) frequency of visiting with friends over the phone, and 3 ) whether the respondent visited friends over holidays.

The result of the analysis was a significant function with the largest coefficient differentiating the two samples on the basis of those who visited most often with friends in person and those who did so least. Coefficients for the other variables, visiting over the phone and during 
holidays, were smaller and approximately equal. In other words, the major contribution to the function was the frequency with which either hotel or apartment residents reported visiting with friends in person. The function indicated .that, on the average, hotel residents tend to interact more frequently with friends in person than do apartment residents. It also indicated that apartment residents are more likely to visit by phone or over holidays than hotel residents, but these variables contribute a lesser amount of the function. As with the sociodemographic function, this function correctly classified more hotel residents $(76.0$ percent) than apartment residents $(68.8$ percent), but overall correctly classified 73.2 percent of the cases included in the analysis. It explained 21 percent of the variance between the two samples (lambda=.7861, $\mathrm{x}^{2}=9.02, \mathrm{p}=.029$ ).

It is this difference in the mode of interaction with friends that suggests variations in personal choice and life style. It is not known how Section 8 residents interacted with friends when they were hotel residents but their current patterns of interaction can be differentiated from those of the percent hotel residents. If either sample was to be labeled "isolate," it would have to be the apartment residents based on their low rate of visiting with friends in person. But neither sample is composed of extreme isolates; each tends to interact in a special combination of 
in person, over the phone, and during holidays, and it is those combinations which are differentiated by the function. The choice to talk with friends in person suggests a preference for a more active, sociable surrounding whereas telephone or holiday visits suggests a preference for a more controlled environment with less intense interaction. The displeasure Section 8 residents reported regarding noise in their previous hotel and the appreciation of quiet and mostly elderly neighbors in their apartment environment is consistent with their preference for a less intense, more controlled environment.

Life Satisfaction. Another group of variables examined using a discriminant analysis were those of life satisfaction. Though the variables themselves do not represent specific personal choices, they do represent the resident's interpretation of a lifetime of decisions. The variables included in the analysis were part of a more extensive life satisfaction scale (Neugartern, Havighurst \& Tobin, 1961; Alexander, 1978) and were selected based on a maximum difference between means of the two samples. The resultant function was significant and explained 29 percent of the variance between the hotel and apartment residents ( lambda $\left.=.7073, x^{2}=12.47, p=.014\right)$.

of the four variables included in the analysis, two had major contributions to the function, whether or not the respondent thought he had gotten more breaks in life than 
most other people he knew and whether or not he thought his life could be happier than it was. The other two variables, whether or not the respondent would change much of his past life and whether or not he had gotten what he expected out of life, only contributed an additional 5 percent in explanation of variance but increased the percentage of Section 8 residents correctly classified by a substantial amount--31 percent.

In general, the current hotel resident's perception of his life is that even though he got more breaks than others, his life could be happier now. That, coupled with the perception that he got what he expected from life but would change much of the past, if he could, suggests an understanding of options which were available but were not taken. There is a note of regret at not having taken the options but resolution that the decisions made were personal choices. By contrast, the apartment residents were less likely to report a perception of having gotten more breaks in life than others or that they got what they expected from life. Their indication that life could not be much happier nor would they choose to change much of the past suggests a feeling of not having been able to achieve, that forces may have been beyond their control but now they are resolved to their current life. It is important to recall that most of the apartment residents were either widowers or divorced/separated and that their resolution to no happier 
life in part reflects their lingering sense of loss, even after many years of living alone.

It is interesting to note that these perceptions of life satisfaction bear a resemblance to Eckert's (1978) typology of hotel residents. The lifelong loner is most like the current hotel resident who understands that his decision directed his life and chose the unconventional life style. The retreatist and late isolate are more like the apartment residents who suggest resentment at the direction of their life course, a sense of forces working against them and beyond their control. In sum, then, these patterns of life satisfaction which represent the outcome of previous personal decisions distinguish between the hotel and apartment sample and provide another example of life style differences.

Health Eactors. In order to further verify that the Section 8 residents did not suffer from poor quality health and thus had an incentive to move to an apartment, a discriminant analysis using health related variables was carried out. The variables age, mobility, and self-rated health were entered into a step-wise analysis. The resultant function was not significant (lambda=.9249, $x^{2}=3.32$, $\mathrm{p}=.345)$. This meant that even in combination, these variables did not differentiate between hotel and apartment residents. It can therefore be concluded that health related reasons were most likely not a significant factor in 
encouraging the move to section 8 apartments.

To review, then, there are three sets of variables which differentiate between the SRO hotel sample and the Section 8 apartment sample and each set is reflective of variations in personal choice or life style of the residents. Those sociodemographic characteristics which are influenced by personal decisions, such as socio-economic and marital status, form a significant function when entered into a discriminant analysis. Those which are not influenced by personal decisions such as age, health, and mobility do not form a signficant function which differentiates between the two samples. The final set of variables examined were statements on life satisfaction. These variables represented a summary of the respondent's feelings about his life and they too formed a significant function. That these sets of variables came from diverse substantive areas only strengthens the proposition that hotel and apartment residents can be differentiated based on personal choice and life style factors.

\section{Conclusion}

It was the intent of this section to examine the relationship between preferences for housing and life style. As noted in Chapter II, the literature contains many references regarding why elderly persons move and how they attempt to match their personal needs with an appropriate setting through choice of a suitable environment. Phrases 
such as "person-situation congruence" and "seeking one's niche" are used to describe the housing choices made by elderly persons, especially when the decision appears to be other than optimal.

It has been this study's findings that the SRO hotel and Section 8 apartment samples have made different personal choices during their lives and that these choices are representative of their different life styles. More generally, the two samples tend to express concern over different matters related to housing and neighborhood, with the basis for those concerns centered on their personal values and priorities. Assessments of the same hotels and neighborhoods by the residents are substantially different. Their differing values and life styles lead to contrasting perceptions of the same situation.

The implication of these findings is that one form of low-rent housing is not the solution to the housing needs of all elderly persons. That some are satisfied with Section 8 apartments does not imply that all would be. In fact, this research found a general lack of interest in moving to the apartments on the part of hotel residents and of those who reported some level of interest, only one had actually taken some action to pursue such housing. The environmental conditions of hotel living more closely matched the life style of the hotel residents.

Based on the hotel residents' preference for hotel 
living, their adjustment to section 8 apartments would be questionable. The situation would be incongruous between the person and his environment; thus, dissatisfaction and maladjustment could be anticipated. Such a poor match could lead to dissatisfaction by other section 8 tenants depending on the nature of the maladjustment.

A reasonable alternative to providing only Section 8 apartments is the rehabilitation of existing SRO hotels into decent, safe, and sanitary housing. This could be done without altering the basic nature of the hotels and would provide improved housing conditions which were compatiole with the SRO life style.

A COMPARATIVE EXAMINATION OF THE COST OF LIVING FOR AN SRO HOTEL RESIDENT

The overall intent of this study is to examine the viability, of the SRo hotel as a form of housing for single, elderly males. To that end, this section addresses the second hypothesis which states that it is less expensive for a single room occupancy hotel resident to live downtown than to live outside downtown. The purpose for testing this hypothesis is based on the assumption that downtown, with its complement of inexpensive housing units, stores, and services, provides a match between the hotel resident's income and the cost of purchasing needed goods and services. The previous section established that residents who remainea 
in hotels tend to have a lifestyle which is distinguishable from that of those who chose to move to a subsidized apartment, and that preference for the two forms of housing is a reflection of their lifestyle differences. Based on these findings, and the fact that the existing stock of SRO hotels in central city areas across the nation is being diminished, this section examines the cost for the SRO hotel resident to maintain his puchasing habits and level of expenditures in and outside of downtown.

\section{Use of Neighborhoed Eacilities}

This section examines the SRO resident's use of selected facilities and notes that hotel residents tend to have a different pattern of usage than do some other elderly persons. Based on the different patterns of usage, a relationship is posited between lifestyle and facility use. It is suggested that variation in use is reflective of preferences and/or habits and that it is therefore essential to consider patterns of usage as a component of an analysis of cost of living.

The literature review noted that there have been a number of studies which examined the elderly person's use of neighborhood facilities. Among those studies, Ehrlich's (1976) is unique in that it compares an SRO and non-SRO sample on usage; specifically, it compares her St. Louis SRO hotel residents' facility usage with that of Newcomer's (1973) public housing residents. From Table XVII it can be 
T A B L E X V I I

COMPARISON OP PACILITY USAGB GY SRO AND MON-SRO GIDBELT

\begin{tabular}{|c|c|c|c|c|c|c|}
\hline \multirow[b]{2}{*}{ Pacility } & \multicolumn{2}{|c|}{$\begin{array}{l}\text { Percent of Sample } \\
\text { Who Use Facility } \\
\end{array}$} & Portland sRo Sample & iample & \multicolumn{2}{|c|}{$\begin{array}{l}\text { Portland Section } 8 \text { Sample } \\
(N=17)\end{array}$} \\
\hline & $\begin{array}{l}\text { SRo } \\
\text { Sample a } \\
(N=111)\end{array}$ & $\begin{array}{l}\text { Public Housing } \\
\text { Sample b } \\
(N=575)\end{array}$ & $\begin{array}{l}\text { Percent } \\
\text { Who Use } \\
\text { Fectilty }\end{array}$ & $\begin{array}{l}\text { Median } \\
\text { Rate of } \\
\text { Use }\end{array}$ & $\begin{array}{l}\text { Percent } \\
\text { who Use } \\
\text { Facility }\end{array}$ & $\begin{array}{l}\text { Median } \\
\text { Rate of } \\
\text { Use } \\
\end{array}$ \\
\hline Restaurant & 83 & 31 & 100 & at least once per day & 88 & once per week \\
\hline $\begin{array}{l}\text { Small grocery } \\
\text { store }\end{array}$ & - & - & 97 & several times per week & 94 & several t1mes per meek \\
\hline Supermarket & - & - & 77 & once per week & 82 & once per week \\
\hline Food market & 64 & 94 & - & - & - & - \\
\hline Bar & 35 & 10 & 63 & several times per week & 59 & several times per week \\
\hline Barber & 75 & Na $\mathrm{C}$ & 90 & once per month & 100 & once per month \\
\hline Drug store & 71 & NA & 83 & once per month & 100 & once per month \\
\hline Cleaners & 62 & 65 & 77 & once per month & 53 & once per month \\
\hline Benk & 60 & 100 & 83 & once per month & 94 & once per month \\
\hline Church & 38 & 80 & 23 & several tlmes per year & 47 & once per week \\
\hline Bus & 59 & 71 & $80^{d}$ & several times per month & 71 & several times per month \\
\hline $\operatorname{Tax} 1$ & 34 & NA & 73 & several times per year & $\mathbf{5 3}$ & several times per year \\
\hline
\end{tabular}

a Interpolation of Ehrlich's (1976) original data, p. 17.

b Interpolation of Ehrlich's (1976) data, p. 17 which was taken from Newcomer (1973).

c Not avallable.

d Th1s 18 use of the fared bus rather than the downtown "fareless" bus. 
seen that the hotel residents were much more frequent users of restaurants (a difference of 52 percent), slightly more frequent users of bars (a difference on 25 percent), about equal on use of cleaners (a difference of 3 percent), slightly less use of a bus (a difference of 12 percent), and considerably less use of churches, banks, and food markets (a difference of 42,34 , and 30 percent, respectively).

In comparing Ehrlich's hotel residents' usage of facilities with those of the present study sample of hotel residents, some patterns emerge. Both samples of hotel residents report high use of resturants ( 83 and 100 percent, respectively) and less use of food markets $(64$ and 77 , respectively). 2 This is the reverse of the public housing sample, which reports high use of food markets (94 percent) and much lower use of restaurants ( 31 percent). Given that virtually all the public housing residents had cooking facilities, and SRO's don't, this pattern is no doubt reflective of the availability or unavailability of cooking facilities in the different types of housing units. But there are at least two other factors which might influence these different usage patterns. Level of income could have a considerable impact on the frequency of purchasing food in restaurants as could personal preferences for eating in restaurants rather than at home. and most likely alone.

\footnotetext{
2Small grocery stores are used by 97 percent of this study's sample.
} 
Gionet (1978) noted that as income increased, lower income elderly also increased their expenditure for food. And Carp (1976b) noted that of the elderly residents living in Victoria Plaza, not all were interested in having individual cooking facilities. Presumably this meant they took or preferred to take their meals in restaurants or some other type of congregate dining facility.

Examination of the level of use of several other facilities provides additional support that elderly hotel and public housing residents have different patterns of facility usage. Their use of church is the most dramatic example of this difference; hotel residents in both St. Louis and the present study had quite low usage rates (38 and 23 percent, respectively). By comparison, the public housing sample had a rather high usage rate ( 80 percent). Though there was a difference in usage rates between the two hotel samples, both were more frequent users of bars than was the public housing sample. Thirty-five percent of Newcomer's sample reported use of a bar. Taken together, the SRO's more frequent use of a bar and their less frequent attendance at church suggests what might be interpreted as a more secular orientation to life.

Another facility which shows a similar pattern for hotel residents is use of a bank. All public housing residents reported use of a bank but 66 percent of Ehrlich's sample and 83 percent of the Portland sample reported such 
usage. In lieu of a bank, some hotel residents would keep large sums of cash in their rooms or use a local merchant for any "banking" needs such as cashing checks or holding money in a secure place. These different usage rates also suggest a slightly different approach to caring for one's needs.

Two facilities or services which show a different pattern of usage for hotel residents are cleaners and buses. As noted earlier, the St. Louis SRO sample and the public housing sample had nearly identical use rates for cleaners (62 and 65 percent, respectively) but the Portland SRO sample had a higher use rate $(77$ percent). For use of buses, the St. Louis sample had the lowest rate (50 percent) and the public housing sample was slightly higher $(71$ percent). Again, the Portland SRO sample had a higher use rate ( 80 percent). These differences between SRO hotel samples are not seen as too great, especially in light of the fact that except for use of churches, the Portland sample reported higher rates of use for all types of facilities than did the St. Louis sample. The reason for noting this difference is that in some cases the Portland SRO sample also exceeds the usage levels of the public housing sample. It is possible that this difference is due to the manner in which Ehrlich reported level of use of facilities in her study. From a reading of her article, it appears that the usage rates reported are for use of facilities within a particular 
distance from the place of residence. If this were the case, it is presumed that the rate of use would be somewhat lower based on findings that usage drops off as distance from residence increases (Lawton, 1977).

It is interesting to note that previous hotel residents who chose to move to Section 8 apartments in the downtown are still rather frequent users of restaurants. Eighty-eight percent of the sample reported eating in restaurants an average of about once per week. This was substantialiy less than the present hotel residents who, on the average, made daily use of restaurants but still considerably more frequent than the 31 percent usage by the public housing sample. A probable explanation for this level of restaurant use, despite the fact that each has a complete kitchen, may be that the pattern or habit of eating in restaurants is more than a necessity, i.e., that it has some intrinsic values to the elderly person such as opportunity for socialization or to escape their own cooking. On the whole, the Section 8 residents are not more frequent visitors to supermarkets or grocery stores, but it is presumed that they purchase substantially more during each visit than do the hotel residents.

Another interesting comparison between previous and present hotel residents is the use of bars and churches. The percentage of hotel residents who use a bar is only slightly greater than the percentage of Section 8 residents, but the 
frequency of visits is different. Hotel residents make an average of several trips per week to a bar, whereas Section 8 residents only visit a bar an average of several times per month. As for church attendance, the Section 8 residents who attend church ( 47 percent) do so on an average of once per week. The 23 percent of the hotel residents who attend church do so only several times per year, on the average.

It appears that the previous hotel residents tend to have a pattern of facility usage which might be characterized as reflecting some combination of the current hotel and the public housing residents. The number who use facilities such as restaurants and bars is similar to the current residents, but their frequency of use is lower and thus more similar to the lower usage rates of the public housing residents. Their use of churches is more like that of the public housing residents than the current hotel residents.

Based on these differing patterns of use of neighborhood facilities, it appears that hotel residents have a usage rate which complements their lifestyle. This is important in that it suggests that the mix of stores and services which are utilized and perceived as necessary by one elderly population may be different for another elderly population. Lawton would say that the functional resource environment or all the facilities used by a person and the salient resource environment or the level of importance of 
those facilities used tend to vary along with variations in lifestyle (Lawton, 1980). These differences in usage rates, even between low-income elderly populations, confirmed the decision to develop a special SRO market basket and provided guidance in its construction.

Cost of Living for SRO Hotel Residents

The SRO Market Basket. Though the chapter on methodology (Chapter III) contains a detailed description of the development of the survey instrument and market basket, some additional discussion is provided here. It should be recalled that the cost of living survey was the schedule of items for which price information was gathered in the four neighborhoods. The SRO market basket represented the typical monthly expenditure pattern of an SRO hotel resident and was constructed by assigning weights to each item in the survey which approximated the proportion of that item purchased during one month, i.e., three quarts of milk, one-half a jar of instant coffee, etc.

As the previous section noted, hotel residents tend to have a pattern of facility use (consumption) which is characteristic of that elderly population; in particular, they are frequent users of restaurants and less frequent users of grocery stores. But frequency of use, as shown in Table XVII, does not provide the complete picture of facility usage, especially where actual living costs are to be calculated. It is possible that a facility may be visited 
frequently but that purchases are made infrequently. An example is the use of a department store. Hotel residents interviewed for this study noted that they sometimes passed through a department store just to see what was available. In essence, some department store visits were a form of entertainment, a way of passing the time.

For this reason, the expenditure diaries kept by several hotel residents were used to identify any discrepancies between the frequency of use and the level of actual purchases at a particular type of facility. The three residents ${ }^{3}$ who successfully completed a monthly expenditure record represented a range of hotel lifestyles; one was a reformed alcoholic who took all his meals in restaurants and another was a drinker who had the opportunity to prepare some of his meals in the hotel's community kitchen. The third was a modest drinker who took all his meals in restaurants and found it necessary to withdraw at least some money from savings each month in order to cover his purchases. This information, then, provided a guide to the proportion of income a typical hotel resident spent on various goods and services.

The average percentage of monthly income spent by the three residents on the various goods and services was as follows :

Food away from home (restaurant)

3This is 10 percent of the SRO hotel sample. 
Food at home (grocery and supermarket) 12.58

Alcohol (at home and away) 10.38

Personal care (haircut, variety, cleaning, etc.) 3.48

Transportation (bus and taxi) 0.88

Entertainment (movies, money spent on others, including food and drinks, etc.) 5.28

Other (tobacco, phone calls, etc.)

Rent

Total

Because the level of expenditure for certain goods and services such as entertainment tends to vary with income (Goldstein, 1960) and the total monthly income of the hotel resident sample showed a considerable range, these pexcentages were used as a guide rather than as an absolute in assigning appropriate quantity weights.

As noted in the methodology chapter, the quantity weights for the SRO market basket were a product of multiple data sources, including verification by a county health nurse that the food quantities constituted an approximation of the typical SRO diet.

The cest cemparisons. Though the cost of living survey gathered information on the cost of housing in the four neighborhoods, that information was not included as part of the SRO market basket. Instead, the SRO market basket is composed of the non-housing costs a hotel resident is most likely to encounter during the average month. Housing costs are discussed in this section but are done so separately. The purpose for this separation is to enable costs to be assessed, in the various neighborhoods, without the factor of housing cost as an influence. This is important because 
it was presumed that both housing and non-housing costs outside the downtown area would be higher. By controlling for housing costs (or excluding them from the market basket analysis), it is possible to assess the differential for non-housing costs.

The SRQ Market Basket. The total monthly cost of the non-housing SRO market basket and its component categories for each of the four neighborhoods surveyed are shown in Figure 4. Monthly costs for the six basic categories of non-housing goods and services (food away from home, food at home, alcohol, tobacco, personal care and services, and transportation) in Downtown totalled $\$ 151.94$. That same market basket cost more in the other neighborhoods, i.e., $\$ 203.21$ in Irvington, $\$ 198.98$ in Hollywood, and $\$ 208.39$ in Russellville.

The largest portion of that total was comprised of the cost for food away from home. For Downtown, restaurant meals were 57.8 percent of the total market basket cost $(\$ 87.89$ / $\$ 151.94 \times 100)$, while they were $66.8,67.8$, and 66.5 percent, respectively, for Irvington, Hollywood, and Russellville. The costs for food at home (groceries) and alcohol were roughly the same for all four neighborhoods and were also considerably less than food away from home; they were about 10.0 to 15.5 percent of the total costs, depending on the neighborhood. The categories of tobacco and personal care and services were also similar in cost in the 


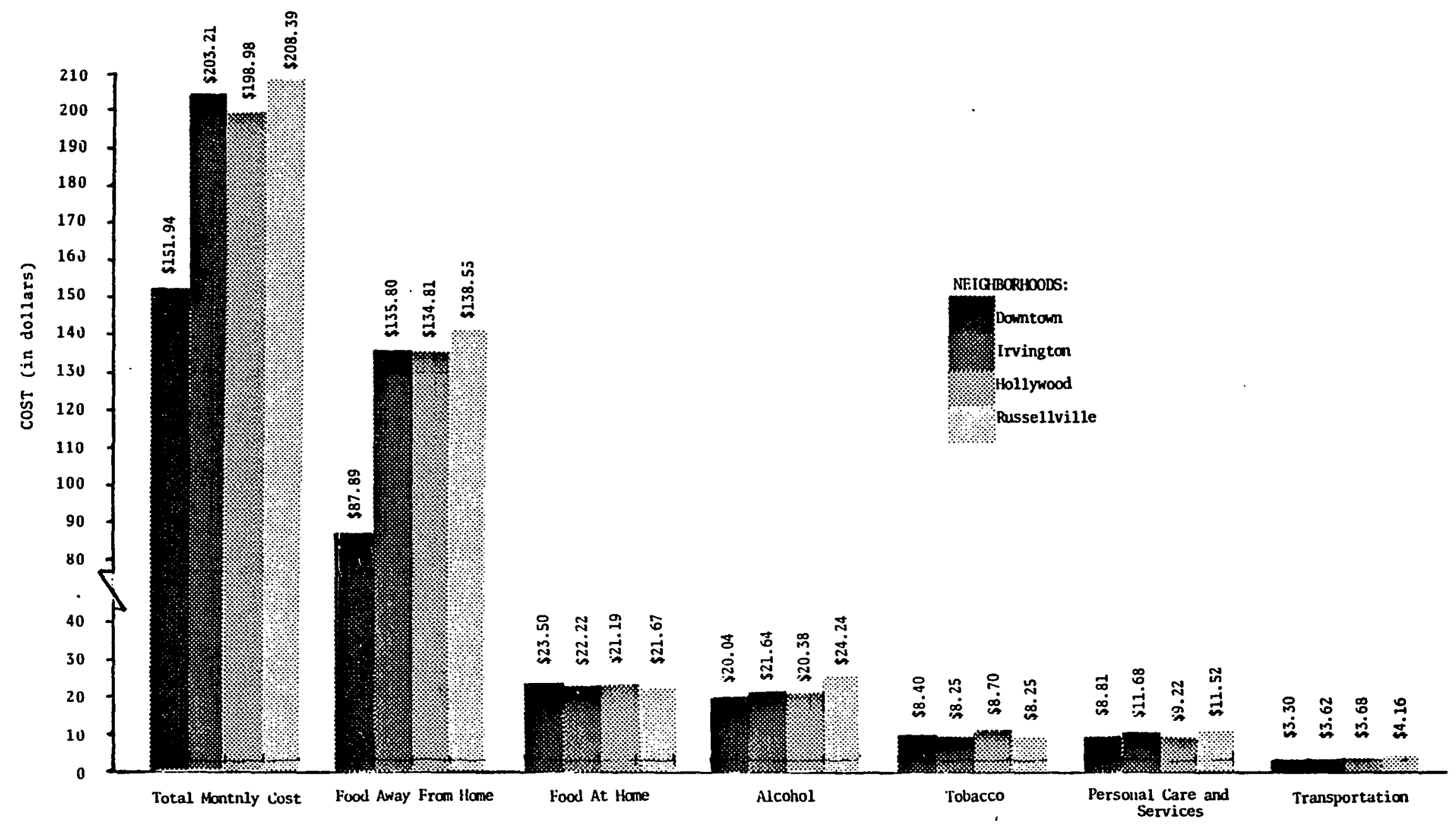

Figure 4. Cost of goods and services, which comprise the SRO Market Basket, in four neighborhoods. 
four neighborhoods and were each about half the cost of food at home or alcohol, i.e., between 4.0 and 5.8 percent of the total market basket cost. Transportation constituted the lowest percentage of the total cost of the complete market basket.

In order to interpret the potential impact of these findings, the costs for the total market basket and its component categories for each neighborhood are compared with those for Downtown. In other words, the cost for each category of good or service in Downtown is subtracted from the cost in each of the other neighborhoods and the resultant "differential" values are displayed in a bar chart (see Figure 5). Those costs which are greater than in Downtown are charted above the baseline and those costs which are less are charted below the baseline. This provides direct comparison of the cost of non-housing goods and services in Downtown and the other three neighborhoods. The purpose for such an analysis is based on the premise that Downtown is the least expensive place to purchase the SRO market basket. The implication is that hotel residents, who are forced to leave their downtown hotel, are almost certainly bound to experience an increase in the cost of non-housing goods and services they are accustomed to purchasing if they relocate outside Downtown.

As can be seen, the differential in total monthly costs for the SRO market basket is relatively similar for 


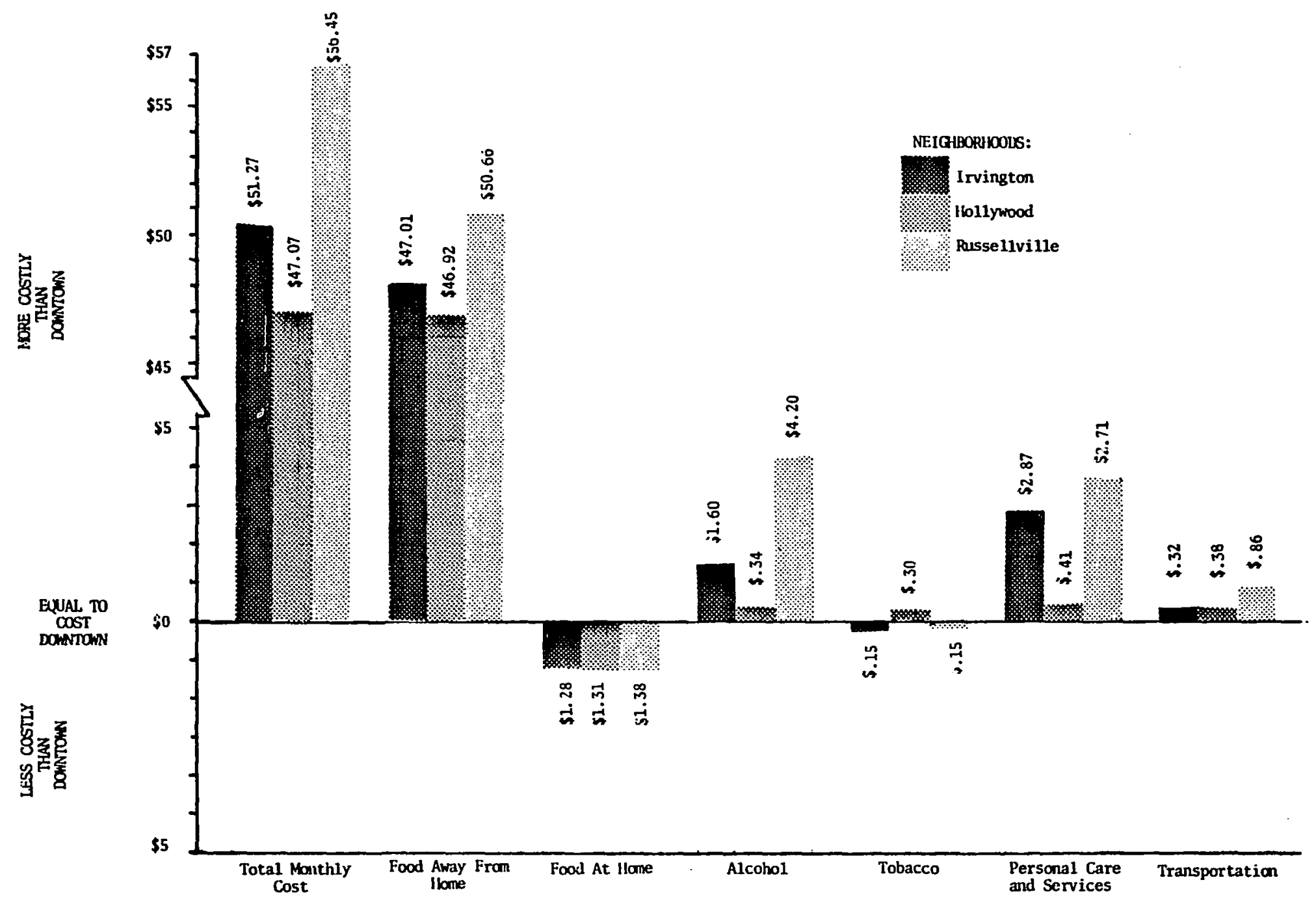

Figure 5. Comparison of cost of goods and services, which comprise the sRo Market Basket, using Downtown as the baseline. 
each of the three neighborhoods. The greatest difference is between Downtown and Russellville (\$56.105) and that is followed by Irvington $(\$ 51.27)$. Hollywood had the smallest differential $(\$ 107.04)$ but it was still a substantial amount.

The major contributor to these differentials is the cost of food away from home. Downtown has a greater number of restaurants within the surveyed area than do the other neighborhoods 4 and the price of meals at these restaurants is substantially lower than in other neighborhoods. The differential in the cost of food away from home accounts for 99.7 percent of the difference in the market basket cost in Hollywood, 93.4 percent of the difference in Irvington, and 89.7 percent of the difference in Russellville.

Food at home is the only categor in which it is more expensive to purchase items in Downtown than in the other three neighborhoods. The differential, however, is quite small, i.e., less than $\$ 2.00$ per month in each neighborhood. The cost of alcohol in Downtown is slightly less than in the other neighborhoods, but again the differential is quite small. Alcohol by the drink is the primary source of the difference, as Downtown has a number of inexpensive bars and

4In the surveyed areas, Downtown had 18 restaurants, Irvington had four, Hollywood had $f$ ive, and Russellville had five. A casual survey of each neighborhood indicates the number of restaurants within the surveyed areas is quite representative of the neighborhood as a whole, i.e., the surveyed area is neither over nor under-represented with restaurants. 
taverns. For all intents and purposes, the cost of tobacco is nearly identical in the four neighborhoods; the monthly expenditure for cigarettes is $\$ .15$ less in two neighborhoods and $\$ .30$ more in the other. Personal care items and services are all more expensive in the neighborhoods outside downtown. Both the Downtown and Hollywood neighborhoods have a barber college and thus have the most similar costs, whereas the other neighborhoods have no similar facility. For this reason, Hollywood is only. slightly more expensive than Downtown for personal items, while the others are a bit more costly. Additionally, Russellville has no dry cleaning facilities within the area surveyed. In order to calculate an average cost, the mean value of the other three neighborhoods was assigned to Russellville. It is expected the differential would be slightly higher due to the need to include travel costs to and from the cleaners. The differential in the cost of transportation is less than $\$ 1.00$ per month more in the neighborhoods outside Downtown, but increases with the distance from low-cost medical services at the Veterans Administration or medical school hospitals which are located near Downtown. Taken together, the portion of the total differential accounted for by these five categories of goods and services is only 0.3 percent for Hollywood, 6.4 percent for Irvington, and 10.3 percent for Russellville.

These findings indicate that given the sRo lifestyle 
and purchasing patterns, it would cost substantially more for a hotel resident to live outside downtown in any one of the other three neighborhoods surveyed. It should be recalled at this point that these three neighborhoods were each identified by the housing authority as good locations for elderly persons to live based on the availability of certain types of stores and services. They are not unduly expensive neighborhoods nor are they void of basic services. This suggests that in order to maintain a pattern of expenditures which a hotel resident could afford in Downtown, it would be necessary to substantially alter his consumption behavior. Primarily, this would mean reducing restaurant use and increasing grocery store use, which presumably would mean having a kitchen and doing at least some cooking. This change would be absolutely essential if other non-food purchases were to remain at the same or even a slightly reduced level. Thus, the SRO hotel in Downtown offers its elderly residents proximity to inexpensive non-housing goods and services which provide the basic necessities of urban living and the option to continue with what has become, to the resident, a familiar lifestyle.

The Monthly cost of Housing. With the goal of providing a more complete picture of the actual cost of living for an SRO hotel resident, this section examines the monthly cost of housing. Each of the four neighborhoods were surveyed for three types of unsubsidized, yet inexpensive, 
housing, i.e., SRO hotel type rooms, housekeeping rooms, and efficiency apartments (see Figure 6 ). Downtown and Hollywood were the only neighborhoods which had all three types of housing. Irvington had efficiency apartments but no SRO hotel type rooms or housekeeping units and Russellville had no units smaller than one-bedroom apartments.

For SRO hotel type rooms, Hollywood had a slightly lower average monthly rent than did Downtown. The average rent in Hollywood was $\$ 70.00$ and in Downtown it was $\$ 73.63$. What these figures seem to suggest is that a SRO hotel resident could rent the same type of unit he has Downtown for $\$ 3.63$ ( 4.9 percent) less per month, on the average. However, that interpretation is misleading in that only one building in Hollywood contained SRO type units and of the 16 units in the building only two were SRO or sleeping rooms. 5 Two units could hardly be described as a housing resource for hotel residents who wanted to move outside downtown.

For housekeeping units, again Hollywood's were slightly cheaper, on the average, than were similar units in Downtown. The difference was $\$ 14.45$ per month with the units in Hollywood renting for an average of $\$ 80.00$ per month and

5 There is little reason to assume that the number of each type of unit per neighborhood counted in the survey is not at least approximately representative of other portions of the neighborhood. It was noted in a previous section that the majority of SRO hotel type units in any particular city are generally located within the central portion of the city. Therefore, it is not surprising that few SRO type rooms were found outside the downtown area. 


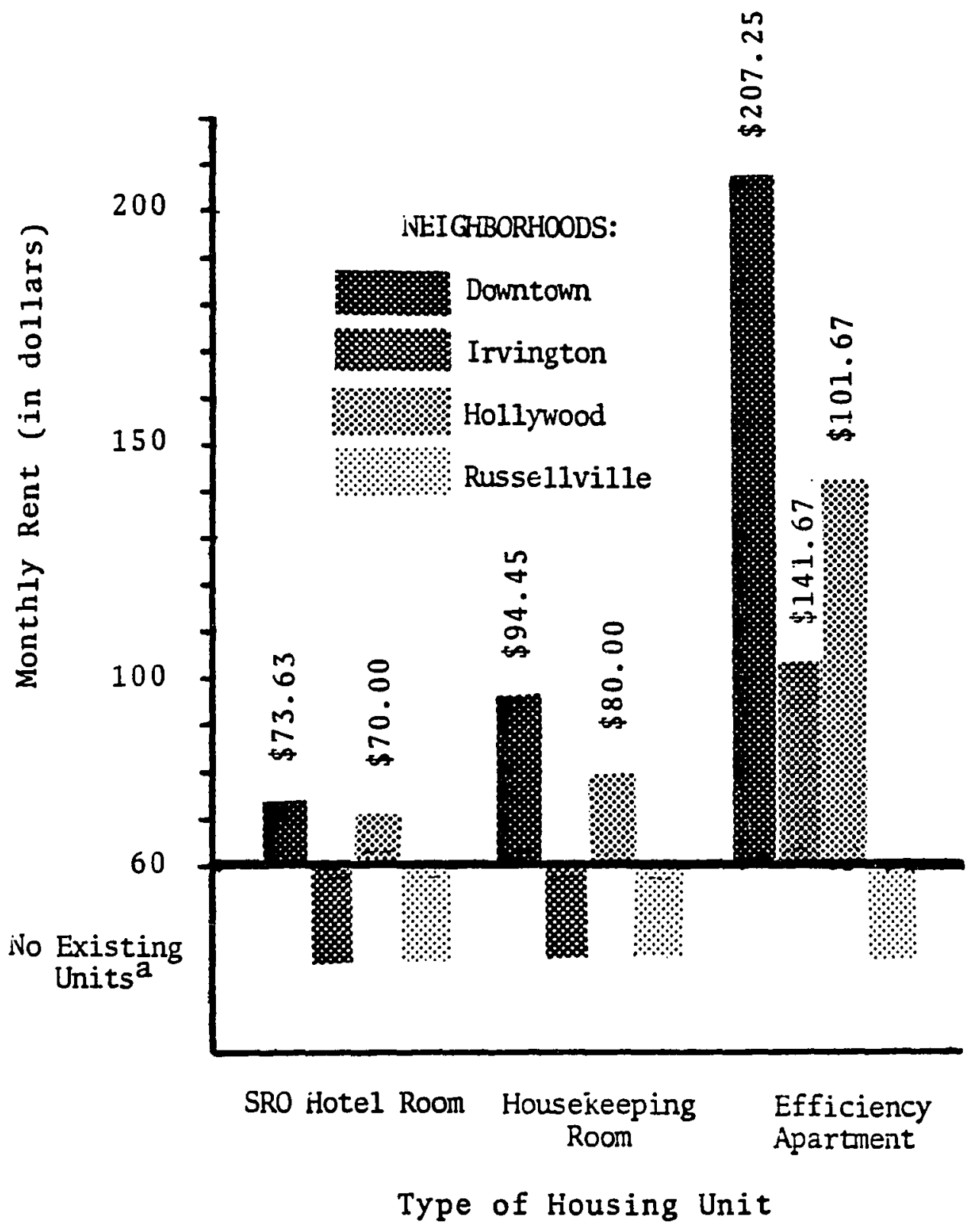

Figure 6. Cost of selected types of housing units in four neiglaborhoods.

anenotes that no housing units of that type existed in the neighbornood area surveyed. 
those in Downtown costing an average of $\$ 94.45$. But once more, the number of existing units is a matter of consideration. One building in Hollywood had one housekeeping unit while two buildings in Downtown had 94 such units. As with sRO type units, one housekeeping unit in a 49 block area does not constitute a housing resource. 'It would cost an additional $\$ 20.82$, or be a rent increase of 28.3 percent, on the average, for a hotel resident to change from living in a Downtown SRO hotel to a Downtown housekeeping unit. The change from a Downtown SRO hotel to a Hollywood housekeeping unit, if one could be located, would, on the average, cost $\$ 6.37$ more or be a rent increase of 8.7 percent.

For efficiency apartments, Downtown's units were the most expensive followed by Hollywood's and the Irvington's. Again, Russellville had no efficiency apartments in the survey area. The average monthly rent in the Downtown neighborhood was $\$ 207.25$, while the cost of apartments in Hollywood and Irvington was $\$ 141.67$ and $\$ 101.67$, respectively. In all cases, the rent for an efficiency apartment represents a considerable increase over the cost of a Downtown SRO hotel. The difference in average monthly rent for the two types of housing in Downtown is $\$ 133.62$ and would be equivalent to a 181.5 percent raise in rent. The increase would be somewhat less for an efficiency appartment in Hollywood or Irvington. The increased average cost to a 
Downtown hotel resident would be $\$ 68.04$ or 92.4 percent rent raise for a unit in Hollywood, and in Irvington neighborhood the average increase would be $\$ 28.04$ or a 38.1 percent raise in rent. Such increases are beyond the modest budgets of most SRO hotel residents.

These findings suggest that, based on the actual rents for the three types of housing and the number of existing units in the four neighborhoods surveyed, Downtown SRO hotels provide the least expensive housing that exists in sufficient quantity to consider it a housing resource. In other words, though an SRO type room in Hollywood was slightly less expensive than the average Downtown SRO hotel room, the survey indicated there were so few units in Hollywood that to emphasize their lower rent in a discussion of housing policies would be ludicrous.

\section{Conclusion}

The hypothesis discussed in this section presumed that the elderly, male SRO hotel resident's lifestyle and consumption pattern was an inexpensive and efficient means of providing for his basic needs. As evidence to support this proposition, the previous section noted that SRO hotel residents tend to have a lifestyle which differs from other elderly populations.

Based on these findings and the knowledge that the number of SRO hotels in most central cities is being reduced, the cost of a typical SRO market basket was 
calculated for four neighborhoods in which elderly persons might live. For non-housing goods and services and housing itself, Downtown was shown to be the least expensive neighborhood. In addition to being the least expensive of the four neighborhoods, Downtown was found to be a resource rich environment containing more of the facilities which SRO hotel residents use such as inexpensive restaurants and bars. The presence of a variety of proximate facilities from which to purchase inexpensive goods and services allows the low-income SRO hotel resident to satisfy his personal needs given his financial constraints.

To presume that an SRO hotel resident could reduce his cost of living by securing a housing unit with cooking facilities is to presume that the hotel residents can and would be interested in preparing his own meals. It is maintained in this study that certainly some hotel residents do make the change from SRO hotel to apartment living (witness the Section 8 residents in this study), but that there are a substantial number who are not interested in that type of change (witness the hotel residents who indicated little or no interest in moving to section 8 apartments and Carp's (1976b) 11 percent who reported no interest in having a kitchen). On the one hand, to achieve the goal of having more money to spend on non-food items, the SRO hotel resident would need to secure housing with accessible cooking facilities, purchase at least some 
cooking utensils, and plan to prepare nearly all meals at home. He might also need to learn to cook. In making such a shift, it would be necessary for the resident not to overspend on housing what might be saved by eating at home. A subsidized housing unit would be less expensive than a unit on the open market and would thus assure a low housing cost. On the other hand, the SRO hotel resident could attempt to remain in a hotel in the downtown area as long as units were available and to avoid the need to change his lifestyle or pattern of consumption. The latter option does not alter the resident's current way of life and this is a circumstance which many elderly persons seek as they grow older and find adjustment to new circumstances difficult. Additionally, the presumption that residents displaced from central city areas as the stock of SRO hotels is depleted could seek housing on the open market, with kitchen, and thus maintain themselves on their present incomes begs the question of whether there is sufficient housing near needed stores and services which the displaced residents could afford. The results of the survey of the three neighborhoods outside the central city area suggest there are few units in those locations which are as inexpensive, on a per month basis, as an SRO hotel room. With this condition as a given, it is likely that as 'SRO hotels are removed from the low-cost housing stock, more and more hotel residents will choose Section 8 units as their 
alternative housing, not because they want or need the amenities which the apartments offer, but because there will be few other housing units which they can afford. This will place an increased demand on the already too few existing subsidized units. In this way, the loss of SRO hotels may force residents, who currently maintain themselves without the assistance of rent subsidization, i.e., they pay their own way, to seek financial assistance for rent, food, or other goods.

\section{A COMPARATIVE EXAMINATION OF THE COST OF} SECTION 8 APARTMENTS AND SRO HOTELS

This section of the study findings examines the third and final hypothesis. That hypothesis states that it is less expensive to maintain and rehabilitate SRO hotels than to provide other modes of housing for at least a portion of the low-income urban elderly population. As the creation of Section 8 apartments is the primary means, at this time, of providing low-cost housing for the elderly, it is used as a comparative mode. The purpose for testing the hypothesis is based on several assumptions; first, that it is generally less expensive to rehabilitate existing buildings than to construct new ones, and second, that it is less expensive to produce housing with shared bathrooms and kitchen facilities than to produce housing with self-contained units. The reasonableness of examining such a hypothesis is based on 
the findings from the two previous hypotheses. The first determined that there is an identifiable component of low-income urban elderly persons that select SRO hotels as their form of housing over rent-subsidized section 8 apartments. The second determined that the SRO life style and pattern of consumption is least expensive, when centered in the downtown area. Given confirmation of this third hypothesis, the decision of policy makers and implementors to ignore SRo hotels as a form of housing for at least a portion of the low-income elderly is to scorn an alternative which could provide more persons with better housing for fewer dollars.

A Comparison of the Actual Cests to Operate and Mainitain, Rehabilitate, and construct Section 8 Apartments and SRO Hetels

As noted earlier, the cost of housing depends on the perspective from which one makes the assessment. Cost from the renter's perspective is substantially different than cost from the owner's perspective. In this section the actual costs are examined, i.e., those costs which are incurred, from the perspective of the owner, for the production and regular operation of a multifamily housing structure. More specifically, actual costs are defined, for the purpose of this study, as including all expenses incurred in a building's normal operation and maintenance. Additionally, actual costs include the expense of producing 
the housing units either through rehabilitation of an existing structure or new construction. Taken together, these expenses cover the bounds of housing costs.

Because interest rates and inflation have had a major influence on housing costs in recent years, an effort has been made to account for that variability. For the purpose of comparison, the housing structures have been grouped into "age" categories and all cost figures have been adjusted to 1981 constant dollars. Furthermore, the type of building, i.e., rehabilitated or newly constructed, was used in the classification scheme. Based on these considerations, the categories or "circumstance" used in the analysis of section 8 apartments are: a) existing buildings which were rehabilitated and were in operation by 1978 , b) existing buildings which have been rehabilitated since 1979 or are proposed to be in the near future, and c) buildings constructed since 1979 or those proposed to be in the near future. The categories used to classify SRO hotels are quite similar but some variation does exist and it is pointed out where appropriate.

It should also be noted that some of the buildings considered in this analysis are still in the planning stages. The information on cost of operation, maintenance, debt service, construction, and the like was taken from loan applications which have or may be submitted for final approval. The inclusion of these buildings was deemed 
appropriate because they provide the most up-to-date expectation of costs and expand the breadth of the analysis by adding additional cases.

operation and Maintenance Costs. The annual per unit cost to operate and maintain a Section 8 apartment is higher than to operate and maintain an SRO hotel for all the circumstances considered (see Table XVIII and XIX). For Section 8 apartments rehabilitated in 1978 or earlier, the annual cost of operation and maintenance per unit ranged from $\$ 2,700$ to $\$ 4,100$ in 1981. A similar cost figure for SRO hotels rehabilitated during that time period was not available. However, information was available on the operation and maintenance costs from the perspective of the lessee. For SRO hotels which had had no rehabilitation work, the operation and maintenance costs ranged from $\$ 600$ to $\$ 1,000$ per unit annually. For a hotel which had received a modest amount of rehabilitation work, the same costs were about $\$ 1,000$ per unit. Direct comparison of costs from the owner and lessee's perspective is difficult because of their differing view of costs. Generally, the lessee pays a fixed amount of rent which covers the owner's costs for such expenses as utilities, taxes, insurance, and debt service. Because the basic purpose of rent is to cover costs incurred by the owner, it is presumed that the $\$ 1,000$ for the rehabilitated units includes sufficient rent to cover the owner's costs. Based on that premise, even a very 
T A B L E X V I I I

THE COBTS TO OPBRATE AHD MAINTAIF, RERABILITATB,

AND CONSTROCT SBCTION 8 APARTMBNTS

(1n 1981 constent dollars)

\begin{tabular}{|c|c|c|c|}
\hline Circumstance & $\begin{array}{l}\text { Operation and } \\
\text { Maintenaacea } \\
\text { (1n dollars/ } \\
\text { untt/year) }\end{array}$ & $\begin{array}{l}\text { Rehabilitation b } \\
\text { (ia dollars/unit) }\end{array}$ & $\begin{array}{l}\text { New Construction b } \\
\text { (in dollars/unit) }\end{array}$ \\
\hline \multicolumn{4}{|l|}{ Owner's perspective } \\
\hline $\begin{array}{l}\text { Existing buildings } \\
\text { which were re- } \\
\text { habilitated and } \\
\text { in operation by } \\
1978 \\
(N=3): c\end{array}$ & $\$ 2,700$ to $\$ 4,100$ & $\$ 14,900$ to $\$ 24,400$ & - \\
\hline $\begin{array}{l}\text { Existing butldings } \\
\text { whlch have been } \\
\text { rehab1litated } \\
\text { slnce 1979 or are } \\
\text { proposed to be 1n } \\
\text { the near future } \\
(\mathrm{N}=3) \text { : }\end{array}$ & $\$ 4,300$ to $\$ 5,200$ & $\$ 28,500$ to $\$ 39,600$ & -- \\
\hline $\begin{array}{l}\text { Buildings construct } \\
\text { since } 1979 \text { or tho } \\
\text { proposed to be in } \\
\text { the near future } \\
(\mathrm{N}=2): \text { d }\end{array}$ & $\$ 4,400$ to $\$ 6,300$ & -- & $\$ 44,500$ to $\$ 48,500$ \\
\hline
\end{tabular}

ancludes utilities, management, payroll, malatenance, 1nsurance, taxes, replacement reserves, and debt service for entire building.

b Includes the construction costs, fees, financing, and developer's profit. No land or site costs are included.

c Information Irom the Area Offlce, Department of Housing and Urban Development, Portland, Oregon.

d Information Irom the Housing Divigion, State of Oregon. Based on units of 450 to 550 square feet. 
T A B L E X I X

THB COSTS TO OPBRATE AND MAINTAIN, REAABILITATB, AND CONSTRUCT NET SRO HOTRLS

(10 1981 constant dollars)

\begin{tabular}{|c|c|c|c|}
\hline Circumstance & $\begin{array}{l}\text { Operation and } \\
\text { Maintenance } \\
\text { (1n dollars/ } \\
\text { unit/year) }\end{array}$ & $\begin{array}{l}\text { Rehabilitation b } \\
\text { (indollars/unit) }\end{array}$ & $\begin{array}{l}\text { New Construction b } \\
\text { (1n dollars/unit) }\end{array}$ \\
\hline
\end{tabular}

\section{Owner's perspective}

Existing hotels with rehabilitation work since 1979

$$
(N=1): C
$$

$\$ 6,600$

Existing hotels to. be rehabilitated assuming approval of SRO Demonstration Project

Hypothetical newly constructed hotel $(N=1)$ :

Lessee's perspective Existing hotels with
no rehabilitation work $(V=6)$ e

$\$ 600$ to $\$ 1,000$

Existing hotels with rehabilitation work in 1978 or earlier $(N=1)$

$\$ 1,000 \mathrm{f}$

a Depends on whose perspective is considered. For the owner it includes utilities, management, payroll, malatenance, insurance, taxes, replacement reserves, and debt service for the entire bullding. For the lessee it includes only those costs incurred by the lessee, 1.e., those costs for the residential portion of the building wich are deftned in the lease agreement.

b Includes construction costs, fees, financing, and developer's profit. Land or site costs are not included.

c Information from the Portland Development Commission.

d Estimate by architect familiar with Section 8 and SHO housing. Based on units of approximately 200 square feet.

e Information from an unpublished survey of hotel lessees by the Portland Development Commission.

1 Information from lessee. 
conservative interpretation of the difference between Section 8 apartments and SRO hotels would a considerable spread in their operation and maintenance costs.

One of the major factors which accounts for the difference in the cost of operation and maintenance is the extent of rehabilitation carried out on the building and the resultant payments necessary to cover the debt service. To meet the minimum property standards prescribed by HUD, especially that of a self-contained unit, the rehabilitation cost for a Section 8 apartment is considerably higher than that for an SRO hotel.

As might be expected, the annual per unit cost to operate and maintain a more recently rehabilitated building is higher. For Section 8 apartments the range was $\$ 4,333$ to $\$ 5,200$ per unit year in 1981 . That represents a substantial per unit cost increase, i.e., from $\$ 1,100$ to $\$ 1,600$ more per unit annually. 6 This is shown by the difference between the two lowest cost figures for each category and the two highest. For the SRO hotel, from the perspective of the owner (which is comparable to the section 8 circumstance), the operation and maintenance costs of recently rehabilitated units was about $\$ 1,100$ per unit per year. This is slightly greater $(\$ 100)$ than the lessee's operation and maintenance cost but far less than the increase for section

6 Represents the difference between the two lowest cost figures for each category and the two highest. 
8 apartments. For the SRO hotels which were proposed as part of the SRO Demonstration Program the cost of operation and maintenance was estimated to be from $\$ 2,300$ to $\$ 2,500$ per unit annually. These costs were more than for the other SRO hotels but were still less than the operation and maintenance costs of any of the rehabilitated section 8 buildings.

Again the cost of operation reflects the differing level of debt service. The total amount of mortgage required per unit for the section 8 apartments ranged from $\$ 29,400$ to $\$ 35,000$ but for the SRO hotels the total mortgage amount was only $\$ 3,100$ to $\$ 11,504$ per unit. As a proportion of the operation and maintenance costs, debt service was between 57 and 75 percent for 1981 for Section 8 units and between 34 and 53 percent for SRO hotels. Thus, not only is the total mortgage amount lower, but the debt service is a lower proportion of the operation and maintenance costs for SRO hotels.

The construction of a new building provides an opportunity for inclusion of the latest energy efficient materials as a means to help reduce operating costs. However, the range of operation and maintenance costs for recently built or proposed section 8 apartments is about equal (only $\$ 100$ more) to the least costly recent rehabilitation and $\$ 1,100$ more than the most costly recent rehabilitation. The additionaly operating cost for the 
latter reflects, in part, the higher proportion of debt service per unit, i.e., 80 percent. No equivalent costs were available for newly constructed SRO hotels for the obvious reason that none have been proposed, much less constructed. However, given the lower cost to construct a smaller unit without individual kitchen and bathroom, the lower per unit cost to heat a smaller space, and the need to service fewer appliances and fixtures, the operation and maintenance costs for new SRo hotels should be well below that of section 8 apartments.

In sum then, under all circumstances discussed, the cost to operate and maintain a Section 8 apartment unit is considerably greater than for an SRO hotel unit. Recalling that rents for a housing unit are generally fixed at an amount plus any profit desired by the owner, the higher operating and maintenance costs for section 8 apartments mean higher rents are also needed for those units.

Rehabilitation costs. The cost to rehabilitate a building is dependent upon a number of factors such as the condition of the building prior to rehabilitation, the extent of rehabilitation undertaken, and the quality of materials used in the rehabilitation. Because the factors of time and inflation are held constant in the following comparisons, it is assumed that any variation in the rehabilitation costs is a resuit of the above mentioned factors. However, from the perspective of the owner, there 
are several factors which also influence the final rehabilitation cost. They include two incentives which encourage the owner to pursue the most substantial level of rehabilitation that could be retrieved from rents and one which encourages a more modest level of rehabilitation. The prospect of reducing future operating and maintenance costs and the greater tax benefits derived from larger interest payments and depreciable value both encourage substantial levels of rehabilitation. More modest levels of rehabilitation tend to be a result of an owner's recognition that the building could not generate enough return to justify a more extensive level of rehabilitation; thus the decision to invest less capital, and as a result, reduce financial risks.

The early rehabilitation of buildings into section 8 apartments ranged in cost from $\$ 14,900$ to $\$ 24,400$ per unit (1981 dollars). These figures include neither land or site costs. They are the actual costs to rehabilitate the building, whatever its condition. Later rehabilitations or proposed projects were more costly ranging from $\$ 28,500$ to $\$ 39,600$ per unit. By comparison, the rehabilitation of SRO hotels was considerably less expensive. A recent renovation cost about $\$ 6,600$ per unit. Renovations proposed under the SRO Demonstration Program would cost between $\$ 9,000$ and $\$ 10,500$ per unit. These costs also included the provision of a combination hot plate, small refrigerator, and sink in 
each hotel room. Thus the least expensive renovation of Section 8 apartments was $\$ 8,300$ more that the least expensive SRO hotel renovation and the most expensive was $\$ 29,100$ over the most expensive SRO hotel. Based on the least costly rehabilitation for both types of units, two hotel rooms could be rehabilitated for each section 8 apartment created. For the most costly options, almost four hotel rooms could be renovated for the cost of one section 8 apartment. That means two to four low-income persons could benefit from upgraded housing rather than just one.

One of the major contributions to the cost of rehabilitating a building into Section 8 apartments is the need to create self-contained units. In nearly all cases, the buildings which became section 8 apartments in downtown Portland were originally hotels. Some were SRO hotels while others had rooms with individual bath facilities. However, in almost none of the cases, did the units contain kitchens or sufficient square feet to meet the minimum property standards. Generally, this meant two hotel rooms were combined to form a single apartment. The end result was about half the number of dwelling units after the rehabilitation as before. This meant an overall reduction in the number of low-cost housing units with the cost to create the apartments between two and four times the amount it would have cost to simply rehabilitate the hotel rooms.

Certainly the quality of apartments in the 
rehabilitated SRO hotels are less than those in the section 8 apartments but the hotels which have been renovated were made to be decent, safe, and sanitary housing for substantially less cost. Given that a select group of urban elderly persons report satisfaction with and preference for life in SRO hotels, then the less costly level of rehabilitation is all that is required to satisfy their housing needs or, put in other words, to achieve a fit between person and environment.

New Construction costs. The cost figures for recent or proposed construction of Section 8 apartments shows that new construction is definitively the most costly method of providing such housing. Actual or anticipated costs in 1981 dollars are $\$ 44,500$ to $\$ 48,500$ per unit, excluding land. For an SRO hotel, it was estimated that construction costs would be between $\$ 16,000$ to $\$ 18,000$ per unit. ${ }^{7}$ Like the section 8 apartments, new construction of SRO hotels is the most costly method of producing those units. The cost spread between recent or proposed rehabilitation and new construction is quite substantial; for Section 8 apartments the difference between the least costly projects is $\$ 16,000$ per unit or 56 percent more for new construction and for the most costly projects is $\$ 8,900$ per unit or 22 percent more

\footnotetext{
${ }^{7}$ As noted earlier, no new construction of SRO hotels has been undertaken or proposed so the estimate of construction costs for such units is based on an architect's interpolation of costs from a recently constructed Section 8 project.
} 
for new construction. A similar comparison of SRO hotels finds the difference between the least costly projects to be $\$ 7,000$ per unit more for new construction or 78 percent above the cost of rehabilitation. The difference between the most costly projects is $\$ 7,500$ per unit or 71 percent more than for rehabilitation.

For SRO hotels, this means the cost to rehabilitate two hotel units is approximately equal to the cost of constructing one new hotel unit $(\$ 18,000$ to $\$ 21,000$ for rehabilitation and $\$ 16,000$ to $\$ 18,000$ for new construction). For Section 8 apartments, the difference is less dramatic from the perspective of actual dollar amounts. The difference between new construction and rehabilitation of a Section 8 apartment would, on the average, be sufficient to rehabilitate at least one $S R O$ hotel unit $(\$ 44,500$ to $\$ \$ 8,500$ for new construction minus $\$ 28,5000$ to $\$ 39,600$ for rehabilitation).

In addition to comparing the costs to rehabilitate or construct new units of the same type, it is interesting to compare rehabilitation of Section 8 apartments with new construction of SRO hotels. It would cost less to construct new SRO hotels than to rehabilitate Section 8 apartments. Compared with recent or proposed rehabilitations the difference is between $\$ 12,500$ and $\$ 21,600$ per unit. On the average, that would mean that nearly two SRO hotel units could be constructed for the cost of rehabilitating one 
Section 8 apartment. Only the earliest rehabilitation of a building into section 8 apartments was less than the anticipated cost to construct more SRO hotel units.

These findings indicate that SRO hotels are definitely a less expensive mode of producing decent, safe, and sanitary housing for a select group of low-income elderly. In essence, either mode of producing improved SRO hotel units is substantially less expensive, on a per unit basis, than rehabilitating a building into section 8 apartments.

Lecation as a Eactor. Based on the understanding that it is less expensive to rehabilitate an existing building in order to produce SRO type units, a next step would be to identify appropriate buildings to rehabilitate. The most obvious would be the existing stock of SRO hotels. As was noted in the discussion of the cost-of-living, there were only scattered SRO type units located in the three neighborhoods outside downtown, but no SRO hotels. This suggests that if rehabilitation were to be pursued, it would almost assuredly mean the renovation of hotels in the downtown area. Given the views of current hotel residents about their neighborhood and the cost of living in several neighborhoods outside downtown, the rehabilitation of existing hotels in downtown would facilitate a match between person and environment.

If new construction were to be pursued, vacant land would be needed. Land outside the downtown area would 
certainly be less expensive but the residents would likely be faced with the problem of locating inexpensive services. The locations outside downtown, which currently contain a mix of commercial facilities, also tend to have higher land costs than less developed areas with more vacant land. Given the greater costs to construct more SRO hotel units, the most cost-effective means of providing units and still assuring reasonable access to services would be rehabilitation of existing units.

The Subsidies

There are currently two major types of subsidies which provide financial assistance to low-cost housing projects--direct subsidization of rents and reduced interest rate mortgages. The former makes up the difference between what the resident can afford to pay toward rent (defined as 25 percent of one's income by HUD) and the fair market rent needed to cover all expenses and service the debt. It does not affect a housing project's actual expenses. The latter has an indirect effect on the fair market rent and a direct effect on the actual project expenses. In either case, the subsidies represent real costs from the prespective of the provider, i.e., government.

Rent Subsidies. As was noted in the literature review, the availability of rent subsidies for Section 8 apartments and the lack thereof for SRO hotels has caused some to question the reasonableness of such a situation. The 
argument has been made that subsidizing an SRO hotel would be less costly than subsidizing self-contained units. The basis for this argument is that the rents needed to cover expenses and debt service for an SRO hotel, which has smaller units and shared bath and kitchen facilities, is considerably less than for larger, complete apartments. Support for such an argument is provided in this section.

The average proportion of the fair market rent paid in subsidy varies from one section 8 apartment to another. That proportion is influenced by their income, of the tenants (the higher their income, the more rent they pay) and the fair market rent (the lower the FMR, the greater proportion the tenant is likely to pay). The Section 8 buildings examined in this study, which were operating in 1981, received between 66 and 78 percent of their residential rents as subsidies from HUD. The average amount was 75 percent and this figure was used to estimate the level of subsidies for those buildings which were still in the late proposal stage. Table $\mathrm{XX}$ shows the cost to HUD for subsidizing the rents of Section 8 apartments and the anticipated cost to subsidized SRO hotels.

The Section 8 buildings, which were in operation by 1978 or before, demand the lowest level of rent subsidy, i.e., from $\$ 1,700$ per unit in 1981 to $\$ 2,800$. Of the three buildings, which fit this circumstance, only one has a subsidy level below $\$ 2,500$; the other two are both above 
THE COST TO HUD POR SUBSIDIZING RENTS OP SECTION 8 APARTMENTS AND THB ANTICIPATED COST TO SUBSIDIZE RENTS FOR SKO BOTELS (1n 1981 dollars/unit/gear)

\begin{tabular}{|c|c|c|}
\hline Circumstance & $\begin{array}{l}\text { Cost to Subsidize } \\
\text { Section } 8 \text { Apartments }\end{array}$ & $\begin{array}{l}\text { Anticipated Cost to } \\
\text { Subsidize SRO Hotels }\end{array}$ \\
\hline $\begin{array}{l}\text { Existing buildings which } \\
\text { have been in } \\
\text { operation since } 1978 \\
(N=3):\end{array}$ & $\$ 1,700$ to $\$ 2,800^{a}$ & No subsidies available \\
\hline $\begin{array}{l}\text { Existing buildings } \\
\text { which have been } \\
\text { rehabilitated since } \\
1979 \text { or are proposed } \\
\text { to be in the near } \\
\text { future, including the } \\
\text { SRO Demonstration } \\
\text { Project }(N=3,2):\end{array}$ & $\$ 3,100$ to $\$ 3,400$ b & $\$ 1,400$ to $\$ 1,800 \mathrm{c}$ \\
\hline $\begin{array}{l}\text { New construction since } \\
1979 \text { or proposed new } \\
\text { construction }(\mathrm{N}=2):\end{array}$ & $\$ 3,600$ to $\$ 4,100 \mathrm{~b}$ & -- \\
\hline
\end{tabular}

a Information from the Area Office, Department of Housing and Urban Development.

b Information from the Housing Division, State of Oregon.

c Estimates based on median income of Section 8 and SRO hotel study samples adjusted to 1981 dollars, $1 . e ., 10$ percent increase over two years, 1979-1981. 
that level. The building with the lower subsidy was rehabilitated in the early 1970 s under a precursor to the section 8 program. 8 For those buildings which were rehabilitated more recently or are still in the late proposal stage, the rent subsidy level is greater; those buildings require or would require from $\$ 3,100$ to $\$ 3,400$ per unit in 1981 to cover the differential between the approved fair-market rent and the tenants' contribution. This means the more recently rehabilitated units demand an additional rent subsidy of between $\$ 300$ to $\$ 1,700$ per unit for 1981 over the buildings in operation by 1978. Assuming that a typical building has 80 units, the cost to HUD to subsidize the differential in 1981 would be at least $\$ 24,000$ and could be as much as $\$ 136,000$ per building. Unless tenants' incomes increase at a faster rate than approved increases in the fair-market rent for section 8 buildings (an unlikely circumstance), the amount of subsidy and hence the differential between older and newer buildings will also increase over the years.

The subsidization of newly constructed Section 8 apartments is more costly than the subsidization of rehabilitated buildings. Of the two buildings which fit this circumstance, the higher subsidy $(\$ 4,100$ per unit in 1981)

8. Though it was a different program the rent subsidy aspect is virtually the same as section 8 's, i.e., residents pay approximately one-quarter of their income toward rent. 
is for a building which is waiting for a final tud approval. In comparison to recently rehabilitated buildings, at a minimum, this represents an additional cost to HUD of $\$ 200$ per unit or, at a maximum $\$ 1,000$ per unit for 1981. For one year of subsidy to an 80-unit building, the difference is at least $\$ 16,000$ and could be as much as $\$ 80,000$. Comparison with buildings rehabilitated and in operation by 1978 reveals a much greater differential. The additional rent subsidy needed is between $\$ 800$ and $\$ 2,400$ per unit 1981 . That translates into $\$ 64,000$ to $\$ 192,000$ for one year of operation of an 80-unit building.

These findings indicate that the rent subsidization of newly constructed section 8 buildings is the most costly alternative and that rent subsidization of rehabilitated buildings is definitely less costly. It is also shown that time is a major factor in determining the level of rent subsidy needed. Those buildings which were completed during a period of lower interest rates have lower debt service requirements and thus have lower income requirements which, in turn, translate into lower fair-market rents.

The anticipated costs to HUD for providing a rent subsidy to SRO hotels is considerably less than that for Section 8 apartments. The two SRO hotels which were to be considered for assistance under the proposed SRO Demonstration Program would require an estimated rent subsidy of $\$ 1,400$ to $\$ 1,800$ per unit in 1981. These 
estimates are based on the difference between the proposed fair-market rents and the rents which the two study samples (SRO hotel and Section 8 ) would be required to pay given their median incomes. 9 The figures represent the least subsidy (highest income residing in lowest rent unit) and the greatest subsidy (lowest income residing in highest rent unit) and comprise between 53 and 73 percent of the total fair-market rent for the SRO hotel units. Given that the fair-market rents for the SRO hotels are lower than for the Section 8 units and that the proportion of subsidy is lower, the result is a lower total subsidy.

Only the one Section 8 building rehabilitated in the early 1970 s has a subsidy level at all close to that which would be needed by the SRO hotels. The other buildings require at least $\$ 1,200$ per unit more than an SRO hotel and new construction of Section 8 apartments would require an additional $\$ 2,700$ per unit per year. Therefore, the rent subsidization of any rehabilitated or newly constructed Section 8 apartments would require two to three times the subsidy required for a rehabilitated SRO hotel.

As noted in the section on actual costs of housing, the reasonableness of producing SRO hotels via new construction is questionable. The cost of new construction

\footnotetext{
9 The median incomes were adjusted to 1981 dollars, i.e., a 10 percent increase over two years, 1979-1981. Any greater adjustment in income would serve to reduce the required subsidy.
} 
is so great and the alternative of rehabilitation so much more justifiable that detailed examination of a subsioy required for a new SRO hotel seems unwarranted. Based on the analysis of costs to subsidize various types of section 8 apartments, it should be clear that the cost to subsidize a new SRO hotel would be less than the cost for new Section 8 's but definitely more than the option of rehabilitating an SRO hotel. That the cost differential between subsidizing rehabilitated SRO hotels and newly constructed ones would be larger, suggests there is an urgency if any SRO hotels are to be subsidized. That urgency is based on the need to preserve the existing stock of hotels prior to their conversion to other uses or demolition if housing which would require a lesser amount of subsidy is to be pursued.

Reduced Interest Rate Mortages. A general rule in the housing business is that the lower the interest rate of the mortgage, the lower the payments, given equal monthly payments over a fixed period of time. Lower mortgage payments mean lower operating expenses and thus require lower income (rent) to cover the operating expenses. By reducing the interest rate of a mortgage, the effect is to substitute an indirect subsidy for the direct subsidization of rents. The cost of the indirect subsidy is, like the direct rent subsidy, born by government. There are two major ways to reduce mortgage interest rates. For tax-exempt bonds, the subsidy is realized through foregone income taxes 
rather than actual cash paid out. The other aproach is for a governmental body to borrow money and loan it at a lower rate; in this case, the difference is made up with general operating funds.

An example of the impact reduced interest rates can have on operating expenses is provided in Table XXI. In each circumstance, the mortgage is for $\$ 4,000,000$ to be repaid over a period of 30 years. The additional amount of annual mortgage payment with an interest rate of 10 percent rather than 7 percent is $\$ 101,960$, with an interest rate of 13 percent, the additional amount is $\$ 211,320$. Assuming the mortgage was for a building with 80 units, the additional annual per unit cost to the operating expense would be $\$ 1,275$ at 10 percent and $\$ 2,767$ at 13 percent. The additional monthly per unit cost would be $\$ 106.25$ at 10 percent and $\$ 230.58$ at 13 percent. These additional costs could be sufficient to prevent a project from having enough income to cover expenses, in which case the project might not be built or if it were to proceed, some type of rent subsidization would be required to make the project "pencil out." This then illustrates how a reduced interest rate mortgage can diminish the need for rent subsidies.

Another example will illustrate the level of indirect subsidy needed to achieve the bond sales which are the primary mechanism for providing reduced interest rate mortgages. Assume the $\$ 4,000,000$ worth of bonds are sold to 
T A B L E $\quad$ X X I

AN EXAMPLE OP THE IMPACT OP REDUCED INTBREST HATES ON OPEHATING EXPENSES

$\begin{array}{lll}\begin{array}{l}\text { Interest } \\ \text { Rate }\end{array} & \begin{array}{l}\text { Annual } \\ \text { Mortgage } \\ \text { Payment }\end{array} & \begin{array}{l}\text { Additional Annual } \\ \text { Expense Over } \\ 7 \% \text { Payment }\end{array} \\ 7 \% & 322,360 & \begin{array}{l}\text { Additional } \\ \text { Per Unit } \\ \text { Expense }\end{array} \\ 10 \% & 424,324 & 101,960 \\ 13 \% & 533,680 & 211,320\end{array}$

Note: All figures are based on a mortgage of $\$ 4,000,000$ for a period of 30 years.

a Assumes 80 units. 
finance a low-cost housing project at an interest rate of 10 percent to be repaid over a period of 30 years. This means the purchasers of the bonds or the bond holders are guaranteed to receive $\$ 424,320$ per year for 30 years as repayment for the use of this money. In order to sell the bonds below the current market interest rates, the payments to the bond holders are exempt from income taxes. That means the federal government foregoes $\$ 127,296$ in income taxes annually if the bond holders have a 30 percent tax liability, $\$ 169,728$ if they have a 40 percent tax liability, and $\$ 212,160$ if they have a 50 percent tax liability. Thus, the exact level of subsidy resulting from any bond sale varies with the purchasers' tax liability.

The figures in the above examples can also be used to explain the direct borrowing approach to reduce mortgage interest rates. Rather than selling bonds, a government entity would borrow $\$ 4,000,000$ at 10 percent for 30 years. If it loaned the full amount at 7 percent for 30 years, the 3 percent differential would be made up from payments out of the general fund. On an annual basis that would amount to $\$ 101,960$.

The three earlier Section 8 rehabilitations were financed with one of the Federal governments direct borrowing methods. All the recent rehabilitation and new construction projects have been financed using the tax-exempt bond approach of fered by the state of Oregon. 
Accordingly, to determine the full amount of subsidy needed to produce and maintain section 8 apartments, it is necessary to add the direct rent subsidy and the indirect subsidy from either direct borrowing or bond sales. Lest the reader be led astray, the purpose of this analysis is not to suggest that direct borrowing or tax-exempt bonds are bad and should be eliminated but rather to note that they exist and must be counted as part of the real cost of producing and maintaining section 8 apartments.

All the rehabilitated SRO hotels examined in this study also had the benefits of a reduced interest rate mortgage. They were not based on the sale of bonds but were made available from several sources of non-general fund dollars from the City of Portland, i.e., primarily Housing and Community Development Block Grant Funds and the repayment proceeds generated from projects financed with tax increment bonds. Because a limited amount of these funds are available, they generate a rather modest amount of mortgage capacity and therefore do not represent an alternative to bond sales but rather only a modest supplement.

Relative to SRO hotels, the important point is that the lower the mortgage amount, the fewer are the bonds that need to be sold to finance a project. Thus, by reducing the total cost to produce low-rent housing, the amount of subsidy required for the sale of tax-exempt bonds is lowered. Using the least costly estimates of rehabilitation 
(since 1979) for Section 8 apartments and SRO hotels from Tables XVIII and XIX, respectively, the cost to produce 80 units of apartments would be $\$ 2,280,000$ whereas the same number of hotel units could be produced for $\$ 720,000$ or one-third the cost and one-third the amount of subsidy required for the sale of tax-exempt bonds. 10

As was found to be the case with the actual costs to produce and operate low-rent housing, the analyses of the cost to subsidize such housing indicates that less subsidy is required to produce and operate SRO hotels than is reguired for section 8 apartments. If a goal is to achieve as many low-rent housing units which are decent, safe, and sanitary at the least cost, then the preceding analyses suggest that Section 8 apartments are not the most cost-effective approach. The analyses suggest that SRO hotels are more cost effective.

Rate of Return

A major aspect of multifamily housing, at least for

10It is important to note that there is one constraint which can prevent the use of tax-exempt bonds for the rehabilitation of SRO hotels. The Internal Revenue Service, which monitors the use of tax-exempt bonds, requires that for residential projects no more than 10 percent of the square footage be used for commercial purposes. However, most SRO hotels are dependent upon rent from their ground floor commercial spaces to assist in covering at least a portion of the hotel's operating costs. Depending on the building's configuration, i.e., primarily the number of floors, the amount of commercial space could well exceed the 10 percent maximum and thus make the use of tax-exempt bonds, under the current regulations, impossible. 
the private market, is that it represents an investment from which an owner can expect to receive a reasonable rate of return. A reasonable rate of return would be a return which was equivalent or greater than what could be earned from another mode of investment, with an adjustment for the risk differential. In the case of housing then, there are two immediate sources of return on investment, i.e., before-tax cash flow and tax shelter. 11 Persons, in particular those with high incomes and high marginal tax rates, can increase their personal income by availing themselves of tax losses which shelter their income. Others, with low, marginal tax rates, are more likely to be interested in the before-tax cash flow because they would not have sufficient income to use the benefit of a tax loss. Thus, the tax status of an owner is a key element in determining what is an appropriate type of return on investment.

There is another source of return on investment and that is the profit from the sale of a building. This type of return is not considered in the present study but it should be recognized that it can have important consequences for

\footnotetext{
11In this study, cash flow or before-tax cash flow means the net operating income a building produces minus its debt service for the period of one year; tax shelter means the annual taxable income a building produces multiplied by the owner's marginal tax rate; investment means the down payment plus any principle amortization, specifically, through December 1981; and return on investment means the before-tax cash flow plus the tax shelter all divided by the owner's investment, specifically, for the period of one year, 1981.
} 
the decisions made by an investor. For instance, an investor might be willing to forego a higher immediate return from either before-tax cash flow or tax shelter for the anticipated return at the time of sale. Such a decision would influence the investor's determination as to what was an acceptable rate of return during the period of ownership. Before proceeding further, it is important to note exactly how housing can provide benefits to an owner over and above the before-tax cash flow. The United States Tax Codes are an essential ingredient. They enable an owner of multifamily housing to deduct both the interest portion of the mortgage payment and an annual depreciation al lowance 12 from the building's cash flow before taxes. This adjusted figure represents the income from the building for the purposes of taxes. The amount of taxes owed on that income depends on the owner's marginal tax rate. When the income for tax purposes is negative, there is no tax liability but rather a tax loss which shelters a portion of the owner's income from other sources. These tax benefits or shelters are only useful to those who pay income taxes. In other

12There are several methods of depreciation commonly used for calculating allowances on multifamily housing units. Based on conversations with persons who are knowledgeable about investor's motives relative to section 8 and SRO hotels in downtown Portland, it was determined that they generally hold the buildings in ownership for some period of time. For this reason all buildings in this study were depreciated using the straight-line method, rehabilitations over 15 years and new constructions over 30 years. 
words, any housing in public or tax-exempt, non-profit ownership could not derive a benefit from a tax loss because its owner would not pay taxes. Such ownership could, however, benefit from a positive cash flow.

In the following analysis, the rate of return on investment is examined only for buildings in private ownership. Using the same Section 8 apartments and SRO hotels, which were scrutinized in the previous analysis of housing costs, the owner's rate of return for 1981, by marginal tax rate, was calculated for each building and is included in Appendix F.

The Section 8 buildings which were rehabilitated prior to 1979 (Buildings $A, B$, and $C$ in Appendix F) show a modest to good rate of return on just the before-tax cash flow for 1981. The lowest return is from the most recently rehaibilitated building $(1.5$ percent or $\$ 5,394)$ and the highest return is from the oldest building $(18.3$ percent or $\$ 24,061) .13$ with the addition of the maximum tax shelter (marginal tax rate of 50 percent) those rates of return increase substantially. The lowest rate of return climbs to 14.0 percent $(\$ 50,848)$ with the highest climbing to 26.2 percent $(\$ 34,432)$. The third building which showed a mid-range of return on before-tax casil "zlow shows a. phenomenal rate of return with the maximum tax loss 139.5

13The rate of return is dependent upon the owner's investment in the project and thus will not vary directly with before-tax cash flow. 
percent or $\$ 46,525)$.

For the more recently rehabilitated buildings $(D, E$, and $F)$ the before-tax cash flow is quite low (\$200 to $\$ 7,691)$ providing only a one percent or less rate of return for 1981. However, adding the maximum amount of tax which can be sheltered by the building's interest and depreciation alters the rate of return considerably. At the 50 percent marginal tax rate the rates of return range from 9.9 to 14.0 percent. Not only could these be seen as sufficient rates of return but the dollar amount of taxes sheltered by those building $(\$ 33,681$ to $\$ 230,417)$ could be a consideraole assistance in reducing an owner's tax liability.

A closer examination of building $F$ will illustrate several points. First, the rehabilitation of the building was substantial and thus created a large depreciation allowance. Second, 75 percent of that building's operating expenses for 1981 are debt service of which almost all is interest payment. Together these deductible items generate a large dollar amount of tax shelter. The before-tax cash flow is almost nonexistent and an analysis of the rate of return from that perspective is zero. However, even at a 20 percent marginal tax rate the amount of taxes sheltered is considerable $(\$ 92,168)$ but the rate of return on the owner's investment is low, only four percent. Clearly the investment in the project is substantial and without the benefits of a tax shelter at 50 percent, the rate of return would be much 
lower. At a marginal tax rate of 35 percent the rate of return would be only 7.4 percent. Thus the larger the mortgaged amount and the lower the owner's investment in a project, the greater will be his/her rate of return from tax 10ss, assuming of course that the owner has sufficient income to utilize the shelter.

Like the recently rehabilitated Section 8 buildings, the newly constructed buildings (Buildings $G$ and $H$ ) provide a low rate of return on before-tax cash flow ( 0 to 2.8 percent) for 1981. Unlike the rehabilitated buildings though, their rate of return at the maximum tax rate is under nine percent, i.e., 5.9 and 7.9 percent. This lower return is primarily due to the need to depreciate the building over 30 years (life of the mortgage) rather than the 15 years used for rehabilitation. Despite these lower returns the maximum dollar amount of tax sheltered is not inconsequential $(\$ 63,287$ to $\$ 132,484)$. Also, on compensation for an initial lower rate of return is that the owner has a new rather than rehabilitated building.

The before-tax cash flow from an sRo hotel rehabilitated with no expectation of rent subsidy (Building I) shows a substantial dollar return $(\$ 72,393$; anà an excellent rate relative to investment (32.2 percent) for the year 1981. However, because the before-tax cash flow was high and the total cost of rehabilitation to the building was far less than for the section 8 buildings (it had lower 
interest payments and depreciation) the building does not generate sufficient tax loss to avoid a tax liability against its income. After taxes, at the 50 percent marginal tax rate, the owner would still receive $\$ 43,143$ in income for a return on investment of 19.2 percent. As noted in the introductory comments to this section, a building with a positive cash flow and little tax shelter is ideal for ownership by public or tax-exempt, non-profit organizations.

Those buildings which were proposed for rehabilitation under the SRO Demonstration Program show a slightly different pattern of return on investment (Buildings $J$ and K). The dollar amount of before-tax cash flow return on the two buildings is nearly identical $(\$ 14,599$ and $\$ 15,100)$ though the rate of return differs $(6.3$ and 9.3 percent, respectively). At the 50 percent marginal tax rate one building provides $\$ 9,969$ in sheltered taxes for a 10.1 percent rate of return while the other provides no tax shelter but generates a tax liability of $\$ 74$ and a relatively unchanged rate of return ( 9.3 percent). Again the cost of rehabilitation and the resultant interest payments and depreciation account for the differences between the two hotel's rates of return on an owner's investment.

In sum then, these findings indicate that SRO hotels can provide a reasonable rate of return on an owner's investment. When compared, the lowest before-tax cash flow from an SRO hotel is higher than that of five out of the 
eight Section 8 apartments. Based on a marginal tax rate of 50 percent, all three SRO hotels produce a higher return on investment than do the newly constructed section 8 buildings. Also based on a marginal tax rate of 50 percent, the return from the hotel with the lowest rate, Hotel $k$, has a rate of return which is within 1.3 percent of two recently rehabilitated Section 8 buildings and 4.7 percent of two others. The remaining two section 8 buildings produce a substantially greater return on investment, i.e. 16.9 and 30.2 percent more than Hotel $\mathrm{K}$.

What this suggests is that an SRO hotel provides a rate of return which is suited to a different type of investor than is a section 8 apartment building. Section 8 apartments can provide tax benefits to those with substantial incomes to shelter. SRO hotels can provide modest amounts of tax shelter and positive before-tax cash flow. This positive cash flow might be particularly attractive to those looking for additional income rather than tax shelter.

A note of caution is needed here. The SRO hotel which shows such a strong positive before-tax cash flow (Building I) had an infusion of grant monies nearly equal to the mortgage amount. This resulted in substantially reduced mortgage payments and thus lower interest payments which meant there was less of a deduction for tax purposes. Given that the availability of grant monies is limited, at least 
for the rehabilitation of SRO hotels, it seems clear that without the assistance of some rent subsidy, SRo hotels will not be rehabilitated.

\section{Conclusion}

The data presented in this section provides convincing evidence to support the third hypothesis that it is less expensive to maintain and rehabilitate SRO hotels than to provide another mode of low-cost housing, i.e., newly constructed or rehabilitated section 8 apartments. The evidence shows that, from the owner's perspective, it is less costly to operate and maintain, rehabilitate, or construct new SRO hotels rather than Section 8 apartments. It is also less costly, from the government's perspective, to provide subsidies to SRO hotels than section 8 apartments. As to the question of whether owners would receive a reasonable rate of return from investment in an SRO hotel, the evidence indicates that with the assistance of some grant money or rent subsidy, the owner of an SRO hotel could rehabilitate a building and expect to receive positive before-tax cash flow and some tax shelter. The amount of subsidy needed to enable such a return is far less than that required to provide a similar return for a section 8 apartment building.

The awful trutin that SRO hotels need a rent subsidy to encourage rehabilitation should not come as a shock, for without rent subsidies, none of the rehabilitated section 8 
apartment buildings examined in this study would be renting to low-income persons. With the passage of the United States Housing Act of 1937 which created the public housing program, the federal government entered into the business of producing or encouraging the production of housing for those least able to secure it on their own. One of the primary reasons they have remained in the business is that the private market cannot afford, and as a result, will not provide, sufficient decent, safe, and sanitary housing for those with low incomes. As was shown earlier, to subsidize the rent of an SRO hotel unit rather than a Section 8 apartment is to spend fewer dollars per unit on production, operation and maintenance, and on overall government assistance.

Based on these findings, the most cost-effective decision for Congress and HUD is to modify the definition of standard housing to allow for the production and operation of SRO hotels. Such an action would encourage the production and maintenance of more units for fewer dollars and as a direct result, house more low-income elderly persons in decent, safe, and sanitary housing. It would also assure that elderly hotel residents could remain in a resource rich environment and thus facilitate their own independence. 


\section{CHAPTER V}

\section{SUMMARY AND OTHER ISSUES}

This final chapter is designed to serve two purposes. The first is to provide a summary of the preceding chapters, and the second is to discuss several other issues which emerge from the study's findings.

\section{Summary of the Study}

The question addressed by this study is whether the single room occupancy hotel has a role in housing a select group of low-income, urban, elderly persons. There would be little need to ask such a question if so many elderly did not live in SRO hotels and if HUD did not view the hotels as substandard dwelling units. But because HUD has adopted the view that self-contained units constitute a basic requirement for decent, safe, and sanitary housing, SRO hotels have generally been excluded from receiving any type of Federal assistance which would facilitate their preservation.

In fact, SRO hotels have been the object of urban renewal efforts in many cities. It has generally been felt that the hotels were slum housing and as such should be removed to allow for more productive uses of the land in and around the central city. As a resuit, many hotels were closed, demolished, or converted to other uses, and since 
many still view the hotels as slum housing, those which remain appear headed for a similar fate. With the value of land in central city areas increasing, particularly during the recent inflationary period, there is an incentive for a hotel owner to seek a greater return on his investment. In the past, this has often entailed closing the hotel and taking a tax loss, demolishing the building in order to make way for another structure, or converting the building to offices or higher cost housing. More recently, it has also included upgrading the hotel to serve the carriage trade. Thus, if the course of events relative to SRO hotels is allowed to continue unimpeded, it appears that there will be few, if any, low-cost sRo hotels remaining in central city areas across the country.

A review of the literature provided some direction in how the question of the role of SRO hotels in housing the urban elderly should be addressed. Because the hotels are utilized as housing, an examination of the general functions of housing was seen as appropriate. It was found that housing could be expected to satisfy at least five basic functions, i.e., the provision of shelter, privacy, access to other locations and neighborhood amenities, and all at an affordable price. Because SRO hotel residents are among the lowest income elderly, the last function, affordability, becomes particularly important. With their limited resources, it is necessary for elderly hotel residents to 
seek maximum satisfaction of those functions at minimal cost. The literature suggests that SRO hotels are among the least expensive, unsubsidized housing units available anywhere in a city, and as such satisfy the function of affordability.

Though the theoretical perspective of person-environment fit goes beyond the consideration of financial matters to address physical and psychological aspects of the person and his environment, financial considerations are certainly a component of any match. Without some fit between income and available goods and services an elderly person is forced to make trade-offs, i.e., to balance the pursuit of needed goods and services with income and personal energy. The literature notes that the pursuit of goods and services becomes more difficult for many elderly persons due to various physical changes which tend to accompany the aging process. As personal energy and physical and mental capabilities become important factors for the elderly in their pursuit of needed resources, easier access to those resources becomes essential. Thus an environment which is rich in needed resources enables the elderly person to satisfy his needs with a limited expenditure of effort. It has been well documented that elderly persons prefer housing environments which provide them with proximity to stores and services and that use of stores and services tends to decrease as distance from 
residence increases.

This is relevant to the role of SRO hotels because they tend to be located in resource rich environments and because many of their elderly residents are not in the best of health, either physically or mentally. Typically, the older SRO hotel resident has at least one health related condition, is dependent upon public transportation or walking for access to stores and services, and is dependent upon a mix of resources which includes inexpensive restaurants and bars. The availability of inexpensive goods and services in the central city area plus their proximity to SRO hotels and the inexpensive rent paid for an SRO hotel all means the elderly hotel resident can provide for his needs with a minimal amount of effort and money.

Three hypotheses are proposed as the means for examining the role of SRO hotels in housing the low-income, urban elderly. Each looks at the issue from a different perspective. The first hypothesis addresses the question of preference, choice, and lifestyle relative to SRO hotels. Because the prevailing view is that SRO hotels provide a deplorable living environment and that almost any alternative would be an improvement, the goal was to obtain an assessment, by the resident, of his housing situation. To provide a comparison, a sample of current SRO hotel residents and a sample of previous hotel residents who had moved to Section 8 apartments were interviewed. Included in 
the interview were questions about the resident's personal characteristics, and views on his current and past housing, possible alternatives for future housing, and satisfactions and dissatisfactions with housing and neighborhood.

The second hypothesis addresses the question of the cost of living for an SRO hotel resident. Based on the understanding that the goods and services consumed by SRO hotel residents were different than those consumed by either the general population or other elderly groups, a special SRO market basket was constructed. This market basket was tested in downtown and three other neighborhoods. The other neighborhoods were included for the purpose of comparison because the depletion of the existing stock of SRO hotels in downtown could mean SRO hotel residents would eventually be forced to relocate outside downtown.

The third hypothesis addresses the cost to operate and maintain, rehabilitate, construct new, and subsidize SRO hotels and Section 8 apartments. It also addresses the rate of return an owner could expect to receive from an investment in either form of housing. This perspective is examined because the consideration of costs is generally the major factor in determining whether a particular low-cost housing project will be produced.

Individually, the results of the analyses affirm a role for the SRO hotel in housing a select group of low-income, urban elderly persons. Examination of the 
resident survey data indicates that the SRO hotel and Section 8 apartment samples have made different personal choices during their lives and that these choices are representative of their aifferent lifestyles. The two samples tend to indicate satisfaction and dissatisfaction over different matters related to housing and neighborhood, with the basis for those concerns centered on their personal values and priorities. More specifically, the analysis shows that current SRO hotel residents are generally satisfied with their. housing and that they are aware of other, less costly, alternative housing but have not pursued it. Based on these findings, it appears at least a portion of the hotel residents choose to live in an SRO hotel and, by choice, remain suggesting, that for some, SRO hotels provide a preferred form of housing.

A comparison of the cost to consume a typical SRO market basket in the four neighborhoods also helps to affirm the role of SRO hotels in housing the low-income, urban elderly. For non-housing goods and services, and housing itself, downtown was shown to be the least expensive neighborhood. In addition to being the least expensive of the four neighborhoods, downtown was found to be a resource rich environment containing more of the facilities which SRO hotel residents use, such as inexpensive restaurants and bars. The presence of a variety of proximate facilities from which to purchase inexpensive goods and services allows the 
low-income SRO hotel resident to satisfy his personal needs given his financial constraints. Thus the existing stock of SRO hotels can be seen as a valuable and unique resource for elderly housing simply because of its location.

A comparison of the cost to operate and maintain, rehabilitate, construct new, and subsidize SRO hotels and Section 8 apartments finds SRO hotels to be the least expensive in all cases. When the cost of operation and maintenance is compared for buildings in roughly similar condition, i.e., rehabbed or newly constructed, the per unit cost is less for SRO hotels than Section 8 apartments. Much of this difference is due to the higher debt service on Section 8 apartment units. For rehabilitation, because there is no need to install individual bathrooms and kitchens in SRO hotels and because the square footage of the hotel units is less, the per unit cost of upgrading is far less for SRO hotels than for section 8 apartments. Likewise, the cost of new construction is considerably less for SRO hotels than Section 8 apartments and the cost to construct a new SRO hotel is also less than the cost of rehabilitation to create Section 8 apartments. Not unexpectedly, because the other costs for apartments are greater, the subsidies required for Section 8 apartments are greater than would be required for SRO hotels. The findings regarding return on investment indicate that with the assistance of subsidies, which would be far less than those needed for section 8 apartments, SRO 
hotels could provide a reasonable return on investment, especially the before-tax cash flow as opposed to the tax shelter aspect of return.

Taken together, these findings provide overwhelming evidence that the existing stock of SRO hotels is a vital resource for housing a select group of low-income, urban, elderly persons. The data indicates that at least some elderly persons chose and preferred to remain in SRO hotels even when they were aware of alternative housing in the same neighborhood for less rent. This preference for SRO hotels over Section 8 apartments parallels a difference in lifestyles between the two samples of low-income, urban elderly. In other words, SRO hotels provide an appropriate fit, between the person and his environment for some elderly persons. The appropriateness of the fit is confirmed by the analysis of the cost of living survey which found that downtown has many more resources than other neighborhoods and that these resources are less expensive than those of other neighborhoods. Additional support for the role of existing SRO hotels is provided by the comparison of the costs for SRO hotels and Section 8 apartments. In all cases compared, SRo hotels were a less costly method of providing low-cost housing.

What follows from these findings is that a policy of preserving and upgrading the existing stock of SRO hotels as low-cost single room dwelling units is needed in order to 
assure a continuing supply of affordable housing in an environment which is supportive of the elderly person's efforts to maintain an independent and dignified lifestyle. Without such a policy, and the accompanying programs and budget authority, the existing stock of SRO hotels will give way to other uses and their low-income, urban, elderly residents will be forced from an environment which enabled them to match their needs with available resources.

\section{Other Issues}

Beyond the conclusion that there definitely is a role for SRO hotels in housing the low-income, urban elderly and the recommendation that such housing be preserved and upgraded as a cost-effective means of providing low-cost housing, there are several issues which emerge as a result of the study's findings. The first is related to planning and policy decisions and the standards which direct these decisions. The second is related to the policy of urban revitalization and its impact on the low-income elderly hotel resident and the third is related to the uses of central city land.

The introduction to this study noted that the primary reason there is a need to address the question of what role SRO hotels might have in housing the low-income, urban, elderly is because the hotels are currently defined by HUD as substandard housing, and as a result, are ineligible for most types of Federal assistance. The question that needs to 
be asked of the planners and policy makers is, Does the presence of a complete kitchen and bathroom in each dwelling unit constitute the essence of "standard" housing? The findings from this study suggest that planners and policy makers have defined an "appropriate" living environment from the perspective of the planner rather than that of the resident.

This is not a new criticism. The text books are filled with examples of how planners from one culture designed housing for residents of another culture with disastrous results. The problem was two-fold; planners were unaware or ignored their own cultural biases and were unaware or ignored the cultural biases of the prospective tenants. In the end, the standards used to design the housing were inappropriate for the situation.

The same can be said of the standards which mandate self-contained units and exclude SRO hotels. This study found that hotels and their downtown location are a preferred environment for many. Other authors have also noted that SRO hotels and the downtown environment appear to be the elderly resident's preferred choice (Ehrlich, 1976). The significance of the difference between what is acceptable to the hotel resident and what the standards mandate is the cost to produce the two types of units. As noted in the analysis of housing costs, under some circumstances as many as four SRO hotel units could be 
upgraded for the cost to produce one "standard" unit. What role do standards have when they are the barrier to more low-cost housing units for fewer dollars?

The second issue is not related to a specific set of standards but to the general policy of urban revitalization. As a national focus, that policy had its beginning with the creation of the urban renewal programs of the late 1940 s and early 1950 s and it continues today. The literature review noted that SRO hotels were frequent targets of the early renewal efforts. As a result, the stock of SRO hotels was substantially reduced as was the stock of other low and moderate-cost housing in and around central city areas. With the increased value of land in central city areas, private developers joined the revitalization efforts even without direct assistance from renewal programs. The result has been a continued reduction of low-cost housing in central city areas.

An obvious impact of the reduction of low-cost housing units in the central city area is a reduction in the number of low-income persons residing in the central city area. This study found that the downiown area contained more resources and less costly resources than a number of other neighborhoods which had been specifically identified, because they contained more than the usual mix of resources. This study also noted that elderly persons tend to depend on their surrounding neighborhood for the goods and services 
they need. Additionally, the literature suggests that older persons have a much more difficult time adjusting to a new environment than do younger persons.

The question that emerges is, what happens to the elderly SRO residents who are uprooted from their downtown neighborhoods and forced to seek housing outside the central city, in neighborhoods which have few, if any, sRo hotel units and fewer resources than were available in their former neighborhoods? Are these elderly persons able to maintain their independent lifestyle? What are the financial, physical, and psychological costs they must bear? If they cannot maintain their independent lifestyle, on whom do they depend? With the displacement of elderly SRO hotel residents, and other low-income persons, from the resource rich environment of the central city, the ultimate impact of urban revitalization could be the creation of greater dependency for those displaced. In the long run, dispersal of the SRO hotel residents will certainly create increased hardships for those displaced and may create increased burdens for the already strained and nearly bankrupt service delivery system. As in the past, the"...heaviest burdens lof urban renewall tend to fall upon citizens least able to bear them because of their low-incomes and generally restricted opportunities" (Downs, 1970 , p. 192).

The third issue also touches on the matter of urban revitalization but addresses the subject from the 
perspective of land use and the economic benefits which can be derived from various types of uses in the central city area. It has generally been held that the development of new office, retail, hotel, or convention space can provide the greatest economic return to a city. Other uses such as parks, housing, and surface parking lots tend to proviue a lower economic return to a city. Thus the efforts to revitalize a city frequently tend to focus on attracting the uses which will provide the greatest economic return.

Because this study recommends the preservation of SRO hotels in the central city area, it could be arguea that such a policy would encourage a use which would not proviae the greatest economic return and therefore possibly prevent development which could provide a greater return. However, most cities have adopted policies which direct the uses of their central city areas. In Portland, the City Councll has approved policies and accompanying zoning regulations which encourage housing in the downtown area. They have also set aside parcels of land to be utilized for park space.

Such decisions to encourage or assign uses which would not provide the greatest economic return are based on the idea of trade-offs. Generally trade-offs are made between a higher economic use and a use which would provide or satisry some type of public good. Park space provides a respite from the hustle and bustle of a city and a contrast from the more intense surrounding development of a central city. Downtown 
housing allows persons to live in the central city area and thus contribute to a city's vitality beyond the typical office worker's hours of 9 to 5 . Both of these land uses are generally perceived to be amenities which contribute to the public good or quality of life in a city.

The argument that SRO hotels should not be preserved because they could be replaced with a use which would generate a greater economic return could be equally applied to other existing housing in the central city area. SRO hotels are housing just as high rise condominums and section 8 apartments are housing. Singling out SRO hotels as a use which should not be preserved is not an economic argument but an argument against that specific type of housing. There are clear precedents for encouraging uses which provide little or no economic return when the alternative is achievement of some public good. Certainly providing a greater number of low-cost housing units for less cost, as would be possible through the preservation of SRO hotels, is a public good.

Though the findings from this study raise some questions, they also answer others. The questions upon which the study focused are answered in the affirmative. The findings indicate that there is a role for SRO hotels in housing the low-income, urban elderly and that there is a demand for such housing. The findings also note that SRO hotels can be produced at less cost than section 8 
apartments and can provide reasonable rates of return on the owners' investments. Only the politicians and policy makers can take these answers and turn them into results. 


\section{A SELECTED BIBLIOGRAPHY}

Alexander, Renee. Determinants of psychological well-being: An analysis of environmental, social, and personal dimensions as related to psychological well-being in late life. In John O'Brien \& Renee Alexander (Eds.), A longitudinal study of a high risk urban elderly population. Portland, ore.: Institute on Aging, Portland State University, 1978.

Alexander, Renee, John Dobra, \& Abdul Qayum. Differential impacts of inflation on the aging. Unpublished manuscript, Institute on Aging, Portland State University, November, 1977.

Altman, Irwin. The environment and social behavior. Monterey, Ca..: Brooks/Cole Publishing Company, 1975.

Anderson, Martin. The federal bulldozer. New York: McGraw-Hill Book Company, 1964.

Bild, R. B. \& R. J. Havighurst. Senior citizens in great cities: The case of Chicago. Gerentolegist, 1976, 16 (1), Part 2, 1-88.

Bogue, Donald J. Skid row in American cities. Chicago: University of Chicago, Community and Family Center, 1963.

Bohannan, Paul. Eating habits of elderly residents of center-city hotels. LaJolla, Ca.: Western Behavioral Sciences Institute, 1977.

Campbell, Angus, Philip E. Converse, \& Willard L. Rodgers. The quality of American life: Perceptions, evaluations, and satisfactions. New York: Russeli Sage Foundation, 1976.

Cantor, Marjorie H. Life space and the social support system of the inner city elderly of New York. Gerontologist, 1975,15 (1), 23-27.

Carp, Frances M. A future for the aged. Austin, Texas: University of Texas Press, 1966. 
Carp, Frances M. Ego-defense or cognitive consistency effects of environmental evaluations. Journal of Gerontelegy, 1975, 30 (6), 707-711.

Carp, Frances M. Housing and living environments of older people. In Robert Binstock and Ethel Shanas (Eds.), Handbook of aging and the social sciences. New York: Van Nostrand Reinhold Company, 1976(a).

Carp, Frances M. User evaluation of housing for the elderly. Gerontologist, 1976, 16 (2), 102-111(b).

Chapin, F. Stuart. Urban land use planning, (2nd ed.). Urbana: University of Illinois Press, 1972.

Chapman, Nancy \& Marie Beaudet-Walters. Housing and neighborhood environment. In John O'Brien \& Renee Alexander (Eds.), A lengitudinal study of a high risk urban elderly population. Portland, Ore.: Institute on Aging, Portland State University, 1978.

Clark, Robert. The role of private pensions in mintaining living standards in retirement. Washington D. C.: National Planning Association, 1977.

Cohen, Carl \& Jay Sokolovsky. Isolation of the inner-city elderly: Myth or method? Paper presented at 30 th Annual Meeting of the Gerontological Society, San Francisco, November, 1977.

Deutscher, Irwin. What we say/what we do: Sentiments and acts. Glenview, Ill.: Scott, Foresman \& Company, 1973.

Downs, Anthony. Urban problems and prospects. Chicago: Markham Publishing company, 1970.

Eckert, J. Kevin. Older persons living in single room occupancy hotels: A study in medical anthropology. Unpublished Ph.D. dissertaiton, Northwestern University, 1978.

Eckert, J. Kevin. Urban renewal and redevelopment: High risk for the marginally subsistent elderly. Gerontolegist, 1979,19 (5), 496-502.

Ehrlich, Phyllis. Study of the St. Louis "invisible" elderly: Needs and characteristics of aged "single room occupancy" downtown hotel residents. St. Louis, Missouri: Institute of Applied Gerontology, St. Louis University, 1976 . 
Erickson, Rosemary \& Kevin Eckert. The elderly poor in downtown $\operatorname{San}$ Diego hotels. Gerontelogist, 1977, 17 (5), 440-446.

Felton, B., S. Lehmann, A. Adler, \& M. Burgio. Social supports and life satisfaction among old and young S.R.O. hotel tenants. Paper presented at 30th Annual Meeting of the Gerontological Society, San Francisco, November, 1977.

Felton, Barbara J., Stanley Lehmann, Arlene Adler. S.R.O. hotels: Their viability as housing options for older citizens. In M. P. Lawton \& S. Hoover (Eds.), Community housing choices for older Americans. New York: Springer Publishing, in press.

Ferraro, Kenneth. Relocation desires and outcomes among the elderly. Research on Aging, 1981, 3 (2), 166-181.

Fielding, Byron. Low-income, single-person housing: What's happening as a result of the "congregate housing" provisions of the 1970 act? Journal of Housing, 1972, $22(3), 133-138$.

Findlay, R. A. \& E. W. Morris. Social determinants of the design of housing for the elderly. In P. Svedfeld, J. A. Russell, L. M. Ward, F. Szigeti, \& G. Davis (Eds.), The behavioral basis of design (Vol. 2). Stroudsburg, $\mathrm{Pa}_{.}:$Dowden, Hutchinson \& Ross, 1976.

Frieden, Bernard J. \& Arthur P. Solomon. The nation's housing: 1975 te 1985 . Cambridge, Mass.: Joint Center for Urban Studies, April, 1977.

Frieden, Elaine. Social differences and their consequences for housing the aged. Journal of the American Institute of Planners, 1960,26 (2), 119-124.

Galbreath, Samuel (Director of Neighborhood Conservation, Portland Development Commission). Personal communication, February 11, 1981.

Gionet, Leonard. An analysis of the economic situation of a high risk urban elderly population. In John O'Brien \& Renee Alexander (Eds.), B lengitudinal study of a high risk urban elderly population. Portland, Ore.: Institute on Aging, Portland State University, 1978 .

Golant, Stephan. The residential location and spatial behavier of the elderly. Chicago: University of Chicago, Department of Geography, 1972. 
Goldscheider, Calvin, Maurice D. Van Arsdol, Jr., \& George Sabagh. Residential mobility of older people. In Frances M. Carp (Ed.), Patterns of living and housing of middle-aged and older people. Washington, D.C.: U.S. Government Printing Office, 1966.

Goldstein, Sidney. Consumption patterns of the aged. Washington, D.C.: McGregor \& Werner, 1960.

Goode, Cecilia, M. Powell Lawton, \& Sally L. Hoover. Elderly hotel and rooming-house dwellers: The population and its housing. Mimeographed report, Philadelphia Geriatric Center, 1979.

Hamovitch, M. B. \& J. E. Peterson. Housing needs and satisfactions of the elderly. Gerontelogist, 1969, 2 (1), 30-32.

Harris, Charles S. Fact book on aging: A profile of D.C.: National Council on Aging, 1978.

Hartman, Chester. The housing of relocated families. Journal of the American Institute of Planners, 1964,30 (14), $266-286$.

Hartman, Chester. The politics of housing: Displaced persons. Society, 1972, 2 (9), 53-65.

Hull, Doris Austin. Single room occupanct housing research study. Arlington, Va.: Calculon, 1980, contract $\mathrm{HC}-5241$.

Human Resource Bureau. Social policy report for the downtown urban renewal area. City of Portland, Oregon, October, 1974 .

Journal of Housing. Skid row gives renewalists rough, tough, relocation problems. Journal of Housing, $1961,18(8)$, $327-336$.

Kahana, Eva. A congruence model of person-environment interaction. In $P . G$. Windley \& G. Ernst (Eds.), Theory development in environment and aging. Washington, D.C.: Gerontological Society, 1975 .

Kart, Cary S., Eileen S. Metress, \& James F. Metress. Aging and health: Bielogic and social perspectives. Menlo Park, Ca.: Addison-Wesley Publishing Company, 1978.

Keller, Suzanne. The urban neighborhood: A sociological perspective. New York: Random House, 1967. 
Rolodrubetz, Walter $w$. Private retirement benefits and relationship to earnings: Survey of new beneficiaries. Social Security Bulletin, 1973, 36 (5), $16-36$.

Kopp, Edward \& Kenneth Murphy. Lower-price hotels in New York city, 1979. City of New York, Human Resources Administration, Crisis Intervention Services, 1979.

Rreps, Juanita $M$. The economy and the aged. In $R$. $H$. Binstock \& E. Shanas (Eds.), Handbook of aging and the Social sciences. New York: Van Nostrand Reinhold, 1976 .

Lamale, Helen $\mathrm{H}$. Measuring retirees' living costs. Aging and Work, 1978, 1 (4), 251-258.

Lawton, M. Powell. Ecology and Aging. In L.A. Pastalan and D.H. Carson (Eds.), Spatial behavior of elder people. Ann Arbor: Ũniversity of Michigan-Wayne State University, Institute of Gerontology, 1970.

Lawton, M. Powell. Environmental options for the aged community resident. Unpublished background paper for Community Support Options for the Elderly. Portland, Ore: Institute on Aging, Portland State University, 1976 .

Lawton, M. Powell. The impact of the environment on aging and behavior. In James E. Birren \& K. Warner Schaie (Eds.), Handbook of the psychology of aging. New York: Van Nostrand Reinhold, 1977.

Lawton, M. Powell. The housing problems of community-resident elderly. In eccasienal papers in housing and community development (Vol. 1). Washington, D.C.: U.S. Department of Housing and Urban Development, 1978.

Lawton, M. Powell. Envirenment and aging. Monterey, Ca: Brooks/Cole Publishing Company, 1980.

Iawton, M. Powell, Morton Kleban, \& Diane Carlson. The inner-city resident: To move or not to move. Gerentelegist, 1973, 13 (4), 443-448.

Lawton M. Powell \& L. Nahemow. Ecology and the aging process. In C. Eisdorfer \& M.P. Lawton (Eds.), The psychelogy of adult development and aging. Washington, D.C.: American Psychological Association, 1973. 
Lawton, M. Powell \& B. Simons. The ecology of social relationships in housing for the elderly. Gerentelegist, 1968,8 (2), 108-115.

Lesher, Samuel (Past Director of Multifamily Housing, Area Office of HUD). Personal communication, October 13, 1981 .

Levy, Herbert. Needed: A new kind of single room occupancy housing. Journal of Housing, 1968, 25 (1), $571-580$.

Lincoln, Sheryl J. Single-room residential hotels must be preserved as low-income housing alternative. Journal of Housing, $1980,37(7), 383-386$.

Maccoll, $\Sigma$, Kimbark. The growth of a city: Power and pelitics in Portland, Oregen 1915 to 1950. Portland, Ore.: Georgian Press, 1979.

Mathieu, James T. Housing preferences and satisfactions. In M. P. Lawton, R. J. Newcomer, \& T. O. Byerts (Eds.), Community planning for an aging society. Stroudsburg, Pa.: Dowden, Hutchinson \& Ross, 1976.

McAuley, William \& Delia Miller. Age and correlates of residential satisfaction. Paper presented at the 30 th Annual Meeting of the Gerontological Society, San Francisco, November, 1977.

Meechan, Eugene J. The $r$ ise and fall of public housing: Condemnation without trial. In Donald Phares (Ed.), A decent home and environment. Cambridge, Mass.: Ballinger Publishing Company, 1977.

Milgram, Grace. The rationale for assisted housing: A review and discussion. Washington, D.C.: Congressional Research Service, August, 1979.

Milgram, Grace. Housing assistance to low- and moderate-income households. Congressional Research Service, Major Issue System. Washington, D.C.: Library of Congress, Febrary, 15, 1980 (updated).

Milgram, Grace \& Keith Bea. A summary of the provisions of the Housing and Community Development Amendments of 1981. Washington, D.C.: Congressional Research Service, Library of Congresss, August, 1981.

Monson, Astrid. Relocation program. Journal ef Housing, $1966,23(3), 136-141$. 
National Commission on Urban Problems. Building the American city. New York: Frederick A. Praeger, 1969.

National Council on Aging (NCOA). The myth and reality of aging in America. Washington, D. C.: National Council on Aging, 1975.

Neugarten Bernice I., R. J. Havighurst, \& S. S. Tobin. The measurement of life satisfaction. Journal of Gerontology, 1961,16 (2), 134-143.

New York Times, Is housing tax incentive too generous? May $25,1979,23$.

Newcomer, Robert. Housing services and neighborhood activities. Paper presented at the 26 th Annual Meeting of the Gerontological Society, Miami Beach, Florida, 1973.

Newcomer, Robert. An evaluation of neighborhood service convenience for public housing and section 202 residents. Unpublished doctoral dissertation, University of Southern California, 1975.

Newcomer, Robert \& Lynn Friss. Activity generating influences on neighborhood services. In $A$. D. Seidel \& S. Danford (Eds.), Envirenmental design: Researcn, theory and application. Washington, D. C.: Proceedings of the loth Annual Conference of the Environmental Design Research Association, 1979.

Newsweek. Can you afford to retire? Newsweek, June 1, 1981, pp. 24-27.

Nie, N. H., C. H. Hull, J. G. Jenk ins, R. Steinbrenner, \& D. H. Bent. Statistical package for the social sciences (2nd ed.). New York: McGraw-Hill, 1975.

Niebanck, Paul L. Rent contrel and the rental housing market. New York City: Housing and Development Administration, January, 1970.

Niebanck, Paul \& J. Pope. The elderly in older urban areas: Problems of adaptation and the effects of relocation. Philadelphia: Institute for Environmental Studies, University of Pennsylvania, 1965.

Noll, P. Site selection criteria for housing the elderly: A proposal for policy change. Paper presented at the 26 th Annual Meeting of the Gerontological Society, Miami Beach, November, 1973. 
Nunnally, Jum C., Jr. Psychometic theory. New York: McGraw-Hill, 1978

oregonian. Financial options outlined for hotel owners. Oregonian, April 23, 1980, B2.

Plutchik, Robert, Martin McCarthy, \& Bernard Hall. Changes in elderly welfare hotel residents during a one year period. Journal of the American Geriatric Society, $1975,23(6), 265-270$.

Plutchik, R., M. McCarthy, B. H. Hall, \& S. Silveroerg. Evaluation of a comprehensive psychiatric and health care program for elderly welfare tenants in a single room occupancy hotel. Journal of the American Geriatric society, 1974,21 (10), 452-459.

Portland Development Commission. Downtown housing inventory. City of Portland, Oregon, April, 1978

Pynoos, Jon, Robert Schafer, \& Chester Hartman (Eds.). Housing urban America. Chicago: Adeline Publishing Company, 1973.

Rapkin, Chester. The private rental housing market in New York City, 1965. City of New York, City Rent and Rehabilitation Administration, 1966.

Regnier, Victor. Neighborhood settings and neighborhood use: Cognitive mapping as a method of identifying the macro environment of older people. Paper presentea at the 26 th Annual Meeting of the Gerontological Society, Miami Beach, 1973.

Regnier, Victor. Neighborhood planning for the urban elderly. In D. S. Woodruff \& J. E. Birren (Eds.), Aging: Scientific perspectives and social issues. New York: Van Nostrand Company, 1975.

Riley, Matilda W. \& Anne Foner. Aging and society, volume one: An inventory of research findings. New York: Russell Sage Foundation, 1968.

Rubenstein, Dan, Annette Howell, \& Caryn Rosenberg. Over the bar, SRO's, and street people elderly--A study of singular life styles. Paper presented at the 30 th Annual Meeting of the Gerontological Society, San Francisco, November, 1977.

Schulz, James $H$. The economics of aging. Belmont, Ca.: Wadsworth Publishing Company, 1976. 
Scott, Mel. American city planning: Since 1890. Berkeley, Ca.: University of California Press, 1969.

Seidman, Bert. Labor's perspective on the future of private pension plans. In Papers for the economics of aging: Toward 2001. Conference on Aging, Institute of Gerontology, University of Michigan-Wayne State University, 1975.

Shanas, E., P Townsend, D. Wedderburn, H. Friis, P. Milhoj, \& J. Stehouwer (Eds.). Old people in three industrial societies. New York: Atherton, 1968.

Shapiro, Joan. Single-room occupancy: Community of the alone. Social Work, 1966,2 (4), 24-33.

Shapiro, Joan. Group work with urban rejects in a slum hotel. Social Work Practice, Columbia University Press, New York, 1967.

Siegal, Harvey A. Qutposts of the forgotten: Socially terminal people in slum hotels and single room eccupancy tenements. New Brunswick, N. J.: Transaction Books, 1978.

Silverberg, Shirley. The Stratford Arms project. In The invisible elderly. National Council on the Aging, Washington, D. C., 1976.

Smith, Wallace F. Housing: The secial and economic elements. Berkeley: University of California Press, 1970 .

Stephens, Joyce. Loners, losers, and lovers: Elderly tenants in a slum hotel. Seattle: University of Washington Press, 1976.

Struyk, Raymond. The housing expense burden of households headed by the elderly. Gerontologist, 1977, 17 (5), 447-452.

Struyk, Raymond \& Sue Marshall. Income and urban home ownership. Washington, D. C.: Urban Institute, 1973.

Thompson, Gayle B. Pension coverage and benefits, 1972: Findings from the retirement history study. Secial Security Bulletin, 1978, 41 (2), 3-17.

Tissue, Thomas. Old age, poverty and the central city. Aging and Human Revelepment, 1971,2 (4), 235-248. 
U.S. Bureau of the Census. Detailed characteristics: U.S. summary, 1950. Washington, D.C.: Government Printing Office, 1953 .

U.S. Bureau of the Census. characteristics of the pepulation, 1960. Washington, D.C.: Government Printing office, 1961 .

U.S. Bureau of the Census. General population characteristics, United States summary, 1970. Washington, D.C.: Government Printing Office, 1972.

U.S. Bureau of the Census. Annual housing survey: Rart A, general housing characteristics for the U.S. and regions, 1978. Washington, D.C.: Government Printing Office, 1980 .

U.S. Bureau of the Census. Money income and poverty statius of families and persons in the United States: current population reports. (series P-60, No. 127). Washington, D.C.: Government Printing Office, March $1981(a)$.

U. S. Bureau of the Census. Advance counts, 1980 Census. Portland, Ore.: Center for Population Research and Census, Portland State University, June, 1981 (b).

United States Conference of Mayors. Resolutions adopted. Pittsburgh, Pennsylvania, 47th Annual Meeting, June, 1979.

U.S. Congress. United States Housing Act. Statutes at large, 50 , part 1, 1937 .

U.S. Congress. Housing Act of 1949. Statutes at large, 63, part 1, 1949.

U.S. Congress. Housing Act of 1956. Statutes at large, 70, 1956 .

U.S. Congress. Housing Act of 1957. Statutes at large, 71, 1957 .

U.S. Congress. Housing Act of 1959. Statutes at large, 73, 1959.

U.S. Congress. Housing Act of 1964. Statutes at large, 78 1964 .

U.S. Congress. Housing Act of 1968 Statutes at large, 82, 1968. 
U.S. Congress. Housing Act of 1970. Statutes at large, 84, $1970(a)$.

U.S. Congress. Housing and Urban Development Act of 1970--Conference Report. Congressional Record, 116 (32) $1970(\mathrm{~b}), 42438-42442$.

U.S. Congress, House of Representatives. Hearings before the Subcommittee on Housing and Community Development of the Committee on Banking, Finance and Urban Affairs. Task Force on Rental Housing. February, March, May, 1980, 96th Congress, 2nd Session.

U.S. Congress, House of Representatives. The omnibus budget reconciliation act of 1981: House report no. 97-158 Washington, D.C.: Government Printing Office, 1981 .

U.S. Congress, Joint Economic Committee. Midyear review of the economv: The outlook for 1979. Washington, D.C.: Government Printing Office, August 9, 1979.

U.S. Congress, Senate, Special Committee on Aging. Single room eccupancy: A need for national concern. Committee Print, Information Paper, Washington, D.C.: Government Printing Office, June, 1978.

U.S. Congress, Senate, Committee on Banking, Housing and Urban Affairs. The elderly in housing: Hearing before the subcommittee on housing and urban affairs. 96 th Congress, 1st Session, April 23, 1979.

U.S. Department of Housing and Urban Development(HUD). Evaluation of the effectiveness of congregate housing for the elderly. Washington, D.C.: U.S. Government Printing Office, 1976 .

U.S. General Accounting Office. Repert to the Congress: Rental housing--a national problem that needs immediate attention. Washington, D.C.: Government Printing Office, November 8, 1979.

Vander Kooi, Ronald C. A digest of the West Madison "skid row" relocation study. Unpublished paper, Department of Sociology, University of Illinois at Chicago Circle, April, 1967.

Walther, Robin J. \& R. Thomas Gillespie. Who benefits? Government housing programs for the independent elderly. In eccasional papers in housing and community affairs, Volume 1, Washington D.C.: U.S. Department of Housing and Urban Development, 1978. 
Yale Law Journal. No room for singles: A gap in the housing law. Yale Law Journal, 1970,80 (2), 395-432.

Yee, William \& Maurice D. Van Arsdol, Jr. Residential mobility, age and the life cycle. Journal of Gerontology, 1977, 32 (2), 211-221. 
MRATS, ETLYDARD DEVIATIOAS, AND t-TBST COMPABISONB OP RUIDOAY AKD MON-RUNDONAT SELBCTED 8 BO BOTEL RESIDENTS

\begin{tabular}{|c|c|c|c|c|c|}
\hline Variable & $\begin{array}{l}\text { Random } \\
\text { Semple } \\
(\mathrm{N}=24)\end{array}$ & $\begin{array}{l}\text { Non-random } \\
\text { Sa=pie } \\
\text { (N=6) }\end{array}$ & \pm -Value & $\begin{array}{l}\text { Degrees } \\
\text { of } \\
\text { Freedom }\end{array}$ & $\begin{array}{l}\text { Two-tail } \\
\text { Probauility }\end{array}$ \\
\hline Age & $\begin{array}{l}69.4 \\
(8.6)\end{array}$ & $\begin{array}{c}66.5 \\
(10.4)\end{array}$ & 0.71 & 28 & 0.48 \\
\hline Marital status a & $\begin{array}{l}1.3 \\
(0.5)\end{array}$ & $\begin{array}{l}1.5 \\
(0.5)\end{array}$ & -0.95 & 28 & 0.35 \\
\hline Yerrs lived downtoma & $\begin{array}{l}13.96 \\
(12.05)\end{array}$ & $\begin{array}{c}9.36 \\
(8.77)\end{array}$ & 0.87 & 28 & 0.39 \\
\hline Years in SRO hotels & $\begin{array}{l}13.49 \\
(11.70)\end{array}$ & $\begin{array}{c}9.33 \\
(8.62)\end{array}$ & 0.81 & 28 & 0.42 \\
\hline Years l1ved elone & $\begin{array}{c}20.34 \\
(14.57)\end{array}$ & $\begin{array}{l}24.50 \\
(13.32)\end{array}$ & -0.63 & 28 & 0.53 \\
\hline Education & $\begin{array}{c}4.83 \\
(1.53)\end{array}$ & $\begin{array}{l}5.50 \\
(1.64)\end{array}$ & -0.95 & 27 & 0.35 \\
\hline $\begin{array}{l}\text { Hollingshead SES } \\
\text { scale }\end{array}$ & $\begin{array}{l}3.09 \\
(1.08)\end{array}$ & $\begin{array}{l}3.17 \\
(.75)\end{array}$ & -0.17 & 27 & 0.87 \\
\hline Monthly lacome & $\begin{array}{l}\$ 371.54 \\
(205.66)\end{array}$ & $\begin{array}{l}\$ 397.40 \\
(146.04)\end{array}$ & -0.27 & 27 & 0.79 \\
\hline $\begin{array}{l}\text { Sell-reported } \\
\text { health }\end{array}$ & $\begin{array}{l}1.83 \\
(1.17)\end{array}$ & $\begin{array}{l}1.83 \\
(1.17)\end{array}$ & 0.00 & 28 & 1.00 \\
\hline Mobility & $\begin{array}{l}1.47 \\
(.61)\end{array}$ & $\begin{array}{l}1.64 \\
(.65)\end{array}$ & -0.62 & 28 & 0.54 \\
\hline $\begin{array}{l}\text { Pavorable responses } \\
\text { to SRO hotel }\end{array}$ & $\begin{array}{l}1.25 \\
(.74)\end{array}$ & $\begin{array}{l}1.50 \\
(.55)\end{array}$ & -0.77 & 28 & 0.45 \\
\hline $\begin{array}{l}\text { Unfavorable responses } \\
\text { to SRO hoteI }\end{array}$ & $\begin{array}{l}0.83 \\
(.82)\end{array}$ & $\begin{array}{l}0.83 \\
(.41)\end{array}$ & 0.00 & 28 & 1.00 \\
\hline Life satisfaction & $\begin{array}{l}1.45 \\
(.22)\end{array}$ & $\begin{array}{l}1.43 \\
(.20)\end{array}$ & 0.22 & 28 & 0.83 \\
\hline $\begin{array}{l}\text { Persons to call } \\
\text { Ior assistance }\end{array}$ & $\begin{array}{l}1.04 \\
(.81)\end{array}$ & $\begin{array}{l}1.50 \\
(.84)\end{array}$ & -1.24 & 28 & 0.23 \\
\hline Use of burs b & $\begin{array}{r}-0.22 \\
(.96)\end{array}$ & $\begin{array}{l}0.69 \\
(.78)\end{array}$ & -2.15 & 28 & $0.04 \mathrm{c}$ \\
\hline Use of cburch b & $\begin{array}{l}0.21 \\
(.78)\end{array}$ & $\begin{array}{c}0.23 \\
(1.12)\end{array}$ & -0.05 & 28 & 0.96 \\
\hline $\begin{array}{l}\text { Visit with friends } \\
\text { io person } b\end{array}$ & $\begin{array}{l}0.02 \\
(.97)\end{array}$ & $\begin{array}{r}-0.29 \\
(.22)\end{array}$ & 0.70 & 27 & 0.49 \\
\hline $\begin{array}{l}\text { Visit oith relatives } \\
\text { in person }\end{array}$ & $\begin{array}{l}0.23 \\
(.94)\end{array}$ & $\begin{array}{r}-0.26 \\
(.75)\end{array}$ & 1.17 & 25 & 0.25 \\
\hline $\begin{array}{l}\text { Talk with friende } \\
\text { on phone } \mathrm{b}\end{array}$ & $\begin{array}{l}0.32 \\
(.84)\end{array}$ & $\begin{array}{l}0.27 \\
(.92)\end{array}$ & 0.12 & 26 & 0.91 \\
\hline $\begin{array}{l}\text { Talk with relatives } \\
\text { on phone }\end{array}$ & $\begin{array}{l}0.13 \\
(.90)\end{array}$ & $\begin{array}{c}-0.26 \\
(.95)\end{array}$ & 0.93 & 25 & 0.36 \\
\hline
\end{tabular}

- Categorles are 1 - ever married and 2 = never married.

b Values were converted to 2 -scores; negetive values are the highest level of use, positive values are the lowest level of use.

c The frequency of using a ber or tevera 18 the only comparison which approsches a algniflcant level. It is possible that managers selected those individuals who drank less, assuming they would be wore easily interviewed. This siagle signiflcant comparison out of 2018 equivalent to chance for $p=.05$. It 18 therefore concluded that the random and nonrandom anmies are simliar. 
APPENDIX B

\section{SRO HOTEL RESIDENT SURVEY SCHEDULE}

RLSIDENT QUESTIONNAIRE:

Respondent's Name

Hote 1 Room No.

Address.

Phone No. (Hotel)

Date of Interview Time

Location of Interview

Type of unit: SRO Hotel

Interviewer

Notes:

Record of contact:

Date

Time

Results *
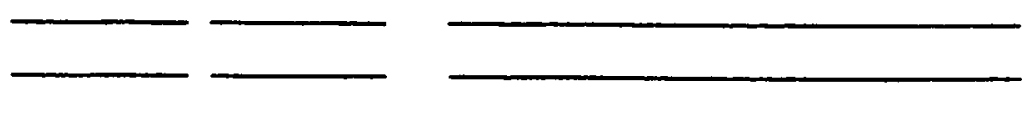

- Refusal, not home

made appointment,

willcall back again, etc. 
Hello, my name is

I'm working on a project that is studying the old hotels in downtow. We are talkıng with about 40 people who live in different hotels to

find out things like what people like about the hotels, what they dislike, and what they would do if they were forced to move out. We know that over the past several years a number of the hotels have been closed and that is a concern to us.

It takes about 45 minutes to ask the questions. In exchange for your answering the questions, I will pay you $\$ 3.00$ for your time. We feel it is very important to get the questions answered so we are willing to pay those we talk with. Anything we talk about would be between just you and me--strictly confidentlal. That means other tenants, the manager or anyone else could not find out what you said.

Would now be a good time to talk or would you rather I came back at another time?

We could talk here or go get a cup of coffee.

I. HOUSING PREFERENCES--Single Room Occupant

1. How long have you lived in the Portland Metropolitan Area? (report in years: $1 \mathrm{mo} .=.08$ years $7 \mathrm{mo} .=.53$ years

$2 \mathrm{mo}=.16$ years $8 \mathrm{mo} .=.67$ years

$3 \mathrm{mo} .=.25$ years $9 \mathrm{mo} .=.75$ years

4 mo. $=.33$ years 10 mo. $=.83$ years

5 mo. $=.42$ years 11 mo. $=.92$ years

$6 \mathrm{mo}=.50$ years no data $=00.00$

2. How long have you lived in the downtown area?

(report in years: $1 \mathrm{mo} .=.08$ years $7 \mathrm{mo} .=.58$ years

$2 \mathrm{mo} .=.16$ years $8 \mathrm{mo} .=.67$ years

$3 \mathrm{mo} .=.25$ years $9 \mathrm{mo} .=.75$ years

$4 \mathrm{mo}=.33$ years $10 \mathrm{mo} .=.83$ years

(Probe: When $5 \mathrm{mo}=.42$ years $11 \mathrm{mo} .=.92$ years

did you move $\quad 6 \mathrm{mo} .=.50$ years no data $=00.00$

to the down-

town area?)

3. How is it you came to live in the downtown area?

1. Knew it was cheap rent

2. Close to things; within walking distance

3. Good, inexpensive public transportation

4. Knew other people in the area, friends on relatives

5. Other (specify)

o. No data

4. How long have you lived in this hotel?

(report in years: $1 \mathrm{mo} .=.08$ years

$2 \mathrm{mo}=.08$ years

$3 \mathrm{mo} .=.25$ years

$4 \mathrm{mo} .=.33$ years

$5 \mathrm{mo} .=.42$ years

$6 \mathrm{mo} .=.50$ years

7 mo. $=.58$ years

8 mo. $=.67$ years

9 mo. $=.75$ years

10 mo. $=.83$ years

11 mo. $=.92$ years

no data $=00.00$

5. How long have you lived in single room hotels?

(report in years: $1 \mathrm{mo} .=.08$ years $7 \mathrm{mo} .=.58$ years

2 mo. $=.16$ years

$8 \mathrm{mo} .=.67$ years

3 mo. $=.25$ years

9 mo. $=.75$ years

$4 \mathrm{mo} .=.33$ years $10 \mathrm{mo} .=.83$ years

$5 \mathrm{mo}=.42$ years $11 \mathrm{mo}=.92$ years

6 mo. $=.50$ years

no data $=00.00$ 
[IF ANSWER TO \#5 > \#4, THEN GO TO $\# 6$ ]

6. Once you moved into a hotel, have you lived in one ever since?

1. YES, always, no breaks (excludes time in hospitals, etc.)

2. NO, there were breaks

3. Only lived in one SRO hotel $(\# 5=\# 4)$

0 . No data

[IF YES, GO TO \#7] [IF NO, GO TO \#8]

7. What other type of housing did you have when you were Nor living in a single room hotel?

1. Efficiency apartment

6. Flop house

2. Apartment with bedroom

7. Nlop house

3. Boarding house

8. Home for the aged

4. Own home

9. Instituticu (īental, prison

5. On the streets/parks residential care facility, etc.)

10. Always in SRO hiotels

0 . No data

8. How many other single room hotels have you lived in in the downtown area?

(report actual number: $00=$ None, no other hotels

$98=$ Others, but NOT downtown

$99=$ No data

[IF AT LEAST ONE OTHER SRO HOTEL]

9. For what reason did you move from one hotel to another?

1. It closed down, was torn or burned down

2. It changed to another use

3. Had problems with the manager/desk clerk

4. Had problems with the other tenants

5. Poor maintenance; could not get repairs

6. Too expensive

7. Too noisy

8. Other (specify)

9. Never moved

0 . No data

10. What type of housing did you have just before you moved into your first single room hotel?

01. Efficiency apartment

02. Apartment with bedroom

03. Boarding house

04. Own home

05. The streets/parks

06. Flop house

07. Nursing home

08. Home for the aged

09. Institution (mental, prison, residential care facility, etc.)

10. Other (specify)

00 . No data

11. What is it you like most about living in a single room hotel?

01. It is cheap

02. Independence

03. Convenient

04. Maid service

05. Other people in hotel: friendliness
06. Security/safety

07. Knowing someone is around to help

08. Cheap transportation

09. Other (specify)

10. Don't like it

00. No data 
c. Where would you look first for a new place to live, in what general area?

1. In downtown Portland

2. In NW Portland

3. Across the river in SE/NE (close in)

4. Further out but still in the city

5. Outside the city

6. In another city

7. Makes no difference/ anywhere

8. Other (specify)

0 . No data

D. Why would you look in that area?

1. Used to live there, know people in area

2. Have relatives in the area

3. It is convenient to stores/services

4. Know rents are cheap in that area
5. It is where the profects are located (Section 8 or HAP)

6. Do not know any other areas of town

7. Has cheap/good transportation

8. Other (specify)

o. No data

E. If you could not find housing there, where would you look second?
1. In downtown Portland
2. In NW portland
3. Across the river in SE/NE (close in)
4. Further out but still in the city
5. Outside in the city
6. In another city
7. Makes no difference/anywhere
8. Other (specify)
0 . No data

F. Why would you look in that area?

1. Used to live there, know people in area

2. Havn relatives in the area

3. It is convenient to stores/services

4. Know rents are cheap in the area

5. It is where the projects are located (Section $B$ or HAF)

6. Do not know any other areas of town

7. Has cheap/good transportation

B. Other (specify)

0 . No data

G. Suppose you just couldn't find a (response to \#15A)

what other kind of housing would you look for?

[HAND RESPONDENT CARD I-15G]

Here is a list of various kinds of housing. Which one would you look for?

01. Hotel room

02. Hotel room with its own bathroom

03. Hotel room with common kitchen

04. Board and room situation

05. Flop house

06. Subsidized apartment (Section B)

07. Hone for the aged

08. One-room apartient

09. Apartment with a hedroom

10. Other (specify)

00 . No data 
H. What do you now pay per month for rent?

(report in $\$$ /month; round off to nearest dollar)

I. If you were forced to move, what is the maximum amount you feel you could afford to spend on housing?

(report in \$/month; round off to nearest dollar)

16. Have you seriously considered moving from where you now live?

1. Yes

2. No

0. No data

17. For how many years have you lived alone?

(report in years: 1 mo. $=.08$ years $7 \mathrm{mo} .=.58$ years

$7 \mathrm{mo}=.58$ years
$8 \mathrm{mo}=.67$ years

$2 \mathrm{mo} .=.16$ years $8 \mathrm{mo} .=.67$ years
$3 \mathrm{mo}=.25$ years $9 \mathrm{mo} .=.75$ years

$3 \mathrm{mo} .=.25$ years $9 \mathrm{mo} .=.75$ years
$4 \mathrm{mo} .=.33$ years $10 \mathrm{mo} .=.83$ years

5 mo. $=.42$ years 11 mo. $=.92$ years

6 mo. $=.50$ years no data $=00.00$

18. Who was the last person you lived with?
1. Spouse
5. Friend
2. Son or daughter
3. Parents
6. Other (specify)
4. Other relatives
0 . No data

19. If you were to consider living with someone else, who would that be?
1. Spouse
2. Son or daughter
3. Other relative
4. Friend

5. Other (specify)

6. Hould not consider living with

someone else

0 . No data

20. Now I would like you to consider a second possibility, that you are offered an opportunity to move into housing where the rent is only one-quarter of your monthly income. In other words, if you receive $\$ 200$ per month, you would pay $\$ 50$ for rent. If you receive $\$ 300$ you would pay $\$ 75$.

A. Have you ever considered moving into such housing?

(Have you tried to get information about such housing?)

1. Did not know it existed

2. Thought about it but waiting list was too long

3. Do not want to live with all old people

4. Do not want to move, period

5. Am currently on the waiting list

6. Need to buy fumiture and that costs too much

7. Other (specify)

0 . No data 
21. The housing I just described to you has its own bathroom and kitchen and sometimes a separate bedroom. Additionally, most all residents of the housing are elderly persons, that is at least 62 years old. Such housing currently exists in downtown and in other parts of the city.

[ONLY IF RESPONDENT DID NOT KNOW ABOUT SUBSIDIZED HOUSING]

A. With this knowledge, would you consider moving into this type of housing?

1. Yes, definiteiy or probably

2. Not sure

3. No, definitely or probably

4. Already knew about subsidized housing

0 . No data

\section{[HAND RESPONDENT CARD I-21B]}

B. I would like to know a little more about how you feel about such housing.

Compared with your present situation, do you see (read items below) as a benefit, it makes no difference, or as a disadvantage?

1. Having your own bathroom?
1. Benefit
3. Disadvantage
2. Makes no difference
o. No data

2. Having your own kitchen?
1. Benefit
3. Disadvantage
2. Makes no difference
o. No data

3. Possibly having a bedroom?
1. Benefit
3. Disadvantage
2. Makes no difference
0 . No data

4. Having more space?
1. Benefit
3. Disadvantage
2. Makes no difference
0 . No data

5. Having a lower rent?
1. Benefit
3. Disadvantage
2. Makes no differice
0 . No data

6. Having to furnish the apartment?
1. Benefit
3. Disadvantage
2. Makes no difference
0 . No data

7. Having mostly elderly neighbors?
1. Benefit
3. Disadvantage
2. Makes no difference
0 . No data

8. Having a place that is new or remodeled?
1. Benefit
3. Disadvantage
2. Makes no difference
0 . No data

9. Other (specify)
1. Benefit
3. Disadvantage
2. Makes no difference
0. No data 
c. If you did choose to move to this type of housing,

in what location of the city would you prfer to be?

1. In downtown

2. Across the river in SE/NE (close in)

3. Further out but still in the city

4. In another city

5. Makes no difference

6. Other (specify)

7. Would not choose this type of housing

0 . No data

[22TO 28 SUBSIDIZED ONLY] 


\section{FUNCTIONAL ASSESSMENT OF HOUSING}

Now I would like to ask you some general questions about your room and the hotel.

[HAND RESPONDENT CARD II-1]
1. Excellent
2. Okay
3. Poor
ט. rió data

1. Generally, how would you rate the amount of heat you receive in your room throughout the day during the winter months? Would you say it was excellent? Okay? or Poor?

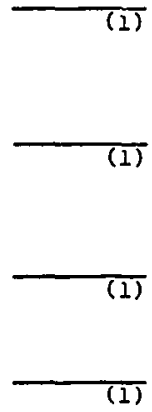

4. How would you rate the amount of quiet or separation from noise that your room provides?

5. How would you rate the plumbing in your room? (illumination vs. daylight)

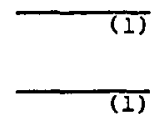

7. How would you rate the cleanliness of the bathroom facilities in the hotel?

8. How would you rate the efforts at rodent and pest control in your hotel?

9. How would you rate the success of those efforts?

10. How would you rate your access to transportation when you need to get somewhere?

11. How would you rate the closeness of stores and shops to the hotel?

12. How would you rate the closeness of services to the hotel? (laundromat, cleaners, clinics, social security, etc.)

13. How would you rate the amount of rent you pay for your room? (excellent deal, okay, or horrible--being taken). 
III. NEIGHBORHOOD AMEINITIES/DISAMENITIES

Now, I would like to ask you some questions about your neighborhood.

1. How concerned are you about the amount or kind of traffic on the streets?

1. very concerned

2. somewhat concerned

3. not at all concerned

0 . no data

2. How concerned are you about walking alone during the day in this neighborhood?

1. very concerned

2. Somewhat concerned

3. not at all concerned

0 . no data

3. How concerned are you about walking alone in the evening in this neighborhood?

1. very concerned

2. somewhat concerned

3. not at all concerned

0 . no data

4. How concerned are you about security, say locks and so forth, for your room or the hotel in general?

1. very concerned

2. somewhat concerned

3. not at all concerned

0 . no data

5. How concerned are you about the kind of people in this neighborhood?

1. very concerned

2. somewhat concerned

3. not at all concerned

0 . no data

6. Do you think this is a good neighborhood for older people to live in?

1. very good

2. okay

3. not good, bad

0 . no data 


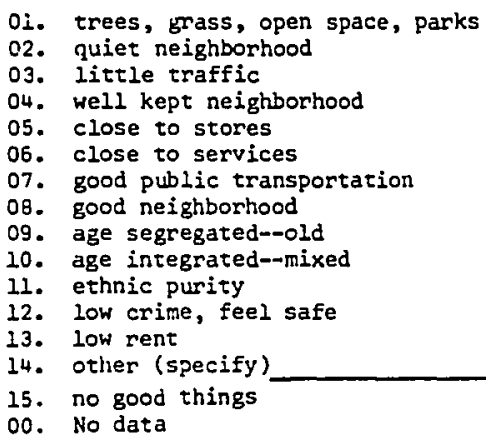

8. What are some bad things about this neighborhood?

0i. no trees, parks, open space

02. noisy neighborhood

03. heavy traffic

04. run-down neighborhood

05. too many commercial establishments

06. Too Ear from stores

07. too far from services

08. poor pubiic transit

09. bad neighbors

10. age composition, too many 01d, too many young

11. no ethnis purity

12. high rent, rent too high

13. other (specify)

14. no bad things

00. No data

9. Since you have lived here, would you say the neighborhood has changed for the better, stayed about the same, or changed for the worse?
1. For the better
3. for the worse
2. about the same
0 . no data

10. When you talk about "walking distance" how many blocks are you referring to? (record actual maximum number)

[HAND RESPONDENT CARD WITH THEIR OWN MAXIMUM BLOCKS]

("walking distance" is the distance a person can walk without tiring too badly)

11. Are there any stores or services you wish were closer to where you live?

1. Yes

2. No

0. No data 
12. What stores or services are they?

11

1. Wish it was closer

2. Close enough (not mentioned)

o. No data

A. restaurant

B. large supermarket

C. small grocery

D. drugstore/pharmacy

E. laundromat

F. cleaners

G. bank/savings \& loan

H. post office

I. barber/beauty shop

J. thrift store

K. department store

L. Library

M. bar

N. movie theater

0 . church/synagogue

$P$. physician/clinic

Q. dentist

$\mathrm{R}$. bus

S. taxi

T. food stamp office

U. social security office

V. meal site/LEF

W. senior center

$\dot{x}$. veterans administration office

$Y$. other (specify)

Z. other (sperify

[ONLY IF RESPONDENT LISTS SOME STORES/SERVICES]

13. Does it cause you any difficulty when you need to go to one of those places?

1. Yes, a great deal

2. Some difficulty

3. No difficulty

o. No data

14. What kind of difficulty does it cause for you?

1. need to pay bus fare

2. need to call taxi

3. need to ride several buses

4. don't get to go

5. must call a friend for help

6. other (specify)

7. other (specify)

d. no difficulty getting around

0 . no data

15. Now I would like to ask you some questions about what stores and services you use. As you will see, I an interested to know how far away they are and how you get there. 


\section{Average Use \\ 1. Once/day at least \\ 3. no more than once/wee \\ 5. Serveral times/month \\ 5. no more than once/month \\ 7. several times/year \\ . no more than once/year \\ . every couple of years \\ 10. never use it}

10. never data

Last Time Used

1. today/yeaterday

2. in the last week

4. in the last 6 months

5. in the last 6 month

5. in the last yea

7. 5-10 years ago

8. more than 10 years ago

9. nover use it

o. no data

1. Mode

1. walk

2. bus

4. ride in a private car

5. taxi

6. driven by an agency
(including Lift)

7. never use

Other than walk

. too far for

2. bus is very convenient

3. bad weather

4. other (specify)

5. never use it

Blocks Away

(record actual number of

blockd from the hotel)

91. 1-5 miles away

95. more than 5 miles awa

99. never use it
(1)

(2)

(3)

What is (are) the

(4)

(5)

(6)

On the average, When was the name(s) of the How do you thy is it you How many bloch

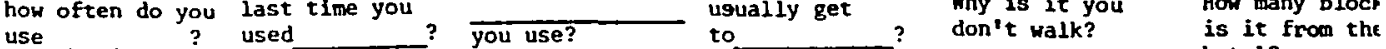

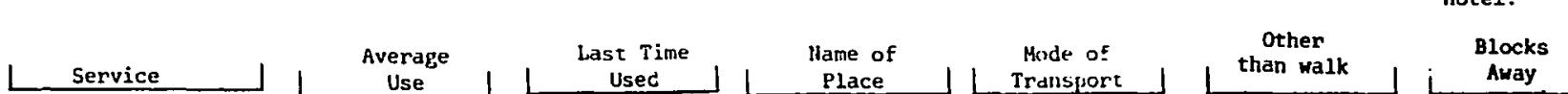

A. Restaurant,

cafeteria,

luncheonette, or

snack bar

B. large supermarket (Safeway)

c. small grocery

store

D. drugstore or

pharmacy

E. laundromat

F. sleaners

G. bank, savings loan, credit

H. post office

I. barber/beauty shop

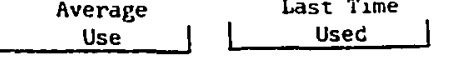

Name of

L Away
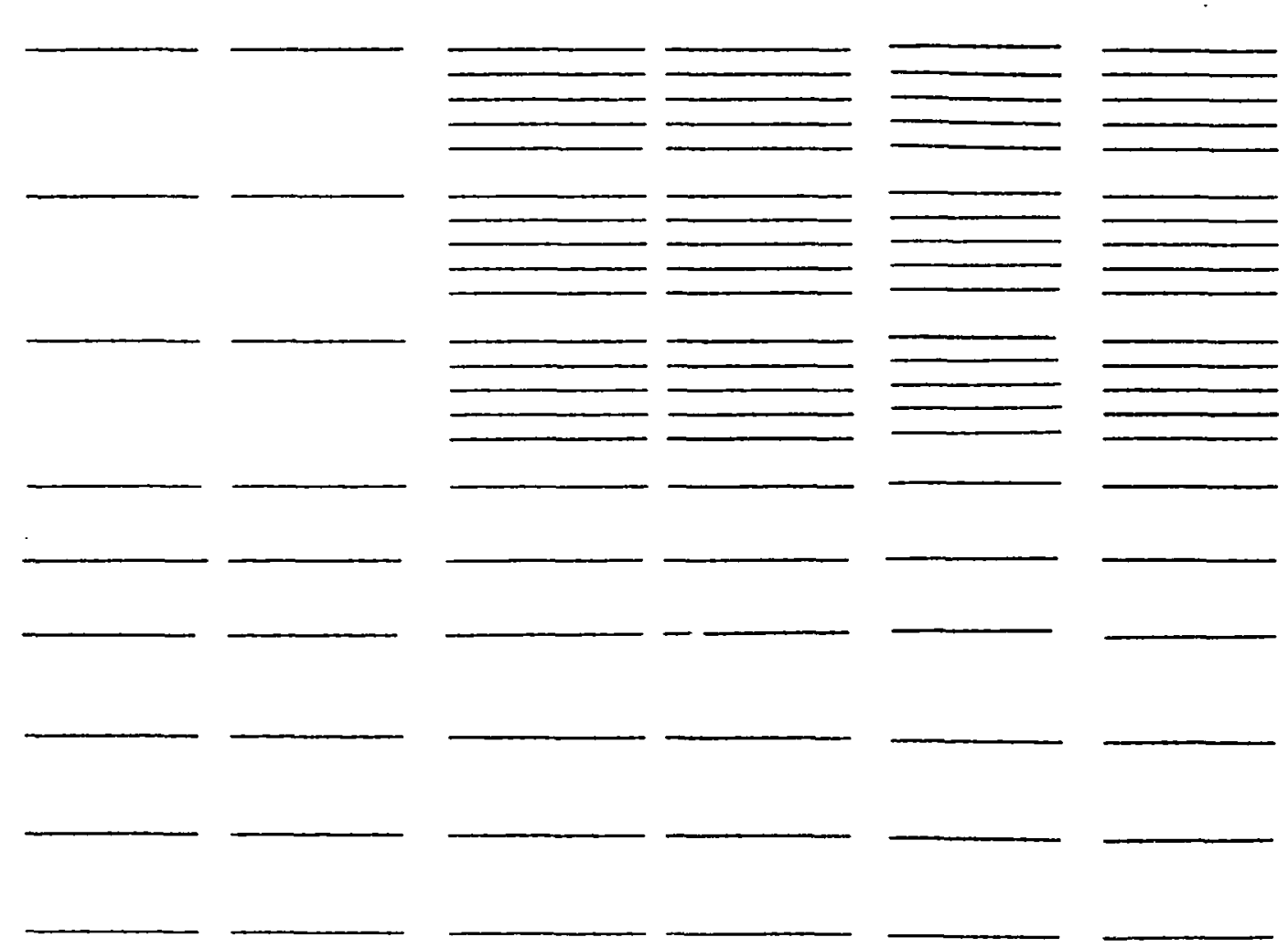
Mode of
Transpiort 


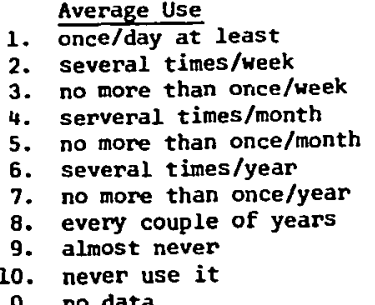

0 . no data

Last Time Used

1. today/yeaterday

2. in the last week

3. in thelast month

4. in the last 6 mont

5. in the last yea

7. 5-10 years ago

g. more than 10 years ago

9. never use it

0 . no data

1. Mode

2. bus

2. bus

4. ride in a private car

5. taxi

6 . driven by an agency

(including Lift)

7. never use it

o. no data

Other than walk

2. bus is very convenient

3. bad weather

4. other (specify)

0.6. no data

locks Away

(record actual number of

blockd from the hotel)

91: 1-5 miles away

95. more than 5 miles away

99. never use it

00. no data
(2)

(3)

(4)

(5)

(6)

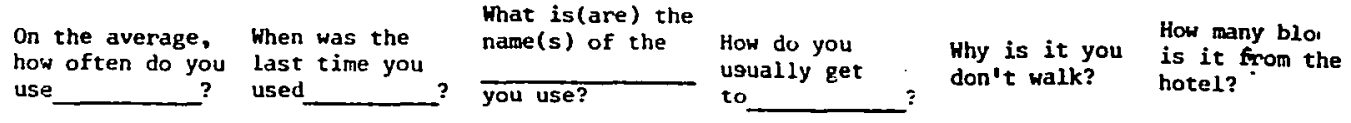

Service

Average

Last Time

Name of

Mode of

Other

than walk

Blocks

J. thrift store

K. department

store

L. Library

M. bar

N. movie theater
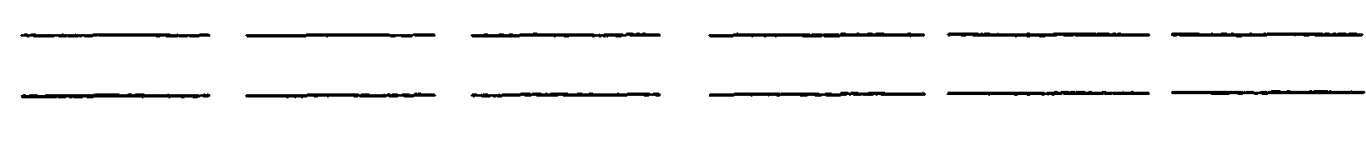

0. church/synagogue

Q. dentist

P. physician/clinic

R. Bus (inside fareles square)

S. Bus (outside fareless square

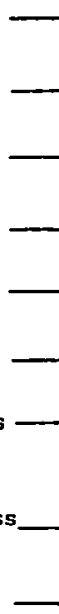

T. taxi 
16. How often have you used the following services?

1. Regularly

2. Off and on

3. For a short time in the past

4. Once

5. Never used it

6. Did not know that service existed

7. Never use any services- a general statement about services

0 . No data

A. the Visiting Nurse

B. special transportation service (i.e., Lift, N.W. Pilot Project)

c. Meals-on-wheels (or home delivery of hot meals)

D. Loaves and Fishes or other senior meal sites

E. a referral service

F. special legal assistance

G. visited/participated in senior center programs

H. food stamps

I. Other (specify) 


\section{PERSONAL HISTORY}

Section A: Demographic

1. Age:

2. Sex:

1. Female

2. Male

0. No data

3. Race:

2. Caucasian

4. Chicano

3. Indian

5. Asian

4. Current Marital Status:
1. Separated
2. Divorced
3. Hidowed
4. Never married
0. No data

5. Number of Children: (all, not just those living now)

6. Generally, what type of jobs did you have?

(record in uargin specific jobs held, also which was major job) (1)

1. major professional, executive \& propritetors or large concerns

2. managers, proprietors of medium sized

businesses, lesser professionals

3. administrative personnel of large concerns, owner of small, independent business, semi-professional

4. owner of little business, clerical E sales, technical

5. skilled worker

6 . semi-skilled worker

7. unskilled worker

0 . no data

7. Number of jobs held during working career:

8. What was the last year of school you completed?

1. graduate or professional training

2. college

3. partial college ( 1 year but less than 4)

4. high or trade school

5. partial high school (10th-11th)

6. junior high school (7th-9th)

7. Less than 7 th grade

0 . no data 
9. As well as you can recall, what was the total amount of your income last month?

10. Did any of that income come from:

A. Hages

B. Social Security (blue or green check)

c. Supplemental Security Income (Gold or Yellow
check)

D. Veterans pension

E. Pensions

F. Investments, Interest, Dividends

G. Welfare

H. Other (specify)

$$
\text { (i.e., odd jobs, }
$$

gifts, etc.)
1. Yes

2. No

0 . No data

1. Yes

2. No

0. No data

1. Yes

2. No

0. No data

1. Yes

2. Ho

0. No data

1. Yes

2. No

0 . No data

1. Yes

2. No

o. No data

1. Yes

0 . No data

1. Yes

2. No .

0 . No data
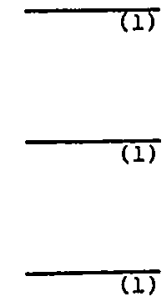

1)

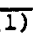

(1)

(1)

1)

11. In what kind of setting have you spent most of your life? An urban, suburban or rural one?

1. Urban

2. Suburban

3. Rural

0. No data 
Section B: Health, Life Satisfaction

11. How often do you worry about your health?

$$
\begin{aligned}
& \text { 1. frequently } \\
& \text { 2. occasionally } \\
& \text { 3. hardly ever } \\
& \text { 4. never } \\
& \text { 0. no data }
\end{aligned}
$$

12. Has your health gotten better or worse during the past two years?

$$
\begin{aligned}
& \text { 1. better } \\
& \text { 2. no change } \\
& \text { 3. worse } \\
& 0 . \text { no data }
\end{aligned}
$$

13. Generally speaking, would you say your health is good, fair, or poor for your age?

$$
\begin{array}{ll}
\text { 1. good } \\
\text { 2. fair } \\
\text { 3. poor } \\
\text { 0. no data }
\end{array}
$$

14. To what degree are you able to do the following:

[HAND RESPONDENT CARD IV-14]

$$
\begin{aligned}
& \text { 2. easily } \\
& \text { 2. some difficulty } \\
& \text { 3. great difficulty } \\
& \text { 4. unable } \\
& \text { 0. no data }
\end{aligned}
$$
A, Get around your room
B. Go up stairs
c. Go down stairs
D. Get out of chair
E. Get out of the hotel
F. Get around the neighborhood

15. How do you spend your time during the day? [HAND RESPONDENT CARD IV-15]
1. a lot of time
2. some time
3. hardly any time
o. no data
A. Talking with triends
B. Reading
C. Watching television
D. Sitting and thinking
E. Sleeping
F. Just doing nothing
G. Doing volunteer work
H. Other (specify) 
16. As I read each of the following statements, please tell me if you agree strongly, agree, disagree, or strongly disagree.

[HAND RESPONDENT CARD IV-16]
1. agree strongly
2. agree
3. disagree
4. disagree strongly
0 . no data

A. As I grow older, things seem better than I thought they would be.

3. I have gotten more of the breaks in life than most people I know.

C. When I think back over my life, I did not get most of the important things I wanted.

D. I expect interesting and pleasant things to happen to me in the future.

E. My life could be happier than it is now.

F. I've gotten pretty much what I expected out of life.

G. If I could, I would shange quite a lot of my past, life.

H. All in all, I an well satisfied with my life.

Section C: Primary Support System

17. How many residents of this hotel do you talk to at least once a week? (More than just hello)

18. How many people in this hotel do you consider to be a close friend rather than just an acquaintence?

[record actual response] 
19. Is there someone you could call day or night if you needed help or needed to talk to someone?

1. Yes

2. 110

0 . Ho data

20. [IF YES] Who is the first person you would call?

$\begin{array}{ll}\text { 01. Son or daughter } & 09 . \text { store clerk } \\ 02 . \text { other relative } & 10 . \text { police } \\ \text { 03. friend } & 11 . \text { hospital } \\ \text { 04. neighbor } & 12 . \text { professional } \\ \text { 05. desk clerk } & 13 . \text { otier (specify) } \\ \text { 06. social worker } & \\ \text { 07. clergyman } & \\ \text { 08. welfare department } & 00 . \text { no data } \\ & \end{array}$

21. Who is the second person you would call if you could not reach (above response)?

22. When was the last time you visited, in person, with friends?
6. 1-5 years ago
1. yesterday/today
2. in the last week
3. in the last month
4. in the last 6 months
7. $5-10$ years ago
5. in the last year
0. no data

23. On the average, how often do you visit in person with friends?
0i. once/day at least
02. several times/week
03. no more than once/we
07. no more than once/year
04. several times/month 10. never
08. every couple of years
05. no more than once/month 00 . no data
06. sereral times/year

24. When was the last time you talked with a friend over the phone?

6. 1-5 years ago

1. yesterday/today

2. in the last week

3. in the last month

4. In the last 6 months

7. 5-10 years ago

5. in the last year

8. more than 10 years ago

0 . no data 
25. On the average, how often do you talk with friends over the phone?

01. once/day at least

02. several times/week

03. no more than once/week

04. several times/month

07. no more than once/year

05. no more than once/month

08. every couple of years

06. several times/year

26. How many living children do you have?

(record actual number)

09. almost never

10. never

00. no data

98. never had children

99. no data

27. Do you have other living relatives?
1. Yes, still some contact
3. No
2. Yes, no contact
4. Don't know
0 . No data

28. When was the last time you spoke, in person, to one of your cluildren?

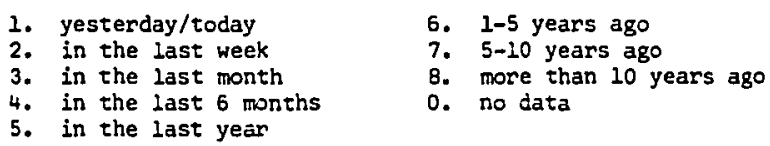

29. On the average, how often do you speak, in person, to one of your children?
01. once/day at least
07. no more than once/year
02. several times/week
03. no more than once/week
08. every coupie of years
04. several times/month
09. almost never
06. several times/year
10. never
00. no data

30. When was the last time you spoke to one of your children over the phone or received a letter from one of them?
1. yesterday
2. in the last week
3. in the last month
4. In the last 6 months
6. 1-5 years
7. $5-10$ years ago
5. In the last year
0 . no data

31. On the average, how often do you speak to one of your children over the phone or receive a letter from one of them?
01. once/day at least
02. several times/week
03. no more than once/week
04. several times/month
no more than once/yea
08. every couple of years
05. no more than once/mont
09. almost never
06. several times/year
10. never
00. no data 
32. When was the last time you spoke, in person, to a relative other than your children?
1. yesterday/today
2. in the last week
3. in the last month
4. in the last 6 months
6. 1-5 years ago
7. 5-10 years ago
8. more than 10 years ago
5. in the last year
0 . no data

33. On the average, how often do you speak, in person, to a relative other than one of your children?

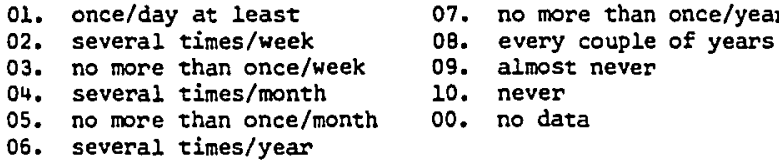

34. When was the last time you sooke to a relative other than your children over the phone or received a letter from one of them?

1. yesterday/today

2. in the last week

6. $1-5$ years ago

3. in the last month

4. In the last 6 months

7. 5-10 years ago

5. in the last year

8. more than 10 years ago

0 . no data

35. On the average, how often do you speak to a relative, other than one of your children, over the phone or receive a letter from one of them?

$\begin{array}{ll}\text { 01. once/day at least } & 07 . \text { no more than once/year } \\ \text { 02. several times/week } & 08 . \text { every couple of years } \\ \text { 03. no more than once/week } & 09 . \text { almost never } \\ \text { 04. several times/month } & 10 . \text { never } \\ \text { 05. no more than once/month } & 00 . \text { no data } \\ \text { 06. several times/year } & \end{array}$

36. Do you see relatives during holidays?

1. Yes

2. Ho

0 . no data

37. Do you see friends during holidays?
1. Yes
2. No
0 . no data

38. Are there any other things about living here that you think I should know about? 
v. INTERVIEHER RATINGS

A. Of Respondent

1. How much trouble did you have persuading Respondent to be interviewed?

1. None, enthusiastic

2. None, not enthusiastic but very willing

3. Took some explanation but no real resistance

4. Took quite a bit of persuasion, not at all willing at first

5. Extremely difficult, didn't think Respondent could be persuaded at first

6. Other (specify)

2. Once Respondent agreed to be interviewed, was $s /$ he generally cooperative or antagonistic toward the interviewer?

1. Cooperative

2. Antagonistic

3. Did Respondent show any signs of confusion (in dates, places, remembering things, etc.)?

1. Yes

2. No

4. How alert was Respondent?

1. Very alert

2. Average

3. Apathetic or lethargic

5. What was Respondent's overall reaction to the interview?

1. Upset

2. Bored but not concerned

3. Interested but not particularly concerned

4. Enjoyed it

B. Of Respondent's Room

1. What was the general condition of Respondent's room?

1. Saw the room, it was very neat and orderly

2. It was organized

3. It was somewhat disamayed

4. It was in considerable disarray

5. Didn't see the room

o. No data 
2. What was the general physical condition of the room?

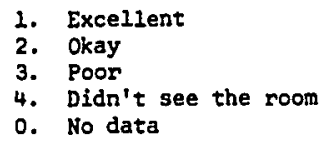

3. What was the general condition of furnishings?
1. Excellent
2. Okay
3. Poor
4. Didn't see the room
0 . No data

c. Of Respondent's Hotel

1. What was the general condition of the hotel?
1. Excellent
2. Okay
3. Poor
0 . No data 


\section{APPENDIX C}

\section{SECTION 8 APARTMENT RESIDENT SURVEY SCHEDULE}

RESIDENT QUESTIONNAIRE

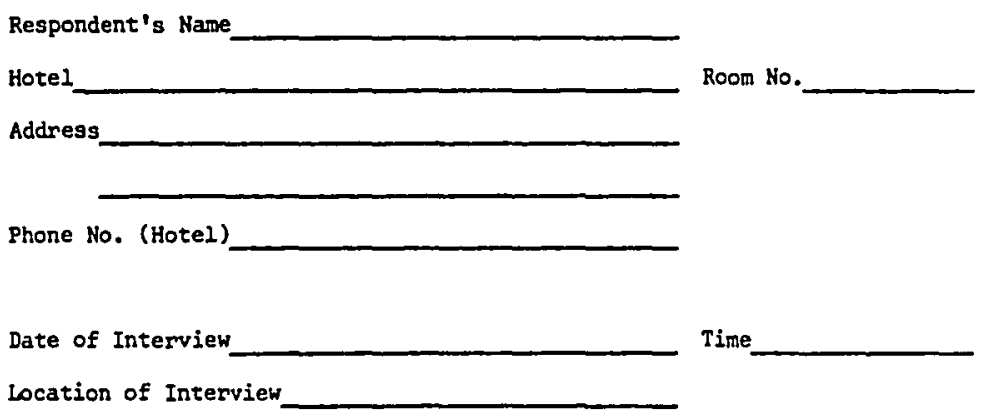

Type of unit:

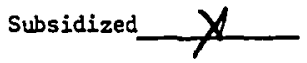

Interviewer

Notes:

Record of contact:

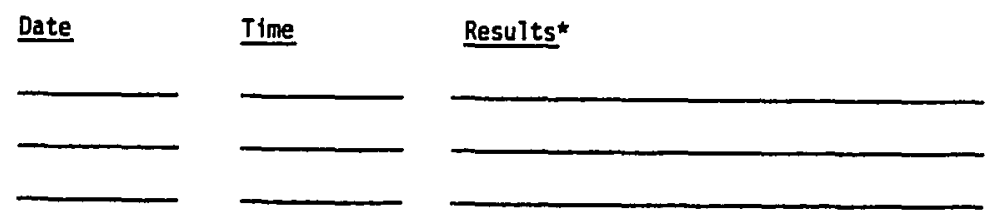

- Refusal, not hone

made appointment.

will call back agatn, etc. 
He1lo, my name is

I'm working on a project that is studying the old hotels in downtown. I understand that you used to live in the Hotel. He are talking with about 20 people who have moved into subsidized housing. He want to know what you liked and disliked about living in a hotel, what you like and dislike about living here, and how you like the neighborhood. It takes about 45 minutes to ask the questions. In exchange for your answering the questions, I will pay you $\$ 3.00$ for your time. He feel it is very important to get the questions answered so we are willing to pay those we talk with. Anything we talk about would be between you and me--strickly confidential. That means other tenants, the manager or anyone else could not find out what you said.

Would now be a good time to talk or would you rather I came back at anothes time.

We could talk here or go get a cup of coffee.

I. HOUSING PREFERENCES---Subsidized Units

1. How long have you lived in the Portland Metropolitan Area? (report in years: $1 \mathrm{mo} .=.08$ years $7 \mathrm{mo} .=.58$ years

$$
\begin{aligned}
& 2 \text { mo. }=.16 \text { years } 8 \text { mo. }=.67 \text { years } \\
& 3 \text { mo. }=.25 \text { years } 9 \text { mo. }=.75 \text { years } \\
& 4 \text { mo. }=.33 \text { years } 10 \text { mo. }=.83 \text { years } \\
& 5 \text { mo. }=.42 \text { years } 11 \text { mo. }=.92 \text { years } \\
& 6 \text { mo. }=.50 \text { years no data }=00.00
\end{aligned}
$$

2. How long have you lived in the downtown area?

$\begin{array}{ll}\text { (rtfort in years: } 1 \mathrm{mo}=.08 \text { years } 7 \mathrm{mo}=.59 \text { years } \\ 2 \mathrm{mo}=.16 \text { years } 6 \mathrm{mo}=.67 \text { years } \\ & 3 \mathrm{mo}=.25 \text { years } 9 \mathrm{mo}=.75 \text { years } \\ & 4 \mathrm{mo}=.33 \text { years } 10 \mathrm{mo}=.83 \text { years } \\ \text { yobe: When } & 5 \mathrm{mo}=.42 \text { years } 11 \mathrm{mo}=.92 \text { years } \\ \text { you move } & 6 \mathrm{mo}=.50 \text { years no data }=00.00\end{array}$

did you move

to the down-

town area?)

3. How is it you came to live in the downtown area?

1. Knew it was cheap rent

2. Close to things; within walking distance

3. Good, inexpensive public transportation

4. Knew other people in the area, friends or relatives

5. Other (specify)

o. No data

3A. How long have you lived at this address?

(report in years: 1 mo. $=.08 \mathrm{yrs} .7 \mathrm{mo} .=.51 \mathrm{yrs}$. $2 \mathrm{mo}=.16 \mathrm{yrs}, \quad 8 \mathrm{mo}=.67 \mathrm{yrs}$ 3. mo. $=.25$ yrs. $9 \mathrm{mo} .=.75$ yrs. $4 \mathrm{mo}=.33 \mathrm{yrs} .10 \mathrm{mo} .=.83 \mathrm{yrs}$. 5 mo. $=.42$ yrs. $11 \mathrm{mo}$. $=.92$ yrs. $6 \mathrm{mo}=.50$ yrs. No dita $=00.00)$

4. How long did you live in the hotel from which you moved?

(report in years: 1 mo. $=.08$ yrs. $7 \mathrm{mo} .=.51 \mathrm{yrs}$. $2 \mathrm{mo.}=.16 \mathrm{yrs} . \quad 8 \mathrm{mo}=.67 \mathrm{yrs}$. $3 \mathrm{mo}=.25 \mathrm{yrs}$. $9 \mathrm{mo} .=.75 \mathrm{yrs}$. $4 \mathrm{mo}=.33 \mathrm{yrs} .10 \mathrm{mo} .=.83 \mathrm{yrs}$. $5 \mathrm{mo}=.42 \mathrm{yrs}$. $11 \mathrm{mo}=.92 \mathrm{yrs}$. 6 mo. $=.50$ yrs. No data $=(0.00)$

5. How many years did you live in a single-room hotel? (report in years: $1 \mathrm{mo} .=00 \mathrm{yrs} .7 \mathrm{mo} .=.51 \mathrm{yrs}$. $2 \mathrm{mo}=.16 \mathrm{yrs} . \quad 8 \mathrm{mo} .=.67 \mathrm{yrs}$. $3 \mathrm{mo}=.25 \mathrm{yrs} .9 \mathrm{mo}=.75 \mathrm{yrs}$. $4 \mathrm{moc}=.33$ yrs. $10 \mathrm{mo}=.83$ yrs. 5 mo. $=.42$ yrs. $11 \mathrm{mo}=.92 \mathrm{yrs}$. $6 \mathrm{mo}=.50 \mathrm{yrs}$. No data $=00.00$ )

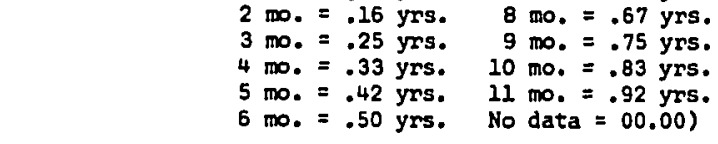


[IF ANSWER TO \#5 > $\#$, THEM GO TO $\# 6$ ]

6. Once you moved into a hotel, have you lived in one ever since?

1. YES, always, no breaks (excludes time in hospitals, etc.)

2. No, there were breaks

3. Only lived in one SRO hotel ( $1 / 5=\| 4)$

o. No data

[IF YES, GO TO \#7] [IF NO, GO TO \#ө]

7. What other type of housing did you have when you were NoT living in a single room hotel?

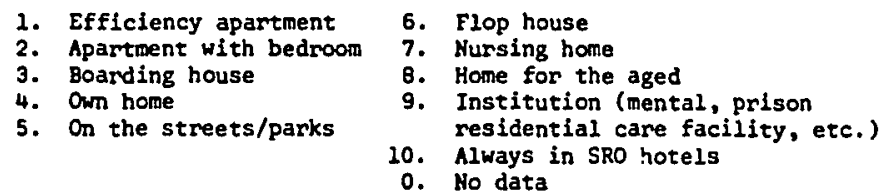

1. Efficiency apartment

2. Apartment with bedroom

3. Boarding house

4. Own home

5. On the streets/parks

6. Flop house

7. Nursing home

8. Home for the aged

9. Institution (mental, prison

residential care facility, etc.)

10. Always in SRO hotels

0 . No data

8. How many other single room hotels have you lived in in the downtown area?

(report actual number: $00=$ None, no other hotels

$98=$ Others, but NOT downtown

99 = Ho data

[IF AT LEAST ONE OTHER SRO HOTEL]

9. For what reason did you move from one hotel to another?

1. It closed down, was torn or burned down

2. It changed to another use

3. Had problems with the manager/desk clerk

4. Had problems with the other tenants

5. Poor maintenance; could not get repairs

6. Too expensive

7. Too noisy

8. Other (specify)

9. Never moved

0 . No data

10. What type of housing did you have just before you moved into your first single room hotel?

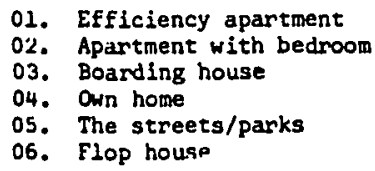

06. Flop house

07. Nursing home

08. Home for the aged

09. Institution (mental, prison, residential care facility, etc.)

05. The streets/parks 10. Other (specify)

00 . Ho data

11. What is it you like most about living in a single room hotel?
01. It is cheap
02. Independence
03. Convenient to stores/services
04. Haid service
05. Other people in hotel; friendilness

06. Security/safety

07. Knowing someone is around to help

08. Cheap transportation

09. Other (specify)

10. Don't like it

00 . No data 
12. What is it you like second best about living in a single room hotel?
01. It is cheap
02. Independence
03. Convenient to stores/services
04. Maid service
05. Other people in hotel: friendiliness

06. Security/safety

07. Knowing someone is around to help

08. Cheap transportation

09. Other (specify)

10. Don't like it

00. Ho data

13. What is it you disjike-most about living in a single room hotel?

01. Too nolsy

02. No privacy

03. Too dirty, bugs, etc.

04. Sharing a bathroom

05. No kitchen

06. The other tenants

07. The manager/desk clerk

OB. It is a dangerous place tolive

09. Nobody cares about others

10. Don't like living alone, lonesome

11. Other (specify)

12. Like everything

00 . No data

14. What is another thing you dislike about living in a single roon hotel?

01. Too noisy
02. No privacy
03. Too dirty
04. Sharing a bathroom
05. No kitchen
06. The other tenants

07. The manager/desk clerk

08. It is a dangerous place to live

09. Nobody cares about others

10. Don't like living alone, lonesome

11. Other (specify)

06. The other tenants 12. Like everything

00. No data

15. Consider thispossibility--that you receive a letter from your current manager saying you must find another place to live, that you are being evicted from your apartment. The letter says you have 30 days to zessu wother place to live.

A. What kind of housing would you look for first?

01. An SRO hotel

02. An SRO with bathroom

03. An SRO with communal kitchen

04. Efficiency apartment

05. Apartment with bedroom

06. Boarding house

07. Flop house

08. A subsidized apartment (Section 8 or HAP)

09. Home for the aged

10. Own home

11. Other (specify)

00. No data

B. How would you go about looking for this new place to live? What would you do first?

1. Ask friends about opanings 2. Ask manager or desk clerk about openings elsewhere

3. Call NHPP-housing service

4. Call the housing authority (Foster, Rosenbaum)

5. Call other Section 8 projects

(Roosevelt, 333 oak, Hashington Plaza, Clay Towers)

6. Begin walking hotel to hotel

7. Call welfare office

8. Try to locate home for the aged

9. Other (specify)

0 . No data 
C. Where would you look first for a new place to

live, in what general area?

1. In downtown Portland

2. In NW Portland

3. Across the river in SE/NE (close in)

4. Further out but still in the city

5. Outside the city

6. In another city

7. Makes no difference/ anywhere

8. Other (specify)

0 . No data

D. Why would you look in that area?

1. Used to live there, know people in area

2. Have relatives in the area

3. It is convenient to stores/services

4. Know rents are cheap in that area

5. It is where the projects are located (Section B or HAP)

6. Do not know any other areas of tow

7. Has cheap/good transportation

8. Other (specify)

0 . No data

L. If you could not find housing there, where would you look second?
1. In downtown Portland
2. In $\mathrm{NW}$ portland
3. Across the river in SE/NE (close in)
4. Further out but still in the city
5. Outside in the city
6. In another city
7. Makes no difference/anywhere
8. Other (specify)
0 . No data

F. Why would you look in that area?

1. Used to live there, know people in area

2. Have relatives in the area

3. It is convenient to stores/services

4. Know rents are cheap in the area

5. It is where the projects are located (Section 8 or HAP)

6. Do not know any other areas of town

7. Has cheap/good transportation

8. Other (specify)

0 . No data

G. Suppose you just couldn't find a (response to \# 15A)

what other kind of housing would you look for?

[HAND RESPONDENT CARD I-15G]

Here is a $l$ ist of various kinds of housing. Which one would you look for?

01. Hotel room

02. Hotel room with its own bathroor

03. Hotel room with common kitchen

04. Board and room sltuation

05. Flop house

06. Subsidized apartment (Section a)

07. Home for the aged

08. One-room apartment

09. Apartment with a bedroom

10. Other (specify)

00. No data

7. What were you paying for rent before you moved here? (date )

(record in S/month; round off to nearest dollar) 
14. What do you now pay per month for rent? (record in $5 /$ month; round off to nearest dollar)

2. If you were forced to move, what is the maximum amount you could afford to spend on housing? (report in S/month; round off to nearest dollar)

16. Have you seriously considered moving from where you now live?

1. Yes

2. No

0 . No data

17. For how many years have you lived alone?

(report in years: 1 mo. $=.08$ years 7 mo. $=.58$ years
$2 \mathrm{mo}=.16$ years $8 \mathrm{mo}=.67$ years
$3 \mathrm{mo}=.25$ years $9 \mathrm{mo}=.75$ years
$4 \mathrm{mo}=.33$ years $10 \mathrm{mo}=.83$ years
$5 \mathrm{mo}=.42$ years $11 \mathrm{mo}=.92$ years
$6 \mathrm{mo}=.50$ years no data $=00.00$

18. Who was the last person you lived with?
1. Spouse
5. Friend
2. Son or daughter
6. Other (specify)
3. Parents
o. No data

19. If you were to consider iiving with someone else, whe would that be?
1. Spouse
2. Son or daughter
3. Other relative
4. Friend
6. Would not consider living with someone else
0. No data

\section{[ 20 TO21 SRO ONLY]}

Now, I would like to ask you several questions about where you live.

22. What do you like best about living here?

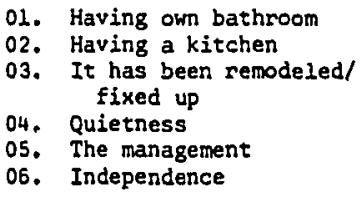

01. Having own bathroom

02. Having a kitchen

03. It has been remodeled/ fixed up

04. Quietness

05. The management

05. Independence

07. That other people look

What is it you like second best about living here?
03. It has been remodeled/
fixed up
04. Quietness
05. The management
06. Independence

23. What is it you like second

23. What is it you like second
01. Having om bathroom
02 . Having a kitchen

07. That other people look

08. The large space

09. It's close to stores/services

10. It's downtown

11. The small amount of rent paid

12. Other (specifv)

13. Don't like anything

08.

09. It's close to stores/services

10. It's downtown

11. The small amount of rent paid

12. Other (snerifu)

13. Don't like anything

00 . No data 
24.

What is it you dislike about living here?

01. Too much space to keep up 06. Too sterile

02. All elderly people here 07. Too prograrmed

03. The management 08. Other (specify)

04. Don't like the tenants 09. Other (specify)

05. Don't see old friends much 10. Like everything

00. No data

25. What is another thing you dislike about living here?

01. Too much space to keep up 06. Too sterile

02. All elderly people here 07. Too programmed

03. The management 08, Other (specify)

04. Don't like the tenants 09. Other (specify)

0S. Don't see old friends wuch 10. Like everything

00 . No data

26. Do you prepare of your meals at hore?
1. a11
2. most
3. half
4. some
0 . no data

27. Would you or have you considered living in an SRO hotel again?

1. Yes, would consider

2. Yes, have considered

3. Hot sure whether I would go back to SRO hotel

4. No, would not consider

0 . No data

28. Sumbrizing, what do you consider to be the most important difference between living here and

living in a single room hotel?

1. Cheaper here

2. Fixed up here

3. Having a kitcher

4. Having a bathroom

5. Other (specify)

6. Other (specify)

0. Ho data

NOTE: NO PAGE 7 ON THE SUBSIDIZED INTERVIEN FORH

Note: From this point on, the Section 8 Apartment Resident Survey is the same as the SRO Hotel Resident Survey. 


\begin{abstract}
APPENDIX D
DETAILED LIST OF ITEMS CONTAINED IN THE

SRO HOTEL RESIDENT COST OF

LIVING SURVEY
\end{abstract}

Food Away From Home:

breakfast

dinner salad

chicken dinner soup

chili

cheeseburger

coffee

danish

pie

\section{Alcohol: \\ draft beer shot of whiskey six-pack of beer}

Tabacco:

pack of cigarettes

Transportation:
bus ride
taxi ride

SRO hotel room housekeeping room

efficiency apartment

\section{Housing :}

Food At Home:

milk

cheese

chopped, pressed beef

baloney

spaghetti \& meat balls

cup of soup

bread

danish

banana

orange

instant coffee

sugar cubes

Personal Care and Services: aspirin

Maalox

shaving cream

razor blades

denture soak

hair cut

jacket cleaned

overcoat cleaned

pants altered 


\section{APPENDIX E}

MEUT8, GTANDARD DETIATICHS, AND E-TEST COMPARISONS OP 8RO BOTBI $A$ ID BBCTIOA 8 APAITUENT RBSIDRNTS ASBESBMENT OF BELBCTBD FUNCTIOA8 OP BOUSIMG

\begin{tabular}{|c|c|c|c|c|c|c|}
\hline $\begin{array}{l}\text { Type of } \\
\text { Function }\end{array}$ & $\begin{array}{l}\text { Variables } \\
\text { Assessed }\end{array}$ & $\begin{array}{l}\text { Sko } \\
\text { Sample } \\
(N=30)\end{array}$ & $\begin{array}{l}\text { Section } 8 \\
\text { Semple } \\
\text { (N=17) }\end{array}$ & t-Value & $\begin{array}{l}\text { Degrees } \\
\text { of } \\
\text { Freedos }\end{array}$ & $\begin{array}{l}\text { One-tail } \\
\text { Probability }\end{array}$ \\
\hline Shelter & $\begin{array}{l}\text { Amount of beat in winter } \\
\text { Amount of protection }\end{array}$ & $\begin{array}{l}1.96 \\
(0.79) \\
1.90 \\
(0.76)\end{array}$ & $\begin{array}{c}2.56 \\
(0.63) \\
2.76 \\
(0.44)\end{array}$ & $\begin{array}{l}-2.58 \\
-4.30\end{array}$ & $\begin{array}{l}42 \\
45\end{array}$ & $\begin{array}{l}.007 \\
.000\end{array}$ \\
\hline Privacy & $\begin{array}{l}\text { Amount of privacy } \\
\text { Amount of quiet or } \\
\text { separation }\end{array}$ & $\begin{array}{l}1.43 \\
(0.63) \\
1.67 \\
(0.80)\end{array}$ & $\begin{array}{l}2.47 \\
(0.72) \\
2.71 \\
(0.69)\end{array}$ & $\begin{array}{l}-5.18 \\
-4.49\end{array}$ & $\begin{array}{l}45 \\
45\end{array}$ & $\begin{array}{l}.000 \\
.000\end{array}$ \\
\hline $\begin{array}{l}\text { Access } \\
\text { to Trans1t }\end{array}$ & $\begin{array}{l}\text { Access to } \\
\text { trensportation }\end{array}$ & $\begin{array}{l}2.22 \\
(0.42)\end{array}$ & $\begin{array}{l}1.50 \\
(0.86)\end{array}$ & -1.40 & 39 & .085 \\
\hline $\begin{array}{l}\text { Access to } \\
\text { Stores } \\
\text { Services }\end{array}$ & $\begin{array}{l}\text { Closeness to stores } \\
\text { Closeness to services }\end{array}$ & $\begin{array}{l}1.59 \\
(0.68) \\
1.21 \\
(0.41)\end{array}$ & $\begin{array}{l}1.73 \\
(0.80) \\
1.87 \\
(0.83)\end{array}$ & $\begin{array}{l}-0.64 \\
-3.53\end{array}$ & $\begin{array}{l}42 \\
42\end{array}$ & $\begin{array}{l}.263 \\
.001\end{array}$ \\
\hline $\begin{array}{l}\text { Alford- } \\
\text { iblitity }\end{array}$ & Amount of rent pald & $\begin{array}{l}1.93 \\
(0.58)\end{array}$ & $\begin{array}{c}2.67 \\
(0.62)\end{array}$ & -3.90 & 43 & .000 \\
\hline $\begin{array}{l}\text { Utility } \\
\text { Services }\end{array}$ & $\begin{array}{l}\text { Plumbing in the room } \\
\text { Amount of light in room }\end{array}$ & $\begin{array}{l}1.87 \\
(0.63) \\
1.87 \\
(0.65)\end{array}$ & $\begin{array}{l}2.59 \\
(0.51) \\
2.47 \\
(0.72)\end{array}$ & $\begin{array}{l}-4.04 \\
-3.01\end{array}$ & $\begin{array}{l}45 \\
45\end{array}$ & $\begin{array}{l}.000 \\
.002\end{array}$ \\
\hline $\begin{array}{l}\text { Senitery } \\
\text { Conditions }\end{array}$ & $\begin{array}{l}\text { Cleanliness of bethroon } \\
\text { facilities } \\
\text { Efforts at rodent and } \\
\text { pest control } \\
\text { Effects of rodent and } \\
\text { pest control }\end{array}$ & $\begin{array}{l}1.68 \\
(0.80) \\
2.66 \\
(0.77) \\
1.77 \\
(0.82)\end{array}$ & $\begin{array}{l}2.38 \\
(0.65) \\
2.44 \\
(0.73) \\
2.73 \\
(0.59)\end{array}$ & $\begin{array}{l}-2.73 \\
-3.33 \\
-4.07\end{array}$ & $\begin{array}{l}36 \\
43 \\
43\end{array}$ & $\begin{array}{l}.005 \\
.001 \\
.000\end{array}$ \\
\hline
\end{tabular}

Note: Categories for ratiag are: 1 = excellent, 2 = okay, 3 = poor. 


\section{APPENDIX $\mathbf{Z}$ \\ RETURN ON INVESTHENT POR ONNERS OF SECTION 8 \\ APARTHENTS AND SRO BOTELS IN DONNTONN \\ PORTLAND, OREGON}

The figures on the next pages show the return on investment (the before-tax cash flow plus the tax shelter all divided by the owner's investment) for the calender year 1981, to owners of Section 8 apartments and SRO hotels.

Buildings A through $F$ are Section 8 apartments which were rehabilitated, Buildings $G$ and $B$ are newly constructed Section 8 apartments, and Buildings $I$ through $R$ are rehabilitated SRo hotel 8 .

The illustrations below provide a guide to interpreting the figures.

RATE OF RETURN HITH

A. TAX LOSS

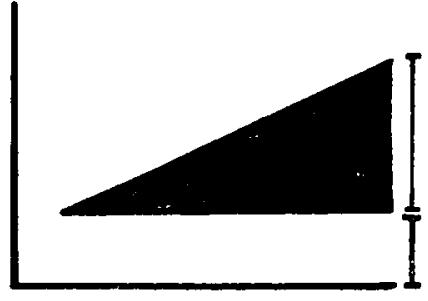

RATE OF RETURN

WITH A

TAX LIABILITY
Marginal Tax Rate

Amount of

Taxes

Sheltered

Amount of

Before-tax

Cash Flow

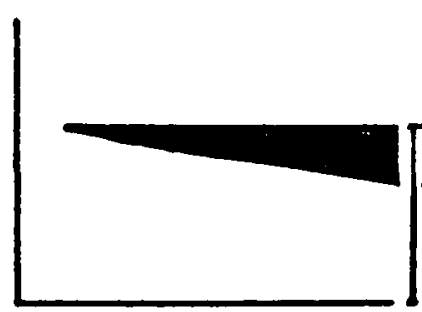

Amount of Tax Liability

Amount of Before-tax Cash Flow

Marginal Tax Rate 

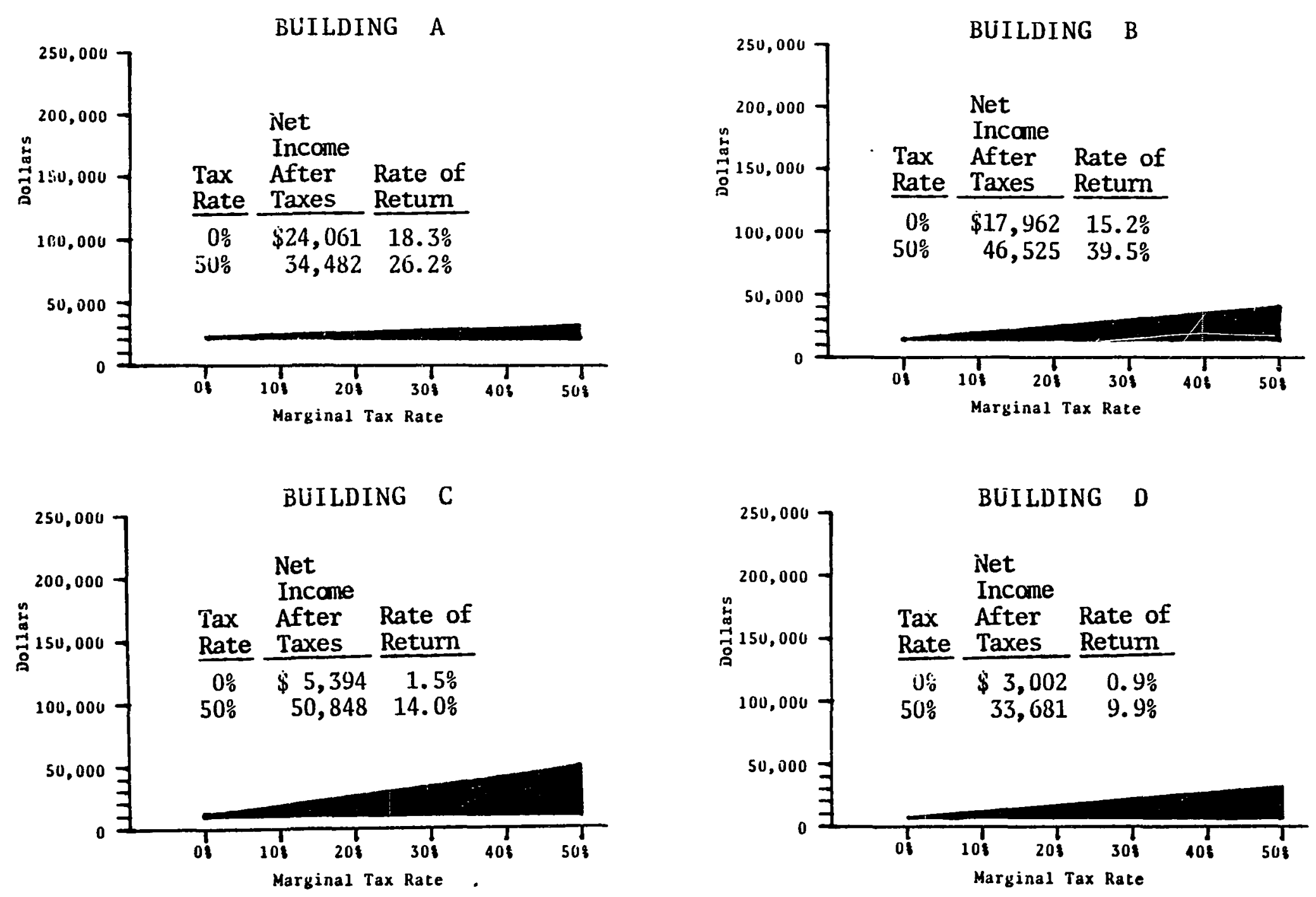

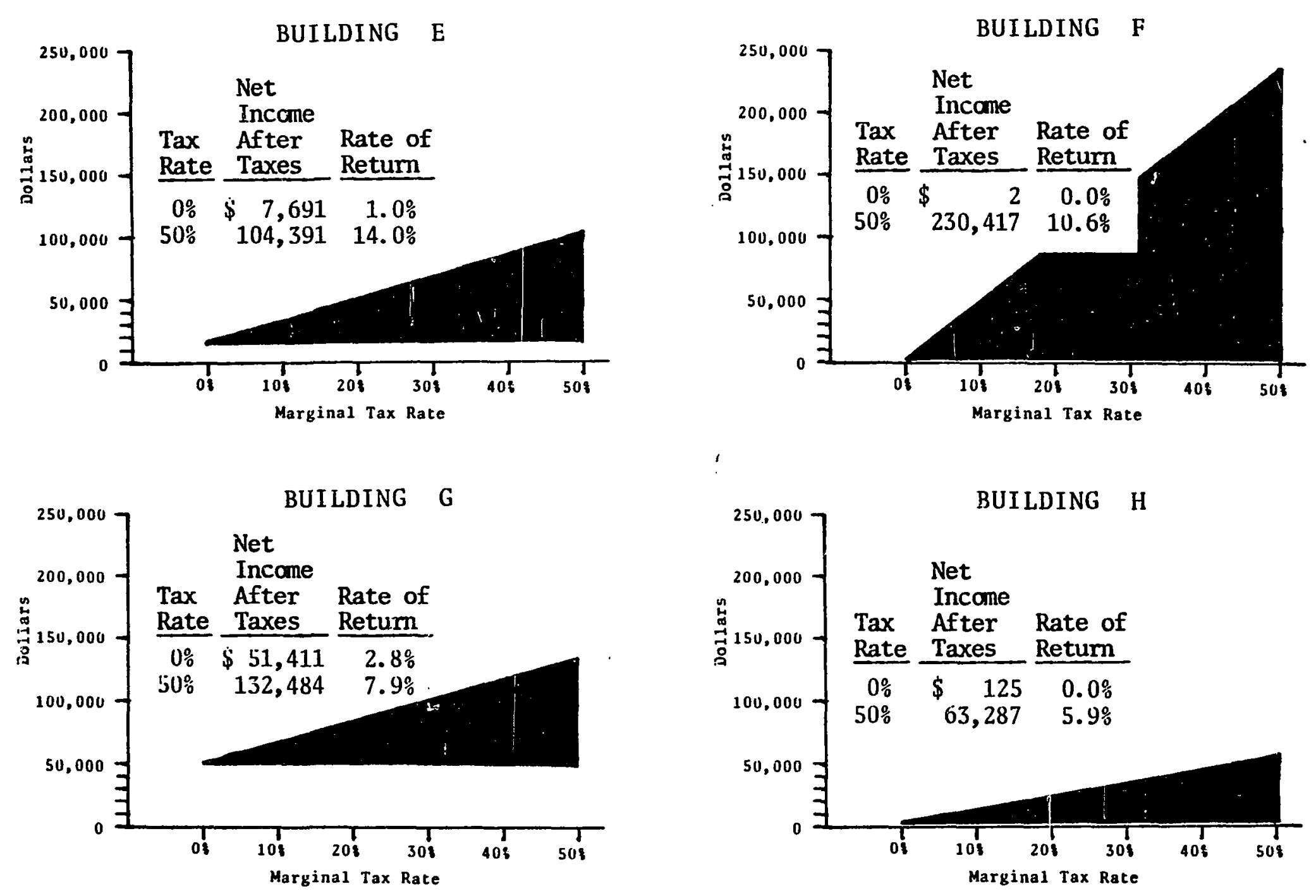

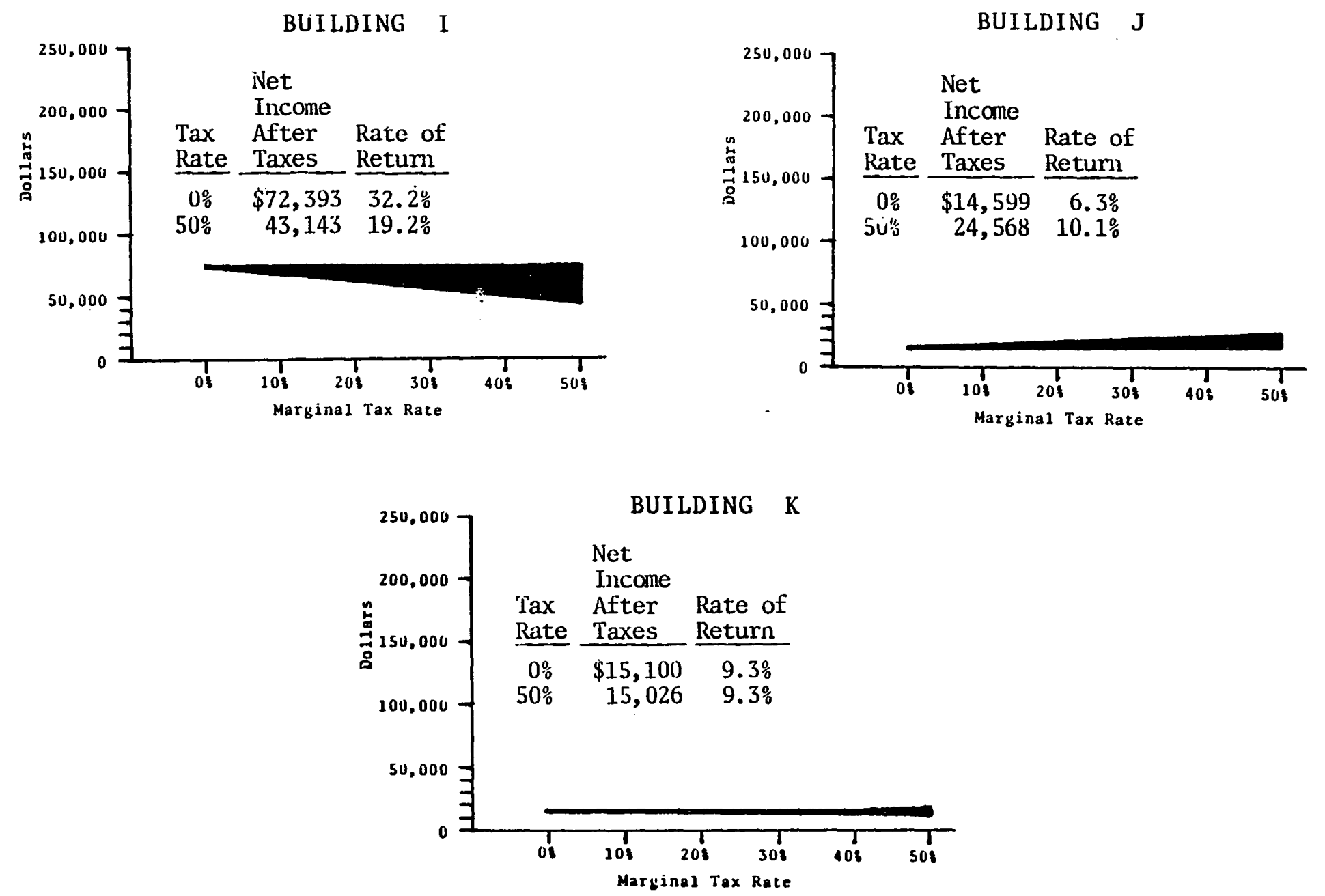